1:45-2:45 p.m. Hyatt Regency, Santa Barbara Room

\section{Awardee's Reception}

By Invitation Only

3:00-5:00 p.m. CC $203 / 204$

2:00-3:00 p.m. CC 301

\section{Cucurbit Genetics Cooperative Meeting}

Chair: Timothy $\mathrm{Ng}$

\section{OPENING PLENARY SESSION}

\section{TEX FRAZIER LECTURE/AWARDS CEREMONY}

14th William A. ("Tex") Frazier Lecture: "Plant-based Multicomponent Vaccines for Protection against Enteric Diseases"

The lecture is sponsored by Seminis Vegetable Seeds. The Tex Frazier Lecture series was named in honor of Dr. William A. "Tex" Frazier, an eminent member of the faculty at Oregon State Univ. The intent of the lecture series is: "to foster and promote reciprocal liaisons between ASHS and other professional groups; to recognize distinguished scholars and to bring their points of view to ASHS members; and to encourage the development of a holistic philosophy within the horticultural science profession so that ASHS members and students can enjoy the benefits of a broader perspective provided by an understanding of the interrelationship of seemingly diverse disciplines."

Summary: Decreases in the ability to treat infectious disease due to excessive use of antibiotics and recombination to greater virulence within the pathogen genome, combined with predictions of dramatic increases in the world population underscore the need for improved disease therapy and especially disease prevention. The observation that many infectious diseases attack the respiratory or digestive tract indicates that mucosal immunization may be the most desirable form of immunological protection. Edible plants provide an ideal inexpensive mucosal vaccine production and delivery system. Frequently, recombinant plants synthesize relatively small amounts of vaccine antigen, which generate modest levels of immune protection. To enhance the efficacy of plant-based mucosal immunization, Dr. Langridge's laboratory is studying mechanisms for targeting antigen proteins to the mucosal immune system.

William H.R. Langridge, Professor, Department of Biochemistry, Center for Molecular Biology and Gene Therapy, Loma Linda University, Loma Linda, Calif.

Biographical Sketch: William Langridge received his BS degree from the Univ. of Illinois, Urbana, in 1962. In 1973 he obtained his $\mathrm{PhD}$ in biochemistry at the Univ. of Massachusetts in Amherst, where he identified a mitochondrial glutamate dehydrogenase essential for differentiation of the multicellular amoeba (Dictyostelium discoidium). His postdoctoral studies at the Boyce Thompson Institute at Cornell Univ. in Ithaca, N.Y., included restriction endonuclease mapping of insect pox virus and granulosis virus genomes and identification of poxvirus and baculovirus proteins synthesized during virus multiplication in insect cells. In 1983, he pioneered electroporation as a method for DNA transfer into plant cells and studied plant hormone regulation of gene expression in vivo in transgenic plants. In 1987, Dr. Langridge moved as Associate Professor to the Plant Biotechnology Centre at the Univ. of Alberta in Edmonton, where he studied auxin-activated gene expression during potato tuber development and tomato fruit ripening. In 1993, he moved to the Center for Molecular Biology and Gene Therapy at the Loma Linda Univ. School of Medicine in southern California, where he is presently leading a research team active in the development of plant-based vaccines for protection against infectious and autoimmune diseases.

\section{Awards Ceremony}

ASHS Horticulture Hall of Fame

Presiding: Paul L. Smeal, ASHS President

Inductees: , Arthur John Heinicke, and John Charles Walker

Presentation of the 2001 Class of ASHS Fellows

Presiding: Paul L. Smeal, ASHS President

Fellows-elect: Judith Abbott, Mary Lewnes Albrecht, Neal E. De Vos, George D. Hochmuth, Dewayne L. Ingram, Alan N. Lakso, William Barry McGlasson, and Jack E. Staub

Presentation of the 2001 ASHS Awards

Presiding: Donald N. Maynard

Outstanding Undergraduate Educator Award

Outstanding Graduate Educator Award

Outstanding Extension Educator Award

Outstanding Researcher Award

Outstanding Industry Scientist Award

Outstanding International Horticulturist Award

Cross-commodity Publication Award

Education Publication Award

Extension Publication Award

Fruit Publication Award

Ornamentals Publication Award

Vegetable Publication Award

5:00-7:00 p.m. CC Ballroom

\section{Welcome Reception/Endowment Fund Raffle}

Meet and greet colleagues and friends and take the opportunity to browse through the fabulous prizes available for the ASHS Endowment Fund Raffle. All of the proceeds from the raffle will benefit the ASHS Endowment Fund, which supports horticulture education and research through student scholarships and other educational tools.

7:00-9:00 p.m. Hyatt Regency Ballroom

\section{Welcome Dinner/Casino Night}

Socialize and network with friends and colleagues at the buffetstyle Welcome Dinner. After dinner, it's time for games: blackjack, craps, poker, or roulette. Dealers will be on hand to give instructions to those who have never played before. Players receive chips to play with as part of their Welcome Dinner package - no additional expenditures are necessary. Additional chips may be purchased if you wish; all proceeds will benefit the ASHS Endowment Fund.

\section{Monday · 23 July 2001}

7:30 a.m.-5:00 p.m. CC West Lobby

\section{Registration Open}

8:00 a.m.-5:00 p.m. CC 101/102

\section{Placement Service}

9:45 a.m. $-6: 00$ p.m. CC Ballroom

\section{Exhibit Hall Open}

7:00-9:00 a.m. Administrators Breakfast

Presiding: Charles Boyer 
8:00 a.m. $-10: 00$ a.m.

CC 317

Membership Committee Meeting

Chair: Teddy E. Morelock

8:00 a.m. $-12: 00$ noon CC 202

Colloquium 2: Genomics: Applications to Horticultural Crops

Working Group Sponsors: Genetics and Germplasm (GG), Vegetable Breeding (VGBR), Intellectual Property Rights (IPR)

Presiding: James Nienhuis, Dept. of Horticulture, Univ. of Wisconsin, Madison

Summary: Genomics is a new and developing area of genetic research, which utilizes an array of technologies to facilitate the identification of favorable genes using sequence information. In many horticultural crops we may feel we are isolated from utilization of these technologies because our crop of interest may not have a library of expressed sequence tags (ESTs) or have been sufficiently sequenced. Our objective in this symposium is to focus on how horticultural crops can benefit and utilize information and techniques that are currently being developed and available in maize and Arabidopsis.

8:00 Introduction James Nienhuis

8:05 What Is Genomics and Why It Might Be Important

Virgin Walbot;; Stanford Univ., Stanford, Calif.

8:35 Functional Genomics of Arabidopsis: Potential Impact on Horticultural Crops

Michael Sussman*; Director, Univ. of Wisconsin Biotechnology Center, Madison, WI

9:05 How Genome Data from Arabidposis Can Be Used to Address Questions in Plant Species for Which There Are No Genome Projects

John Yoder*; Univ. of California, Davis CA 95616

9:35 Bridging Molecular Understanding to Help with Applied Problems, and How We Anticipate Using Genomics to Further Our Germplasm Enhancement Mission

Mitch McGrath; Michigan State Univ., East Lansing, MI

10:05 Functional and Comparative Genomics of Disease Resistance Genes in Arabidopsis and Lettuce

Richard Michelmore; Univ. of California-Davis

10:35 Overview of Genomics and Applications to Agriculture Catherine Ronning; The Institute for Genomic Research

11:05 Discussion

8:00-10:30 a.m. CC 304

Workshop 8: Panorama of the Vegetable Industry in Mexico, Central America, and the Caribbean Region into the XXI Century

Working Group Sponsor: Tropical Horticultural Crops (TROP)

Presiding: Juan Carlos Diaz-Perez, Dept. of Horticulture, Univ. of Georgia, Tifton

Summary: At the dawn of the 21st century, the horticultural industry in Mexico, Central America, and the Caribbean region is experiencing a rapid change due to the dynamics of globalized international markets and the increasing demand for safer, more nutritious and diverse horticultural products. The objective of this workshop is to discuss the present status of the industry and possible directions the industry is moving to in the near future.

8:00 Introduction Juan Carlos Diaz-Perez

8:05 Present Status of the Horticultural Industry in Mexico Jorge Siller-Cepeda, Centro de Investigacion en Alimentacion y Desarrollo

8:25 Greenhouse Production in Mexico: A Grower's Perspective Mario Steta, AGROS
$8: 45$

Cuban Vegetable Industry

John J. VanSickle ${ }^{\star 1}$ and Juan Carlos Diaz-Perez ${ }^{2}$; ${ }^{1}$ Professor Food \& Resource Economics Dept., IFAS Univ of Florida, Gainesville; ${ }^{2}$ Univ. of Georgia

The vegetable industry in Cuba suffered from a lack of inputs and technological expertise after the break up of the Soviet Union. Yields, which were comparable to those in the U.S., suffered and increases in land devoted to horticultural production were not enough to offset those lower yields. Changes in policies toward Cuba have increased the level of interest in Cuban agriculture. European and Chilean firms have invested in Cuba and could lead an increase in production of fresh fruits and vegetables. Vegetable crops with potential for development with international trade include tomatoes, cucumbers, peppers, boniato and malanga.

9:05 Distribution of Horticultural Products in a Globalized Market Roberta Cook; Agricultural Economics, UC Davis

9:25 Discussion

10:00 Business Meeting of the TROP Working Group Presiding: Juan Carlos Diaz-Perez

8:00 a.m.-10:30 a.m. CC 205

Workshop 9: Issues in Ornamental Weed Control

Working Group Sponsor: Nursery Crops (NUR)

Presiding: Hannah Mathers, Ohio State Univ., Columbus

Summary: To make researchers aware of issues surrounding ornamental weed control, including: loss of herbicide registrations, leaching into recirculation ponds, movement of certain weed species within the United States, and lack of controls for serious weeds, such as liverworts and mosses. Chemical alternatives will be discussed, and the need for alternatives.

8:00 Introduction Hannah Mathers

8:05 Herbicide Losses in Runoff of Containerized Plant Production Nurseries

Melissa Riley, Clemson Univ., Clemson, S.C.

8:30 Experiences with Weed Discs and Other Nonchemical Alternatives for Containers

Calvin Chong, Univ. of Guelph

8:55 Innovative Weed Control Methods in Ornamentals Hannah Mathers, Ohio State Univ.

9:15 Controlling Liverwort and Moss Now and in the Future Jason Fausey, Valent U.S.A. Corporation

9:40 Approaching New Weed Problems: Managing Liverwort (Marchantia sp.) in Nurseries

Andrew Senesac, Cornell Cooperative Extension

10:05 Business Meeting of the NUR Working Group Presiding: Michael A. Schnelle

8:00 a.m.-10:30 a.m. CC 301

Workshop 10: Foliar Application of Nutrients to

Horticultural Crops: Past, Present, and Future

Working Group Sponsor: Mineral Nutrition (MNUT)

Presiding: Charles A. Sanchez, Univ. of Arizona

8:00 Business Meeting of the Mineral Nutrition (MNUT) Working Group

Presiding: Charles A. Sanchez

8:30 Introduction Charles A. Sanchez

8:35 Foliar Nutrient Supplements for Vegetable Crops: Present and Future

Eric H. Simonne*, UF/IFAS Horticultural Sciences Dept., Univ. of Florida, Gainesville, FL 32611

Applying fertilizers onto vegetable leaves in order to enhance 
uptake and growth is an idea that has been in the minds of horticulturists for a long, long time. The presence of a largely impermeable cuticle on leaves restricts foliar absorption to a small fraction of the total leaf surface. Consequently, recommendations exist to apply fertilizer through the leaf for micronutrients such as boron or iron. Yet, despite some isolated conflicting reports, foliar fertilization is unpractical for macronutrients including nitrogen, potassium, and calcium. Recently, several new products labeled as fertilizers have been marketed with the claim that they increase nutrient uptake not directly through physical absorption, but indirectly through diverse mechanisms. The objectives of this review are to: 1) present the anatomy of the cuticle and discuss the physical barriers to foliar absorption; 2) review past work and current vegetable recommendations in Florida for foliar applied nutrient supplements; and 3) present new advances in non-classical foliar fertilizers.

8:55 Application of Foliar Nutrient Sprays and Their Effects on Fruit Quality in Deciduous Fruits

Esmaeil Fallahi ${ }^{* 1}$ and Frank J. Peryea ${ }^{2} ;{ }^{1}$ Univ. of Idaho, Parma Research and Extension Center; ${ }^{2}$ Washington State Univ., Tree Fruit Research and Extension Center, Wenatchee, Washington 98801

Deciduous tree fruit yield and quality will suffer in response to insufficiency of any mineral nutrient; however, there are some elements, including nitrogen $(\mathrm{N})$, calcium $(\mathrm{Ca})$, potassium $(\mathrm{K})$, and boron (B), that are closely tied to fruit quality. Fruit growers have applied nutrients in foliar sprays for many years to influence tree and fruit nutritional status. Sprays of macronutrients and secondary nutrients typically are supplementary to soil applications. Such sprays may be made to target specific plant organs. For example, postharvest and prebloom foliar urea sprays are applied to enhance flower bud vigor, and Ca is applied directly to fruits during the growing season to reduce fruit susceptibility to physiological disorders. Macro- and secondary nutrient sprays also are applied to quickly alleviate nutrient deficiencies that appear suddenly, such as those induced by excessive vegetative growth or elemental imbalances caused by improper applications of fertilizers or soil amendments. Sprays of $\mathrm{K}$, magnesium $(\mathrm{Mg})$, sulfur, and phosphorus fall into this category; however, these elements are more appropriately managed using soil applications. Over-zealous application of N, $\mathrm{K}$ or Mg in foliar sprays can negate the beneficial effects of Ca by inducing elemental imbalances within fruit. Micronutrients typically are applied in foliar sprays to uniformly distribute the small quantities of these required nutrients. Fruit quality is particularly sensitive to fruit $B$ status, with both insufficient and excessive amounts of $B$ causing severe deleterious responses. Recent research focuses on developing foliar spray programs that enhance nutrient phytoavailability, thereby reducing nutrient requirements and minimizing release of potentially deleterious elements into the environment, and that allow safe tank-mixing of multiple nutrients, which would reduce the number of sprays required per season.

9:15 Foliar-applied Low-biuret Urea: Its Past, Present, and Future in Citriculture

Carol J. Lovatt*, Dept. of Botany and Plant Sciences, Univ. of California, Riverside, CA 92521

Use of urea (low-biuret urea, $<0.25 \%$ biuret to avoid phytotoxicity) as a foliar fertilizer for Citrus was pioneered in the late 60's. Sharples and Hilgeman demonstrated that foliar-applied urea was more efficient than soil-applied $\mathrm{N}$ in maintaining the yield of 'Valencia' orange trees for 7 years. Jones and Embleton established that the annual amount of $\mathrm{N}$ required for maximum nutritionally attainable yields for sweet orange cultivars could be met by either soil-applied N or foliar-applied urea. However, foliar urea fertilization was not readily adopted. In many parts of the world low-biuret urea is expensive or unavailable. Due to the potential for ammonia toxicity, there is a limit in the amount of urea that can be applied in a single application, necessitating multiple sprays to supply the amount of $\mathrm{N}$ required in a given year. Thus, the practice was considered more costly than soil $\mathrm{N}$ fertilization and complicated by the risk of ammonia or biuret toxicity. Pressure on agriculture worldwide to reduce the potential for nitrate pollution of groundwater led the California citrus industry to become proactive in supporting additional research on foliar urea fertilization. A metabolic link between ammonia (a breakdown product of urea) and polyamine synthesis and flowering and fruit development in Citrus was established. The results suggested that a winter prebloom foliar application of urea would increase flowering, fruit set and yield, whereas a foliar urea application at the end of the cell division stage of fruit development would increase fruit size. Time of application was the key to developing foliar urea fertilization strategies that successfully increase fruit number or size and net dollar return to the grower.

9:35 Correcting Micronutrient Deficiency in Bedding Plants at High Media pH

Paul Fisher, Univ. of New Hampshire

9:55 An Industry-based Foliar Fertilizer R\&D Program for Horticultural Crops

Eric A. McGee*, Western Farm Service, Fresno, CA 93711

Foliar fertilization has established itself as a useful technique to supply critical nutritional needs of many crops. A component of Western Farm Service's R\&D efforts have been focused on developing foliar programs and products to meet these needs. Initially, small plot replicated trials are conducted in grower's fields to determine the relative effect of foliar treatments on quality and/or production compared to an untreated control. When positive treatment results are obtained across different seasons, soils and cropping practices the treatments are placed within split field trials. These trails allow the treatments to be economically evaluated against a grower's standard practice on a commercial scale. Once foliar fertilization has been proven to add value to a standard cropping system marketing efforts are made to create awareness of this value.

\section{0:15 Discussion}

8:00 a.m.-9:00 a.m. CC 305

\section{Oral 8: Undergraduate Education}

Presiding: Cynthia B. McKenney, Texas A\&M Univ. Research and Extension Center, Dallas

8:00 a.m.

A Comparison of Two Instructional Modes in an Univ. Horticulture Course: Computer-Assisted Instruction vs. Traditional Instruction

Linda M. Seals* and Susan L. Hamilton; Univ. of Tennessee, Ornamental Horticulture \& Landscape Design Dept., PO Box 1071, Knoxville, TN 37901-1071

Although many university educators are integrating computerassisted instruction (CAI) into their courses, the effectiveness of $\mathrm{CAl}$ in horticulture education has not been determined. It is essential for educators to evaluate the pedagogical effectiveness of CAI in horticulture courses to provide the best possible learning environment for their students. This study focused on the relationships between instructional mode and student performance, student attitudes toward computers and CAI, student study time, and student demographics. The research sample included undergraduate students who were enrolled in the Fall 2000 course of Introduction to Ornamental Horticulture and Landscape Design (OHLD 110) at the Univ. of Tennessee. Courselnfo, a courseware management system, and the Internet were used to supplement the CAI treatment. Results of the study and the effectiveness of CAI will be discussed. 
8:15 a.m.

Changing Student Demographics: Current Student Profiles and Implications for Program Planning

C.B. McKenney ${ }^{* 1,2}$ and M. Kamp-Glass ${ }^{3} ;{ }^{1}$ Dept. of Plant \& Soil Sci., Texas Tech Univ.; ${ }^{2}$ Texas A\&M Univ. Res. and Ext. Center, Dallas, TX; and ${ }^{3}$ Dept. of Natl. Res. \& Environ. Design, North Carolina A\&T State Univ.

The demographics of U.S. college students have changed over the past 30 years. Nationally, higher education enrollments increased 13\% between 1977 and 1987 and had a similar level of increase between 1987 and 1997. Undergraduate minority enrollments steadily increased during this period while overall university enrollments experienced some periods of fluctuation. Graduate student enrollments continuously increased in all ethnic and racial categories. Women composed much of this increase and surpassed men in both baccalaureate and masters degrees conferred by the mid-1980's. Men continued to have a higher number of doctoral degrees conferred than women. Foreign student enrollments increased steadily during this period due primarily to an increase in the number of Asian students attending U.S. institutions. The number of agricultural degrees conferred has fluctuated greatly. Agricultural baccalaureate degrees conferred dropped sharply in the mid-1980s and did not recover until the late 1990s. To a lesser extent, the number of agricultural graduate degrees also followed this trend. Horticultural enrollment demographics from three categories of higher education institutions will be further explored providing a glimpse at current Horticulture enrollment patterns that may be useful for program planning. Profiles of the current graduate and undergraduate student will also be provided.

8:30 a.m.

Using WebCT as a 'Traditional' Course Supplement to Enhance Student Learning, Test Competency Efficiently, and Obtain Comprehensive Student Evaluations

Milton E. Tignor, Jr. ${ }^{*}$ and Mark Starrett; Plant and Soil Sciences Dept., Univ. of Vermont, Burlington, VT 05405-0082

On-line courses have increased exponentially in the last few years. Likewise the web course development tools available to instructors have improved, resulting in more efficient application of this technology. Web Course Tools (WebCT) is one such commercial instrument, which has been used extensively by college teaching faculty around the country. In addition to its application for selfcontained course development, WebCT can be a useful tool to supplement 'traditional' courses. WebCT was used to supplement the traditional Plant and Soil Science Dept. lecture courses 010 Home and Garden Horticulture (lower-division, nonmajors), 011 Principles of Plant Science (lower-division, majors), and 127 Greenhouse Operations and Management (upper-division, majors) during the 2000-01 academic year at the Univ. of Vermont. Using WebCT in this manner allowed the instructors the ability to simply add course material to the web, efficiently evaluate student competency with regular quizzes, and receive more comprehensive student evaluations at the conclusion of the course. This technological resource also allows the instructors to track student access to web-based materials. These accomplishments would have been too timeconsuming to utilize in high enrollment courses without WebCT. In general student reactions to WebCT were favorable, however there were a few details that need to be addressed. The intricacies of using WebCT as indicated, student opinions, and student outcomes will be discussed for each course.

\section{8:45 a.m.}

\section{The UConn Plant Database: An Educational Website}

Kimberly A. Mason* and Mark H. Brand; Univ. of Connecticut

The growth of the ornamental plant industry has rapidly increased over the last several years creating a strong demand for well-trained graduates and industry personnel. It is vital for a person entering this industry to have a solid and broad plant material background. The Univ. of Connecticut has developed the UConn Plant Database website. The purpose of the website focuses on incorporating an elearning approach to a traditionally taught plant identification course. Recent pedagogical studies have shown a positive attitudinal effect on learning through technology, changing a passive classroom into an active one. This project provides a "virtual classroom" for students giving them the opportunity to take charge of their education. Students are able to study plant material whenever they want, regardless of the time of day or weather and are not limited by "office hours" of the professor. This project also looks at the major factors and decision processes involved in developing an educational website, with emphasis on usability and accessibility. For the past five semesters students have been surveyed to test their attitude towards the website and e-learning. Surveys reveal that $80 \%$ believe the website improved their grades and $76 \%$ claimed the website decreased their study time. This evidence will promote the continued and expanded use of the website. Currently the website receives over 10,000 hits a month, indicating that the website is reaching a diverse audience of students as well as nursery and landscape industry personnel, agricultural consultants, extension personnel, landscape architects and the general gardening public.

8:00 a.m.-9:15 a.m. CC 316

\section{Oral 9: Herbs/Medicinals: Herbs to Humans}

Presiding: Robert J. Dufault, Dept. of Horticulture, Clemson Univ CREC, Charleston

8:00 a.m.

Consumer Ratings of Edible-flower Quality, Mix, and Color Kathleen M. Kelley*, Bridget K. Behe, John A. Biernbaum, and Kenneth L. Poff; Dept. of Horticulture, Michigan State Univ., East Lansing, MI 48824

Two identical surveys were conducted with separate samples to determine consumer perceptions of quality of three edible flower species. Participants were either members of a class which reviewed the history and uses of edible flowers at Garden Days $(n=23)$ or were Michigan Master Gardeners $(n=51)$ attending a similar class. Participants were shown a randomized series of projected photographic slides of five edible flower species and asked to indicate whether or not they found the flower quality acceptable. The slides depicted a range of ratings of mechanical damage, insect damage or flower senescence of the taxa on a scale (1-5) developed by the researchers. A flower that was rated 5 was flawless while a flower that was rated 1 had substantial damage. Nearly half of all participants had eaten edible flowers prior to the study and $57 \%$ to $59 \%$ had grown them personally for their own consumption, indicating many had previous direct experience. Both samples rated flower quality equally and found Viola xwittrockiana Gams. 'Accord Banner Clear Mixture' (pansy), Begonia xtuberhybrida Voss 'Ornament Pink' (begonia), and Viola tricolorL. 'Helen Mount' (viola) acceptable from stage 5 to 3 . Both groups found the Tropaeolum majus L. 'Jewel Mix' (Nasturtium) flowers acceptable at only rating 5. Garden Days participants rated Borago officinalis L. (borage) acceptable from ratings 5 to 3 , while the Master Gardeners only rated their acceptability to from ratings 5 to 4 . Participants also rated flower color (yellow, orange, and blue), as equally acceptable.

\section{8:15 a.m.}

\section{Growth, Quality, and Yield of Marketable Medicinal Crops in} Kansas

Rhonda Janke ${ }^{* 1}$, Ted Carey ${ }^{1}$, and Steve Moring ${ }^{2}{ }^{1}$ Dept. of Horticulture, Forestry, and Recreation Resources, Kansas State Univ; ${ }^{2}$ Higuchi Biosciences Center, Univ. of Kansas

Medicinal herbs have been one of the fastest growing markets from 1994 through 1999, though it shows signs of leveling off at the present. Many growers would like to know which species they should grow, the planting and cultural requirements for each herb, the expected yield, and potential marketability. Insect pest and disease pressure are potential problems. Sites in northeastern Kansas (Olathe Research Center) and south central Kansas (John C. Pear 
Research Center in Wichita) were chosen for a screening trial of 20 medicinal herbs that could be grown and sold in Kansas. Three species of Echinacea (pupurea, pallida, and angustifolia) were planted in replicated plots at both sites, and observation plots of the other species were planted in Olathe, and replicated plots of the other species were established in Wichita. The soils and climate are quite different at the two locations. Irrigation was used in Wichita, but not at Olathe. All were started from seeds in the greenhouse in the late winter and early spring, and transplanted into the field in May and June of 2000. Organic practices and sources of fertility have been used on all plots, though the fields are not certified organic. Results show most of the species selected for the screening trial had good vigor ratings and acceptable yields for the first year after establishment. The species with the poorest survival and vigor rating was Echinacea angustifolia, ironically a species native to central and western Kansas. Little insect or disease pressure was noted, with the exception of a fairly high incidence of 'aster yellows' disease symptoms on the Echinacea purpurea plots.

8:30 a.m.

Germination and Seedling Development of St. John's Wort (Hypericum perforatum L.) Vary in Response to Different Wavelengths of Light

Cyril E. Broderick, Sr. * and George A. Jones, III.; Associate Professor \& Graduate Student, Respectively, Delaware State Univ., Dover, DE 1990

Although St. John's wort (Hypericum perforatum L.) is traditionally recognized as a weed it has found popularity as a medicinal plant. Its use as a medicine and nutritional supplement has increased its U.S. and world revenues to hundreds of millions of dollars and encouraged its cultivation. Propagation of Hypericumfrom seeds, however, is the popular practice, but reports note serious variability in germination and subsequent growth and development. The objectives of the study, consequently, were set to determine how light quality affects germination of St. John's wort seeds. Six (6) light treatments were provided to seeds in Petri dishes. Some $0.05 \mathrm{~g}$ of seeds $(\approx 100$ seeds) per Petri dish formed the treatment. There were two (2) or four (4) replications per treatment. The light period was 16 hours of day and 8 hours of night. Only deionized distilled water was used to support the seeds during the germination period, and during two months of growth and development. We found that seed germination varied significantly among the different treatments. The red, yellow and Sylvania soft white light had the highest germination percentage and best development rates. The worst treatments were the black, blue, and Sylvania Grow Lux light. These results confirm that weed seed germination may be inhibited by light with a low red to far-red ratio, results that indicate that light quality does affect the mobilization of starch in the process of seed germination and establishment. These responses and the fact that the Sylvania Grow Lux light gave poor results confirm that the germination mechanisms of St. John's wort seeds are typical of undomesticated seeds, having a defined light requirement for germination.

8:45 a.m.

$N, P$, and K Fertility Affects Growth and Active Principle in the Medicinal Plants, Feverfew and Echinacea purpurea and Echinacea pallida

Robert J. Dufault*, Richard L. Hassell, James W. Rushing, and B. Merle Shepard; Dept. of Horticulture, Clemson Univ.'s Coastal Research and Education Center, Charleston, SC 29414

Three N, P, and K fertilizer regimes ranging from 220 to 440 N, 95

The program schedule and abstracts are presented in chronological order and presenting authors are indicated by asterisks (*).

An index of all participants listed in the program is provided at the end if this issue. to $189 \mathrm{P}$, and 194 to $387 \mathrm{~K} \mathrm{~kg} / \mathrm{ha}$ were evaluated in the field on coneflowers (Echinacea pallida and Echinacea purpurea) and feverfew (Tanacetum parthenium) growth and active principle (marker substance used to determine purity by the dietary supplement industry). Biomass production and active principles of leaf parthenolide in feverfew, root echinacosides in E. pallida, and root chicoric acid in E. purpurea were optimized with $330 \mathrm{~N}-142 \mathrm{P}-288 \mathrm{~K} \mathrm{~kg} / \mathrm{ha}$. The greatest fertility regime $(440 \mathrm{~N}-189 \mathrm{P}-387 \mathrm{~K} \mathrm{~kg} / \mathrm{ha})$ tended to increase biomass production but apparently reduced the content of active principle compounds in all three medicinal plant species.

\section{9:00 a.m.}

Influence of Temperature Gradients on Medicinal Plant Seed Germination

Richard L. Hassell*, Robert J. Dufault, James W. Rushing, and B. Merle Shepard; Dept. of Horticulture, Clemson Univ.'s Coastal Research and Education Center, Charleston, SC 29414

The ideal temperature range to achieve the highest seed germination in the shortest time period were determined on various seed lots of differing vigor of Echinacea pallida and purpurea, feverfew (Tanacetum parthenium) and valerian (Valeriana officinalis). Replicated petri dishes were placed on a thermogradient table ranging in temperature from 16 to $36{ }^{\circ} \mathrm{C}$ for seven days and germination counted. A germination index or rate was calculated to determine the critical temperature for maximum speed of germination. Seed lots interacted with temperature within all crops, except valerian, indicating that diverse seed vigor affected germination index and percent germination. The temperature requirements of the best seed lot were 19 to $23^{\circ} \mathrm{C}$ for Echinacea pallida and Echinacea purpurea, 17 to $21^{\circ} \mathrm{C}$ for feverfew, and 19 to $27^{\circ} \mathrm{C}$ for valerian. At each crop's ideal germination temperature, maximum germination rate on the thermogradient table occurred after 3 days for Echinacea purpurea and valerian, and after 5 days for Echinacea pallida and feverfew.

9:00 a.m.-9:30 a.m. ................................................ CC 103 Working Group of the Orient (WGO) Business Meeting Chair: Shi-Ying Wang

9:00 a.m. $-9: 30$ a.m. CC 319

\section{Ornamental Landscape and Turf (O/LT) Business \\ Meeting}

Chair: R. Thomas Fernandez

9:00 a.m.-12:00 noon CC 303

\section{Publications Committee Meeting}

Chair: Mikal E. Saltveit

9:45 a.m. $-10: 30$ a.m. CC Ballroom

\section{Networking Coffee Break}

10:00 a.m. $-11: 00$ a.m. CC 302

\section{ASHS Centennial Planning Committee Meeting}

Chair: Paul L. Smeal

10:00 a.m. $-12: 30$ p.m. CC 305

\section{Workshop 11: Pest Management during Transition}

\section{from Conventional to Organic Farming}

Working Group Sponsor: Weed Control and Pest Management (WCPM)

Presiding: Gladis Zinati, Univ. of Florida

Summary: Transition from conventional to organic practices requires changes in the pest management tactics. Addition of compost and organic amendments have positive effects on weed control, soil health nematodes, and soilborne pathogens.

10:00 Business Meeting of the WCPM Working Group Presiding: Gladis Zinati 
10:30 Going Organic Changes Weed Population Dynamics Milt McGiffin and Mathieu Ngouajio, Univ. of California

10:55 Nematode and Insect Management in Transitional Systems Robert McSorley, Univ. of Florida

11:10 Root Rot Management in Organic Farming Systems James Downer, Univ. of California Cooperative Extension

11:30 Pest Management in Transition Farming Systems Gladis Zinati, Univ. of Florida

12:00 Discussion

10:00-11:15 a.m. CC 103

Oral 10: Floriculture/Foliage: Crop Production

Presiding: Robert H. Stamps, Univ. of Florida, Apopka 10:00 a.m.

Canopy Management System Affects Quality of Cut Stems of Rosa xhybrida L.

Ryan M. Warner* and John E. Erwin; Dept. Horticultural Science, Univ. of Minnesota, 1970 Folwell Ave., Saint Paul, MN 55108

An experiment was conducted to evaluate differences in quality and postharvest life of cut roses grown using two different production systems. Every two weeks from 16 June to 7 Sept. 2000, 20 stems were selected randomly from all harvested stems from two plots of Rosa xhybrida 'Kardinal' in rockwool media irrigated with a hydroponic solution containing all necessary nutrients under the traditional upright hedge system, or under the bent-shoot canopy management system in a commercial greenhouse in Plymouth, Minn. Stem length, caliper at two points along the stem, flower size, and leaf number were determined. Stems were then divided into stem, leaf, and flower tissues for dry mass determination. Another group of 10 stems from each plot was collected to determine postharvest life. All measured attributes were greater on stems grown using the bent-shoot system, compared to the traditional upright system. Stem length was $75.1 \pm 7 \mathrm{~cm}$ for bent-shoot stems compared to $49.5 \pm 5 \mathrm{~cm}$ for traditional upright stems across all harvest dates. Flower size and dry mass declined for bent-shoot stems, but not traditional upright stems, from June to September. However, across all harvest dates, flower diameter and dry mass were $14 \%$ and $44 \%$ greater on stems harvested from plants grown in the bent-shoot system than on stems from plants grown in the traditional upright system. Total dry mass of stems harvested from plants grown in the bent-shoot system was $1073 \pm 28 \mathrm{mg}$ compared to $480 \pm 7 \mathrm{mg}$ for stems harvested from plants grown in the traditional upright system. Postharvest life of individual cut stems was $11 \pm 2 \mathrm{~d}$, regardless of canopy management system or harvest date.

10:15 a.m.

Injection of a Hydrophilic Polymer and Its Effectiveness in Postproduction for Annual Plants Grown in Hanging Baskets

D. Brisson ${ }^{* 1}$, J. Caron ${ }^{2}$, P. Jobin ${ }^{1}$, C. Menard ${ }^{1}$, and B. Dansereau'; ${ }^{1}$ Département de Phytologie, ${ }^{2}$ Département des Sols et de Génie agroalimentaire Centre de Recherche en Horticulture, Faculté des Sciences de l'Agriculture et de l'Alimentation, Université Laval, Québec, Québec, Canada, G1K 7P4

Adding a hydrophilic polymer into the growing mix of container plants could theoretically increase water-holding capacity, minimize plant responses to water stress and facilitate water management. However, little information is available concerning the incorporation and the effectiveness of a hydrophilic polymer for hanging baskets, especially at postproduction period. Two experiments, in greenhouse and in outside conditions, were done in Summer 1999 and 2000 . A crosslinked polyacrylate-K polymer was incorporated into the growing mix of hanging baskets at the beginning of production and injected at postproduction. Two ornamental spreading-type plants were used for the experiments: Petunia xhybrida L. and Torenia xhybrida $\mathrm{L}$. The first experiment showed that adding the polymer at the beginning of production was inefficient to reduce irrigation frequency, but the injection of $3 \mathrm{~g} / \mathrm{L}$ of polymer at postproduction reduced irrigation needs and had no influence on Petunia's growth. For the second experiment, three injection levels $(0,1,5$, and $3 \mathrm{~g} / \mathrm{L})$ and two application patterns (in 6 and 12 points) of the polymer at postproduction were tested. Results have shown that only the level of $3 \mathrm{~g} / \mathrm{L}$ of polymer increased significantly wilting delay by one day for Petunia. However, the polymer had no significant effect on the wilting delay of Torenia, regardless of the injection level. The injection patterns had no influence on the effectiveness of the polymer, which means that an application in 6 points would be as beneficial as one in 12 points. This research has demonstrated that the injection of a polymer at postproduction can facilitate water management of plants grown in hanging baskets, and that its effectiveness is preserved even if the number of points is reduced by $50 \%$.

\section{0:30 a.m.}

Yield and Vase Life Comparisons of Eight Leatherleaf Fern Cultivars

Robert H. Stamps*and Annette L. Chandler, MREC, IFAS, Univ. of Florida, 2725 Binion Road, Apopka, FL 32703-8504

Eight cultivars of leatherleaf fern [Rumohra adiantiformis (Forst.) Ching] were planted in a fernery in Tavares-Millhopper fine sand. Forty-eight rhizome pieces of each cultivar, $10-15 \mathrm{~cm}$ in length, were planted per plot. Plots were $3 \mathrm{~m}^{2}$ in size and were replicated six times per cultivar. During the first year, frond development from crosier to mature leaf was monitored. When fronds in the plantings reached marketable size, they were harvested, graded by size, counted and weighed. Periodically, mature fronds were harvested, stored at $4{ }^{\circ} \mathrm{C}$ for 16 days, and then evaluated under simulated home/office conditions for postharvest longevity (vase life). At the first harvest after planting, frond numbers and fresh weights were lower for the two tissue culture-derived (TC) cultivars (Dutch, Mayfield TC) and Fancy compared to the other cultivars (Adair, Baker, Mayfield, Price, and Roy Ruth). Yields for all cultivars were significantly higher at the second harvest, but fresh weights were still lower for those three cultivars. However, frond numbers were only reduced for 'Fancy'. This was the result of the TC cultivars producing a greater proportion of small fronds compared to the other cultivars. Vase life was longer for the TC cultivars than the others and there was a trend for vase life to decrease with increasing frond size for a majority of the cultivars. The percentage of fronds without sori also decreased with increasing frond size for all cultivars except Fancy, which did not produce sori.

\section{0:45 a.m.}

Productivity, Quality, and Value Estimation of Cut-flower Roses Grown in Soilless Media in Response to Shootbending

Soo-Hyung Kim and J. Heinrich Lieth*; Dept. of Environmental Horticulture, Univ. of California, Davis, CA 95616

Cut-flower production of Rosa hybrida 'Kardinal' and 'Fire'N Ice' was evaluated for two canopy management regimes: (shootbending vs. nonbending) and two rooting media (Coir vs. UC Mix). The number and length of harvestable flowering shoots were measured from Sept.1997 to Aug. 1999. Shoot-bending increased the average shoot stem length and dry matter for both cultivars while decreasing the number of harvestable shoots. 'Fire' $\mathrm{N}$ Ice' plants grown in Coir produced more harvestable flowering shoots than plants grown in UC Mix while 'Kardinal' plants did not exhibit any difference in the number of harvestable shoots between the two rooting media. Neither cultivar showed differences in stem length and dry matter production between the two media. Calculation of market value showed that with 'Fire'N Ice' the improvement in stem length achieved by shoot-bending did not offset the economic loss due to the reduction in the number of shoots $/ \mathrm{m}^{2}$. For 'Kardinal' the increased quality as a result of shoot-bending did offset the reduced production. The combination of bending and 
Coir, a common combination being used by many rose growers, did not generate significant improvements in value over the other treatment combinations. However, under market conditions where short stems are discounted significantly and extra-long stems garner a substantial bonus, shoot-bending can result in greater economic gain.

\section{1:00 a.m.}

\section{Effects of Gibberellin Treatments on Leaf and Flower} Quality of Cut Oriental, Asiatic and LA-Hybrid Lilies Anil P. Ranwala* and William B. Miller; Dept. of Horticulture, Cornell Univ., Ithaca NY 14853

The effects of gibberellin treatments on postharvest cut flower quality of several Oriental, Asiatic, and LA-hybrid lily cultivars were investigated. Lily stems were harvested when the first flower bud of the inflorescence showed full color, and held in a postharvest room $\left(20^{\circ} \mathrm{C}, 15 \mu \mathrm{mol} \cdot \mathrm{m}^{-2} \cdot \mathrm{s}^{-1}\right.$ fluorescent light $(12 \mathrm{~h} /$ day $\left.)\right)$ for the evaluation of leaf and flower quality. Another set of cut stems was held in water at 2 to $3^{\circ} \mathrm{C}$ for 2 weeks in darkness before transferring to the postharvest room. Cut stems were treated with gibberellins $\left(\mathrm{GA}_{3}, \mathrm{GA}_{4+7}\right.$ or a combination of $\mathrm{GA}_{4+7}$ and $\left.\mathrm{BA}\right)$ as a pulse treatment or a foliar spray before moving into the cold storage or as a component in the vase solution during the evaluation phase. All three means of gibberellin applications were effective in delaying leaf chlorosis and necrosis during the postharvest phase. Gibberellin treatments also prolonged the inflorescence life span by several days. Although both $\mathrm{GA}_{3}$ and $\mathrm{GA}_{4+7}$ delayed leaf chlorosis, $\mathrm{GA}_{4+7}$ was effective in much lower concentrations compared to $\mathrm{GA}_{3}$. For example, 6-hour pre-treatment of cut stems in a $100 \mathrm{ppm}$ $\mathrm{GA}_{4+7}$ solution completely prevented leaf chlorosis up to 3 weeks during the postharvest phase. As a component in the vase solution, $\mathrm{GA}_{4+7}$ concentrations as low as $5 \mathrm{ppm}$ completely prevented leaf chlorosis throughout the postharvest life. Cold storage of cut stems after harvest accelerated the leaf chlorosis during the post-storage phase. Gibberellin treatments, however, completely prevented this cold-induced leaf chlorosis in all the cultivars tested.

10:00-12:00 noon CC 316

\section{Oral 11: Fruits/Nuts: Crop Irrigation \& Nutrition}

Presiding: Ian A. Merwin, Dept. of Horticulture, Cornell Univ., Ithaca, NY

\section{0:00 a.m.}

Irrigation Scheduling Protocols for Fruit Trees Using Continuously Recorded Trunk Diameter Measurements David Goldhamer ${ }^{* 1}$, Elias Fereres ${ }^{2}$, Mario Salinas ${ }^{1}$, Alfonso Moriana $^{3}$, and Merce Soler Anaya4; ' $U$ niv. of California, Davis; ${ }^{2}$ IAS-CSIC and Univ. of Cordoba, Spain; ${ }^{3} I A S-C S I C$, Cordoba, Spain; ${ }^{4} I R T A$, Lleida, Spain

Theoretical and experimental aspects of developing irrigation scheduling indicators using continuous measurements of trunk diameter are presented. The behavior of parameters derived from trunk diameter measurements (TDM), including maximum daily trunk shrinkage (MDS), maximum daily trunk diameter (MXTD), and minimum daily trunk diameter (MNTD) is evaluated for both rapidly growing peach [Prunus persica (L.) Batsch, cv. September Snow] and mature almond [Prunus dulcis (Mill.) Webb cv. Price] trees subjected to mild deficit irrigation. Stem water potential (SWP) and MDS were highly correlated in the mature almond trees but a poor relationship was found in the rapidly growing peach trees. Conversely, daily changes in MXTD and MNTD correlated well with SWP in the fast growing trees. While there was relatively high variability ("noise") in the MDS measurements (CV of $15.8 \%$ ), the greater changes in the magnitude of MDS ("signal") resulted in a significantly higher signal to noise ratio than found with the SWP measurements. In addition to soil water and trunk growth rate, irrigation frequency and evaporative demand influenced MDS patterns. Based on the experimental results, protocols for utilizing the trunk diameter-derived indicators for scheduling irrigations are presented for three cases: 1) mature trees under low frequency irrigation; 2) mature trees under high frequency irrigation; and 3) young trees under high frequency irrigation. The scheduling protocols provide guidelines that address both under- and over-irrigation and are predicated on the sensitivity of TDM to very mild tree water deficits. The necessity for and approaches to developing reference (baseline) and threshold values derived from TDM are emphasized. We conclude that protocols using TDM for use precise irrigation scheduling hold promise as an additional tool for progressive growers that want to link irrigation management to an automated, electronic, plant-based stress indicator.

\section{0:15 a.m.}

Almond Yields and Leaf Analyses as Influenced by Nitrogen Source and Acidification Remediation Treatments through Drip Irrigation

Roland D. Meyer*, John P. Edstrom, H. Schulbach, and J. Deng; Univ. of California-LAWR Dept and Cooperative Extension, Davis, Colusa, Colusa and Davis. One Shields Ave. Davis, CA 95616

The nitrogen sources urea, calcium nitrate, urea-ammonium nitrate solution-32, 28-27 urea-sulfuric acid, urea-odd years + calcium nitrate-even years, and 5 additional urea treatments were applied beginning in 1985 to three varieties (Butte, Carmel, NonPareil) of almonds [Prunus dulcis (Mil) D.A. Webb] planted in 1981 on a $3.65 \mathrm{x}$ $5.47 \mathrm{~m}$ spacing ( 550 trees/ha) on Arbuckle gravelly loam (Fine-loamy, mixed, thermic Typic Haploxeralf). In Apr. 1995, the remediation treatments gypsum (Ca eq. to lowest lime rate), lime-272 \& $545 \mathrm{~g}$ rates, lime at $1634 \mathrm{~g}$ mixed in drip basin $45-\mathrm{cm}$ deep x $30-\mathrm{cm}$ diameter and sodium-potassium nitrate + gypsum $(\mathrm{Na}-\mathrm{K}-\mathrm{Ca}$ ratio $=1: 1: 1)$ were applied per tree. Trees were drip-irrigated to basins (3 per tree) $\approx 7 \mathrm{~cm}$ deep and $30 \mathrm{~cm}$ in diameter, located $76 \mathrm{~cm}$ and $183 \mathrm{~cm}$ on either side of the trees in the tree row. N rates of $681,1022,1362,1362,1022$, 681,681 , and $681 \mathrm{~g} /$ tree respectively from 1985 to 1992 , and $454 \mathrm{~g} /$ tree from 1993-99 were applied on a monthly basis in 3 to 6 increments beginning in April. No significant kernel yields were measured from 1995-99. Leaf manganese levels were the highest for urea-sulfuric acid and lowest for calcium nitrate treatments while soil $\mathrm{pH}$ was the inverse for these two treatments. During some years leaf nitrogen was significantly lower for the calcium nitrate treatment.

\section{0:30 a.m.}

Irrigation and Bed Shape Affect Growth and Yield of 'Flameprince' Peach Trees in Oklahoma

B.D. McCraw* and B.L. Carroll; Dept. of Horticulture and Landscape Architecture, Oklahoma State Univ., Stillwater, OK 74078

Effects of irrigation and water-logged soil on peaches are well documented. Little information is available on bed shape and irrigation on southeast peaches. In this study, berms $55.8-\mathrm{cm}$ high, $61-\mathrm{cm}$ wide at the top sloping $\approx 30^{\circ}$ to a base width of $4.3 \mathrm{~m}$ were constructed in Oct. 1993 on a Teller Fine Sandy Loam soil. 'Flameprince'/Lovell trees were planted Mar. 1994, $6.1 \mathrm{~m}$ between rows and $5.5 \mathrm{~m}$ between trees. The experiment was a split plot design with four replications of three trees each. Treatments consisted of no irrigation, $40 \%$ or $80 \%$ pan evaporation replacement in combination with berm or flat planting surface. Irrigation was supplied by means of emitters that applied 3.7 $L$ per hour in 1994 and 95. Two emitters per tree were located in the row $45.7 \mathrm{~cm}$ either side of the tree trunk. Prior to the 1996 season emitters were replaced by one micro-sprinkler per tree delivering 26.5 liters per hour, in a 2.5 m diameter circle centered on the tree. The 1996 and 1997 crops were lost to freezes. The irrigation by bed shape interaction was nonsignificant. Trunk caliper of trees in $40 \%$ and $80 \%$ $\mathrm{PE}$ replacement plots were significantly greater than non-irrigated plots until the 4th leaf season. In heavy crop years of 1998 and 1999 trunk caliper increased with increasing level of irrigation. Berm effect on trunk caliper was significant in 3 of 7 years. Increasing level of irrigation resulted in more and larger fruit regardless of bed shape.

\section{0:45 a.m.}

Management Guidelines for Efficient Surface Irrigation of 
Desert Horticultural Crops

Charles A. Sanchez ${ }^{*}$ and Dawit Zerihun; The Univ. of Arizona, Yuma, AZ 85364

Surface irrigation is widely used for vegetables and citrus produced in the low desert region of the southwestern United States. These irrigation systems are often characterized by low performance. Previous studies on irrigation scheduling have provided tools to estimate required time and required depth of irrigation. However, information on management criteria necessary to attain high water application efficiencies and distribution uniformity are needed. Field and modeling studies were conducted to develop management guidelines for furrow irrigated vegetable crops and basin irrigated citrus. Water inflow hydrographs and water depth profiles determined during irrigation events were used to determine infiltration and roughness parameters using volume balance based field parameter estimation models. Surface irrigation hydraulic models were calibrated using these field data and validated using independent data sets. The validated models were used to perform scenario analysis and generate management criteria for optimal system efficiency and uniformity. The implementation of the proposed management guidelines would increase irrigation application efficiencies considerably.

11:00 a.m.

Reclaimed Water as a Source of Nutrients for Citrus

Production

Larry R. Parsons*, T. Adair Wheaton, and William S. Castle; Univ. of Florida, IFAS Citrus Research and Education Center, Lake Alfred, FL 33850

Reclaimed water from the Water Conserv II project in central Florida contains nutrients required for citrus production. Irrigation at $400 \mathrm{~mm}$ per year would supply only a small part of the recommended nutrition, but $2500 \mathrm{~mm}$ per year would theoretically supply most of the recommended nutrients. An existing irrigation rate experiment using mature 'Hamlin' orange and 'Orlando' tangelo trees on four rootstocks was modified to determine if $2500 \mathrm{~mm}$ of reclaimed water could supply their annual nutritional requirements. Leaf $\mathrm{N}$ and yield declined rapidly when fertilizer was omitted and remained low even when half of the recommended $\mathrm{N}$ was supplied by fertilizer. However, leaf levels of all other nutrients remained in the optimal range without added fertilizer that suggests citrus may be grown successfully on this source of reclaimed water supplemented only with nitrogen.

11:15 a.m.

The Effect of Preplant Monoammonium Phosphate and Apple Compost on the Growth of Newly Planted Apple Trees

R.E. Moran ${ }^{1 *}$ and J.R. Schupp ${ }^{2}$; ${ }^{\text {Dept. of Biosystems Science and }}$ Engineering, Univ. of Maine, Monmouth, ME 04259; ${ }^{2}$ Dept. of Horticultural Sciences, Hudson Valley Lab, Cornell Univ., Highland, NY 12528

Preplant phosphorous fertilizer and compost were tested for their effect on improving growth of newly planted apple trees. Macoun/ Bud.9 apple trees were planted in May 1998 in one of four preplant treatments which were: 1) urea; 2) monoammonium phosphate (MAP); 3) compost and urea; and 4) compost and MAP. MAP was applied at $150.3 \mathrm{~kg} / \mathrm{acre}$ and urea at $35.9 \mathrm{~kg} /$ acre so that each treatment received equivalent $\mathrm{N}$. Apple pomace compost was applied and leveled to a uniform thickness of $10 \mathrm{~cm}$. All preplant treatments were tilled to a depth of $15 \mathrm{~cm}$. Each treatment was replicated six times with 3 trees per plot and guard trees between each plot. Preplant MAP lowered soil pH in 1999 and soil K in 2000 compared to urea plots. Organic matter, $\mathrm{P}, \mathrm{Mg}$ and $\mathrm{Ca}$ were not affected by MAP. There was no interaction between MAP and compost on soil properties, foliar nutrients or tree growth. Compost increased soil organic matter and $\mathrm{P}$ in 1998, and these were not measured again. Compost increased soil $\mathrm{pH}, \mathrm{K}, \mathrm{Mg}$ and $\mathrm{Ca}$ in 1998 , 1999 and 2000 compared to plots with no compost. Compared to urea, leaf nutrients were not affected by MAP. Compost increased leaf $\mathrm{N}$ and $\mathrm{K}$ in all three years. Compost decreased leaf $\mathrm{Mg}$ in 1998, but not in 1999 or 2000. MAP increased trunk growth in 1998 and shoot growth in 2000 compared to urea. Compost increased trunk cross-sectional area in 1999, the total number of shoots and spurs in 2000, shoot length in 1998 and 2000, and tree height in 2000. Both MAP and compost increased tree growth in the first three years after planting, but the effect of compost was greater.

\section{1:30 a.m.}

Groundcover Management Influences Nitrogen Release, Retention, and Recycling in a New York Apple Orchard lan A. Merwin*, Mary A. Hopkins, and Rachel R. Byard; Dept. of Horticulture, Cornell Univ., Ithaca, $N Y$

We have been studying groundcover management system (GMS) impacts on nitrogen $(\mathrm{N})$ mineralization, uptake, retention and loss in an apple (Malus domestica) orchard where four GMSs have been maintained since 1992: 1) Mowed red fescue (Festuca rubra) sodgrass (MWSOD); 2) Hardwood bark-chip mulch, renewed biennially (MULCH); 3) Pre-emergence residual herbicide (norflurazon and diuron) treatments (PREHRB); and 4) Post-emergence herbicide (glyphosate) treatments (POSTHRB). Using $0.5 \mathrm{~g}$ of $99 \%$ enriched $\mathrm{K}^{15} \mathrm{NO}_{3}$ isotopic fertilizer applied beneath trees in May for three years, we traced $\mathrm{N}$ dynamics year-round in each GMS, sampling root-zone soil, lysimeter and runoff water, tree shoots, leaves and fruit, and groundcover vegetation. Soil $\mathrm{N}$ and carbon contents were greatest in MULCH plots, where mulch biomass inputs of $0.35 \mathrm{~kg} \mathrm{~N} / \mathrm{m}^{2}$, with a $\mathrm{C}: \mathrm{N}$ ratio of 65 , resulted in negligible $\mathrm{N}$ leaching from plots. Uptake of ${ }^{15} \mathrm{~N}$ by trees was lower in MwSod, intermediate in mulch, and higher in the herbicide GMSs_peaking in May and June, and then declining gradually for the rest of the growing season. The ${ }^{15} \mathrm{~N}$ tracer was detected in leaves and spurs within days after mid-May applications. Leaf ${ }^{15} \mathrm{~N}$ remobilized into shoot tissues during autumn leaf senescence, moved into trunk and root storage tissues during winter, then remobilized into shoots during spring. Atom $\%{ }^{15} \mathrm{~N}$ content was $3-4$ times greater in groundcover vegetation than apple tissues. Leaching of soil nitrate$\mathrm{N}$ was greater from plots of POSTHRB and PREHRB than the other GMSs, but remained quite low in all treatments, averaging 0.2 to 1.1 $\mathrm{ppm}$ during the first two years. Nitrate- $\mathrm{N}$ leaching losses during the summer irrigation season were often greater than during the dormant season.

\section{1:45 a.m.}

The Effect of Early Water Deficit on Olive Fruit Development H.F. Rapoport ${ }^{\star 1}$; G. Costagli'; and R. Gucci2 ${ }^{2}{ }^{1}$ Instituto de Agricultura Sostenible, CSIC, Córdoba, Spain; ${ }^{2}$ Dept. Coltivazione Difesa Specie Legnose, Univ. of Pisa, Italy

Irrigation was withheld from 3-year-old container-grown Olea europaea L. CV. Leccino plants from 4 to 9 weeks after full bloom (AFB) in order to determine the effect of early water deficit on fruit growth. Size and number of cells in mesocarp sections were determined by microscope image analysis at 6,8 and 22 (color change) weeks AFB. At 6 weeks, AFB pre-dawn leaf water potential of stressed plants averaged $-3.2 \mathrm{MPa}$, whereas that of control plants was $-0.9 \mathrm{MPa}$. At 8 weeks AFB fruit fresh weight was 0.20 $\mathrm{g}$ and $0.72 \mathrm{~g}$ for the stressed and control plants respectively. At the end of the stress period fruit volume of stressed plants was $29 \%$ of the controls, whereas at harvest that ratio was $55 \%$. Seasonal nondestructive measurements of fruit volume showed a clear effect of crop load on fruit development. Cell number in the fruit mesocarp, largely determined by cell division during the first 8 weeks AFB, was only slightly reduced in the stressed plants. Mesocarp cell size for stressed plants, however, was $45 \%$ and $69 \%$ of the controls at 8 and 22 weeks AFB, respectively. Early stress delayed endocarp development so that while final endocarp diameter for the stressed plants was $97 \%$ that of controls, at 8 weeks it was only $60 \%$. Both total fruit and mesocarp size appear to be strongly affected by the interaction between endocarp and mesocarp growth. 
10:00-12:00 noon CC 319

\section{Oral 12: Fruits/Nuts: Postharvest}

Presiding: Bhimanagouda S. Patil, Texas A\&M Univ., Welasco 10:00 a.m.

Delaying Papaya Fruit Ripening by 1-Methylcycylopropene

Muharrem Ergun* and Donald J. Huber; Horticultural Sciences Dept., PO Box 110690, Univ. of Florida, Gainesville, FL 32611-0690

Papaya fruit have a limited shelf life due to rapid fruit softening. Preclimacteric (PC) and ripe (R) 'Sunrise Solo' papaya fruit were treated with 1 to $10 \mathrm{ppm}$ 1-methylcyclopropene (1-MCP), an ethylene action inhibitor, at $20^{\circ} \mathrm{C}$ for 12 to $18 \mathrm{~h}$, and the fruit were stored at $20^{\circ} \mathrm{C}$. Firmness, skin color, respiration and ethylene rate, brix, and electrolyte leakage were monitored during storage for 12 days at 20 ${ }^{\circ} \mathrm{C}$. Both PC and R fruit fumigated with 1 -MCP retained firmness longer than control fruit although the response to 1-MCP was greater in $\mathrm{PC}$ fruit. After 12 days, $\mathrm{PC}$ fruit treated with 1-MCP had significantly higher mesocarp firmness $(14 \mathrm{~N})$ than control fruit $(6.1 \mathrm{~N})(P$ $=0.005)$. $\mathrm{R}$ fruit treated with $1-\mathrm{MCP}$ also had higher mesocarp firmness $(4.7 \mathrm{~N})$ than controls $(3.9 \mathrm{~N})(P \leq 0.05)$. Ethylene production was significantly lower in $\mathrm{PC}$ fruit treated with 1-MCP than fruit without 1-MCP $(P \leq 0.001)$. Ethylene production by PC control fruit reached a maximum of $1.81 \mu \mathrm{L} \cdot \mathrm{kg}^{-1} \cdot \mathrm{h}^{-1}$ on day 5 , at which time ethylene production in MCP-treated fruit was $0.38 \mu \mathrm{L} \cdot \mathrm{kg}^{-1} \cdot \mathrm{h}^{-1}$. Maximum ethylene production in MCP-treated fruit $\left(1.38 \mu \mathrm{L} \cdot \mathrm{kg}^{-1} \cdot \mathrm{h}^{-1}\right)$ was observed after 10 days of storage. 1-MCP treated PC fruit had lower electrolyte leakage than non-treated ones $(P \leq 0.005)$. The total electrolyte leakage of 1-MCP treated and non-treated PC fruit was $18.9 \%$ and $20.7 \%$, respectively, on the last day of the treatment. PC fruit treated with 1-MCP maintained green skin color 2 more days. On the basis of firmness, skin color, and overall appearance, 1-MCP extended the shelf life of papaya fruit $2-3 \mathrm{~d}$ at $20^{\circ} \mathrm{C}$. Current experiments are addressing the effect of MCP on the performance of fresh-cut papaya fruit.

\section{0:15 a.m}

\section{Patterns in the Volatile Profile for 'Redchief Delicious' Apple} Fruit during Ripening and Senescence

Alejandra Ferenczi* and Randolph Beaudry; Michigan State Univ., Horticulture Dept., Uast Lansing, MI 48824-1325

The volatile profile of apple fruit was tracked from 3 weeks prior to 8 weeks after the onset of the ethylene climacteric. The peak in ester production roughly coincided with the maxima for respiration and ethylene production. The hexanoates were evaluated as an ester class. As ripening progressed, the chain length of the alcoholderived portion of the predominant ester declined. Prior to the onset of the ethylene climacteric, hexyl hexanoate predominated. Throughout the early portion of the climacteric, butyl hexanoate predominated. Propyl hexanoate was the predominant hexanoate ester during the late climacteric and early senescence phase. In late senescence, ethyl hexanoate was the predominant hexanoate ester. Free hexanoic acid was detected only after the respiratory and ethylene climacteric peaks, coinciding with the decline in total hexanoate synthesis. The data suggest that the ester precursor production is developmentally regulated throughout ripening and senescence. The free hexanoic acid may indicate that fatty acid precursors are in excess during the latter stages of ripening and throughout senescence.

10:30 a.m.

Effective Use of 1-MCP to Store 'Redchief Delicious' Apples Sastry S. Jayanty*, Nazir Mir, Erin Curell, Najma Khan, Melissa Butkiewicz, and Randolph Beaudry; Dept. of Horticulture, Michigan State Univ., East Lansing MI-48824

1-Methylcyclopropene (1-MCP), a specific inhibitor of the ethylene binding, adheres to the ethylene receptors, regulating the fruit ripening process and delaying senescence. We earlier showed that the repeated exposure of 1-MCP gas is more effective than single application in retarding fruit softening in apples only at temperatures greater than $0{ }^{\circ} \mathrm{C}$. To further investigate the interaction of fruit sensitivity and temperature, we conducted experiments by treating 'Redchief Delicious' apples of single harvest with 1-MCP gas at different concentrations ( $10 \mathrm{ppm}$ to $0.02 \mathrm{ppm})$ at different temperatures $(0,5,10,15$, and $20^{\circ} \mathrm{C}$ ). Samples were collected at regular intervals and analyzed for firmness and chlorophyll fluorescence. The concentration of 1-MCP needed to saturate its response did not appear to change with temperature during the first 80 days of the study, suggesting that the relative decline in effectiveness of repeated applications is not likely due to a change the dose response to the gas per se. Chlorophyll fluorescence data indicate that a loss of chloroplast function was not protected by 1-MCP treatment. To reduce the decay encountered at higher temperatures, a commercial fungicide treatment was applied to small lots of fruit. There was no measurable benefit to fungicide treatment under the conditions of the experiment.

\section{0:45 a.m.}

\section{Ionizing Radiation on Grapefruit Functional Components} during Prolonged Storage

Bhimanagouda S. Pati ${ }^{\star 1}$, Jairam Vanamala', and Guy J. Hallman²; ${ }^{1}$ Texas A\&M Univ., Kingsville Citrus Center, 312 N. International Blvd., Weslaco, TX 78596; ' $U S D A-A R S, 2301$ S. International Boulevard, Weslaco, TX 78596

Grapefruits (Citrus paradisi Macf.) shipped to certain U.S. states and some export markets such as Japan and South Korea, must be certified free of quarantine pests. Irradiation has been studied as a quarantine treatment for over 40 years and recently several scientists suggested low dose irradiation treatment as a non-chemical alternative quarantine treatment for grapefruit. Grapefruit functional compounds such as flavanones [naringin, narirutinosides (NR)], limonin 17-beta-D glucopyranoside (LG), and vitamin $C$ have been shown to have potential human health benefits including cancer and cardiovascular disease prevention. This study was undertaken to test the feasibility of irradiation as a treatment for increasing the functional components during postharvest storage. 'Rio Red' grapefruit were treated with $0,70,200,400,700$ Gy radiation and stored up to 4 weeks at $10{ }^{\circ} \mathrm{C}$ followed by 1 week at $24^{\circ} \mathrm{C}$ and relative humidity during both temperature was maintained at $90 \%$ to $95 \%$. The effect of irradiation on functional components was measured immediately after treatment, and again after five weeks. Naringin, $\mathrm{NR}$ and total flavonones concentrations were significantly increased $(P<0.05)$ in fruits treated with 70 Gy irradiation at the end of storage period and concentrations of $L G$ and ascorbic acid were slightly increased but not significantly affected. In contrast, no significant differences were observed in fruits treated with 0 , and at or above 200 Gy irradiation although some deviations from this trend were noticeable in case of NR.

\section{1:00 a.m.}

Mitigation of Impact Injury by Common Packing Materials Kathryn Taylor* and Karol Kelly; Horticulture Dept., Univ. of Georgia, 21 Dunbar Rd., Byron, GA 31008

Packing line facilities in Georgia were assessed for impact force and those forces were then simulated in the laboratory. Along packing lines in which steps have been taken to mitigate damage the most injurious steps were dry dumps (few houses still have these) and the dropping of fruit into the box. Impact injury under simulated conditions varied by variety and was only somewhat correlated with fruit firmness at the time of impact. Fruit architecture and flesh type appear to have the greatest effect on degree of injury. Packing line velocities can be slowed to reduce this injury with the most susceptible varieties. Extended study addressed practical inexpensive methods for mitigation of impact injury. Several industry recommended padding materials were compared against bubble wraps and common packing peanuts. For drops into the box, the best material appeared to be common packing peanuts. At the dry dump, forklift operators can be trained to alter the velocity of dumping to reduce impact force and therefore injury. 
11:15 a.m.

A Nondestructive Method for Measuring Apple Quality to which Consumers Can Relate

A. Nathan Reed*; Dept. of Horticulture, Penn State Univ., Fruit Research \& Extension Center, Biglerville, PA 17307

In the quest to find a nondestructive method for assessing apple firmness, acoustical resonance properties have been promoted as an alternative method. Two acoustical bench top instruments have been developed and successfully tested. Three taste panels trials have found that consumers can distinguish between apples based on their acoustical quality indices (AQI). In the first trial, AQI values of 23 and 25 were found to be acceptable by consumers in 'Golden' and 'Red Delicious', respectively. Consumers were able to identify apples with greater AQI values as more desirable with respect to texture, firmness intensity and overall preference. In a second trial experienced panelists were able to distinguish both 'Red' and 'Golden Delicious' fruit with low AQI values. In a third trial conducted with trained panelists, a third variety, 'Fuji', was added. Similar results were obtained in 'Red' and 'Golden Delicious'. Consumer differences between high and low AQI values in 'Fuji' were not as strong. Implications for apple storage and packing along with consumer expectations will be presented.

\section{1:30 a.m.}

Flesh Browning of Blossom End Part of 'Fuyu' Sweet Persimmon Related to Calcium Content during MA Storage Wol Soo Kim and Hyung Shim Choi; Dept. of Horticulture, Chonnam National Univ., Kwangju 500-757, South Korea

This study was conducted to investigate the effect of principal cation contents on the browning of blossom end part of 'Fuyu' persimmon occurred during cold MA storage. The principal cation contents of soil sampled at the orchards where the browning of persimmon fruit didn't appear were compared with that of soil sampled at the orchards where the browning of persimmon fruit sometimes appeared. Ca content was higher in soil of orchards where the browning of persimmon fruit did not appear than that of orchards where the browning of persimmon fruit sometimes appeared. $\mathrm{K}$ and $\mathrm{Mg}$ contents were higher in normal soil than in abnormal soil. Among storage tissues, the mineral content of bark tissue was analyzed. The bark tissue sampled at the orchards where the browning of persimmon fruit didn't appear contained more calcium than bark tissue sampled at the orchards where the browning of persimmon fruit sometimes appeared. Principal cation contents of the persimmon fruits were analyzed. Ca content of the flesh and peel had the lowest calcium concentration in the blossom end part which the browning was observed mainly among various parts of fruit. Ca distribution of outer, middle and inner parts of flesh was lowest in the outer part. The severer the degree of blossom end browning was, the lower calcium content of peel and flesh was. $\mathrm{Ca} /$ $\mathrm{K}+\mathrm{Mg}$ ratio of fruit seemed to be low, as the degree of fruit browning was severe. As well as negative correlations were found between $\mathrm{Mg}$ and $\mathrm{Ca}$ content, $\mathrm{K}$ and $\mathrm{Ca}$ content in fruit peel and flesh. These results suggested that the calcium content in the fruit seemed to be low because of decrease of calcium uptake toward tree due to antagonism with other ions and competition of $\mathrm{Ca}, \mathrm{Mg}$ and $\mathrm{K}$ cations in the limited binding sites of fruit peel and flesh. Ca deficiency in fruit associated with occurrence of blossom end part browning of 'Fuyu' persimmon.

\section{1:45 a.m.}

The Effect of Harvest Time and Postharvest Diphenylamine Treatment on the Scald Control in Red Delicious Apple

Ali Reza Talaie ${ }^{* 1}$ and Abbas Hassani2; ${ }^{1}$ Tehran Univ., Karaj, Iran; ${ }^{2}$ Tarbiat Modarres Univ.

Every year, a considerable portion of apple production is wasted in the process of cold storage as a result of storage physiological disorders, the most important of which in Iran, making bad effects on apple quality are: scald, bitter pit, water core and mealy breakdown. In this experiment, a completely randomized factorial design was used to study the effect of harvesting time and postharvest treatment with DPA and their interactions on extent of scald induction, fruit juice $\mathrm{pH}$, acidity, fruit flesh firmness and its total soluble solid contents. 'Red Delicious' apples were harvested in 3 intervals of 10 days each (i.e. 128 days after full bloom, 138 days after full bloom, and 148 days after full bloom). Apple trees in Baghe-Kowsar were selected for this experiment. Harvested fruits were dipped in DPA (with 0,1000 , and 2000 ppm) and then stored for 5 months under $0^{\circ} \mathrm{C}$. The fruits were taken out at the end of this period and kept for 6 days under $20^{\circ} \mathrm{C}$ and thenafter development of scald disorder was studied. The results of this experiment indicate that both the time of harvest and postharvest treatment with DPA had significant effect on scald, so far that the first harvest has the highest rate of scald while the third harvest had the lowest rate. However, the check fruits had the highest rate of scald and there were not significant differences between treatments with $1000 \mathrm{ppm}$ and $2000 \mathrm{ppm}$. Thus, the best treatment combinations for controlling scald are recommended as follows: 1) $2^{\text {nd }}$. harvest date, plus postharvest treatment of fruits with $1000 \mathrm{ppm}$ and 2000 ppm, DPA; 2) $3^{\text {rd }}$ harvest date, plus post-harvest treatment of fruits with 1000 and 2000 ppm, DPA. Finally the $3^{\text {rd }}$ harvest time associated with 1000 ppm DPA treatment is recognized as the most economic treatment combination for controlling scald.

10:30 a.m.-12 noon .............................................. CC 205

\section{Education Division Advisory Council} Chair: Curt R. Rom

11:00 a.m.-12 noon CC 317

\section{Awards Committee Meeting}

Chair: Donald N. Maynard

11:00 a.m.-12 noon ... CC 304

\section{VCM Business Meeting}

Chair: Laurie Hodges

11:30 a.m.-12:30 p.m. CC 318

\section{EMER Business Meeting}

Chair: William L. Sims

1:00-2:00 p.m. CC Ballroom

\section{Poster Session 1: Genetics/Breeding/Biotechnology}

Poster 1

Glucosinolate Profiles in Broccoli (Brassica oleracea): Stability over Environments and Implications for Cancer Chemoprotection

Allan F. Brown ${ }^{* 1}$, Gad G. Yousef', Elizabeth H. Jeffery', Barbara P. Klein $^{2}$, Mosbah M. Kushad', Mathew A. Wallig ${ }^{3}$ and John A. Juvik'; ${ }^{1}$ Dept. of Natural Resources and Environmental Sciences, Univ. of Illinois, 61801; ${ }^{2}$ Dept. of Food Science and Human Nutrition, Univ. of Illinois, 61801; ${ }^{3}$ Dept. of Veterinary Pathobiology, Univ. of Illinois, 61801

Ten broccoli cultivars were grown in four environments to estimate the proportion of glucosinolate variability associated with genotype, environment, and genotype x environment interaction and to identify differences in the stability of glucosinolate profiles. Genetic variability was the most important component of phenotypic variability for aliphatic glucosinolates but not for indolyl-glucosinolates. Both qualitative and quantitative differences in aliphatic glucosinolate profiles were detected among the cultivars. Differences in the stability of the aliphatic glucosinolate profiles among the cultivars were observed between the spring and fall plantings. Results suggest that genetic factors necessary for altering aliphatic glucosinolate profiles in both a qualitative and quantitative manner are present in within current broccoli germplasm and that breeding for cancer chemoprotectant activity is feasible. 


\section{Poster 2}

Genetic Diversity in Garlic (Allium sativum L.) as Assessed by Amplified Fragment Length Polymorphism (AFLP)s and Isozymes

Meryem Ipek* and Philipp W. Simon; USDA-ARS, Dept. of Horticulture, Univ. of Wisconsin-Madison, 1575 Linden Dr., Madison, WI 53706

Garlic (Allium sativum L.), an asexually propagated crop displays great morphological diversity. The genetic diversity of 46 garlic clones and three A. longicuspis clones, the proposed progenitor of A. sativum, was evaluated using AFLP. Three primer combinations of EcoRI $+4-\mathrm{Mse} \mathrm{I}+3$ (where +4 and +3 are the number of selective bases used for the corresponding primer) generated a total of 183 polymorphic fragments.. The Jaccard's similarity matrix was used for UPGMA cluster and principle component analyses. Although similarities between the clusters were low $(>0.30)$, some clones within the clusters were very similar $(<0.95)$ with AFLP analysis. Furthermore, 17 clones represented only six different types, within which they shared $100 \%$ polymorphic AFLPs. These may, therefore, be duplicates. In agreement with the results of other investigators, $A$. longicuspis and $A$. sativum clones were clustered together with no clear separation, suggesting these species are not genetically distinct. A subset of 49 clones has been analyzed with polymorphic isozyme systems. Cluster analysis of AFLP will be compared with the results of isozyme analysis.

\section{Poster 3}

Single- vs. Multiple-Row Plots in Watermelon Yield Trials Grant P. Neppl, Todd C. Wehner, and Jonathan R. Schultheis, Dept. of Horticultural Science, North Carolina State Univ., Raleigh, NC 27695-7609

Researchers interested in evaluating watermelon (Citrullus lanatus (Thunb.) Masum. \& Nakai) cultivars for yield use multiple-row plots to simulate the monoculture system growers use, or single-row plots to save on land, labor, and seeds. We were interested in whether there is significant interaction of border with center row when diverse cultivars are planted in adjacent rows. Charleston Gray, Crimson Sweet, and Sugar Baby were chosen to represent long, medium, and short vined cultivars, respectively. Cultivars were planted in threerow plots with all nine combinations of the three represented in border and center rows. The experiment was a randomized complete block with nine plot treatments, two locations (Clinton, Kinston), and three replications. Vine length was measured during the season, and fruit were graded (marketable and cull), counted and weighed at four harvests. Results showed that Charleston Gray had the longest vines, followed by Crimson Sweet and Sugar Baby. In the analysis of variance, the largest effects ( $F$ ratio size) on yield were from cultivar, location, and the interaction of the two. The smallest effects were due the interaction of center with border row, although center $x$ border interactions were significant $(5 \%$ level) in some cases. Therefore, researchers interested in running trials with many cultivars and small seed quantities can obtain good data using single-row plots. However, there is a small (but significant) interaction of center with border in some cases, so testing at the final stage should be with trials having multiple-row plots. Finally, cultivars having different plant types (dwarf vines for example) should be tested in separate trials.

\section{Poster 4}

\section{Methods for Screening Watermelon for Resistance to} Gummy Stem Blight

Ronghao Song, Todd C. Wehner*, and C. Lee Campbell; Dept.s of Horticultural Science and Plant Pathology, North Carolina State Univ., Raleigh, NC 27695

Gummy stem blight, caused by Didymella bryoniae (Auersw.) Rehm is one of the major diseases of watermelon (Citrullus lanatus (Thunb.) Matsum. \& Nakai) in the U.S. Plant breeders need sources of resistance that can be incorporated into adapted breeding lines to control the disease. In order to screen the watermelon germplasm collection for resistance, a reliable screening method is needed. Previous studies have demonstrated the importance of moisture in disease development. The objective of this study was to develop reliable greenhouse and field screening methods for gummy stem blight resistance. Pathogen isolate, spore concentration, culture age, culture growth medium, disease chamber construction, seedling age, leaf pre-damage, overhead irrigation frequency, and growth season were studied to determine optimum test conditions. Isolate $\mathrm{J}-1$ was one of most virulent and stable of the isolates tested. Pathogen culture on a medium of potato dextrose agar (PDA) provided the best disease conditions of the media tested, and a culture time of 2 to 3 weeks produced more virulence than longer growth periods. During the summer season in the greenhouse, a disease chamber having clear plastic film on the sides but not the top was better than one with sides and top. Three days of incubation was optimum for plant growth and symptom development. Damaging the leaf before inoculation, use of a high spore concentration, and high humidity at night in the greenhouse test all increased watermelon susceptibility to gummy stem blight. However, in the field, only irrigation and cultigen (cultivar or $\mathrm{PI}$ accession) affected disease development, with little effect from spore concentration, isolate, and plant pre-damage if other factors were optimum.

\section{Poster 5}

An Initial Genetic Linkage Map for Watermelon Based on Randomly Amplified Polymorphic DNA(RAPD) Markers Amnon Levi ${ }^{\star 1}$, Xingping Zhang ${ }^{2}$, Claude E. Thomas ${ }^{1}$, Tarek Joobeur ${ }^{3}$, Bruce R. Carle 4 , and Todd C. Wehner ${ }^{5}{ }^{1}$ USDA, ARS, U.S. Vegetable Laboratory, 2875 Savannah Highway, Charleston, SC 29414; 2Syngenta Seeds, Inc., 21435 Road 98, Woodland, CA 95695; ${ }^{3}$ Dept. of Plant Pathology, North Carolina State Univ., Raleigh, NC 27695-7609; ${ }^{4}$ Hollar Seeds, Inc. P.O. Box 106, Rocky Ford, CO 81067; ${ }^{5}$ Dept. of Horticultural Science, North Carolina State Univ., Raleigh, NC 27695-7609

An initial genetic linkage (RAPD-based) map was constructed for watermelon using a $\mathrm{BC} 1$ population [U.S. Plant Introduction accession (PI) 296341-FR (Fusarium resistant) x New Hampshire Midget (Fusarium susceptible)] x New Hampshire Midget. The map contains 154 RAPD markers produced by 106 primers, and includes a 700 bp SCAR marker that corresponds to a fragment produced by the RAPD primer GTAGCACTCC. This marker was previously reported as linked $(1.6 \mathrm{cM})$ to race 1 Fusarium wilt resistance in watermelon. The markers segregated to 17 linkage groups. Of these, 10 groups included 8 to 18 markers, and 7 groups included 2 to 4 markers. The map covers a genetic linkage distance of 1086.3 cM. Each of the 10 large linkage groups contained segments with low (or no) level of recombination (0-2.7 cM) among markers, indicating that the watermelon genome may contain large chromosomal regions that are deficient in recombination events. The map should be useful for identification of markers closely linked to genes that control fruit quality and Fusarium wilt (races 1 and 2 ) resistance in watermelon.

\section{Poster 6}

A Low-Resolution Genome Map for Cucurbita

Rebecca Nelson Brown* and James R. Myers; 4017 Agriculture Life Sciences Bldg., Oregon State Univ. Corvallis, OR 97331

Morphological traits, disease resistance traits, and RAPD markers were used to construct a low-resolution scaffold map of Cucurbita. The mapping population was the $\mathrm{BC} 1$ of a cross between a yellow straightneck inbred (C. pepo) and 'Nigerian Local' (C. moschata), with the yellow squash as the recurrent parent. A segregating population of 162 individuals was grown in the greenhouse along with the parental lines. Data was collected on twenty morphological traits and on resistance to powdery mildew and zucchini yellow mosaic virus. RAPD analysis was used to generate 200 molecular markers which fit the expected 1:1 segregation ratio. A map containing the expected twenty linkage groups was constructed using Mapmaker. This map is intended to serve as a foundation for further 
mapping work in Cucurbita, and as a potential source of molecular markers for use in marker-assisted selection.

\section{Poster 7}

Production of Transgenic Cucumber Plants Expressing the Arabidopsis Cold Stress-related Transcription Factors, CBF1 and $\mathrm{CBF} 3$

Rebecca Grumet ${ }^{*}$, and Mohamed S. Tawfik*; Dept. of Horticulture, Michigan State Univ., East Lansing MI 48824

Cucumber (Cucumis sativus L), like other crops worldwide, is subjected to yield losses due to abiotic stresses of cold, drought, and salinity. In an attempt to engineer enhanced stress resistance, transgenic cucumber plants (cv. Straight 8) were produced using the Arabidopsis thaliana transcription factors CBF1 and CBF3 (C-repeat binding factor). CBF genes up-regulate transcription of a group of genes designated as COR (Cold-Regulated) genes in Arabidopsis plants subjected to various stress conditions. PCR-verified shoots were transferred to the growth chamber and then greenhouse for seed production. Northern blot analysis of several transgenic individuals showed a range of expression of the 35S-CBF 1 and CBF3 genes. Successful transfer of the CBF 1 and 3 genes of T1 progeny was verified by PCR. Initial screening of three families suggested single gene integration events. Transgenic progeny are currently being tested for phenotypic responses associated with CBF expression.

\section{Poster 8}

Influence of Heterologous ACC Synthase Gene on Sex Expression of Melon

Ekaterini Papadopoulou*, S.A. Hammar, and R. Grumet; Dept. Horticulture, Michigan State Univ., East Lansing, MI

The plant hormone ethylene regulates many physiological and developmental plant processes, including sex expression in cucurbits. Application of ethylene or ethylene-releasing agents induces formation of female or perfect flower buds on melon (Cucumis melo) plants. The effect of increased endogenous ethylene production on sex determination was investigated on andromonoecious melon plants transformed with a carnation ACC synthase gene (ACS). Constitutive expression of the ACS gene increased ethylene evolution of leaves and male buds. Plants carrying the ACS gene showed one or more of the following measures of femaleness; the first perfect flower bud on the main stem appeared earlier, increased number of nodes carrying perfect flower buds and increased number of the perfect buds that reached anthesis, relative to wild type plants. The phenotypic observations indicate that the heterologous ACS gene affected sex expression of melon plants.

\section{Poster 9}

Tactical Assessment of Inter- and Intra-accession Variation in Spanish Melon using RAPD and SSR Markers

Anabel López-Sesé ${ }^{\star 1}$, Jack E. Staub ${ }^{1}$, NuritKatzir ${ }^{2}$, and María Luisa Gómez-Guillamón ${ }^{3}$ ' ${ }^{1}$ USDA/ARS, Vegetable Crop Unit, Dept. of Horticulture, Univ. of Wisconsin, 1575 Linden Dr., Madison, WI 53706; ${ }^{2}$ Newe Ya'ar Research Center, ARO, Ramat Yishay, 30095, Israel; ${ }^{3}$ Experimental Station La Mayora, CSIC, 29750 Málaga, Spain

An intra-accession marker analysis of 15 Spanish melon landraces group Inodorus (C. melo L.) of diverse geographic origin and fruit morphology was carried out as an appraisal of population structure for structuring future bulk analyses. Sixteen individuals of each accession were assessed using 100 RAPD bands produced by 36 primers, and 12 SSR loci (23 alleles). A relatively high level of polymorphism (25.5\%) was detected using RAPD markers and eight SSR loci were informative for discrimination of the accessions. Cluster analysis using RAPD- and SSR-based genetic distance estimates resulted in similar grouping of most of the accessions, generally according to their geographic origin. The mean genetic distance (GD) among accessions estimated by RAPD variation was $0.42 \pm 0.09$, and the SSR-based GD estimates were $0.29 \pm 0.15$.
Deviation from test ratio ( $53.1 \%$ of segregating RAPD markers) and from Hardy-Weinberg expectations for many putative loci per accession (91.7\% of SSR loci) suggests some populations were in genotypic disequilibrium. Although allelic fixation was detected in these populations, the relatively high level of heterogeneity indicates that these accessions possess a relatively broad genetic background. The results indicate that bulk sampling techniques coupled with molecular analysis employing discriminating markers can be effective for large collection diversity analyses.

\section{Poster 10}

Resistance to Powdery Mildew in Melon PI 313970

James D. McCreight; U.S. Dept. of Agriculture, Agricultural Research Service, U.S. Agricultural Research Station, 1636 E. Alisal St., Salinas, CA 93905

Melon (Cucumis melo L.) PI 313970 is resistant to lettuce infectious yellows closterovirus (LIYV). It was resistant to powdery mildew incited by Sphaerotheca fuliginea (Schlecht ex Fr.) Poll. during the studies on the inheritance of resistance to LIYV. Three genes were found to condition resistance of PI 313970 to powdery mildew races 1 and 2 in the $F_{1}, F_{2}$, and backcrosses from a cross with 'Top Mark'. An isolate of race 1 , which had been maintained on 'Marketer' cucumber (Cucumis sativus L.), was used for inoculation in a growth chamber $\left(25^{\circ} \mathrm{C}\right.$ with a $12 \mathrm{~h}$ photoperiod). An isolate of race 2, which had been maintained on 'Grey Zucchini' squash (Cucurbita pepo L.), was used for inoculation in a greenhouse (mean hourly temperature was $23^{\circ} \mathrm{C}$ with a natural photoperiod from April through July). Cotyledons and true leaves were evaluated on a 1 (no disease) to 9 (infected, abundant sporulation) scale. Cotyledons of PI 313970 and 'Top Mark' were susceptible to race 1 in contrast to those of 'PMR 45', 'PMR 5', PI 124111, and PI 124112 which were resistant. Cotyledons of PI 313970, 'PMR 5', PI 124111, and PI 124112 were resistant to race 2 , while 'Top Mark' and 'PMR 45' were susceptible. A recessive gene conditioned resistance of true leaves to race 1. Two genes conditioned resistance to race 2: a recessive gene for cotyledons and a semi-dominant gene for true leaves. Limited data suggest that the genes for resistance of true leaves to race races 1 and 2 may be linked. The genes for resistance to race 2 were linked with a recombination fraction of $16 \%$.

\section{Poster 11}

Study of Gene Expression in Melon Roots During Drought Stress by Differential Display

Margarita Rojas and Eliezer S. Louzada*, Texas A\&MUniv.-Kingsvile Citrus Center

The response of plants to drought stress is mediated by changes in gene expression. Although a large number of drought-induced genes have been identified in a wide range of plant species, the molecular basis for plant tolerance to water stress remains far from being completely understood. In an attempt to identify genes involved in drought stress in melon roots a comparative study of gene expression was performed using differential display RT-PCR. Total RNA was isolated from irrigated and eight-days non irrigated melon and reverse transcribed using three one base oligo dT anchored primer. High stringency PCR was performed using eight 15 mer random primers in combination with the oligo $\mathrm{dT}$ anchored primers. The PCR 33P labeled products were separated on a $6 \%$ polyacrylamide sequencing gel and the X-ray film exposed for $16 \mathrm{~h}$. Confirmation of true positive bands were performed by reverse northern blotting. The comparison of mRNA transcripts between irrigated and non-irrigated melon reveled that several genes were shut down as a consequence of the drought stress while few genes were triggered. The differentially expressed bands will be sequenced for comparison with known gene sequences already published in the database.

\section{Poster 12}

Variability for Cooking Time in Dry Bean

George L. Hosfield ${ }^{* 1}$ and James S. Beaver ${ }^{2}$; ${ }^{1}$ USDA-ARS, MWA, Dept. of Crop and Soil Sciences, Michigan State Univ., East Lansing, 
MI 48824; '2Dept.of Agronomy and Soils, Univ. of Puerto Rico, Mayaguez, PR 00681

Cooking time is a major criterion for dry bean (Phaseolus vulgaris L.) utilization in many countries of Central American and the Caribbean where this crop is a dietary staple and firewood is the main fuel source for cooking. We conducted an experiment to develop baseline data on an array of genotypes that have gained the interest of growers in the Dominican Republic, Haiti, and several Central American countries. Thirty-seven accessions consisting of cultivars and breeding lines were screened for their cooking time using a 25well Mattson pindrop cooker. The genotypes were representative of pinto, black, red-mottled, white, kidney, pink, and small-red market classes. Beans were soaked and blanched and positioned into each of the 25 cylindrical holes of the cooker. The piercing tip of the $105 \mathrm{~g}$ rod was placed in contact with the surface of each bean. Cooking time was calculated as the elapsed time from initiation of cooking until 19 of the 25 pins of the instrument had dropped and penetrated seeds in the cooker. The experiment was replicated 4 times. Significant differences were detected among genotypes which individually ranged from $1.7 \mathrm{~min}$ for MUS-N-8 (black seeded to $124.6 \mathrm{~min}$ for Tio Canela 75 (small-red). As a group, pinto beans were the fastest cooking (5.8 $\mathrm{min})$ and the small-red market class genotypes the slowest ( $80.3 \mathrm{~min}$ ). Sufficient genetic variation exists in this material to shorten cooking time through intermating and selection. Breeders in national programs where beans are a staple food would find it worthwhile to include cooking time reduction as a selection criterion in addition to yield and pest resistance.

\section{Poster 13}

The Morphological Expression of the Asp Seedcoat Gene and Its Relationship to Water Uptake and Leaching in Phaseolus vulgaris

Shawna M. Bushey ${ }^{1}$, Shirley Owens ${ }^{2}$, and George L. Hosfield ${ }^{* 1}$; ${ }^{1}$ USDA-ARS, MWA, Sugarbeet and Bean Research, Dept. of Crop and Soil Sciences, Michigan State Univ., East Lansing, MI 48824; ${ }^{2}$ Center for Advanced Microscopy, Michigan State Univ., East Lansing, MI 48824

The ability of dry seed of common bean (Phaseolus vulgaris $L$.) to imbibe water and retain their color during thermal processing is essential to providing a quality cooked product to consumers. Color leaching in black beans is especially noticeable and makes a large impact on a consumer's acceptance of a bean. Four black beans that differ in their seed coat glossiness and in their ability to imbibe water and retain color (leaching) during thermal processing were examined by Scanning Electron Microscopy (SEM) and light microscopy. The Asp gene, when dominant, causes structural changes in the seed coat to make the bean appear glossy or shiny. 'Shiny Crow' with its dominant Aspgene has a smooth, waxy cuticle, and palisade cells of a greater length than the other three varieties. Of the four varieties, 'Shiny Crow' imbibes water at the slowest rate and retains most of its black color during thermal processing. 'Raven' with its dull seed coat, imbibes water at the fastest rate and loses most of its seed coat color during thermal processing. The palisade cells of 'Raven' were shortest in length and appeared to have the thinnest waxy cuticle. 'Black Jack' and 'Black Magic' both have dull seed coats and are intermediate between 'Raven' and 'Shiny Crow' with regards to leaching and water uptake. All three of the dull seed coat varieties showed extensive texturing of the waxy cuticle. Our data suggests a relationship between the Asp gene and morphological differences in the seed coat which affect a seed's ability to imbibe water and retain its seed coat color even after heat treatment.

\section{Poster 14}

Inheritance and Heritibility of Leafhopper Resistance in Common Beans (Phaseolus vulgaris L.)

Jorge W. Gonzales" ${ }^{*}$, Dermot P. Coyne ${ }^{1}$, Dale T. Lindgren ${ }^{1}$, Kent Eskridge $^{1}$, James Steadman ${ }^{1}$, and Geunhwa Jung ${ }^{2}$; ${ }^{1}$ Univ. of Nebraska, Lincoln, NE 68583; ${ }^{2}$ Univ. of Wisconsin, Madison, WI 53706
The potato leafhopper (LH) Empoasca fabae Harris is the most important Empoasca species attacking dry beans in North America. Yield losses of about $20 \%$ were reported on susceptible bean varieties in North Platte (NP), NE. Resistance to LH injury has been identified but no heritability values for resistance have been reported. The objectives were to determine the inheritance of $\mathrm{LH}(E$. fabae) injury in dry beans, and to determine the narrow sense heritability $\left(h^{2}\right)$ of LH injury in populations derived from crosses of resistant $x$ susceptible parents. The resistant dry bean parents, Tacaragua (black) and pinto Sierra, and the susceptible great northern Starlight were used in crosses. $F_{1}$ generations were grown under greenhouse conditions to produce $F_{2}$ seed.Parents, $F_{1}$, and $F_{2}$ progenies from both crosses were grown in 1999 under field conditions at NP, NE. Parents and F3 families were planted in two different fields at NP in 2000 using a square lattice design. Visual scores $1=$ no injury to $5=$ severe injury were used to rate LH injury. SAS statistical procedures were used to analyze the data. The LH injury ratings were quantitatively inherited. The narrow sense heritability (NSH) values $(0.28 \pm 0.10,0.29 \pm 0.06)$ were estimated by regressing $\mathrm{F}_{3}$ progeny mean ratings on individual $\mathrm{F}_{2}$ plants. Low NSH estimates indicated that selection on a single plant basis in early generations would not be efficient. Testing of advanced lines in replicated trials is recommended to detect superior resistant lines. RAPD molecular markers linked to QTL for resistance to $\mathrm{LH}$ are being investigated.

\section{Poster 15}

Progress in Backcross Breeding with RAPD Molecular Markers to Pyramid QTLs for Resistance to Common Bacterial Blight in Pinto and Great Northern Beans

Nedim Mutlu*1, D.P. Coyne ${ }^{1}$, J.R. Steadman², J. Reiser ${ }^{1}$, and L. Sutton ${ }^{1} ;{ }^{1}$ Dept. of Agronomy and Horticulture, and ${ }^{2}$ Dept. of Pathology, Univ. of Nebraska, Lincoln, NE 68503

Common bacterial blight (CBB) in common bean (Phaseolus vulgaris L.), caused by Xanthomonas campestris pv. phaseoli (Xcp), reduces bean yields and quality. Pinto 'Chase' is a high-yielding variety with moderate resistance to $X_{c p}$ derived from great northern (GN) NE \#1 selection 27, whose resistance is derived from an unknown tepary ( $P$. acutifolius) bean source. XAN-159 is a black mottled small seeded breeding line with different genes for high resistance to $X c p$ derived from a different tepary source (PI 319443). Our objective was to pyramid different genes for $X c p$ resistance from the donor parent XAN-159 into the rust-resistant recurrent parents pinto 'Chase' and GN 'Weihing' using the classical backcross (BC) breeding method, with confirmation of resistance using RAPDB(SCAR) markers. Resistance was confirmed in some pinto BC4F5 and BC5F4 lines. Line and single plant selections were made in the field and are now being increased for replicated field tests. Pinto seed coat color of these lines was better than 'Chase'. Advanced CBB resistant BC pinto 'Chase' lines are being used to BC the XAN-159 genes into GN 'Weihing' because the $F_{1}$ of the cross XAN-159 x GN 'Weihing' was lethal due to the presence of dominant DL1 and DL2 genes in the parents. $\mathrm{CBB}$ resistant selections were made in $\mathrm{BC} 1 \mathrm{~F} 2$.

\section{Poster 16}

\section{Mapping Genes for Brown Spot Resistance in a SnapBean} Population

James Nienhuis*; Dept. of Horticulture, Univ. of Wisconsin, Madison, WI 53706

Brown spot by Pseudomonas syringae pv. syringae is a disease of snapbeans (Phaseolus vulgaris) which results in reduced pod quality. A recombinant inbred population consisting of 72 inbred lines was developed from a cross between 'Puebla' (resistant) and 'Eagle' (susceptible). The Eagle $x$ Puebla population was evaluated phenotypically for disease resistance in the field and also quantitatively using the leaf freezing assay. $42 \%$ of the observed field variation for brown spot was explained by leaf freezing data. The leaf freezing assay is a methodology for quantifying bacterial populations which is specific for ice nucleating bacteria such as Pseudomonas. Molecular data for 212 mapped RAPD markers was combined with available leaf freezing 
and phenotypic data to detect quantitative trait loci associated (QTL) with brown spot resistance. QTLs detected from the Eagle $\times$ Puebla population were consistent with the main QTLs previously identified by Dr. Geunhwa Jung in a similar experiment using an independent dry bean population (BelNeb $x$ A55). The genetic variability present in the population, the reliability of the leaf freezing assay evaluation and the polymorphic markers used provided an important way for the detection of factors associated with brown spot resistance. Markers associated with resistance to brown spot and lines carrying resistance to it should prove important in the development of high quality, disease resistant snapbeans varieties in the near future.

\section{Poster 17}

STS Markers for Comparative Mapping in Legumes

N.F. Weeden ${ }^{* 1}$, R.L. Murphy ${ }^{1}$, J.G. Walling ${ }^{1}$, J.A. Przyborowski and S. Brauner ${ }^{3} ;{ }^{1}$ Dept. Plant Sciences and Plant Pathology, Montana State Univ.; ' 2 Dept. of Plant Breeding and Seed Production, Univ. of Warmia \& Mazury in Olsztyn; ${ }^{3}$ Dept. of Biology, Ashland Univ.

PCR primers for $\approx 40$ genes have been developed in pea (Pisum sativum L.). Most of these primers also amplify homologous sequences in other legume genera, including Lens, Phaseolus, and Lupinus. The primers were designed to be complementary to highly conserved sequences in exons of known genes. In addition, the priming sequences were selected to be 1000 to $5000 \mathrm{bp}$ apart on the genomic DNA and to amplify a fragment that contained at least one intron. Sequence polymorphism was observed by restriction of the amplified fragment with an endonuclease with a 4-base recognition site. Mapping of these genes in lentil and pea indicate that the primers should have general utility for comparative mapping in legumes. The possible use of these STS markers within domesticated pea is discussed.

\section{Poster 18}

\section{Genetic Dissection of Tolerance to Common Root Rot} (Aphanomyces euteiches) and Other Root Pathogens in Pea (Pisum sativum)

N.F. Weeden ${ }^{\star 1}$, R.J. McGee ${ }^{2}$, L. Hadwiger ${ }^{3}$, R.L. Murphy', C.R. Grau $^{4}$, D.E. Mathre ${ }^{1}$, J.A. Przyborowskis, and F.J. Muehlbauer6; ${ }^{1}$ Dept. Plant Sciences and Plant Pathology, Montana State Univ.; ${ }^{2}$ Pillsbury Ag. Research Dept, Le Sueur, MN; ${ }^{3}$ Dept. Plant Pathology, Washington State Univ.; ${ }^{4}$ Dept. Plant Pathology, Univ. of WisconsinMadison; ${ }^{5}$ Dept. of Plant Breeding and Seed Production, Univ. of Warmia \& Mazury in Olsztyn; ${ }^{6} U S D A-A R S$, Washington State Univ.

Several recombinant inbred populations derived from crossing the Aphanomyces-tolerant line MN313 with different susceptible lines were subjected to analysis of the genes involved in the tolerant response. The RIL populations were grown on Aphanomyces-infested fields in two locations, LeSueur, MN and Pullman, WA. The relative and absolute responses among the RILs differed between the two localities, suggesting that different combinations of pathogens or races of Aphanomyces euteiches were present in the two fields. At Le Sueur several regions of the pea genome were associated with tolerance except in one population. This latter population consisted of over $50 \%$ highly tolerant lines, with susceptibility being mapped to a single region on linkage group VII. At Pullman most populations displayed little variation among the lines for tolerance. However, one population gave a monogenic segregation pattern that appeared to be due to the gene DRR49. These results will be discussed in terms of candidate genes and the genetic basis of tolerance in MN313.

1:00-2:00 p.m. CC Ballroom

\section{Poster Session 2: Propagation/Tissue Culture \\ Poster 91}

In Vitro Culture of Some Cultivars of Date Palm (Phoenix dactylifera L.) in Saudi Arabia

N. Al-Khalifah*, R. Okawara, Y. Al-Hafidh, M. Yaneshita, T. Omura, F. Khan, E. Askari, and A. Al-Hindi; King Abdulaziz City for Science and Technology, Riyadh 11442, Saudi Arabia
This study is part of a Saudi- Japanese joint research program on the cultivation of date palm in Saudi Arabia. It deals with the in vitro culture of some cultivars, i.e., Barhee, Khowriah, Sabbaka, Shakra, and Sukkary. Shoot tip and 4-5 young unformed leaves were considered as explant and sterilized with sodium hypochlorite and mercuric chloride. Modified Murashige and Skoog media with sodium monophosphate, sugar, inositol glutamine, glycine, Thiamine $\mathrm{HCl}$, pyridoxine, nicotinic acid, calcium pantothenate, 2,4-D, kinetin, 2iP, NAA activated charcoal and agar were used at a pH of 5.6. Barhee and Khodriah showed good response to the media and culture conditions, showing good initiation of callus and embryogenesis and they produced embryos within 6 months of initial culture. Sabbaka, on the other hand, exhibited slow growth and only callus was developed, and, similarly, Shakra exhibited poor response, with minimal callusing tendency. The growth of Sukkary was excellent and the callus development started within 3 weeks of the initial culture. It is yet early to relate such responses to any factor.

\section{Poster 92}

Somaclonal Variation in Tissue Culture-derived Date Palm (Phoenix dactylifera) Trees

Abdelrahman S. AL-Wasel*; King Saud Univ., Dept. of Horticulture and Forestry, P.O. Box 1482. Al-Qassim, Saudi Arabia

Somaclonal variants arose among populations of in vitro-derived date palm trees of Barhee and Khalas cultivars. Dwarfism and abnormal floral development most often occurred. A total of 42 of Barhee from 234 trees (17.9\%) in the first plantation were dwarf with packed leaves around their trunk and 126 dwarf trees from a total of $1026(12.3 \%)$ trees of Barhee in the second plantation, whereas, Khalas cultivar exhibited $53(24.3 \%)$ and $72(17.9 \%)$ dwarf trees with packed leaves, as well, from a total of 218 and 403 trees in the first and second plantations, respectively. Average height of dwarf trees of both cultivars varied from 36.1 to $102.7 \mathrm{~cm}$ after 4 years of transplantation while the height of normal trees varied from 152.6 to $214.3 \mathrm{~cm}$. Leaves with albino stripes in their mid ribs and albino and variegated leaflets were also observed in Khalas cultivars with frequency of $0.25 \%$ to $1 \%$. A large number of mature trees of Barhee in all plantations failed to set fruits in comparison to normal in vitro derived trees or offshoot-derived trees of the same cultivar. About 786 trees out of $1000(78.6 \%)$ trees in the first plantation and 296 $(59.2 \%)$ out of 500 trees and $430(86.0 \%)$ trees out of 500 trees transplanted in 1992 and 1993 in the second transplantation, respectively, were not able to set fruits. Supernumerary carpels $(4,5$, and 6 carpels) developed with frequency of $7.8 \%$ to $16.9 \%, 2.4 \%$ to $7.7 \%$, and $0.7 \%$ to $3.5 \%$ for 4,5 , and 6 carpels, respectively. Very low frequency $(1.5 \%$ to $5.6 \%$ ) of twisted spikelets also occurred.

\section{Poster 93}

Plant Regeneration from Seedling Explants of the Vine Cactus Selenicereus megalanthus (Yellow Pitaya) Ram Avtar Kaushik*1, Dan Pelah ${ }^{*}$, Yosef Mizrahi1 ${ }^{2}$, and Yaron Sitrit'; 'The Institutes for Applied Research and ${ }^{2}$ Dept. of Life Sciences, Ben-Gurion Univ. of the Negev, Beer-Sheva 84105, Israel

Yellow pitaya fruits are becoming popular among consumers because of their good taste and attractive appearance. However, there is still a need for improvement of the germplasm to enhance a number of quality traits. To achieve this in a short period of time, genetic transformation via tissue culture has been chosen. A prerequisite for genetic manipulation is the development of a regeneration protocol. To this end, segments were excised from distal and proximal parts of the cotyledons, hypocotyles and epicotyls. The segments were sterilized and placed on Murashige \& Skoog (MS) medium containing serial concentrations $(100,200$, and $400 \mu \mathrm{mol})$ of Thidiazuron (TDZ). Segments of proximal part of the cotyledons were found to be the most responsive explants. Maximum bud regeneration was achieved in the presence of 200 micromoles TDZ. For shoot elongation, organogenic callus was transferred to various media with and without growth regulators. MS medium lacking plant growth regulators was found to be the best medium for shoot 
elongation. Shoots were rooted on MS medium supplemented with 5.3 micromoles naphthalene acetic acid. After the plantlets had rooted, they were transferred to a soil medium and acclimatised successfully in a greenhouse. In conclusion, this protocol may provide a tool for future genetic transformation of yellow pitaya.

\section{Poster 94}

Response of Jojoba Propagules to Ventilation in the First Two Stages of Micropropagation

David Mills*, Zhou Yanqing, Ruth Friedman, and Aliza Benzioni; The Institutes for Applied Research, Ben-Gurion Univ. of the Negev, P.O. Box 653, Beer-Sheva 84105, Israel

Jojoba (Simmondsia chinensis) plants grown in vitro are characterized by anatomical, morphological, and physiological disorders that lead to difficulties in acclimatizing the plants ex vitro. The objective of this research was to examine ventilation of jojoba propagules in vitro as a means of facilitating better acclimatization ex vitro. Jojoba propagules were grown in vessels capped with lids with different membrane sizes to permit a range of ventilation rates. At the proliferation stage, ventilated jojoba shoots, generally elongated faster, developed bigger leaves and more nodes, and accumulated more dry biomass. The response to ventilation varied among clones. At the elongation stage, reduced relative humidity sometimes caused tip necrosis depending upon ventilation rate and the particular clone. In such cases, however, the original apex was rapidly replaced by an auxiliary bud. At high ventilation rates, there was a reduction in shoot length and number of leaves and an increase in leaf surface area, fresh and dry weights, and percentage of dry matter. Under ventilation jojoba propagules were less vitrified: water content was lower, more wax was deposited on leaf surfaces, and cells were more lignified, had a better developed vascular system, and were more resistant to water loss. It has yet to be shown that the improved leaf structure obtained as a result of ventilation facilitates acclimatization of jojoba plantlets ex vitro.

\section{Poster 95}

\section{A Comparison of Somatic Embryogenesis Capacity among} Various Long-term Subcultured Citrus Calli

Langtao Xiao*1, Jiajin Hu', and Carol J. Lovatt ${ }^{2}$; Hunan Agricultural Univ., PRC; Xiuxin Deng, Huazhong Agricultural Univ., PRC; ${ }^{2}$ Univ. of California, Riverside, $C A$

Long-term subcultured calli of Newhall Navel Orange (Citrus sinensis Osbeck cv. Newhall) and Valencia Orange (Citrus sinensis Osbeck cv. Valencia) were cultured to study the capacity of their somatic embryogenesis. The results indicated that after these calli (subculture for five years in MT medium supplemented with $5 \%$ sucrose) were transferred onto multiplication medium (MT medium supplemented with $3 \%$ sucrose), they all divided and multiplicated rapidly. Some somatic embryos occurred on embryogenic callus pieces of Newhall and calli of Valencia (diploid) as well. The frequency of somatic embryogenesis for embryogenic calli was $36.7 \%$ for Newhall and $45.2 \%$ for Valencia (diploid) respectively. Most of these formed somatic embryos were white and abnormal, few were green and globular embryo; but no somatic embryos formed on non-embryogenic calli from Newhall Navel and calli from Valencia (tetraploid and hexaploid). 2 weeks after those white or light yellow calli formed on multiplication medium were transferred onto differentiation medium (MT medium supplemented with $30 \mathrm{ml} / \mathrm{L}$ glycerol), a large number of green and globular or heart-shaped somatic embryos occurred on embryogenic callus pieces of Newhall and calli of Valencia (diploid). Both calli had a somatic embryogenesis frequency of $100 \%$. In addition, a few green or white somatic embryos also occurred on calli from Valencia (tetraploid) $18.2 \%$. No somatic embryos formed on non-embryogenic calli of Newhall and calli of Valencia (hexaploid).

\section{Poster 96}

Rooting Ability of Walnut Cultivars and Peroxidase Analysis Kourosh Vahdati*, Pedro Martinez-Gomez, Charles Leslie, and
Gale McGranahan; Dept. of Pomology, Univ. of California, Davis, CA 95616

The rooting ability of four cultivars of Persian walnut (Sunland, Chandler, Chandler1 and Vina) was studied. In vitro shoots were cultured in the induction medium (MS gelled with Kobe Agar supplemented with IBA, $3 \mathrm{mg} / \mathrm{L}$ ) for a week and transferred to the development medium (1/4 DKW + vermiculite, 25\%). Rooting indexes were measured after 4 weeks. Walnut cultivars exhibited a clear difference in rooting ability in the same medium. Isozyme analysis was utilized to identify markers associated with the rooting ability of the studied cultivars. Peroxidase activity has been shown to be a good marker for walnut rooting. Peroxidase isozymes were analyzed using the horizontal starch gel system. Differences in the presence and intensity of the peroxidase bands and polymorphic behavior were observed. The implication of these results in the micropropagation of walnut is discussed.

\section{Poster 97}

\section{Micropropagation of Paradox Walnut Rootstock}

Parakrama de Gurusinghe, Tina Uppal, and Parm Randhawa; California Seed and Plant Lab, 7877 Pleasant Grove Rd., Elverta, CA 95626

Paradox, a natural cross between Black x English walnut, is a preferred root stock for walnuts. Because of seed to seed variability, clonal propagation is desired by the walnut industry. There have been some attempts to propagate Paradox by cuttings or through tissue culture but the success was limited. As a result, there is no commercial program in operation in the United States. We compared two tissue culture protocols (Driver and Kuniyuki, 1984; Allemand et al., 1992) using two California sources of Paradox. Allemand et al. protocol differs from Driver and Kuniyuki protocol in having less IBA in the multiplication medium and incorporation of vermiculite in the rooting medium. We observed that Allemand et al protocol consistently produced higher number of explants in 3-week multiplication cycles. In addition, the internodal lengths of shoot produced by Allemand et al. protocol were significantly longer $(11.3 \mathrm{~mm})$ than Driver and Kuniyuki protocol $(4.68 \mathrm{~mm})$. Three-week-old shoots were root induced for 5 days and rooted on the rooting media. Rooting efficiency was variable from experiment to experiment over one year period. Allemand et al. protocol produced $60 \%$ to $80 \%$ rooting whereas Driver and Kuniyuki produced only $30 \%$ to $40 \%$ rooting. Root quality was also superior in the Allemand et al. protocol. However, overall quality of plants varied among various experiments. In some experiments, the leaves turned yellow and abscised due to unknown reasons. Rooted cuttings from Allemand et al. protocol were acclimatized in the greenhouse under humid conditions maintained by wet burlap, mist, and plastic tent. Recovery rate in the greenhouse was variable from $10 \%$ to $80 \%$. The main reason of poor recovery of the rooted shoots appeared to be poor health of rooted cuttings coming out of the tissue culture room. Over $80 \%$ of the rooted plants shed all the leaves and had no active apical buds despite of vigorous roots. Plants that survived in the greenhouse continued to grow when transferred to bigger pots maintained outside the greenhouse. Further optimization of various factors to produce healthy plants on consistent basis is in progress.

\section{Poster 98}

Evaluation of Citokinines on Regeneration In Vitro of Pitahaya (Hylocereus undatus $\mathrm{H}_{\text {.) }}$

J.L. Narváez González¹, M.A. Bustamante García ${ }^{2}$ E. Payró de la Cruz ${ }^{* 1}$ and S. González Guzmán ${ }^{3}{ }^{1}$ Inst. Tecnol. Agrop. \# 28. Zaragoza s/n. Ocuiltzapotlán, Tabasco 86100, México; ${ }^{2}$ U.A.A.A.N. Saltillo Coahuila; ${ }^{3}$ Fac. de Cien. Biol. Agrop. Univ. de Colima. Tecomán, Colima, 28100. México

Hylocereus undatus $\mathrm{H}$. is a tropical cactaceus highly cotice-like exotic fruit in the international market. The objective of this work was to determine the concentration and type of citokinines that better induce the pitahaya's regeneration in vitro. Shoot's segments of $1 \mathrm{~cm}$ of length were dissected from aseptics plantlets and cultivated on 
MS culture medium supplemented with several concentrations of thiadiazuron (TDZ) or benziladenine (BA). After 24 incubation days on direct light, we found that TDZ at $1 \mu \mathrm{m}$ and BA at 4, 6, $810 \mu \mathrm{m}$ induced the same number of shoots by explant (17-20). However the longitud of the induced shoots by TDZ $(0.5 \mathrm{~cm})$ was minor that they induced by BA $(1 \mathrm{~cm})$. The number of shoots in the cultivations without citokinines was lower. In contrast to BA, the callus formation was stimulate to higer levels that $\mu \mathrm{m}$ by TDZ. This results, allows to broaden the field for futures researches.

\section{Poster 99}

Evaluation of Grafting Methods in Macadamia (Macadamia sp.) in the Dry Tropic of Mexico

J.M. González-González*, M. Vázquez-Gonzaga, J. Molina-Ochoa, R. Lezama-Gutiérrez, J.G. Lorenzana-Salazar, and L. VidalHernández; Universidad de Colima, Facultad de Ciencias Biológicas y Agropecuarias, A. P. 36, Tecomán, Colima, 28100, México

Macadamia is Australian rainy forest nut tree from the Subtropical Region. It is a woody tree that produces a rich nut in proteins, carbohydrates, minerals and vitamins, its products and byproducts in pharmacology and snack are used. Grafting in Macadamia is a difficult procedure, because its wood is fragile and hard, exceptionally. Grafting requires a $1 \mathrm{~cm}$ scion diameter, an age about 2 to 3 years and low number of leaves, and girdling on the bottom and without active growing. The objective was to evaluate the grafting methods, splice side graft, wedge graft and whip graft and their success in Macadamia in Colima, Mexico. The experiment was conducted in Federal Nursery belonging to Secretaria de Agricultura, Ganadería y Desarrollo Rural at Asmoles, Colima. Twenty-monthold Macadamia rootstocks, 2-cm stem diameter and $80-\mathrm{cm}$-high plants were used. The terminal scions without previous girdling from 15-year-old trees, vigorous and productive, insect pest and disease free were obtained from a commercial orchard located at Comala, Colima. The scions were disinfected with fungicide and used the same day of the excision. The grafting methods, splice side graft, wedge graft and whip graft, were evaluated. The experiment was distributed under a completely randomized design. Success in grafting was only observed in splice side graft with $35 \%$. Terminal scion without previous girdling and immediately after the excision used showed $35 \%$ of grafting, 28.4 days for grafting success, 2 buds, $7.8 \mathrm{~cm}$ bud length, and 9.3 leaves/bud. This is the first report of success in grafting of Macadamia in the dry tropic of Mexico.

\section{Poster 100}

Evaluation of Three Grafting Methods for Propagating Tamarindus in the Western Coastal Region of Mexico J.M. González-González*, J. Molina-Ochoa, R. Fonseca-Gongora, and L. Vidal-Hernández; Universidad de Colima, Facultad de Ciencias Biológicas y Agropecuarias, A.P. 36, Tecomán, Colima, 28100, México

Tamarindus (Tamarindus indica L.) is reproduced by seeds from Criollo cultivars in Mexico. The replication of desirable agronomic traits is difficult when selected plants are from sexual reproduction. The heterogeneity of plants is observed as higher trees, irregular fresh fruit yield, variable fruit quality, differential insect pest and disease susceptibilities and lower number of plants per hectare, and extended period for recovering the invest, and problems of commercialization due to fruit quality and price. Vegetative propagation is an alternative for reducing the heterogeneity of Tamarindus trees. Three grafting methods for propagating Tamarindus in the Coast of Colima, Mexico, splice side graft, wedge graft and bud graft, were evaluated. The experiment was carried out in a commercial nursery in Tecoman, Colima. Rootstocks were from 8-months healthy plants with $1 \mathrm{~m}$ height, and $1 \mathrm{~cm}$ diameter, obtained from Criollo seedlings, and the scion was obtained from a healthy 15-year old "Criollo Veracruz" donator tree. This donator was selected for its excellent agronomic traits and fruit yield. Naturally defoliated, vigorous and terminal scions were used, these were disinfected with fungicide and used the same day of excision. The experiment was distributed under a completely randomized design. Splice side grafting had $79.1 \%$ of success 20 days after, wedge graft and bud graft had $0 \%$ of success.

\section{Poster 101}

Response of Sapodilla (Achras sapota L.) to Five Grafting Methods and Three Grafting Periods

J.M. González-González*, R. Ruíz-Bello, C.M. Hernández-Suárez, J. Molina-Ochoa, and L. Vidal-Hernández; Universidad de Colima, Facultad de Ciencias Biológicas y Agropecuarias, A. P. 36, Tecomán, Colima, 28100, México

Sapodilla (Achras sapota L.) is mostly propagated by seedlings. This procedure produces plants from genetic recombination that shows heterogeneity in fruit size and quality, plant vigor, and variation in phenotypic characteristics into the orchards. Plants in Sapotaceae have certain failures in grafting due to latex flowing from the performed cuts in the rootstock and scion. The response of $A$. sapota to five grafting methods and three grafting periods was determined. The experiment was carried out during three grafting periods: May, August, and September. Each period had four grafting dates (each week of the month), and 2-year-old Criollo Sapodilla rootstocks with $\approx 1-\mathrm{cm}$ diameter, selected by vigor and health, were used. Grafting height on the rootstocks was $\approx 20 \mathrm{~cm}$ from the ground. Five grafting methods, splice side graft, whip side graft, whip graft, wedge graft, and bud graft, were evaluated. Terminal and vegetative buds from 10-year-old 'Betawi' cultivar were excised and used during the grafting dates and disinfected with fungicide. The experimental units were distributed in a split-plot randomized block design, and data were performed for ANOVA and means separated by Tukey's test. The best grafting method was splice side graft, with $\approx 96 \%$ accumulated grafting percent during May and the best results during weeks 2,3 , and 4 , with same grafting percent (75\%). Whip side graft had $95.2 \%$, whip graft $91 \%$, wedge graft $84 \%$ and bud graft $4.3 \%$. The latex flowing had no influence on the graft success.

\section{Poster 102}

The Effect of BAP and IBA on the In Vitro Multiplication of Blackberry (Rubus idaeus) cv. Tupy

Alan Cristiano Erig ${ }^{1}$, Gerson Renan de Luces Fortes ${ }^{\star 2}$, and Andrea de Rossi'; ' ${ }^{1}$ FAEM/UFPel - P.O. Box 354, 96001-970- Pelotas, RS, Brazil; '2Embrapa Temperate Climate, P.O. Box 403, 96001-970, Pelotas, $R S$

This work aimed to evaluate the effect of BAP $(0.0 ; 2.0 ; 4.0 ; 6.0$; 8.0 and $10.0 \mathrm{~mm})$ and IBA $(0.0 ; 0.5$ and $1.0 \mathrm{~mm})$ on the in vitro multiplication of blackberry, cv. Tupy. The MS nutrient medium was used added with myoinositol (100.0 mg $\left.\cdot \mathrm{L}^{-1}\right)$, sucrose $\left(30 \mathrm{~g} \cdot \mathrm{L}^{-1}\right)$ and agar $\left(6.0 \mathrm{~g} \cdot \mathrm{L}^{-1}\right)$. The explants were inoculated in flasks and then kept at 16 hours photoperiod, temperature of $25 \pm 2{ }^{\circ} \mathrm{C}$ and $25 \mu \mathrm{mol} \cdot \mathrm{m}^{-}$ ${ }^{2} \cdot \mathrm{s}^{-1}$ radiation. The number of buds and shoots was evaluated weekly for one month. In the final evaluation, it was also taken into consideration the plantlet height and the rate of multiplication. In the absence of IBA, it was observed a higher number of buds; and the presence of BAP in the medium promoted the highest number of buds at $2.0 \mathrm{~mm}$, which was achieved in the third week of cultivation. IBA at 0.0 and $1.0 \mathrm{~mm}$ promoted a linear decrease in plantlet height when associated with increase in BAP concentrations. It was also observed that an increase in BAP levels for all IBA levels reduced the plantlet height. IBA at 1,0 mM associated with BAP influenced negatively the rate of multiplication at $5.9 \mathrm{~mm}$ BAP. BAP with no IBA addition promoted an increase in the rate of multiplication up to 5.1 $\mathrm{mm}$. IBA at $0.5 \mathrm{~mm}$, associated with all levels of BAP, did not influence significantly the rate of multiplication.

\section{Poster 103}

Field Performance of Strawberry Plugs Propagated from Micropropagated Runner Tips Compared to Conventional Nursery Stock as well as the Influence of Summer Growing Environments on Marketable Yield and Fruit Size of 'Chandler' and 'Camarosa'

E. Barclay Poling ${ }^{* 1}$ and Gordon S. Miner ${ }^{2}$; ${ }^{1}$ Dept. of Horticultural 
Science, ${ }^{2}$ Dept of Soil Science, North Carolina State Univ., Raleigh, NC 27615

A number of diseases are still having a great economic impact on the North Carolina strawberry industry, including anthracnose. Canadian nurserymen, who supply strawberry transplants to North Carolina growers, have indicated a definite interest in having a cleaner source of stock plants, especially for 'Chandler' and 'Camarosa'. The plants they supply to North Carolina have essentially had three years of field exposure since leaving the screenhouse ( 2 in California, 1 in Canada). The North Carolina Micropropagation Unit can produce disease free micropropagated plants of 'Chandler' and 'Camarosa' for runner tip production in a controlled greenhouse environment during the winter. A number of important interrelationships are being addressed in this research project, including how plant stock (micropropagated or conventional) and growing environment (greenhouse or field) may act to influence the field and fruiting performance of two important commercial strawberry plasticulture cultivars in North Carolina, Chandler and Camarosa. Based on one year of data (1999-2000) we observed that: 1) Chandler was $24 \%$ more productive than 'Camarosa'; 2) plant type (micropropagated vs. conventional Calif. "purple tag") was not a statistically important effect for marketable yield, but there was a trend towards slightly higher yields for the micropropagated source; 3) field grown tips produced a statistically significant higher marketable yields the greenhouse-raised tips; and, 4) there was a significant cultivar $x$ location interaction for 'Chandler', but not for 'Camarosa'. Essentially, 'Chandler' yields were higher when runner tips were produced in a cooler mountain region compared to the coastal plain.

\section{Poster 104}

\section{Clonal Propagation of Pistachio Rootstock by Rooted Stem} Cuttings

Ali A. Almehdi, Dan E. Parfitt*, and H. Chan; Dept. of Pomology, One Shields Ave., Univ. of California, Davis CA 95616

The most widely used pistachio rootstock, UCB-1, was propagated by leafy cuttings using five mature trees that were pruned severely for two consecutive years. Three shoot lengths, three cutting positions and four different IBA concentrations were tested. Tree, cutting position, year and the interactions of tree $x$ cutting position, tree $\mathrm{x}$ year, cutting position $\mathrm{x}$ year, and tree $\mathrm{x}$ cutting position $x$ year were significant. IBA concentration, shoot length, Julian date, and the interactions of tree $x$ IBA, IBA $x$ cutting position, IBA $x$ year, tree $x$ IBA $x$ cutting position, tree $x$ IBA $x$ year, IBA $x$ cutting position $x$ year, tree $x$ IBA $x$ cutting position $x$ year were not. $83 \%$ rooting was obtained using the upper cutting position of the $90-\mathrm{cm}$ long shoot from seedling tree in 1999 . Survival rate was $91 \% \pm 4 \%$.

\section{Poster 105}

\section{Comparative In Vitro Culture of White and Green Ash from Seed to Plantlet Production}

J.W. Van Sambeek ${ }^{1}$ and John E. Preece ${ }^{*_{2}}$; North Central Research Station, USDA Forest Service, 202 Natural Resource Bldg., UMC, Columbia, MO 65211-7260; Dept. of Plant, Soil, and General Agriculture, Southern Illinois Univ., Carbondale, IL 62901-4415

Procedures have not been reported for the routine micropropagation of green ash (Fraxinus pennsylvanica). In this study we compared the in vitro response of green ash using procedures developed for white ash ( $F$. americana). Mature fruits were collected from four trees of each species, air-dried, and refrigerated. Fifteen cut seeds from each source tree were established on MS supplemented with $3 \mu \mathrm{M} \mathrm{TDZ}, 1 \mu \mathrm{m} \mathrm{BA}$, and $1 \mu \mathrm{m}$ IBA alternating bi-weekly between liquid overlays and new agar-solidified medium. After four weeks, more than $80 \%$ of seeds for both species had germinated with most germinants having poorly developed roots, well developed cotyledons, and 5 to $10 \mathrm{~mm}$ long epicotyls. At week 4, epicotyls with cotyledons attached were subcultured vertically on new medium. Four weeks later, less than $20 \%$ of the green ash explants had produced axillary shoots while more than $60 \%$ of white ash shoots had produced 2 or more axillary shoots primarily from the cotyledon- ary node. At week 8 , epicotyls only were subcultured vertically. Four weeks later, green ash epicotyls had produced nearly twice as many axillary shoots (5.8) as the white ash epicotyls (3.1). At week 12, axillary shoots were divided into two-node segments and subcultured horizontally. Four weeks later, white ash segments had produced 1 to 2 axillary shoots per node and had nearly twice as many axillary shoots as the green ash segments. Ten microshoots from each clone were pulsing on quarter-strength MS supplemented with $5 \mu \mathrm{M}$ IBA and $5 \mu \mathrm{M}$ NAA for 8 days before transferring to auxin-free MS medium. Microshoots of most clones had rooted within 3 weeks. The four white ash sources averaged two adventitious roots per microshoot while the green ash sources averaged between 2 and 3.5 roots per microshoot. Plantlets transferred to sterile potting medium and placed under a mist bench initiated new shoot growth within a few weeks.

1:00-2:00 p.m. CC Ballroom

\section{Poster Session 3: Crop Production \\ Poster 132}

Effect of Four Different Rootstocks on 'Gala' Apple Fruit Size Yahya K. Al-Hinai* and Teryl R. Roper; Dept. of Horticulture, Univ. of Wisconsin-Madison, Madison, WI 53706

Apple growers receive higher prices for larger fruit. The effect of rootstock on scion fruit size is not clear. This study was conducted during the 2000 growing season at the Peninsular Agriculture Research Station near Sturgeon Bay, WI on 6-year-old 'Gala' apple trees (Malus domestica Borkh.) on dwarfing rootstocks. The effects of four different rootstocks (EMLA 26, V-605-1, Ottawa 3, and Pajam 1 ), fruit loads, and their interactions on fruit size were investigated by measuring fruit diameter weekly. The results indicated that there were no differences between rootstocks in fruit size regardless fruit load. However, there was a linear relationship between fruit size and fruit load indicating that increasing fruit load decreases fruit size. Fruit volume and weight measurements at harvest also showed no differences between rootstocks in fruit size. No significant differences were found in cell counts between rootstocks. This indicates that apple fruit size could be affected more by fruit load and other factors rather than rootstock.

\section{Poster 133}

Cultivar and Rootstock Influence Fruit Size, Red Color, Packout, and Dollar Value of Crop in 1990 NC-140 Apple Rootstock Trial

John A. Barden*, and Richard P. Marini; Dept. of Horticulture, VA Tech, Blacksburg, VA 24061

An NC-140 apple cultivar/rootstock trial was conducted near Blacksburg, VA from 1990-1999. Cultivars were 'Golden Delicious', 'Jonagold', 'Empire', 'Rome', 'Stayman', and 'York'. Rootstocks were Mark, Ottawa 3 (O.3), Budagovsky 9 (B. 9), Malling 9 EMLA (M.9EMLA) and Malling 26 EMLA (M.26EMLA). There were six single-tree replications in a randomized complete-block design. Trees were spaced at $2.5 \times 5.0 \mathrm{~m}$, and were trained as modified slender spindles. Support was provided by a $3 \mathrm{~m}$ bamboo stake supported by a single wire at $2.5 \mathrm{~m}$. When judged to be commercially mature, all trees of each cultivar were harvested in a single harvest. Fruits from individual trees were sized with a chain sizer (1992-94) or a weight sizer (1995-99). In some years and with selected cultivars, a 20 fruit random sample was taken for visual estimation of $\%$ red color. Our objective was to evaluate the cultivar and rootstock effects on fruit size, color, and packout. Over the 8 years of this part of the study, there were very few significant cultivar $x$ rootstock interactions so main effects are presented. Fruit size was largest for 'Rome' and 'Jonagold', intermediate for 'Stayman' and 'York', and smallest for 'Golden Delicious' and 'Empire'. Trees on M.26EMLA and M.9EMLA produced somewhat larger fruit than trees on Mark and O.3; fruit from trees on B.9 were intermediate. Red color was affected by rootstock, but the effect varied among cultivars. Projected dollar value/tree based on yield, fruit size, and red color was 
greatest for trees on M.26EMLA and M.9EMLA, intermediate for trees on O.3, and lowest for trees on Mark and B.9.

\section{Poster 134}

Clonal Rootstocks Affect Performance of 'Harvest Queen' Pear

David M. Hunter*; Agriculture and Agri-Food Canada, Southern Crop Protection and Food Research Centre, 4902 Victora Ave. N., P.O. Box 6000, Vineland Station, ON LO

Rootstock trials were planted in 1976 and 1977 at Harrow, Ontario, Canada, to evaluate the performance of 'Harvest Queen' pear on clonal rootstocks [Old Home x Farmingdale ( $\mathrm{OHxF}$ ) clones $51,69,87$, and 181, and Quince A] in comparison with trees on Bartlett seedling rootstocks. The most productive rootstocks were

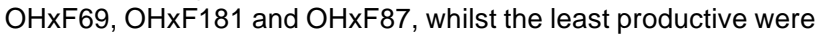
$\mathrm{OHxF333}$ and Quince A. Mean fruit weight was greatest on OHxF69 and $\mathrm{OH} x \mathrm{~F} 87$. Trunk cross-sectional area was greatest on $\mathrm{OHxF69}$, and smallest on $\mathrm{OHxF333}$ and Quince A. Cropping efficiency (accumulated yield/trunk cross-sectional area) was greatest on OHxF181 in the 1976 trial, and OHxF51, OHxF69 and OHxF87 in the 1977 trial. No rootstock differences were observed for fruit maturity. Based on the results from these trials, OHxF69 and $\mathrm{OHxF87}$ are suitable clonal rootstocks for Ontario pear production.

\section{Poster 135}

Performance of Hedelfingen and Montmorency Varieties on New Cherry Rootstocks in Michigan

Ronald L. Perry ${ }^{* 1}$ and Gail V. Byler ${ }^{2}{ }^{1}$ Dept. of Horticulture, Michigan State Univ., ${ }^{2}$ Clarksville Hort. Experiment Station, Clarksville, MI

Trees were established in the NC-140 cherry rootstock trial at the Northwest Horticulture Research Station in Traverse City, Mich., in 1998. Trees of Hedelfingen and Montmorency were established on 19 and 12 rootstocks, respectively. The trials are adjacent to each other and are arranged in an experimental design in single plant plots with rootstock treatments replicated 8 times in a randomized complete-block design. Hedelfingen is most dwarfing on rootstocks Gi.209/1, Edabriz, Gi.5 and Weiroot 53. Seven treatments are dwarfing the scion $50 \%$ or less in vigor compared to trees on Mazzard (standard) seedling rootstock. The most precocious trees in 2000 were on Gi.209/1, Gi.7, Gi.195/20, and Gi.5 (measured by blossom cluster density per trunk cross sectional area). All rootstocks in the Montmorency trial are less vigorous than the standard Mahaleb seedling rootstock. Trees on Gi.5, Edabriz and Gi.209/1 are most dwarfing and precocious. Two trees of Montmorency on Gi.53 died in 2000 to virus shock syndrome, caused by either PD or PNRS viruses. Details of performance will be presented.

\section{Poster 136}

\section{Early Growth and Yield of Three Apple Cultivars Grown on} Four Training Systems

R.M. Crassweller ${ }^{\star}$ and D.E. Smith; Dept. of Horticulture, The Pennsylvania State Univ. University Park, PA 16802

A planting containing 'Ginger Gold', 'Gala', and 'Fuji' all on M.9 was established in 1997 at the Horticulture Research Farm at Rock. Trees were trained to a, Slender Spindle (SS), French Axe, (A) and Low Hedgerow Trellis $(T)$ all planted at 1,495 trees/ha and an Offset $\mathrm{V}(\mathrm{V})$ planted at 2,242 trees/ha. At the end of the 4th growing season trees in the $V$ system were smaller and had less trunk area increase. Training system did not impact average or cumulative yield per tree for 'Ginger Gold' or 'Gala' in either year. Fuji in the T system had the highest per tree yield in 1999. The next year Fuji in the SS system had the highest per tree yield but it was not significantly better than the T system. Within a system 'Fuji' generally had higher per tree yields than 'Gala'. Average fruit weight was not affected across training systems in 1999 but was significantly lower from the T system in 2000. In both years average fruit weight was lowest for Gala. Tree efficiency was not impacted by system for either 'Gala' or 'Ginger Gold' in either year. In 1999 'Fuji' in the A system was more efficient than in the $\mathrm{V}$ system on a per tree basis. Cumulative yield per tree for 'Fuji' in the SS and T systems were similar and significantly better than trees in the $V$ system. The trellis system took significantly longer to prune and train than all systems mainly due to tying branches to the wire. The $V$ system took significantly longer to prune and train than the SS and A trees.

\section{Poster 137}

Comparative Performance of 'Royal Gala' Apple in Five Tree Training Systems after Eight Years

Cheryl R. Hampson*, Harvey Quamme, and Rob Brownlee; Agriculture and Agri-Food Canada, Pacific Agri-Food Research Centre, Summerland, BC, Canada $\mathrm{VOH} 1 \mathrm{ZO}$

In 1993, a planting of 'Royal Gala' apple on M9 was established at Summerland, B.C. Trees were trained in one of five ways: slender spindle (SS), Y-trellis (YT) modified Solen (YTS), or V-trellis (LDV), all at 2976 trees/ha, or a V-trellis at 7143 trees/ha (HDV). The plots were drip-irrigated, with supplemental overhead irrigation. The design was a randomized complete block with four blocks. All training systems were fully guarded, with measurements taken on the three central trees of one five-tree plot per block. Trees were minimally pruned and fruit was hand-thinned. After 8 years, trunk crosssectional area was least for YTS and HDV. Among the four systems at 2976 trees/ha, cumulative yield efficiency was greatest for YTS, but the difference was partly due to greater crop load on this system in most years. This greater crop load was associated with lower average fruit weight. The two Y-shaped canopies (YTS and YT) had poorer fruit color in warm autumns than SS or LDV. In comparison to the LDV, the HDV had no greater yield efficiency, but cumulative yield per unit area was still $65 \%$ greater by year eight. Despite similar annual crop loads, fruit on the HDV tended to be smaller (by $8 \%$ to $16 \%)$ and more poorly colored than on the LDV.

\section{Poster 138}

Yield of Peach Trees Grown with Different Competition and Pruning

T.J. Tworkoski* and D.M. Glenn; USDA-ARS, Kearneysville, WV 25430

Peach tree size can be managed by pruning and by growing trees continuously with grass after planting but the interactive effects of these cultural practices on yield are not well characterized. This research determined the effects of pruning intensity and grass competition on growth and yield of peach trees. Two cultivars ('Jersey Dawn' and 'Redskin' on 'Lovell' rootstock) of peach [Prunus persica (L.) Batsch] trees were planted in an orchard in 1993 and grown in weed-free row widths of 0.6 or $2.4 \mathrm{~m}$. Beginning in 1995, trees were pruned to maintain canopy size with an open center (heavy pruning) or to maintain canopy size without an open center (light pruning). The experiment was a factorial design with grass competition, pruning intensity, and cultivar as main effects. Significant reductions in pruning weight and times were observed in trees grown in narrower weed-free rows and with light pruning. Trees of both cultivars that received light pruning and that grew in $2.4 \mathrm{~m}$ weedfree rows required about half the pruning time ( $5 \mathrm{~min}$ per tree) of heavy-pruned trees. From 1995 to 2000, trees grown with light pruning yielded 29 to $58 \%$ more marketable fruit (fruit diameter more than $5.7 \mathrm{~cm}$ ) than heavy-pruned trees in the $2.4 \mathrm{~m}$ weed-free rows. Marketable fruit weight was 5 to $42 \%$ greater in light-pruned trees. Marketable fruit weight was about 51\% lower in trees grown in 0.6 than $2.4 \mathrm{~m}$ weed-free rows. Yield efficiency was increased by light pruning, particularly in the narrower weed-free rows. The results indicate that peach tree pruning should be adapted to the intensity of grass competition in the orchard.

\section{Poster 139}

Pruning Severity Influences Peach Fruit Size and Crop Value Richard P. Marini*; Dept. of Horticulture, Virginia Tech, Blacksburg, VA 24061

For three years mature 'Cresthaven' trees were dormant pruned to retain $73,110,146$, or 220 fruiting shoots per tree. At about 45 days 
after bloom each tree was hand-thinned to retain 440 fruit per tree. Thus the average number of fruit per shoot varied from 6 to 2 . Number of fruit thinned per tree, thinning time per tree, and average fruit weight were negatively related to the number of shoots per tree. Fruit were graded into six sizes and crop value was calculated. Crop value and "net profit" (crop value minus thinning costs) were negatively related to number of shoots per tree. One year a spring frost reduced the crop load of severely pruned trees to below the target level, resulting in a loss of $\$ 800$ per ha. Crop loads were excessive the other two years, and net profit was increased from $\$ 2,000$ to $\$ 3,500$ per ha by retaining only 73 rather than 220 shoots per tree.

\section{Poster 140}

\section{Whole Canopy Photosynthesis of Apple Trees Treated with} 'Surround WP' Crop Protectant

D. Michael Glenn ${ }^{* 1}$, Amnon Erez ${ }^{2}$, and Gary Puterka $;{ }^{1}$ USDA-ARS, Appalachian Fruit Research Station. Kearneysville, WV 25430; ${ }^{2}$ Institute of Horticulture, ARO Volcani Center, Box 6, Bet Dagan, Israel 50250

The purpose of the study was to determine if season-long applications of a reflective, particle film material influenced photosynthesis and fruit size. Four, whole canopy photosynthesis chambers of Mylar ${ }^{\circledR}$ were constructed for 'Empire' apple trees with a volume of $\approx 25 \mathrm{~m}^{3}$. The treatments were a control vs. weekly applications of 56 $\mathrm{kg} / \mathrm{ha}$ of 'Surround WP' ${ }^{\circledR}$ Crop Protectant (Engelhard Corp. Iselin, N.J.). All treatments were oversprayed with conventional pesticides. About every three weeks during the growing seasons of 1999 and 2000 , measurements were made on two trees of each treatment beginning at $0900 \mathrm{HR}$ and ending at $1500 \mathrm{HR}$. A CIRAS- 1 photosynthesis system (PP Systems, Haverhill, MA) measured carbon dioxide and water vapor fluxes. In 1999, whole canopy photosynthesis was greater for the 'Surround WP' treatments on all sampling dates and on only one date in 2000 . Fruit size, adjusted for fruit number, was greater in the 'Surround WP' treatments in both years. Overall, we found that the application of 'Surround WP' increased whole canopy photosynthesis and the increased carbon assimilation was partitioned to fruit.

\section{Poster 141}

Controlling Growth of Superspindle Gala/M.9 Apple Trees with Prohexadione-Ca, NAA, and Ethephon

Sunghee Guak* and Norman E. Looney; Agriculture and Agri-Food Canada, Pacific Agri-Food Research Centre, Summerland, BC, Canada

Six-year-old superspindle Gala/M.9 apple trees were treated with NAA, prohexadione-Ca (Apogee; a registered name) and ethephon, alone and in combination, to determine effects on shoot growth and cropping. About 2.5 weeks after full bloom (AFB) a mixture of NAA (K salt) and wallpaper paste (1:2.5) was painted to the freshly cut end of the central leader. Apogee (250 ppm a.i.) was sprayed 4 weeks AFB (about $25 \mathrm{~cm}$ of terminal shoot growth). Ten days later (about $35 \mathrm{~cm}$ terminal growth), $18 \mathrm{ppm} \mathrm{K}$ salt of NAA and/or $300 \mathrm{ppm}$ ethephon were sprayed to whole trees. All spray treatments involved $0.1 \%$ surfactant. Apogee alone effectively controlled shoot elongation on these ultra high density apple trees. NAA paint, NAA spray, and ethephon were less effective in growth control and showed some undesirable effects on the crop. Fruit set was consistently increased by Apogee and reduced by ethephon. Fruit weight was reduced by Apogee and also by NAA treatments; the NAA spray treatment having the greatest effect. Overall yield was increased by Apogee but decreased by NAA spray and ethephon. Fruit firmness was slightly reduced by NAA paint and by some combination treatments involving ethephon. Fruit soluble solids and titratable acidity were slightly decreased by Apogee and by the NAA paint treatment. Apogee slightly delayed fruit coloration and time of harvest. Ethephon advanced fruit maturity. Overall, Apogee showed considerable promise as a plant bioregulator for use in high density apple orchards.

\section{Poster 142}

Effect of Nitrogen Content, Root : Shoot Ratio, Trunk Caliper, and Number of Feathers on Canopy Development of Young Apple Trees after Transplanting from the Nursery

Alejandro Valencia* and Terence Robinson; Dept. of Horticultural Sciences, New York State Agricultural Experiment Station, Cornell Univ., Ithaca, NY 14850

Three field experiments were conducted in Summer 2000 with different sizes of maiden apple trees on M.9 rootstock which had been treated with three levels of foliar urea sprays the previous fall in the nursery, two levels of canopy pruning and/or root pruning at planting. Total nitrogen amount per tree ( $\mathrm{g} /$ tree) at time of planting was increased by foliar urea sprays applied to the trees the previous fall in the nursery and was reduced by either root pruning, or canopy pruning. The greatest leaf area development during the first year in the orchard was obtained with the unpruned (root or canopy) trees while trees that received both root and canopy pruning had the least leaf area development. Root pruning had a minimal effect on shoot growth and dry weight increment during the first year in the orchard while canopy pruning had a larger effect in both. The amount of nitrogen per tree was positively correlated and root : shoot ratio was negatively correlated with total shoot growth, tree dry weight increment and leaf area.

\section{Poster 143}

Almond Production using Subsurface Drip Irrigation

John P. Edstrom ${ }^{* 1}$, and Larry J SchwankP; ${ }^{1}$ Univ. of California Cooperative Extension² Univ. of California, Davis

Drip irrigation has been successfully used in California almond production for over 30 years to improve water use efficiency and to expand production onto marginal soils. However, placement of the drip hoses on the soil surface exposes the system to environmental degradation and interferes with numerous farming operations. Subsurface placement of hoses could avoid most associated problems but has not been tested for almond production nor for potential problems to the system in the rhizosphere. An 8 hectare (20 acre) field test was conducted at the Nickels Soils Lab in the central valley of California to evaluate three types of microirrigation systems; Surface Drip, Subsurface Drip (SDI) and Micro-jet on four cultivars of almonds [Prunus dulcis (Mill.) D.A.Webb.]. Ten years of field evaluation has shown that comercial yields of high quality almonds can be produced using SDI. Tree growth under SDI, as measured by trunk size, was comparable to surface drip irrigation and slightly smaller than micro-jet irrigated trees when equal amounts of irrigation water were applied. No significant root intrusion was found in trifluralin impregnated SDI emitters but standard emitters were invaded and plugged by almond root growth after five years of field operation. Minor root pinching occurred on the buried flexible supply hoses in both SDI and Surface drip treatments.

\section{Poster 144}

Improving Growth in Young Peach Trees by Subsurface Drip Irrigation

D.R. Bryla', T.J. Trout ${ }^{1}$, R.S. Johnson' ${ }^{2}$, and J.E. Ayars ${ }^{1}{ }^{1}$ USDAARS, Water Management Research Laboratory, 2021 S. Peach Ave., Fresno, CA 93727; ${ }^{2}$ UC Kearney Agricultural Center, 9240 S. Riverbend Ave., Parlier, CA 93648

The goal of this project was to develop and evaluate water and nutrient management practices for peach during early stages of development. Little is known about irrigation and fertilization requirements of stone fruit during initial non-bearing years. In 1999, three different irrigation systems - microjet, drip (surface and subsurface), and furrow-were installed in a 1.7-ha field prior to planting. Using these systems, we are testing variations in timing and placement of irrigation water, as well as differences in application of total amounts of water and nitrogen fertilizer. For the past two growing seasons, shoot canopy measurements were made periodically to determine the effects of the irrigation and fertilization treatments on tree development. Root system development was also monitored the 
second year using minirhizotrons. During the first year, trees irrigated by surface drip were $8 \%, 10 \%$, and $16 \%$ larger canopy volumes than those irrigated using microjets, furrows and subsurface drip, respectively. By the second year, however, subsurface drip irrigated trees were the largest with $16 \%$ to $32 \%$ more canopy volume than trees irrigated by any other method. The young trees did not respond to nitrogen fertilizer regardless of irrigation method; e.g., trees fertilized with $0 \mathrm{~kg} \cdot \mathrm{ha}^{-1} \mathrm{~N}$ were the same size as trees irrigated with $90 \mathrm{~kg} \cdot \mathrm{ha}^{-1} \mathrm{~N}$. Belowground, surface and subsurface irrigation resulted in more restriction of root system volume (roots were concentrated near the drip lines), while trees irrigated with microjets had the widest root distribution. Findings from this study will help identify practices that maximize the rate of tree development while minimizing water and nutrient costs for growing peach.

\section{Poster 145}

Arbuscular Mycorrhiza in the Growth of Papaya (Carica papaya) var Maradol in Nursery and Field Conditions in Dry Tropic

R. Flores-Bello ${ }^{1}$, S. Aguilar-Espinosa ${ }^{* 2}$, R. Flores-Zepeda ${ }^{2}$, and A. Zamora-Cruz ${ }^{2} ;{ }^{1}$ Facultad de Medicina Veterinaria y Zootecnia, UdeC.

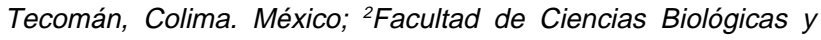
Agropecuarias, UdeC. Tecomán, Colima. México

Arbuscular mycorrhiza (AM) presents a great potential as biofertilizer; this offers an important way in new alternatives in agriculture. This work was made to determine the effect of AM in seedlings production of papaya plants in nursery and field conditions. Papaya plants were grown in pots containing soil : germinaza $(2: 1, v / v)$ in nursery. Treatments imposed were: inoculation of Glomus intraradices (T1), inoculation of Glomus etunicatum (T2), inoculation of Glomus intraradices + Glomus etunicatum, and noninoculated (control). Plants were sown in field at 60 days. Response on the growth of the inoculated plants was not appreciated in seedlings. Plants inoculated with Glomus intraradices and Glomus etunicatum survived until in a $60 \%$ at 50 days of transplanted to field and in noninoculated only $40 \%$. To the first harvest the height was greater for the inoculated plants in respect to the noninoculated, with $70.54,64.33$, and $66.11 \mathrm{~cm}$ for each one of the AM fungi and the mixture, respectively, and 61.97 for the noninoculated. In respect to the fruit, the mixture of AM fungi presented a value average of 25 fruits by plant, and plants inoculated with a AM fungal (Glomus intraradices or Glomus etunicatum) had an average of 10 fruits by plant and the noninoculated had not fruited. This work was financed by PROADU-SEP.México.

\section{Poster 146}

Mycorrhizal Colonization and Growth of Papaya (Carica papaya ) var. Maradol Seedlings with Native Arbuscular Mycorrhizal Inoculum in the Nursery

S. Aguilar-Espinosa ${ }^{* 1}$, C. Hernández-Benítez ${ }^{2}$, and R. Flores-Bello3; ${ }^{1}$ Facultad de Ciencias Biológicas y Agropecuarias, UdeC. Tecomán, Colima, México; '2Instituto Tecnológico Agropecuario No. 20. SEPSEIT-DGETA. Jalisco. México; ${ }^{3}$ Facultad de Medicina Veterinaria y Zootecnia, UdeC. Tecomán, Colima, México

The lack specificity of arbuscular mycorrhizal fungi (AMF) for the infection of plants does not mean that they behave equally in promoting plant growth. However, has been observed that mixture of the two species is better than either fungus alone. Is necessary to know the behaviour of the AM fungi that are found in the soil field. This experiment examined the effects of indigenous populations of AMF of two farm cultivated with papaya, on the infection and growth of papaya seedlings in the greenhouse. They were collected from soil and papaya roots of two sites and they were sown with corn (Zea mays) and Guinea grass (Panicum maximum), as trap crop to propagate the AMF of each farm. Treatments were: AM fungal from site 1 (S1), AM fungal from site 2 (S2), mixture of $S 1+S 2$, and non inoculated (control). The papaya seeds were previously sterilized and sown in pots containing soil : germinaza $(2: 1 \mathrm{v} / \mathrm{v})$; the height and the diameter of stem were registered each 10 days and the coloni- zation, height, stem diameter, number of leaves, shoot volume, shoot dry weight, root dry weight and radical volume was measured at 80 days. Plant height during all the experiment was always smaller for the non inoculated, and for the inoculated always it was an equal value statistically. The stem diameter did not present differences in none of the treatments. The mycorrhizal infection, it was not different for any sources of MAF. To the end of the experiment, the shoot and root dry weights were different between inoculated plants and non inoculated about $100 \%$; the other variables had not statistical differences, but the infection was smaller for these variables. These results suggest further study to obtain efficient AMF strains and adapted on dry tropic. This work was financed by PROADUSEP.México.

\section{Poster 155}

Effect of Container Volume and Nitrogen Application on the Growth of Young Citrus Seedlings

George Ouma*; Dept. of Horticulture, Maseno Univ., P.O. Box 333, Maseno, Kenya

Studies were conducted in a shade house at Maseno Univ., Kenya, to determine the effect of nitrogen fertilization and container volume on the growth of young citrus (Citrus sinensis) 'rough lemon' rootstocks. Nitrogen fertilizer was applied in the form of calcium ammonium nitrate to 6 -month-old seedlings at the rates of $0,6,12,18$, and $24 \mathrm{~g} / \mathrm{plant}$. The container volumes were $1.7,2.7$, and $4.5 \mathrm{~L}$. The media used was a mixture of soil and sand at a proportion of 50:50 (or half soil, half sand). The seedlings were watered every other day by hand to wetness. The results showed that nitrogen significantly increased the number of leaves, height of plants, height of canopy and weight of shoots. Volume of the containers significantly $(P<0.05)$ increased the number of leaves, height of plants, height of canopy, but did not affect the weight of shoots and weight of roots as it increased. The interaction between volume and nitrogen was significant for number of leaves, height of plants, height of canopy, weight of whole plants, weight of roots, and weight of shoots. The effects of $\mathrm{N}$ on the above parameters varied depending on the container size.

\section{Poster 148}

Effect of Container Volume and Watering Frequency on the Growth of Young Citrus Seedlings

George Ouma*; Dept. of Horticulture, Maseno Univ., P.O. Box 333, Maseno, Kenya

Studies were conducted at Maseno Univ., Kenya, to determine the effect of watering frequency and container volume on the growth of young 'rough lemon' rootstocks that were 6 months old. The watering frequency was as follows: $\mathrm{W} 1$ = watering everyday to wetness, W2 = watering every other day to wetness and $\mathrm{W} 3=$ watering after 3 days to wetness. Watering was carried out by watering cans. The container volumes were: $1.7,2.7$, and $4.5 \mathrm{~L}$. The media consisted of $50 \%$ soil and $50 \%$ sand. The studies were conducted in a shade house made of dried grass and not completely covered. The results showed that the higher the watering frequency the greater the increases in the parameters, height of canopy, weight of plants, weight of shoots, number of leaves. The magnitude of the increase was higher the bigger the container volume. The interaction between volume and watering frequency was significant $(P<0.05)$ for all parameters except height of canopy, weight of roots and weight of shoots. The weight of roots was only significantly $(P<0.05)$ increased by volume but not watering frequency nor interaction.

\section{Poster 149}

Copper Hydroxide in Nursery Flats Does Not Improve Papaya Growth and Yield following Transplanting

Thomas E. Marler*; Univ. of Guam, UOG Station, Mangilao, Guam 96923

Nursery flats with $2.5-\mathrm{cm}$ cells were used to determine the influence of copper hydroxide on growth of 'Tainung 2' and 'Sunrise' papaya seedlings in the nursery and after transplanting to the field. Copper hydroxide effectively controlled root growth along the edges 
of the cell walls, but did not influence stem or leaf growth during the 8 -week nursery cycle. Following 6 months in the field, stem circumference, height, and yield were not affected by the copper hydroxide treatment. The root system was excavated, and morphology of the nuclear root system was not influenced by the nursery treatments. Copper hydroxide did improve papaya root morphology in the nursery, but there was no lasting influence on plant growth and development in the field.

\section{Poster 150}

Effect of the Application of Mexican Lime (Citrus aurantifolia Swingle) Industrialization Wastewater on Soil Parameters and Yield of Forage Sorghum (Sorghum bicolor L. (Moench.) $x$ S. sudanense)

Jaime Molina-Ochoa*, José Gerardo López-Aguirre, Javier FaríasLarios, and Arturo Tejeda-George; Universidad de Colima, Facultad de Ciencias Biológicas y Agropecuarias, A.P. 36, Tecomán, Colima 28100, México

The Mexican lime production in Colima, Mexico, is one of the most important incomes for the State of Colima. Products and byproducts of the fruit industrialization are sources for other industries in Mexico and worldwide. The distillation of the essential oils generates a byproduct named "cooked citrus juice", "citrus wastewater" (CW) or "caldo residual", the volumes produced are about 78 million of liters, annually. This byproduct represents a serious problem for discharging the produced wastewaters. The industries discharge their $\mathrm{CW}$ in the neighboring lands. The application of $\mathrm{CW}$ on soil parameters and its effect on the yield of forage sorghum are evaluated. Two experimental phases were conducted. First, the effect on the physical and chemical parameters of soils were determined, and second, the effect on yield and agronomic traits of forage sorghum were evaluated. The field experiment was conducted under a randomized blocks design with a factorial distribution, 3 genotypes of forage sorghum and $4 \mathrm{CW}$ volumes were evaluated. The soil parameters shown a decrease on the $\mathrm{pH}$, reduction on the pore size percent a slightly accumulation of organic matter at the sampled depth of 0 $100 \mathrm{~cm}$. Association between agronomic traits and volumes shown an exponential performance, plant height, fresh forage yield and dry forage yield tended to have an increase with the $\mathrm{CW}$ volumes applied. Application of $24,000 \mathrm{l} / 25 \mathrm{~m}^{2}$ produced the higher fresh and dry forage yields and height. Accumulation of organic matter was higher in the $100 \mathrm{~cm}$ depth. CW application to sandy soils is a good alternative for discharging byproduct and avoiding the soil and water pollution in Colima.

1:00-2:00 p.m. CC Ballroom

\section{Poster Session 4: Plant Nutrition}

Poster 230

Development of Nitrogen and Potassium Fertilizer Recommendation Models to Improve $N$ and $K$ Use Efficiency and to Alleviate Pollution from Pistachio Orchards

Richard C. Rosecrance ${ }^{* 1}$, Steven A. Weinbaum ${ }^{2}$, and Patrick $H$. Brown ${ }^{2}{ }^{1}$ California State Univ., Chico CA 95929; ${ }^{2}$ Univ. of California, Davis, CA 95616

Overfertilization in pistachio orchards can be attributed to the lack of reliable tools for measuring tree nutrient status, tree nutrient demand, and soil nutrient availability. The purpose of this project was to provide a better tool for distinguishing between fertilizer applications that are essential and those that are excessive, and guide growers in determining when and how much $\mathrm{N}$ and $\mathrm{K}$ fertilizer should be applied. The ultimate goal of the project is to optimize yields while minimizing the potential for pollution. To achieve these goals, two web based computer models have been developed for the pistachio industry (a nitrogen and a potassium model). Both models require input from the grower on such things as previous yield history, last year's leaf $\mathrm{N}$ and $\mathrm{K}$ concentrations, the farmer's best estimate of this year's crop load, soil type, fertilizer application method, irrigation water applied, and use of cover crops or mulches. The program integrates the information and estimates next year's yield, $\mathrm{N}$ and $\mathrm{K}$ requirement, and when the fertilizer should be applied.

\section{Poster 231}

Absorption, Withdrawal, and Remobilization of Foliar Urea Derived-N in Apple Trees

Sunghee Guak ${ }^{1}$ Denise Neilsen ${ }^{1}$, Peter Millard², and Norman E. Looney'; ${ }^{1}$ Pacific Agri-Food Research Centre, Summerland, BC VOH 1 ZO Canada; ' Macaulay Land Use Resource Institute, Aberdeen, Scotland UK

Six-year-old Jonagold/M.9 apple trees were foliar sprayed with fall urea $(2 \%)$ enriched with $15 \mathrm{~N}$ to quantify leaf absorption of ureaderived $\mathrm{N}$, withdrawal during leaf senescence, and spring remobilization for growth of flower clusters and spur leaves in arid conditions, and also to determine if $\mathrm{N}$ supplementation through autumn foliar urea application can strengthen flower buds and improve fruit set. Leaves absorbed about $17 \%$ of the $15 \mathrm{~N}$ intercepted. During leaf senescence, about $47 \%$ of that amount was withdrawn. In winter, $92 \%$ of the $15 \mathrm{~N}$ withdrawn was stored in the woody tissues of the treated branch; $59 \%$ in bark, $28 \%$ in wood, and $5 \%$ in dormant spur buds. The following spring, by pink stage, $57 \%$ of the $15 \mathrm{~N}$ stored in the dormant branch had been remobilized for growth of flower clusters and spur leaves, which accounted for about $3.5 \%$ of the total $\mathrm{N}$ in those tissues. Fall urea treatment slightly advanced leaf abscission and flower opening the following season, and slightly increased fruit set.

\section{Poster 232}

Effects of Copper Chelate in Combination with Foliar Urea on Defoliation and Reserve Nitrogen Levels of Apple Nursery Trees with Different Background Nitrogen Status

L. Cheng ${ }^{* 1}$, S. Dong ${ }^{2}$, and L.H. Fuchigami ${ }^{2} ;{ }^{1}$ Dept. of Horticulture, Cornell Univ., Ithaca, NY 14853; ${ }^{2}$ Oregon State Univ., Corvallis, OR 97331

Bench-grafted Fuji/M.26 plants were fertigated with five nitrogen concentrations $(0,5,10,15$, and $20 \mathrm{~mm})$ from 30 June to 1 September. In Mid-October, one set of plants from each $\mathrm{N}$ treatment were destructively sampled to determine background $\mathrm{N}$ status of the trees, while the rest of the plants were divided into 3 groups. One group of trees was sprayed with $1 \%$ CuEDTA on 28 October. The second group was sprayed with $3 \%$ urea solution twice at weekly intervals first, then followed by a 1\% CuEDTA application on 28 October. The third group was allowed to defoliate naturally (controls). After CuEDTA application, the number of leaves on each tree was counted every 3 days for 3 weeks. All the trees were harvested after control trees finished their natural leaf fall. Control trees had very little defoliation during the 3 -week period, except those fertigated with $0 \mathrm{~mm} \mathrm{~N}$ showed about $40 \%$ defoliation. The time course of defoliation caused by CuEDTA is similar across the background tree $\mathrm{N}$ status. All the trees reached $90 \%$ to $95 \%$ defoliation within 18 days after CuEDTA application. Foliar urea spray prior to CuEDTA application did not significantly affect defoliation. Application of CuEDTA alone significantly decreased reserve $\mathrm{N}$ content. Foliar urea spray before CuEDTA application significantly increased reserve $\mathrm{N}$ level with low $\mathrm{N}$ trees being more responsive than high $\mathrm{N}$ trees. It is concluded that defoliation effect of CuEDTA was not dependent on tree background $\mathrm{N}$ status. Foliar urea spray prior to CuEDTA application improved reserve $\mathrm{N}$ status while maintaining the same defoliation effect of CuEDTA.

\section{Poster 233}

Effects of Manual Defoliation and Foliar Urea on Reserve Nitrogen and Carbon Status, Growth, and Yield of Apple Trees

L. Cheng ${ }^{* 1}$ and L. H. Fuchigami ; ${ }^{1}$ Dept. of Horticulture, Cornell Univ., Ithaca, NY 14853; ' 2 Oregon State Univ., Corvallis, OR 97331

Six-year-old Marshall Mclntosh/M.9 trees were subjected to one of the following four treatments after harvesting: 1) manual defoliation;2) foliar urea spray; 3) foliar urea followed by manual defoliation; 
and 4) natural defoliation without foliar urea (control). Manual defoliation alone decreased both reserve carbohydrates and nitrogen in spurs and shoots. As a result, spur leaf development, leaf $\mathrm{N}$ content, and fruit number and yield per tree were reduced. Foliar urea application alone increased reserve nitrogen, but decreased reserve carbohydrates. Fruit number and yield per tree tended to be higher in foliar urea treatment than in controls. Trees sprayed with foliar urea followed by manual defoliation tended to have higher reserve nitrogen content, better spur leaf development, and higher fruit number and yield per tree than those manually defoliated. When regression analysis was used to examine fruit number and yield in relation to reserve nitrogen and carbohydrates, it was found that fruit number and yield were significantly related to reserve nitrogen content in spurs and shoots, but not reserve carbohydrates. These results suggest that growth and fruiting of apple trees are more related to reserve nitrogen than reserve carbohydrates.

\section{Poster 234}

Response of Cabernet Sauvignon Grapes to Various Levels of N Fertilizer Added at Pre-Bloom \& Early Veraison

E. Dickson ${ }^{\star 1}$, D.R. Bryla ${ }^{2}$, R.L. Wample ${ }^{1}$, M.A. Duarte ${ }^{3}$, and G.T. Berg'; ' Viticulture Enology Research Center, California State Univ., Fresno, CA 93740; ' $U S D A$ ARS, Water Management Research Laboratory, Fresno, CA 93727; ${ }^{3}$ Duarte Nursery Inc., Hughson, CA 95326

During wine grape production, fruit and wine quality are affected by $\mathrm{N}$ application. However, optimum $\mathrm{N}$ fertilization rates for premium wine grapes are generally unknown. We examined the effect of applying three different levels of $\mathrm{N}$ fertilizer at pre-bloom and at early veraison to Vitis vinifera L. Cv. Cabernet Sauvignon (FPMS Clone 8) on Freedom rootstock grown in Linden, CA. All vines were fertigated with $7.8 \mathrm{~kg} \cdot \mathrm{ha}^{-1} \mathrm{~N}$ added as $\mathrm{CAN}-17$ at bud break. At prebloom, vines were fertigated with $3.7 \mathrm{~kg} \cdot \mathrm{ha}^{-1} \mathrm{~N}$ added as $15-4-4$ and 0 (treatment 1), 5.8 (treatment 2), or 11.5 (treatment 3) kg.ha${ }^{1} \mathrm{~N}$ added as UN32. During early veraison, vines were fertigated with $3.5 \mathrm{~kg} \cdot \mathrm{ha}^{-1} \mathrm{~N}$ added a $3-10-10$ and 0 (treatment 1), 1.7 (treatment 2), or $3.5 \mathrm{~kg} \cdot \mathrm{ha}^{-1} \mathrm{~N}$ added as UN32. Over the entire growing season, treatment 1 received $15 \mathrm{~kg} \cdot \mathrm{ha}^{-1} \mathrm{~N}$, treatment 2 received $22 . \mathrm{kg} \cdot \mathrm{ha}^{-1} \mathrm{~N}$, and treatment 3 received $30 \mathrm{~kg} \cdot \mathrm{ha}^{-1} \mathrm{~N}$. Fruit was collected from each treatment at harvest, juiced and analyzed for $\mathrm{N}$. Although $\mathrm{N}$ applications equaled or exceeded recommended levels of fertilizer in each treatment, total $\mathrm{N}\left(124.1 \pm 2.2 \mathrm{mg} \cdot \mathrm{L}^{-1} \mathrm{~N}\right)$ and arginine- $\mathrm{N}\left(63.0 \pm 2.7 \mathrm{mg} \cdot \mathrm{L}^{-1} \mathrm{~N}\right)$ content of the juice were deficient and not significantly different among fertilizer treatments. Vegetative growth of the vines however, was greater in the higher $\mathrm{N}$ treatments. This suggests that fruit $\mathrm{N}$ content at harvest may be more related to timing of fertilizer application rather than to the total amount of $\mathrm{N}$ applied.

\section{Poster 235}

Strategies to Reduce Nitrate Applications to Fertigated Strawberries (Fragaria xananassa Duch.)

Daniel S. Kirschbaum ${ }^{\star 1}$, Hillel Magen ${ }^{2}$, Luis S. Quipildor ${ }^{1}$, Javier González ${ }^{3}$, Ana M. Bórquez', and María Correa'; ' 'INTA Famaillá, CC 11 (4132) Famaillá, Tucumán, Argentina; ${ }^{2}$ International Potash Institute, P.O. Box 75, Beer Sheva, 84100 Israel; ${ }^{3}$ Municipalidad de Lules, (4128) Lules, Tucumán, Argentina

Potassium nitrate and $\mathrm{Ca}\left(\mathrm{NO}_{3}\right)_{2}$ are the main sources of $\mathrm{K}$ and $\mathrm{Ca}$ in fertigated strawberries (Fragaria $x$ ananassa Duch.) grown in northwestern Argentina. A considerably lost of marketable yield is usually attributed to excessive $\mathrm{N}$ rates applied especially in spring, when the production peak occurs. As there are no economic alternatives to $\mathrm{Ca}\left(\mathrm{NO}_{3}\right)_{2}$, only $\mathrm{K}$ sources can be changed to maintain the levels of fertilization with $\mathrm{K}$ and $\mathrm{Ca}$, without increasing $\mathrm{N}$ levels. Bareroot 'Camarosa', 'Milsei' and 'Sweet Charlie' strawberries were grown using polyethylene-mulched and fumigated beds. The target level of $\mathrm{K} 2 \mathrm{O}$ was $235 \mathrm{~kg} \cdot \mathrm{ha}^{-1}$. Four treatments were weekly applied from August to October: $\mathrm{KCl}, \mathrm{KNO}_{3}, \mathrm{KNO}_{3} / \mathrm{KCl}$, and $\mathrm{KNO}_{3} / \mathrm{K}_{2} \mathrm{SO}_{4}$. The final $\mathrm{N}$ level was $142 \mathrm{~kg} \cdot \mathrm{ha}^{-1}$ for all treatments, except for $\mathrm{KNO}_{3}$, where the
$\mathrm{N}$ level was $199 \mathrm{~kg} \cdot \mathrm{ha}^{-1}$. Spring (Sep.-Nov.) marketable fruit yields were not influenced by $\mathrm{K}$ source. 'Camarosa' had the highest yield while 'Sweet Charlie' the lowest. These preliminary results suggest that under the conditions of this study, $\mathrm{NO}_{3}$ - levels can be significantly reduced without affecting marketable yields in strawberry.

\section{Poster 236}

Effect of Composted Biosolids on Fruit Quality in Organically Grown Apricots

S. Pasakdee ${ }^{1,2}$, G.S. Bañuelos ${ }^{1}$, S.E. Benes ${ }^{2}$, and S. Gu $;{ }^{3}$ USDAARS-Water Management Research Laboratory, 2021 South Peach Avenue, Fresno, CA 93727; ${ }^{2}$ Dept. Plant Science, ${ }^{3}$ Dept. Viticulture \& Enology, California State Univ., Fresno, CA

Research data on the use of biosolids as an alternative nutrient source in stone fruit production are not readily available for the Central Valley of California. Concern has been raised regarding negative its impacts on fruit quality due to nitrogen loading from longterm application of biosolids. We evaluated the use of biosolids in apricot trees (Patterson variety on Marianna rootstock) that received annual applications of composted biosolids since 1994. The biosolids fully replaced synthetic fertilizer applications to the trees. The control treatment (1) received no biosolids and treatments 2,3 , and 4 received the equivalent of 57,170 , and $340 \mathrm{~kg} \mathrm{~N} / \mathrm{ha}$, respectively. Soil samples were collected twice annually to a depth of $60 \mathrm{~cm}$. Fruit were collected at harvest in late June and separated by overall color. These included: green, green-yellow, yellow, orange and darkorange. Each group was counted and tested for quality parameters that included soluble solid content (SSC), Brix, acidity, firmness and organic acid (ascorbic, citric, and malic) contents. Soil and fruit samples were analyzed for major and minor ions using inductive couple plasma technique (ICP). Biosolid treatments delayed fruit maturity: fruit from the control trees reached maturity earlier than fruit from trees receiving biosolid applications. Marked difference in the tested fruit quality parameters were not detected with the application of biosolids. Although there were significant differences in applied macro and micro nutrients to the soil, there were no differences in nutrient accumulation in the fruit. Fruit quality and fruit maturity data will be presented.

\section{Poster 237}

What Causes the Mouse-ear Disorder of Pecan?

Bruce W. Wood* and Charles C. Reilly; USDA-ARS, Byron, GA 31008

"Mouse-ear" (ME) can be a severe form of growth distortion of pecan [Carya illinoinensis (Wangenh.) C. Koch] foliage and shoots characterized by small, rounded, and often cupped and slightly wrinkled leaves. Incidence in orchards is typically associated with acidic soils and has been previously attributed to multiple causes, including deficiencies of $\mathrm{Cu}$ or $\mathrm{Mn}$ or an excess of $\mathrm{Ca}$. A 10-year field study of ME on a variety of orchards indicates that a common form of ME seen in orchard trees appears to be due to a complex interaction involving $\mathrm{Mn}, \mathrm{Fe}, \mathrm{Ca}$, root absorption of cations, and biosynthesis of gibberellic acids. Observations indicate that abnormally cold and/or dry springs increase the severity and incidence of ME. Foliar and soil treatment with high rates of $\mathrm{Cu}$, and all other major and minor nutrients, had no influence on symptoms; however, soil applications of Mn occasionally corrected symptoms. Affected foliage contained relatively high concentrations of all cations, with the degree of abnormality positively correlated with increased concentration of these cations. ME severity of foliage was correlated with increasing leaf concentrations of $\mathrm{P}, \mathrm{Zn}$, and $\mathrm{Ca}$, but unrelated or weakly related to concentrations of other elements. The soils on which affected trees grew, had very high soil levels of $\mathrm{P}, \mathrm{Ca}, \mathrm{Zn}, \mathrm{K}$, and $\mathrm{Cu}$, but low to moderate levels of $\mathrm{Mg}, \mathrm{S}, \mathrm{Mn}, \mathrm{Fe}$, and $\mathrm{B}$. Foliar symptoms of ME could be corrected by foliar sprays with either Mn or Pro-Gibb if applied during the early parachute stage of bud break (but not at other times), whereas foliar sprays with several other micronutrients did not significantly alter symptoms. Sprays with chelated Fe enhanced the severity of mouse-ear. Affected foliage 
always exhibited low $\mathrm{Mn}$, a $\mathrm{Mn}: \mathrm{Fe}>1$ and had high leaf $\mathrm{Ca}$. This suggests that this $\mathrm{Mn}, \mathrm{Mn}: \mathrm{Fe}$ and $\mathrm{Ca}$ situation disrupts the biosynthesis of gibberellins that are involved in normal leaf growth and development. This process appears to be caused by a disruption in $\mathrm{Mn}$ absorption(and also absorption of other elements)from the soil by roots. This root damage appears to be due to nematodesespecially rootknot-and might potentially influence the mycorrhiza of roots. The root system of severely affected trees are smaller than on equal size non-mouse-ear trees.

\section{Poster 238}

Effects of Fertilizer Application Date on Lowbush Blueberry John M. Smagula* and Walter Litten; Horticulture Program, Univ. of Maine, Orono, ME 04469

At two commercial lowbush blueberry fields consisting of mostly $V$. angustifolium Ait., fertilizer was applied to correct $\mathrm{P}$ deficiency $(<125 \%)$ indicated in 1996 leaf samples, according to the Univ. of Maine Analytical Lab recommendations. For Field 1, with a heavier soil, the recommendation was $89 \mathrm{~kg} \mathrm{P} / \mathrm{ha}$ from monoammonium phosphate (MAP) and for Field 2 with a typical gravelly, sandy loam soil it was $89 \mathrm{~kg} \mathrm{P} /$ ha from diammonium phosphate (DAP). Fertilizer was hand applied to $1.5 \times 15 \mathrm{~m}$ treatment plots on 19 May, 2 June, 16 June, or 30 June 1998. Along with a control, a split application of half the recommended fertilizer rate on 19 May and half on 16 June was included as a sixth treatment at each location. Treatments were replicated 8 times in a RCB design. At Field 1, all fertilizer applications increased leaf $\mathrm{N}$ concentrations in leaf samples taken the first week in July, compared to the controls which were above the standard (1.6\%). Application on 16 June and the split application treatment resulted in higher leaf $\mathrm{N}$ concentrations than other application dates. Leaf $P$ concentrations were raised by all treatments to sufficiency, except the June 30 application, compared to the controls. Blueberry yield was not increased by fertilizer application. At Field 2 with a more typical sandy soil, where control leaf $\mathrm{N}$ concentrations were below the standard, leaf $\mathrm{N}$ was raised above the standard by DAP at all application dates; the highest concentrations resulted from 2 June, 16 June, or split application on 19 May and 16 June. Leaf $P$ was raised from deficient to sufficient concentrations by DAP at all fertilizer application dates but the 2 June application resulted in the highest leaf $P$ concentration. Yield was increased by all fertilizer treatments but was highest when DAP was applied on 2 June. It appears that date of fertilizer application may be more important on sandy textured soils than on heavier soils for maximizing lowbush blueberry Cranberry vines appeared to tolerate elevated nutrient uptake and yield.

\section{Poster 239}

Sodium and Chloride Effects on Cranberry Growth in Aeroponics T.R. Roper ${ }^{* 1}$, A.R. Krueger ${ }^{1}$, C.J. DeMoranville ${ }^{2}$, and J.R. Davenport ${ }^{3}$; ${ }^{1}$ Dept. of Horticulture, Univ. of Wisconsin, Madison, WI 53706; ${ }^{2}$ UMASS Cranberry Experiment Station, E. Wareham, MA; ${ }^{3}$ Washington State Univ. Irrigated Ag Research and Extension Center, Prosser, WA

Cranberry (Vaccinium macrocarpon Ait.) plantings adjacent to roads can show damage due to contamination from salt $(\mathrm{NaCl})$ applied to the roads for deicing. Knowing tissue $\mathrm{Na}$ and $\mathrm{Cl}$ concentrations where a reduction in growth begins would allow tissue testing to be used as a diagnostic and predictive tool. Rooted cranberry cuttings were grown in solution culture with increasing concentrations of either $\mathrm{Na}$ (0 to $1500 \mathrm{ppm}$ ) or $\mathrm{Cl}(0$ to $2500 \mathrm{ppm}$ ). Higher concentrations of both $\mathrm{Na}$ and $\mathrm{Cl}$ were found in the shoots than the roots. Chloride caused browning of older leaves when tissue levels reached $500 \mathrm{ppm}$. Sodium caused reduced growth when tissue levels were as low as $50 \mathrm{ppm}$. Exposure to $500 \mathrm{ppm} \mathrm{Cl}$ in aeroponics slowed cranberry growth shortly after the $\mathrm{Cl}$ was introduced, but then resumed. Chloride had no apparent effect on root growth. Growth of cranberry vines slowed when exposed to $500 \mathrm{ppm}$ $\mathrm{Na}$ in aeroponics. $\mathrm{Na}$ or $\mathrm{Cl}$ tissue levels in soilless culture.
1:00-2:00 p.m. CC Ballroom

\section{Poster Session 5: Postharvest}

\section{Poster 267}

1-Methylcyclopropene Delays Ripening of Pink and Light Red Tomatoes

Charles L. Rohwer ${ }^{*}$ and Richard J. Gladon; Dept. of Horticulture, lowa State Univ., Ames, IA 50011-1100

The ethylene analog 1-methylcyclopropene (1-MCP) is an effective inhibitor of ethylene action and plant responses elicited by ethylene, including ripening and senescence. Research has been conducted on the use of 1-MCP for delaying ripening and senescence in many horticultural species, but 1-MCP has not yet been proven valuable in the commercial handling and storage of tomato fruits. The objective of this research was to determine the 1-MCP treatment conditions that delay postharvest ripening of tomato (Lycopersicon esculentum Mill.) fruits without blocking the ripening response irreversibly. Tomato fruits at the breaker, turning, pink, and light red stages were treated with 1$\mathrm{MCP}$ at 0,58 , and $580 \mathrm{~nL} / \mathrm{L}$ (a. i. $1-\mathrm{MCP}$ from $0.14 \%$ a. i. $1-\mathrm{MCP}$, by calculation) for 8 hours at 20 to $21{ }^{*} \mathrm{C}$. Application of $1-\mathrm{MCP}$ slowed red color development, and the response was dependent upon the initial stage of ripeness and the 1-MCP concentration applied. Fresh weight loss depended upon concentration of 1-MCP applied. Tomatoes treated at the breaker and turning stages did not develop any red color over the 10-day holding period. The most desirable delay in ripening was obtained by treating fruits in the pink stage with $58 \mathrm{~nL} / \mathrm{L}(\approx 3$-day delay) or fruits in the light red stage with $580 \mathrm{~nL} / \mathrm{L} 1-\mathrm{MCP}(\approx 4$-day delay). Fresh market tomato handlers, distributors, and retailers can use 1-MCP to delay tomato fruit ripening for a predictable, short time period to compensate for unfavorable or unpredictable market conditions.

\section{Poster 268}

Single and Repeated MCP Preconditioning Postpones Ethylene Sensitivity of the Cut, Continuous-Growth Raceme of Lupinus havardii Wats

Mario Valenzuela-Vázquez*and Geno A. Picchioni;Dept. of Agronomy and Horticulture, New Mexico State Univ. Box 30003, Las Cruces, NM 88003-0003

Preliminary study shows that 1 -methylcyclopropene (MCP) vase preconditioning partially blocks ethylene-induced flower abscission and desiccation of $L$. havardiicut racemes. We compared postharvest performance of cut racemes after single and multiple (cumulative) MCP additions against silver thiosulfate (STS) treatment (4 $\mathrm{h}$ preconditioning), and no postharvest (control) treatment, in both the presence and absence of exogenous ethephon ( $50 \mu \mathrm{m}$ for 0 or 2 days in the vase solution). MCP application was made at the harvest (cutting) day (day-0), at 0 and 2 days, at 0,2 , and 4 days, or at $0,2,4$, and 6 days. In the absence of ethephon, no mature flower abscission occurred following treatment with STS and MCP (3 or 4 multiple applications) on cut racemes maintained for 10 days, as compared to a final $86 \%$ mature flower abscission on control racemes $(P<0.01)$. When racemes were exposed to ethephon, flower abscission of about $21 \%$ was observed on racemes treated 3 times with MCP, as compared to $98 \%$ flower loss on control racemes by day- 6 . Following ethephon exposure, the number of new flowers that had expanded at the raceme apex during vase observation increased in proportion to the number of MCP applications, indicating enhanced overall raceme tissue viability. Greatest vaselife extension was obtained in the ethephonfree vases and four repeated MCP applications (average of 9.2 days required for $50 \%$ abscission or visible desiccation of mature flowers). Multiple MCP applications present a practical problem in handling of $L$. havardii cut racemes. However, results suggest that the senescence-delaying influence of MCP is probably of finite duration. This information will be helpful in optimizing MCP use on this species.

\section{Poster 269}

Duration of Inhibition of Ethylene Action by 1-MCP in Carnations 
Xinjia X ${ }^{* 1}$, Donald Hunter ${ }^{1}$, Michael Reid', and Fisun Celikel2; ${ }^{1}$ Dept. of Environmental Horticulture, Univ. of California, Davis, CA 95616; ${ }^{2}$ Ataturk Central Horticultural Research Institute, Yalova, Turkey

Although treatment with (1-MCP) is very effective in preventing the negative response of carnation flowers to ethylene, its inhibitory effects eventually are lost. In treated White Sim carnations held at 20 ${ }^{\circ} \mathrm{C}$, for example, petals recover $50 \%$ of their ethylene response (inrolling) within 4 days. We report here an examination of variability in this recovery among carnation cultivars, and discuss the possible mechanism of recovery.

\section{Poster 270}

Reduced Ethylene Concentration and Postharvest Quality of Transgenic Netted Melon (Cucumis melo L.) Expressing Sadenosylmethionine Hydrolase

Krista C. Shellie*; USDA-ARS 2413 E. Highway 83, Building 200, Weslaco, TX 78596

The effect of incorporating a gene encoding the enzyme $S$ adenosylmethionine hydrolase (SAMase), originally isolated from bacteriophage T3, into the genome of netted melon (Cucumis melo L. var. reticulatus Naud.), commonly known as cantaloupe or muskmelon, was evaluated in a series of greenhouse trials conducted from 1997 to 2000 at the ARS research facility in Weslaco, TX. Transgenic and non-transgenic seed for greenhouse trial entries was provided to the ARS research laboratory in Weslaco TX by Harris Moran Seed Company, in collaboration with Agritope, Inc. The ethylene concentration inside the cavity of melon fruit grown from $F_{1}$ seed was monitored from 28 days after pollination until 3 or $10 \mathrm{~d}$ after harvest using an "on the vine" non-destructive gas sampling method. Real-time ethylene concentration and ripening attributes of melons were evaluated in fruit grown from multiple plants of eight transgenic events, as well as seven other single or double event hybrid crosses and their non-transgenic counterparts. Melons grown from transgenic plants all possessed a phenotype characteristic of non-transgenic netted melon. The onset and pattern of ethylene concentration in melons grown from transgenic events was similar to non-transgenic melons. Transgenic events with desirable market quality were identified that expressed a $30 \%$ to $50 \%$ reduction in maximum ethylene concentration, firmer texture and extended shelf-life compared to their non-transgenic counterparts. Maximum ethylene concentration in melons grown from double event hybrids was similar to that of melons grown from single event and single event hybrids.

\section{Poster 271}

Effects of Single and Continuous Application of 1-Methylcyclopropene on Ripening of Tomato

Mauricio A. Canoles* and Randolph Beaudry; Horticulture Dept., Michigan State Univ., East Lansing, MI 48824

The effect of 1-MCP on ripening tomato (Lycopersicon esculentum Mill) was evaluated during storage at $20^{\circ} \mathrm{C}$. Roma-type tomatoes were treated with 1-MCP at two different stage of ripening, turning $(\mathrm{T})$ and half-ripe (HR), with $1000 \mathrm{~nL} \cdot \mathrm{L}^{-1}$ by a single application for $16 \mathrm{~h}$ and by continuous application for 34 days. A single application of 1 MCP delayed the color development by $\approx 6$ days in both maturity stages, T and HR. On the other hand, the color development was completely inhibited by $34 \mathrm{~d}$ continuous application of 1-MCP for approximately 40 days in $\mathrm{T}$ and HR tomatoes. In the same way, the firmness loss was delayed in $\mathrm{T}$ and HR tomatoes with a single application of $1-\mathrm{MCP}$, and largely prevented during the $34 \mathrm{~d}$ continuous application of 1-MCP. Unlike single application, continuous application delayed color development to a greater degree than firmness loss. Continuous application of 1-MCP for 34 days had a longer post-application effect than a single application, delaying color development by an additional 4-day period. The ability of 1 MCP to arrest color development temporarily for a period of 5-7 days by a single application and 40 days by continuous application for 34 days suggest that color development in tomato is under strict control by ethylene. The potential use of 1-MCP by tomato industry could be focused on vine-ripened tomatoes, allowing the preservation of fruit at advanced stages of ripeness without substantially quality loss, at least in color and texture.

\section{Poster 272}

Effects of MCP Treatment on Postharvest Skin-Color Changes in Black-Spined Cucumber Cultivars

Jae-Rim Choi' ${ }^{1}$ Hae-Jeen Bang ${ }^{1}$, Soo-Jung Hwang ${ }^{1}$, Ji-Young Hong ${ }^{1}$, Young-Ka Kim', and Jung-Myung Lee ${ }^{\star 2},{ }^{1}$ Dept. of Horticulture, Kyung Hee Univ., Yongin 449-701, Korea; ${ }^{2}$ Rohm and Haas Korea Co., Ltd., Seoul, Korea

1-Methylcyclopropene (MCP, $\mathrm{C}_{4} \mathrm{H}_{6}$ was treated to freshly harvested cucumber fruits of four popular cultivars that usually exhibit severe undesirable skin-color yellowing shortly after harvest. Within $6 \mathrm{~h}$ after fruit harvesting, cucumber fruits of four popular cultivars were treated with MCP at $0,250,500$, and $1,000 \mathrm{ppb}$ for $12 \mathrm{~h}$. The fruit were then stored in open basket in 20 to $24^{\circ} \mathrm{C}$ room in order to provide the similar environment of retail stores. Fresh weight of the fruit was measured everyday and the skin color change was also evaluated with color chart. After 2-week storage, fruit firmness was measured and soluble solids contents, acidity, and electric conductivity of the juice were also determined. MCP treatment, especially $1,000 \mathrm{ppb}_{4} \mathrm{H}_{6}$, was highly effective in delaying yellow color development in cucumber and the differences in skin color was most pronounced 5-7 days after storage at room temperature. MCP was also effective in reducing the moisture loss from the fruit. Cultivars showed somewhat different response to MCP treatment.

\section{Poster 273}

Exogenous Acetaldehyde-induced Internal Browning in "Braeburn" Apple Fruit

Yiping Gong*, and James P. Mattheis; USDA-ARS, Tree Fruit Research Laboratory, 1104 N. Western Ave., Wenatchee, WA 98801

'Braeburn' apple fruit (30 fruit for each treatment) were sealed in polyethylene bags $(\mathrm{Pa})$ and $1 \mathrm{~mL}$ of $1 \%$ acetaldehyde $(\mathrm{AA})$ was injected in the bags once every two days $(\mathrm{Pa}+\mathrm{AA})$. Control bags $(\mathrm{CK})$ had 20 holes per side ( $1 \mathrm{~mm}$ diameter). The concentration of $A A$ in $\mathrm{Pa}+\mathrm{AA}$ reached $400 \mathrm{ppm}$ after $2 \mathrm{~h}$ of the injection. After 10 days at $20^{\circ} \mathrm{C}$, the concentration of $\mathrm{CO}_{2}$ in the bags for $\mathrm{Pa}$ and $\mathrm{Pa}+\mathrm{AA}$ was $>10 \mathrm{kPa}$. Ethanol $(\mathrm{EtOH})$ and $\mathrm{AA}$ accumulated $(\mathrm{EtOH}: 10$ to $40 \mathrm{ppm}$, $\mathrm{AA}: 6$ to $12 \mathrm{ppm}$ ) in Pa bags, and exogenous $A A$ treatment increased AA accumulation $(0.6 \mu \mathrm{m})$ in flesh tissue, but did not increase EtOH compared to $\mathrm{Pa}$. After 10 days of storage, the incidence of internal browning (IB) was the highest in $\mathrm{Pa}+\mathrm{AA}(20 \%)$. IB also occurred in $\mathrm{Pa}(3 \%)$, but did not in CK $(0 \%)$. Development of IB following exogenous $A A$ application suggests that $A A$ accumulation is related to the occurrence of IB in 'Braeburn' apple fruit.

\section{Poster 274}

Treatment with 1-MCP Delays Dissipation of Watercore during Controlled Atmosphere Storage of 'Fuji' Apple Fruit J.P. Mattheis ${ }^{* 1}$, L.C. Argenta ${ }^{2}$, and X. Fan ${ }^{3} ;{ }^{1}$ USDA, ARS Tree Fruit Research Laboratory, Wenatchee, WA 98801,2EPAGRI, Estacao Bom Sucesso - C.P. 591, CEP: 89500-000, Cacador, SC, Brazil; ${ }^{3}$ USDA, ARS ERRC, 600 E. Mermaid Lane, Wyndmoor, PA 19038

'Fuji' apples harvested after development of watercore were used to evaluate responses to treatment with 1-methylcyclopropene (1$\mathrm{MCP}$ ) and controlled atmosphere (CA) storage protocols that can minimize development of $\mathrm{CO}_{2}$ injury. All fruit was stored at $1^{\circ} \mathrm{C}$. Storage treatments included air, $\mathrm{CA}\left(1.5 \mathrm{kPaO}_{2}, 0.1,1\right.$ or $\left.3 \mathrm{kPa} \mathrm{CO}\right)$ established within 3 days of harvest, 2 to 6 week delay in $\mathrm{CA}$ establishment, 1 to 3 month delay in accumulation of $\mathrm{CO}_{2}$ to $3 \mathrm{kPa}$ during $\mathrm{CA}$, or pre-storage treatment with $1 \mu \mathrm{L} \cdot \mathrm{L}^{-1} 1-\mathrm{MCP}$ for $18 \mathrm{~h}$ at $20{ }^{\circ} \mathrm{C}$. Treatment with $1-\mathrm{MCP}$ delayed dissipation of watercore during CA compared to air storage. After 9 months storage, watercore scores were highest for 1-MCP treated fruit with no delay or a 2-week delay prior to CA with $3 \mathrm{kPa} \mathrm{CO}$. These treatments also had the highest values for firmness, and high titratable acidity compared to fruit stored in air. Treatments having with the highest incidence of 
internal browning after storage were $\mathrm{CA}$ with $3 \mathrm{kPa} \mathrm{CO}$, established with no delay regardless of $1-\mathrm{MCP}$ treatment. Treatment with 1-MCP reduced the effectiveness of delaying $\mathrm{CA}$ to reduce development of $\mathrm{CO}_{2}$ injury.

\section{Poster 275}

1-Methylcyclopropene (1-MCP) Delays Ripening and Extends Storage Life of 'Simmonds' Avocado Fruit

Jiwon Jeong*, Donald J. Huber, and Steven A. Sargent; Horticultural Sciences Dept., Univ. of Florida, Gainesville, FL 32611-0690

Avocado fruit (Persea americana Mill. cv. 'Simmonds'), harvested during the commercial harvesting season, were treated with two different concentrations ( 0.09 and $0.45 \mathrm{ppm}$ ) of 1 -methylcyclopropene (1-MCP) for three different exposure times $(6,12$, and $24 \mathrm{~h})$ at $20^{\circ} \mathrm{C}$. The fruit were then stored at $20^{\circ} \mathrm{C}$ in ethylene-free air for ripening assessment. 1-MCP treatment at $0.45 \mathrm{ppm}$ for $24 \mathrm{~h}$ at $20^{\circ} \mathrm{C}$ delayed ripening of avocado fruit by 4 days at $20^{\circ} \mathrm{C}$. This delay was characterized by a significant reduction in the rate of fruit softening and in the onset of the ethylene and respiratory climacterics. Avocado treated with $0.45 \mathrm{ppm} 1-\mathrm{MCP}$ for $24 \mathrm{~h}$ at $20^{\circ} \mathrm{C}$ also showed significantly less weight loss and retained more green color than air-treated fruit (control) at the full ripe stage. The delay in avocado ripening was influenced by 1-MCP concentration, and exposure duration and temperature. 1-MCP treatment affected the activity trends of selected cell wall enzymes (polygalacturonase, pectinmethylesterase, alpha, beta-galactosidase, and $\mathrm{C}_{x}$-cellulase) and completely suppressed the appearance of $P G$ activity for up to12 days. At the full ripe stage $(10-20 \mathrm{~N})$, water- and CDTA-soluble polyuronides of control fruit comprised approximately $65 \%$ and $7.5 \%$ of the total polyuronide content, while those of 1 -MCP treated fruit comprised approximately $38 \%$ and $9.7 \%$ of the total polyuronide content. Even when fully ripe, polyuronides from 1-MCP treated fruit exhibited reduced molecular mass downshifts compared with control fruit. Molecular mass downshifts in hemicelluloses and xyloglucan were also delayed in 1-MCPtreated fruit.

\section{Poster 276}

Influence of 1-Methylcyclopropene on Shelf Life of Peach and Nectarine Cultivars

Sylvia M. Blankenship and Michael L. Parker; Dept. of Horticultural Science, North Carolina State Univ., Raleigh, NC 27695

Seven peach and nectarine cultivars were harvested at tree-ripe maturity. The cultivars ranged from early to late season in maturation time. The cultivars included were: 'Candor' (early peach), 'Goldprince' (early peach), 'Carolina Red' (nectarine), 'Redhaven' (midseason peach), 'Contender' (midseason peach), 'China Pearl' (white-fleshed peach), and 'Big Red' (late peach). Fruit were cooled to remove field heat then treated with the ethylene action inhibitor, 1- methylcyclopropene (1-MCP), for $24 \mathrm{~h}$ at $4{ }^{\circ} \mathrm{C}$. One microliter/liter 1-MCP was shown to be an effective concentration. Fruit were then held at $21^{\circ} \mathrm{C}$ to simulate retail conditions. Treatment with 1-MCP increased fruit flesh firmness, particularly during the first 5 days at $21^{\circ} \mathrm{C}$. Respiration rate of the fruit was reduced with 1-MCP treatment. Treated fruit were also significantly firmer than untreated fruit after approximately 1 week, but this was somewhat dependent on harvest maturity. 1-MCP had little effect on fruit that had substantially softened prior to harvest. Effects on soluble solids were often negligible. All cultivars tested responded to treatment. It was concluded that use of 1-MCP significantly increased firmness of tree-ripe peaches and nectarines during a shelf life holding period at $21^{\circ} \mathrm{C}$.

\section{Poster 277}

Inhibition of Ethylene Production in Apple Fruit Discs by Acetylsalicylic Acid and Hydrogen Peroxide

Yongbing Yuan and Preston K. Andrews*; Dept Hort \& LA, Wasington State Univ. Pullman, WA 99164

Both salicylic acid and acetylsalicylic acid (aspirin, ASP) affect the growth and development of plants. They have been reported to inhibit ethylene production (Leslie and Romani, Plant Cell Reports 5:144,
1986) and also catalase activity, thereby inducing disease resistance through hydrogen peroxide $\left(\mathrm{H}_{2} \mathrm{O}_{2}\right)$ accumulation (Chen et al., Science 262:1883, 1993). Apple (Malus xdomestica Batsch. 'Fuji' and 'Granny Smith') fruit cortical discs were used to determine if $\mathrm{H}_{2} \mathrm{O}_{2}$ accumulation induced by ASP results in the inhibition of ethylene production. Both ASP and HP inhibited ethylene production in these fruit discs. Exogenous application of $0.01,0.1$, and $1 \mathrm{~mm}$ ASP resulted in similar ethylene inhibition as $\mathrm{H}_{2} \mathrm{O}_{2}$ at concentrations of 1,10 , and $100 \mathrm{~mm}$, respectively. Both ASP and $\mathrm{H}_{2} \mathrm{O}_{2}$ initially inhibited ethylene production, and later increased it. This response was concentration dependent, with lower concentrations resulting in less initial inhibition. Earlier stimulation of ethylene production occurred at lower concentrations for both ASP and HP. Treatment with both ASP $(0.5 \mathrm{~mm})$ and $\mathrm{H}_{2} \mathrm{O}_{2}(20$ $\mathrm{mM}$ ) resulted in greater inhibition of ethylene production than did either ASP or $\mathrm{H}_{2} \mathrm{O}_{2}$ alone. Hydrogen peroxide inhibited 1-aminocyclopropane1-carboxylic acid (ACC) oxidase activity, as did ASP and salicylic acid. Pretreatment of discs with dimethylthiourea (DMTU), a trap for $\mathrm{H}_{2} \mathrm{O}_{2}$, only partially reversed the ethylene inhibition induced by ASP, although DMTU alone greatly stimulated ethylene production. It is postulated that ASP inhibits ethylene production partly because it stimulates $\mathrm{H}_{2} \mathrm{O}_{2}$ accumulation, which in our study appears to be an effective inhibitor of ethylene production in apple fruit.

\section{Poster 278}

Effect of 1-Methylcyclopropene on Fruit Qaulity, Ethylene Evolution, and Respiration in Apple 'Tsugaru' and 'Fuji' Chung-Kil Kang ${ }^{\star 1}$, Sung-Eun Kim, Jung-Myung Lee, Young-Ka Kim, and Jae-Hoon Jung; ${ }^{1}$ National Institute of Agricultural Science and Technology, RDA, Suwon 441-707, Korea

'Tsugaru' apples were harvested in an apple orchard in Dongryangmyun, Chungju-si, on 18 Aug. 2000. Every $15 \mathrm{kgs}$ of the apples was put into 40- $\times 80-\times 36-\mathrm{cm}$ plastic boxes on 21 Aug. 2000 and exposed to $250,500,1000$, and $2000 \mathrm{ppb}$ of MCP gas for $4 \mathrm{~h}$ and $12 \mathrm{~h}$. After exposure, fruits were placed in laboratory for evaluation at room temperature. Post-harvest storage assessment was conducted by checking ethylene concentration at $1,3,7$ and 10 days after treatment and $\mathrm{CO}_{2}$ and $\mathrm{O}_{2}$ concentration at 7 and 10 days after treatment by GC. Storability of fruits was evaluated at $1,3,7$, and 10 days after treatment by checking fresh weight, sugar content, and firmness of the fruits. 'Fuji' apples were harvested in 1999 and stored in cold $\left(2^{\circ} \mathrm{C}\right)$ storage room until this experiment and treated with same method as 'Tsugaru'. Fresh weight, sugar content, and firmness of the fruits were evaluated at 1, 3, 6, 9 and 12 days after MCP exposure. Ethylene evolution and $\mathrm{CO}_{2} / \mathrm{O}_{2}$ ratio were significantly reduced by $\mathrm{MCP}$ treatment depending on concentration and exposure time. Above $1000 \mathrm{ppb}$ at $4 \mathrm{~h}$ and above $500 \mathrm{ppb}$ at $12 \mathrm{~h}$ treatment, fresh weight and firmness in MCP treated apples were higher than in untreated after the storage. Effect of MCP was more significant on 'Tsugaru' apple than on 'Fuju' apple. As a result, MCP treatment was very effective on extending shelf life and maintaining freshness of apples in this experiment.

\section{Poster 279}

\section{Apple Cultivar Response to 1-Methylcyclopropene}

R.S. Mueller ${ }^{* 1}$, D.P. Murr' and J.R. DeEII; ; Dept. of Plant Agriculture, Univ. of Guelph, Guelph, ON, N1G 2W1, Canada; ${ }^{2}$ Ontario Ministry of Agriculture, Food and Rural Affairs, Vineland, ON, Canada

The potential of 1-methylcyclopropene (1-MCP) treatment to maintain quality of early to late season apple fruit was evaluated using 13 apple cultivars. Most 1-MCP evaluations to date have focused on two or three of the more commonly grown cultivars, such as McIntosh, Empire, and Delicious. This study was initiated to investigate the effects of 1-MCP on a wider range of apple cultivars grown in Southern Ontario. Apples harvested by commercial growers were treated with 0,300 , and $600 \mathrm{ppb} 1-\mathrm{MCP}$ at $20^{\circ} \mathrm{C}$ for $20 \mathrm{~h}$, then placed into air storage at 0 to $1{ }^{\circ} \mathrm{C}$ for 60,120 , and 180 days. Fruit respiration, ethylene production, total hydrophobic volatiles evolved, firmness, and physiological disorders were evaluated over a 1 week simulated marketing period at $20^{\circ} \mathrm{C}$ after removal from cold storage. The cultivar response to 1-MCP treatment varied and could be divided into three 
groups: low, moderate, or high response to 1-MCP treatment at harvest. These response groups did not seem to correlate to fruit harvest date, as hypothesized initially. Apple cultivars that matured early, mid, or late in the season could be classified into any of the response groups. For example, Gala, an early season cultivar, was highly responsive to 1-MCP treatment, whereas Mutsu, a late season cultivar, and Mclntosh, an early season cultivar, displayed a relatively low response to 1-MCP. As well, cultivars displaying a high response to 1-MCP did so regardless of concentration. The ability of 1-MCP to inhibit respiration, ethylene and volatile production over a 7-day period at $20^{\circ} \mathrm{C}$ and to reduce fruit softening and physiological disorders varied considerably among the cultivars.

\section{Poster 280}

Enzymic Hydrolysis of Cell-wall Polysaccharides and Membrane Lipids in Watermelon Fruit Exposed to Ethylene Yasar Karakurt ${ }^{* 1}$, Noboru Muramatsu', and Donald J. Huber ${ }^{1} ;{ }^{1}$ Horticultural Sciences Dept., Univ. of Florida, Gainesville, FL 32611-0690; ${ }^{2}$ Breeding Station, Institute of Fruit Tree Science, Fujimoto 2-1, Tsukuba, Japan

Watermelon fruit are extremely sensitive to ethylene, exhibiting acute symptoms of softening and water-soaking following short periods of exposure to the gas. This study addressed the influence of exogenous ethylene on the firmness, activities of membrane and cell wall hydrolases, ethylene biosynthetic enzymes, and cell wall matrix polysaccharides. Watermelon fruit were harvested at the full-ripe stage and exposed to $50 \mathrm{ppm}$ ethylene for 6 days at $20^{\circ} \mathrm{C}$. The firmness of ethylene-treated fruit decreased nearly $80 \%$ after 6 days of ethylene exposure, but the firmness of fruit maintained in air remained relatively constant up to day 3 and then decreased slightly $(\approx 12 \%)$ after 6 days at $20^{\circ} \mathrm{C}$. Polygalacturonase, pectinmethylesterase, alpha-galactosidase, ACC synthase and oxidase, lipoxygenase, and phospholipase $D$ and $C$ activities increased significantly in placental tissue in response to ethylene. Beta-galactosidase activity was not affected significantly in ethylene-treated fruit. The increase in the activities of cell wall hydrolases was accompanied by an increase in water-soluble polyuronides (72\%) and downshifts in polyuronide mol mass. Depolymerization of hemicelluloses was also accelerated in ethylene-treated fruit. The changes in enzyme activities in air-treated fruit and solubility and mol mass downshifts of matrix polysaccharides were significantly lower than those observed for ethylene-treated fruit. The results suggest that extensive degradation of cell-wall matrix polymers as a result of enhanced activity of cell wall hydrolases and degradation of membrane lipids caused by increased activities of lipases contribute to softening and water-soaking in watermelon.

\section{Poster 281}

Ethylene Production and Fruit Softening during Pawpaw Ripening

Rumphan Koslanund"1, Douglas D. Archbold", and Kirk W. Pomper ${ }^{2}$; ${ }^{1}$ Dept. of Horticulture, Univ. of Kentucky, Lexington, KY 40546-0091; ${ }^{2}$ Atwood Research Center, Kentucky State Univ., Frankfort, KY 406012335

Pawpaw [Asimina triloba (L.) Dunal] is a highly perishable fruit that can be kept at room temperature for 5-7 days if harvested at the initiation of ripening. This rapid ripening of pawpaw may significantly slow its commercialization. These studies were conducted to characterize ethylene biosynthesis and production, respiration, and the activity of cell wall loosening enzymes of pawpaw during ripening. The results indicated that pawpaw is a climacteric fruit with a peak in ethylene production at 2 days after harvest, coincident with high levels of ACC synthase and ACC oxidase activities. ACC content was high from 3 to 5 days after harvest. $\mathrm{CO}_{2}$ production was highest at 2 and 3 days after harvest. Both internal and external firmness decreased over time starting at harvest. Fruit at four stages - green mature, early, mid, and late ripening - were evaluated for relative activity of cell wall loosening enzymes by a tissue print technique. The tissue prints indicated that the activities of endo-b-mannanase and cellulase appeared when the fruit began to soften and were high by mid- ripening. However, the activity of pectin methylesterase was present in green mature fruit and had highest activity at late ripening.

\section{Poster 282}

Sucrose Loading Affects Ethylene Responsiveness of Carnation (Dianthus caryophyllus cv. White Sim) Petals Jose Julio Vicente Garcia*, and Sven Verlinden; West Virginia Univ., Morgantown, WV 26506

Changes in ethylene responsiveness were monitored in petals of carnation flowers treated with sucrose. Flowers were treated with a $10 \%$ sucrose solution for $24 \mathrm{~h}$ or a $2 \%$ sucrose solution for the duration of the vase life of the flowers. These treatments were used to simulate a bud opening and standard postharvest treatment of carnation flowers. Ethylene responsiveness, measured as ethylene production of the petals upon ethylene exposure, was recorded daily. An increase in ethylene responsiveness was observed in the control flowers, held in distilled water, during the vase life of the flowers. A significant delay in this increase in ethylene responsiveness of 3 and 2 days was observed in the $2 \%$ and $10 \%$ sucrose treatment, respectively. Both the ACC oxidase and ACC synthase activity of the same tissue show similar delayed but increasing patterns, indicating sucrose has an effect on both ethylene biosynthetic enzymes. The control treatment flowers maintain stable levels of ACC throughout the experiment. The levels of ACC are significantly lower in the petals of sucrose treated flowers, especially after the initial sucrose treatment, but increase throughout the vase life of the flowers to levels seen in the control treatment. In addition to these data, we will also present changes in mRNA abundance, due to sucrose loading, of several genes, including ACC synthase and ACC oxidase. The results of this study indicate that sucrose loading significantly decreases ethylene responsiveness of carnation flowers and that this decrease in ethylene responsiveness is mediated by a decrease in ACC oxidase and ACC synthase activity.

1:00-2:00 p.m. CC Ballroom

\section{Poster Session 6: Postharvest \\ Poster 283}

Characterization of Postharvest Chlorophyll Formation of Soybean Sprout Cotyledons

Young-Sang Lee* and Yong-Ho Kim; Div. of Life Sciences, Soonchunhyang Univ. Asan, South Korea

The postharvest greening of cotyledons resulting from chlorophyll formation is an important factor limiting the marketability of soybean sprouts. To quantitatively characterize the greening, soybean sprouts were exposed to different environmental conditions, and changes in cotyledon chlorophyll contents were measured. The chlorophyll contents showed linear increment in proportion to the time duration of light exposure. Sprouts under 12 and $20^{\circ} \mathrm{C}$ exhibited 3.5 and 14 times higher chlorophyll contents, respectively, than $4^{\circ} \mathrm{C}$. The utilization of growth stimulating regulators such as BA significantly enhanced the rate of greening. Chlorophyll formation was affected by the wavelength of light in that cotyledon accumulated higher chlorophylls under yellow $>$ red $>$ blue $>$ green light conditions. Modified atmospheric conditions such as low $\mathrm{O}_{2}$ and high $\mathrm{CO}_{2}$ successfully decreased the greening but induced some off flavor. These results suggest that postharvest greening of soybean sprouts could be minimized by controlling environmental factors such as temperature, MA packing conditions as well as by using packing film of specific wavelength reflection.

\section{Poster 284}

Simulation Model of Respiration Rate of Leaf Lettuce Considering Elapsed Time

Shinichiro Kuroki*, Eriko Yasunaga, Wenzhong Hu, Toshitaka Uchino, and Koichi Akimoto; Dept. of Bioproduction Environmental Science, Kyushu Univ., Japan

There are some models concerned with respiration rate in response to temperature. The mathematics of the model is based on the Arrhenius equation, however, it could not express any 
influences of time exposing under some temperatures. Furthermore, there were few data available in wide range of temperature including comparatively high temperature. In this study, the new mathematical model of respiration rate considering passing time under some temperature was proposed and the fitness was verified. carbon dioxide production rate of leaf lettuce (Lactuca sativa L.) was measured by ventilation method at various temperatures. The gas flow rate was $200 \mathrm{~mL} / \mathrm{min}$ and all air was humidified by bubbling through water prior to introduction into the respiration chamber. The value of $\mathrm{kc}$ that means coefficient of the thermal denaturation rate of enzyme or the activity lowing rate after harvest was minute in the range from 0 to $30^{\circ} \mathrm{C}$. In the ordinary temperature range, the change of the respiration rate with elapsed time was able to be disregarded and carbon dioxide production rate just obey the Arrhenius equation. While, the value of $\mathrm{kc}$ was increased linearly with temperature rise over $30^{\circ} \mathrm{C}$, therefore there were remarkable effects of respiration rate by elapsed time. The proposed rate equation that estimated respiration rate before it received the thermal denaturation by the Arrhenius equation agreed well with the experimental data. And respiration rate for the temperature when a certain time elapsed showed the tendency that is very similar to the general relationship between enzymatic activity and temperature.

\section{Poster 285}

Factor Analysis on Respiration of Cucumber Fruits Under Unsteady Gas Conditions

Eriko Yasunaga*, Shinichiro Kuroki, Daisuke Hamanaka, Wenzhong Hu, Toshitaka Uchino, and Koichi Akimoto; Dept. of Bioproduction Environmental Science, Kyushu Univ., Fukuoka, Japan, 812-8581

In order to clarify the respiration reactions of the fruits and vegetables under the changeable gas condition during commercial distribution, the respiration rate of cucumber fruits was measured under the unsteady gas conditions by the flexible chamber methods at $20^{\circ} \mathrm{C}$. The cucumber fruits, varieties of 'Sharp 1' and 'Natsunokaori', were harvested in local farm at the market size. The concentrations of oxygen and carbon dioxide gas, the change rate of oxygen gas concentration and the elapsed time were taken up as the factors of the respiration control and the induction of anaerobic respiration for the cucumber fruits under the unsteady gas conditions. And these factors were analyzed using measured results of the respiration rate. The result of factor analysis indicated that the respiration rate of cucumber fruits was mainly influenced by the concentration of oxygen. Three difference regression lines were obtained at oxygen concentration of $4 \%$ or less, $4 \%$ to $10 \%$ and $10 \%$ to $20 \%$, when the respiration rate and the concentration of oxygen were plotted on the reciprocal scale. Therefore, the existences of three factors influenced on the respiration were considered with decreasing in the oxygen gas concentration.

\section{Poster 286}

Reduction of Hypoxia-induced Injury in Mclntosh Apples G. Lévesque ${ }^{* 1}$, D.P. Murr' ${ }^{1}$, and J.R. DeEII ; ${ }^{1}$ Dept. of Plant Agriculture, Univ. of Guelph, Guelph, ON, N1G 2W1, Canada; ${ }^{2}$ Ontario Ministry on Agriculture, Food and Rural Affairs, Vineland, ON, LOR 2EO, Canada

Acclimatization to standard CA (SCA) conditions and low temperature prior to low oxygen (LO) or ultra-low oxygen (ULO) CAstorage was examined with three strains of 'Mclntosh' apple. The objectives were to: 1) reduce low temperature- and low oxygenrelated physiological disorders; 2 ) integrate the benefits of hypoxic storage to low oxygen susceptible fruit; and 3) improve the quality and shelf-life of 'McIntosh' apples. Marshall 'McIntosh' (low oxygen sensitive) and Morspur 'Mclntosh' ('typical' low oxygen response) were subjected to SCA $\left(3 \% \mathrm{O}_{2}+4.5 \% \mathrm{CO}_{2}\right)$ for 60 days, transferred to $\mathrm{LO}\left(1.5 \% \mathrm{O}_{2}+2.0 \% \mathrm{CO}_{2}\right)$ for an additional 60 days, then transferred to ULO $\left(0.7 \% \mathrm{O}_{2}+1.0 \% \mathrm{CO}_{2}\right)$ for a final 60 days at 0 and $3^{\circ} \mathrm{C}$. Fruit from both strains also were stored continuously in SCA and ULO for 180 days at 0 and $3{ }^{\circ} \mathrm{C}$; control fruit were stored in air at $0^{\circ} \mathrm{C}$. Rodger 'Mclntosh' ('typical' low oxygen response) were placed in $\mathrm{CA}\left(2.5 \% \mathrm{O}_{2}+2.5 \% \mathrm{CO}_{2}\right)$ at $3{ }^{\circ} \mathrm{C}$ for 60 days, transferred to $\mathrm{LO}\left(1.5 \% \mathrm{O}_{2}+1.5 \% \mathrm{CO}_{2}\right)$ at 0 or $3^{\circ} \mathrm{C}$ for $60 \mathrm{~d}$, and then transferred again for 60 days to ULO at 0 or $3^{\circ} \mathrm{C}$. Fruit firmness and disorders were assessed during a 1 -week simulated marketing period at $20^{\circ} \mathrm{C}$ following storage. The gradual reduction of $\mathrm{O}_{2}$ to $0.7 \%$ at $0{ }^{\circ} \mathrm{C}$ significantly reduced firmness loss and physiological disorders, especially hypoxia-induced injuries in Marshall, and low temperature injuries in all three 'McIntosh' strains. For low $\mathrm{O}_{2}$-sensitive fruit, a programmed reduction in $\mathrm{O}_{2}$ content during storage appears promising and has added quality benefits compared to standard CA conditions.

\section{Poster 287}

\section{Acclimatization to Hypoxic and Near-anoxic Atmospheres Improves Apple Quality}

G. Lévesque*, D.P. Murr, and J.R. DeEII'; Dept. of Plant Agriculture, Univ. of Guelph, Guelph, ON, N1G 2W1, Canada; ${ }^{1}$ Ontario Ministry on Agriculture, Food and Rural Affairs, Vineland, ON, LOR 2EO, Canada

Rapid establishment of hypoxic and near-anoxic conditions at $0{ }^{\circ} \mathrm{C}$ prior to ultra-low oxygen (ULO) or low oxygen (LO) CA-storage was investigated. The objectives were: 1) improvement of fruit quality and shelf-life; 2) increased ability of fruit to cope with long-term exposure to ultra-low oxygen conditions; and 3) reduction in physiological disorders in response to low temperature stress and extended hypoxic exposure. Within 24 hours of harvest for long-term storage, 'Delicious', 'Empire', 'Idared' and 'Mclntosh' apples were placed at $0{ }^{\circ} \mathrm{C}$ in a low oxygen and moderate carbon dioxide atmosphere $\left(1.5 \% \mathrm{O}_{2}+1.0 \% \mathrm{CO}_{2}\right)$ for 49 days, then transferred to ULO $\left(0.7 \% \mathrm{O}_{2}+1.0 \% \mathrm{CO}_{2}\right)$ for an additional 147 days. In addition, 'Cortland' apples were subjected to near-anoxic initial low oxygen stress (ILOS) of $0.25 \%$ or $0.5 \% \mathrm{O}_{2}$ at $3^{\circ} \mathrm{C}$ for a period of 2 weeks prior to storage in $\mathrm{LO}\left(1.5 \% \mathrm{O}_{2}+1.5 \% \mathrm{CO}_{2}\right)$ at 0 or $3{ }^{\circ} \mathrm{C}$ for 155 days. Fruit quality assessed during a 1 -week post-storage simulated marketing period at $20^{\circ} \mathrm{C}$ indicated oxygen reduction from $1.5 \%$ to $0.7 \%$ for the latter three-fourths of the storage period and ILOS prior to LO resulted in a significant reduction in physiological disorders, especially superficial scald and core browning in susceptible fruit. CAstored fruit were as much as $2.25-2.65 \mathrm{~kg}$ firmer than air-stored fruit 1 day out of storage, and this firmness advantage was retained for the 7-day duration at $20^{\circ} \mathrm{C}$. Results support the notion that rapid imposition of an elastic stress or strain (e.g., short-term hypoxia or near-anoxia) improves fruit response to subsequent temperature and oxygen stress during long-term CA storage.

\section{Poster 288}

Activities of Enzymes Associatated with Succinate and 4Aminobutyrate Metabolism of Strawberry Fruit Exposed to Elevated Carbon Dioxide Concentrations

Rik van Gorsel* and Christopher B. Watkins; Dept. of Horticulture, 126 Plant Science Bldg., Cornell Univ., Ithaca, NY 14853

Some strawberry varieties respond to high $(15-30 \mathrm{kPa}) \mathrm{CO}_{2}$ partial pressures with succinate accumulation rather than the more common response of acetaldehyde and ethanol production. To test the hypothesis that differences in the tricarboxylic acid (TCA) cycle or the 4aminobutyrate (GABA) shunt may favor a flux of pyruvate to succinate, we are analyzing the activities of succinate dehydrogenase and the enzymes associated with the GABA shunt. 'Jewel' and 'Cavendish' strawberries were treated with 0,15 , or $30 \mathrm{kPa} \mathrm{CO}_{2}$ in the presence of $20 \mathrm{kPa} \mathrm{O}_{2}$ for up to 9 days. Subsequently, the fruits were peeled to remove achenes and either frozen or used directly. Succinate semialdehyde dehydrogenase (SSADH) activity was barely detectable and there were no significant differences between treatments. 4Aminobutyrate transaminase (GABA-T) activity was assayed with both pyruvate and oxaloacetate as amino group acceptor. The alanine and glutamine produced in these reactions is being assayed by HPLC. Preliminary results indicate a significant transamination of pyruvate. The research is supported in part by USDA-NRI grant \#1999-01522. 


\section{Poster 289}

Replacing Sulphur Dioxide in Postharvest Management of Thompson Seedless Grapes by Using High- $\mathrm{CO}_{2}$ Controlled Atmosphere

D. Manríquez ${ }^{1}$, B. Defilippi ${ }^{* 1,2}$, M. Arias $^{3}$, and J. Retamales ${ }^{1,3},{ }^{1}$ Instituto de Investigaciones Agropecuarias (INIA), P.O. Box 439/3, Santiago, Chile; ${ }^{2}$ Pomology Dept., Univ. of California-Davis; ${ }^{3}$ Facultad de Ciencias Agronómicas, Universidad de Chile

Research work has been conducted in the past two seasons in Thompson Seedless grapes in Chile aiming at completely replacing presently used $\mathrm{SO}_{2}$ fumigation and/or inclusion of metabisulphite $\mathrm{SO}_{2}$ generating) pads during storage/transport for export. $\mathrm{SO}_{2}$ usage prevents rotting, mainly the one caused by Botrytis cinerea, which is prevalent under such circumstances. However, possible development of organic table grapes, together with expected restrictions in some markets, precludes the use of $\mathrm{SO}_{2}$ during postharvest handling. An alternative to $\mathrm{SO}_{2}$ is being presently sought by replacing it with controlled atmosphere $(\mathrm{CA})$ and several combinations of $\mathrm{O}_{2} / \mathrm{CO}_{2}$ have been tested. Fruit were normally inoculated with Botrytis in order to have increased propensity towards the rotting problem and were kept for periods between $20-40$ days in containers inside a cold chamber at $0{ }^{\circ} \mathrm{C}$ to simulate export conditions. CA conditions were maintained within containers by attaining given gas combinations and compensating for changes caused by respiration with an automated system (Kronenberger Systemtechnik, Germany). Using $15 \%$ to $20 \% \mathrm{CO}_{2}$ levels, an adequate control of rotting, comparable to the one attained with the use of $\mathrm{SO}_{2}$, can be achieved. $\mathrm{CO}_{2}$ concentrations higher than $20 \%$ resulted in some off-flavor and increased internal browning. Stems and pedicels were less green when using $\mathrm{CA}$ instead of $\mathrm{SO}_{2}$ and work is in progress to overcome this quality problem.

\section{Poster 290}

Fermentative Metabolism and Quality of 'Thompson Seedless' Grapes in Response to Insecticidal Controlled Atmosphere

Raywat Chairat ${ }^{*}$ and Adel A. Kader; Dept. of Pomology, Univ. of California, Davis, CA 95616

'Thompson Seedless' grapes were kept at $0^{\circ} \mathrm{C}$ in air (control); $45 \%$ $\mathrm{CO}_{2} ; 0.25 \% \mathrm{O}_{2}$; or $0.25 \% \mathrm{O}_{2}+45 \% \mathrm{CO}_{2}$ to investigate the effects of insecticidal controlled atmosphere (ICA) on quality and induction of fermentative metabolism. Quality attributes including firmness, soluble solids content, titratable acidity, $\mathrm{pH}$, color and visual quality, and production of fermentative volatiles (mainly acetaldehyde and ethanol) and activities of corresponding enzymes that catalyze their production, pyruvate decarboxylase (PDC) and alcohol dehydrogenase (ADH), were measured initially and after 4,8 , and 12 days of exposure and after 1 and 3 days following transfer to air at $0{ }^{\circ} \mathrm{C}$. Although quality parameters were not significantly affected by ICA treatments compared to air control, production of both acetaldehyde and ethanol increased by 5 to 10 fold and 40 to 50 fold, respectively, over a 12-day exposure to ICA with greatest increase found in grapes kept in $45 \% \mathrm{CO}_{2}$, while the levels of these volatiles remained low and relatively constant in air control fruit. Concentration of acetaldehyde in grapes kept in $45 \% \mathrm{CO}_{2}$ decreased by $70 \%$ after transfer to air for 3 days at $0^{\circ} \mathrm{C}$, while ethanol concentration decreased slightly. Activities of PDC and ADH increased significantly during exposure to ICA, particularly under $45 \% \mathrm{CO}_{2}$, with slight reduction on day 12 of storage. ADH activity in grapes kept in $45 \% \mathrm{CO}_{2}$ sharply increased after transfer to air for 1 day. Low $\mathrm{O}_{2}$ seemed to reduce the effect of high $\mathrm{CO}_{2}$ on both production of the volatiles and enzymatic activity as indicated by lower accumulation of acetaldehyde and ethanol and lower activities of PDC and $\mathrm{ADH}$ in grapes kept in $0.25 \% \mathrm{O}_{2}+45 \% \mathrm{CO}_{2}$ compared to those kept in $45 \% \mathrm{CO}_{2}$ alone.

\section{Poster 291}

Short-chain Acyl CoA Synthetase in Banana Fruits

S.K. Wendakoon, Y. Ueda", M. Ishimaru, and Y. Imahori; Osaka Prefecture Univ., Graduate School of Agriculture and Biology, 1-1, Gakuen-cho, Sakai, Osaka 599-8531, Japan

Esters are one of the most important aroma components in fruits. The activity of the ester synthetase (Alcohol Acyl CoA transferase) plays a critical role in the formation of esters. However, during normal ripening of fruits, the surrounding factors, like temperature or atmosphere, may affect the ester formation with another metabolic reaction. Acetyl CoA synthetase or short-chain acyl CoA synthetase may be one of the limiting factors in the formation of esters because it requires ATP. The formation of esters decreased in fruit slices stored in anaerobic conditions, such as nitrogen-purged PE bags or water soaking. However, the addition of ATP solution in the fruit slices improved the formation of esters. The activity of Acyl CoA synthetase was easily detected by HPLC. Substrates used were either acetate or butyrate in combination with CoA, ATP, and Mg. The double reciprocal plots of acetate and butyrate did not show competitive inhibition. Km value of $\mathrm{Mg}$ was very high when butyrate was used as the substrate instead of acetate. Hence, different enzymes can mediate the acetate and butyrate $\mathrm{CoA}$ formations. From this enzymatic reaction, the ester formation acts as one of the ATP dissipation systems, and it is affected by surrounding stress that fluctuates the ATP formation.

\section{Poster 292}

Studies on the Ripening and Storage of Mango Fruits Grown in a Plastic House

Yasuo Tatsumi" ${ }^{*}$, Naomi Sato', Kaname Tanaka ${ }^{2}$, and Akira Yamazaki2 ${ }^{1}$ Faculty of Agriculture, Miyazaki University, 1-1 Gakuen Kibanadai-nishi, Miyazaki, 889-2192 Japan; ${ }^{2}$ Agricultural Electrification Testing Center, Research Laboratory, Kyushu Electric Power Co. Inc., 1-10-1 Takagise-higashi, Saga, 849-0922 Japan

The mango fruits (cv. Irwin) grown in a plastic house were harvested 90 (90d), $100(100 d), 110(110 d)$ days after flowering and stored at $20^{\circ} \mathrm{C}$. The respiratory climacteric was found by day 11 and 8 in the fruits of $90 \mathrm{~d}$ and $100 \mathrm{~d}$, respectively. In the fruits of $110 \mathrm{~d}$, the climacteric peak did not found and the respiratory rate decreased continuously during storage at $20^{\circ} \mathrm{C}$. The ethylene production was detected during 3 to 5 days after climacteric peak in all harvested fruits. The sugar content was increased during ripening in $90 \mathrm{~d}$ and $100 \mathrm{~d}$ fruits, but in the fruit of $110 \mathrm{~d}$, the changes of sugar content were small amount. The acid content was higher in the early harvest fruits and then decreased in all fruits during ripening. The fruits harvested $100 \mathrm{~d}$ after flowering stored at 15 and $10^{\circ} \mathrm{C}$. The respiratory rate was suppressed and increased gradually during storage in both temperatures. The respiration was increased sharply and showed climacteric rise after removed to 20 ${ }^{\circ} \mathrm{C}$. The climacteric rise in the fruits stored at $10^{\circ} \mathrm{C}$ after transfer to $20^{\circ} \mathrm{C}$ was lower than those stored in 15 or $20^{\circ} \mathrm{C}$. Full mature fruits were stored in air or controlled atmosphere (CA) containing $5 \%$ and $10 \% \mathrm{O}_{2}$ combined with $5 \% \mathrm{CO}_{2}$, or packed with LLDPE film $(0.03$ $\mathrm{mm}$ thickness) or MA film (P-plus) at $7{ }^{\circ} \mathrm{C}$ for 1 month. The fruits decay (anthracnose) was suppressed in MA film and slightly suppressed in LLDPE film. The storage atmosphere condition of $5 \%$ and $10 \% \mathrm{O}_{2}$ combined with $5 \% \mathrm{CO}_{2}$ had no effect to reduce fruits decay compared with in air storage.

1:00-2:00 p.m CC Ballroom

\section{Poster Session 7: Sustainable Agriculture \\ Poster 461}

Disposal Ways of Plastic Mulches Used for Horticultural Production in Western Mexico

J. Farias-Larios*, J.G. López-Aguirre, D. Sandoval, and M. OrozcoSantos; Universidad de Colima, Facultad de Ciencias Biológicas y Agropecuarias, Tecoman, Mexico

An increase in the use of agricultural plastics stems from a variety of factors, such as increasing demand for efficiency in livestock agriculture and increasing public demand for food safety. However, when plastics are used, the problem is what the farmers should do to disposal them from the field. In Western Mexico, horticultural production depends of high-input systems to maximize yield and product quality. Plasticulture and fertigation, are the principal management practices. Mulching films are spread widely, 
however after using a great deal of energy and working hours to remove the films is required. A survey with 49 questions was applied to 43 farmers during the 1999 season, covering a total area of 1992 Has, to determine quantity, mulch types and color, and strategies used for the growers for their elimination. Results showed that $50 \%$ of the farmers burn the plastics and only $7 \%$ participate in a recycling program developed by the same company that market the polyethylene. Rest of the farmers put it into the soil or sends it to the dump. Factors that restrict the use a recycling program for the farmers are: the expensive disposal (including: high cost to pick up, clean and transport of used plastics), lack of governmental recycling program, contamination of used plastic mulch (contain soil, organic mater and several chemicals residues), low volumes of plastics and dispersed over large area, lack of equipment for baling, washing, pelletizing and remanufacturing plastics, and diversity of color plastics used in horticulture and corresponding diversity in market value. At present, the use of organic mulch, sprayable or biodegradable films, are not considered by the growers as alternative to use them.

\section{Poster 462}

\section{Counting Farmers Markets}

Allison Brown*; 335 Oakwood Lane, State College, PA 16803

Farmers markets selling locally grown produce were, at one time, vital components of urban food supply systems. In the modern era, an extended wholesale supply system has reduced markets to negligible importance in provisioning. Yet tallies of US farmers markets show that their numbers are increasing. Examination of the literature on U.S. farmers markets in the twentieth century reveals cycles of expansion and decline. Four surges in numbers reported, with the most rapid rise following the passage of PL 94-463, the Farmer-to-Consumer Direct Marketing Act of 1976. Between 1970 and 1986 some states increased their markets ten-fold with the national total rising nearly $500 \%$ by one estimate. Beginning in the late 1980 s, farmers markets entered another growth phase, which continues. Research into farmers markets is hindered by the lack of consistency in classification, by incomplete descriptions of market characteristics and by lost data.

\section{Poster 463}

\section{Conservation Tillage Research and Extension Education in} California

J.P. Mitchell ${ }^{* 1}$, E.M. Miyao ${ }^{2}$, M. McGiffen ${ }^{3}$, and M.D. Cahn ${ }^{4},{ }^{1}$ Univ. of California, Davis, Dept. of Vegetable Crops and Weed Science; ${ }^{2}$ Univ. of California Cooperative Extension, Yolo and Solano Counties; 'Univ. of California, Riverside, Dept. of Botany and Plant Sciences; ${ }^{4}$ Univ. of California Cooperative Extension, Sutter and Yuba Counties

Despite a $300 \%$ increase in conservation tillage (CT) acreage in the Midwest during the last decade, less than $0.5 \%$ of row crop acreage in California is currently farmed with CT practices (CT Information Center, 2000). Primary reasons why CT approaches have not been more widely adopted in California include lack of experience and information related to $\mathrm{CT}$, limited locally-available CT equipment, concerns about irrigation management in surface residues, and the fact that planting bed dimensions typically change from one rotation crop to the next. Despite these concerns, however, there has been a well-documented increase not only in interest in CT, but also in terms of CT research and demonstration activities during the last five years throughout California. Whereas in 1996 there was one CT research/demonstration site in the state, there were upwards of twenty in 2000. The Univ. of California's Division of Agriculture and Natural Resources Conservation Tillage Workgroup has been involved in many of these research and extension education efforts and during the last five years has increased the number of its members and affiliates from three to over 60 in 2000. Primary incentives for evaluating CT options in California include cutting production costs, improving soil quality, managing weed with surface residues, and minimizing soil compaction. The extent to which these goals might be realized in California's highly productive and intensive row crop production valleys is the subject of considerable ongoing research and innovation.

\section{Poster 464}

Effect of Composted Biosolids on Trace Element Extraction by Canola Intercropped with Apricot Trees

G.S. Bañuelos ${ }^{1}$ and S. Pasakdee ${ }^{* 1,2} ;{ }^{1}$ USDA-ARS, Water Management Research Laboratory, 2021 S. Peach, Fresno, CA 93727; ${ }^{2}$

Dept. Plant Science California State Univ., Fresno, CA

Agricultural use of biosolids or wastewater treatment plant sludge as a fertilizer is becoming increasingly widespread. The organic material contains nitrogen and a wide variety of inorganic elements, including nutrients and possibly trace metals. The contamination of soil with high levels of soluble trace metals can result in phytotoxic effects with the increased entry of metals into the food chain. We are investigating the use of phytoremediation as a strategy for extracting soluble elements from soils that have received biosolids applied at different rates fir six years on 6-year old apricot trees already established at the USDA research facilities in Fresno, CA. Composted municipal waste (biosolids) were donated by Pima-Gro Systems, Redwood City, CA for the multi-year study. Rates of biosolid fertilization to apricot trees were based on the following nitrogen equivalents: $0,57,170$, and $340 \mathrm{~kg} \mathrm{~N}^{-1}$ respectively. Canola (Brassica napus) was planted in a $4 \mathrm{~m}^{2}$ site around each tree of each treatment when apricot trees were dormant (Dec. thru March). Soil samples were taken in $15 \mathrm{~cm}$ depth and a depth of $45 \mathrm{~cm}$ at preplant and at harvest of canola each year. Plants were harvested between 75 and 90 days after seeding before leaf abscission had occurred. Dry matter yields were recorded and composite leaf samples were collected from plants. Both soil and leaf samples were analyzed for selected inorganic elements, including total and water extractable fractions in soil. The use of canola to extract soluble trace elements deposited to soil via biosolids will be discussed for the last three years.

\section{Poster 465}

Bioremediation of Swine Waste Using Greenhouse Tomatoes: A Systems Approach

M.M. Peet*, Kelly Ponce, D.H. Willits, and J. Cheng; North Carolina State Univ., Raleigh, NC 27695

An interdisciplinary research project is being conducted by the Horticultural Sciences, Biological and Agricultural Engineering and Agricultural and Resource Economics Depts. of North Carolina State Univ. as well as the Univ. of North Carolina School of Public Health in cooperation with Barham Farms of Zebulon, NC, a 4000 sow farrow-to-weanling operation. The purpose of this project is to develop and evaluate an innovative swine waste management system which will fertigate greenhouse vegetable crops with effluent from a secondary, aerobic lagoon. The primary lagoon on-farm is anaerobic and methane generated in this lagoon will be burned to provide $\mathrm{CO}_{2}$ and waste heat for the greenhouse operation. Although crops of tomatoes, cucumbers and peppers have been grown in this system, several limitations have been identified. First, although the material from a secondary (aerobic) lagoon, fed from the primary lagoon, has the appropriate nutrient levels for fertigation of greenhouse tomatoes, the ammonium levels are too high. Significant levels of blossom-end rot (BER) result when this material is used raw. By treating the effluent from the secondary lagoon in a simple biofilter, it was possible to convert $90 \%$ of the ammonium to nitrate, reducing problems with $\mathrm{BER}$, and somewhat reducing $\mathrm{pH}$. High salts, especially sodium and high $\mathrm{pH}$ remain problems, but levels of heavy metals are well within normal limits. After the tomatoes go through a normal packing line, levels of microbial contaminants, measured by cooperators at the UNC School of Public Health, are also within normal limits. The greenhouse complex is currently being doubled in size and the irrigation and environmental control systems upgraded to provide better control over rootzone $\mathrm{pH}$ and salts levels. 


\section{Poster 466}

Soil Nitrate Nitrogen and Bell Pepper Yield Following Application of Varying Rates of Compost or Feather Meal With and Without Prior Green Manure

Mark Gaskell ${ }^{* 1}$ and Helmut Klauer ${ }^{2} ;{ }^{1}$ Univ. of California Cooperative Extension, 624 West Foster Rd., Santa Maria, CA 93455; ${ }^{2}$ Nojoqui Farm, Buellton, $C A$

Little research base exists to guide increasing numbers of organic vegetable growers. Previous studies have indicated that compost nitrogen $(\mathrm{N})$ mineralization rates may not match crop $\mathrm{N}$ needs. Prior studies have shown that $\mathrm{N}$ mineralization from feather meal (FM) is more rapid and may be useful as a more efficient $\mathrm{N}$ source to complement compost application. During the 2000 season, we compared varying rates of manure-based compost (MBC) and FM at $\mathrm{N}$ rates equivalent to $0,120,208$ and $296 \mathrm{~N}$ in plots previously cropped or not cropped to legume green manure (GM). The MBC and FM were applied as $0 \mathrm{~N}, 88 \mathrm{~N}$, or $176 \mathrm{~N}\left(\mathrm{~kg} \cdot \mathrm{ha}^{-1}\right)$ incorporated pre-transplant for the 120, 208 and 296 treatments respectively. All $\mathrm{N}$ treatments received $40 \mathrm{~kg} \cdot \mathrm{ha}^{-1} \mathrm{~N}$ at 15,40 , and 60 days post transplant. Weekly residual soil nitrate $\mathrm{N}$ (SNN) over 18 weeks post transplant and fresh fruit yields were determined for all treatments. Weekly SNN varied from $2 \mathrm{mg} \cdot \mathrm{kg}^{-1}$ to over $71 \mathrm{mg} \cdot \mathrm{kg}^{-1}$. Residual SNN was higher with higher $\mathrm{N}$ application within each material. The 296 N FM treated plots with green manure showed highest SNN most weeks. The MBC treated plots showed lower weekly SNN than FM treated plots at each $\mathrm{N}$ rate. Total pepper yield was not as markedly affected as early yield and fruit size. Statistically significant regression relationships were observed between rate of FTM up to 208 $\mathrm{kg} \cdot \mathrm{ha}^{-1} \mathrm{~N}$ and both early yield $\left(r^{2}=0.68\right)$ and extra large yield $\left(r^{2}=\right.$ 0.56 ). Yield from MBC treated plots was not statistically related to $N$ rate with or without prior green manure.

\section{Poster 467}

\section{Evaluation of Soil Amendments and Cover Crops for} Certified Organic Pepper Production

Kathleen Delate* and Vince Lawson; lowa State Univ., Ames, IA 50011

Several experiments have documented the beneficial effects of natural soil amendment and compost products for certified organic vegetable and herb crop production. In 1998, we began a comparison of the productivity of organic peppers compared with conventional peppers produced with synthetic fertilizers and herbicides. In 1998 and 1999, at the ISU Muscatine Island Research and Demonstration Farm, organic peppers fertilized with compost at $114 \mathrm{~kg} \cdot \mathrm{ha}^{-}$ ${ }^{1} \mathrm{~N}$ plus Bio-Cal ${ }^{\circledR}$ at $1,017 \mathrm{~kg} \cdot \mathrm{ha}^{-1}$ were not significantly different in growth and yield from conventional peppers. Beginning in 1999, our research has included legume cover crops [hairy vetch (Vicia villosa) and rye (Secale cereale)] in a strip-tilled and fully incorporated system in the fertility comparison trials. Vetch growth in Fall 1999Spring 2000 was impacted by hot and dry weather conditions. In 2000 , due to poor vetch growth, peppers in vetch strip plots produced significantly less peppers and pepper weight than the controls. Based on these results, vetch can supply equivalent nitrogen from compost applications only when cover crop growth is adequate, as observed in 1999. The greatest pepper weight in the 2000 organic plots was obtained from plants fertilized with compost. There were significantly greater numbers of blemished and culled peppers from the conventional plots compared with the organic plots.

\section{Poster 468}

\section{Eggplant Gas Exchange Response to Nitrogen Sources at} Three Stages of Fruiting

Wayne F. Whitehead ${ }^{*}$ and Bharat P. Singh; Agricultural Research Station, Fort Valley State Univ., Fort Valley, GA 31030-4313

The object of this study was to compare the effects of organic and inorganic $\mathrm{N}$ sources on gas exchange (GE) at different fruiting stages of eggplant. Measurements of transpiration (E), photosynthesis $\left(\mathrm{P}_{\mathrm{n}}\right)$ and internal leaf $\mathrm{CO}_{2}$ concentration $\left(\mathrm{C}_{\mathrm{i}}\right)$ are reported. The following winter-spring fertility treatments were applied using ran- domized complete-block design with four replications: 1) $0 \mathrm{~N}$ winter$0 \mathrm{~N}$ spring, 2) $0 \mathrm{~N}$ winter $-70 \mathrm{~kg} \mathrm{~N} / \mathrm{ha}$ spring, 3) $0 \mathrm{~N}$ winter $-140 \mathrm{~kg} \mathrm{~N} /$ ha spring, 4) $0 \mathrm{~N}$ winter+abruzi rye- $0 \mathrm{~N}$ spring, 5) $0 \mathrm{~N}$ winter+hairy vetch- $0 \mathrm{~N}$ spring, and 6) $0 \mathrm{~N}$ winter+crimson clover- $0 \mathrm{~N}$ spring. In Spring 2000, 'Megel' eggplants were transplanted in all plots. Maximum $\mathrm{E}\left(14.9 \mathrm{mmol} \cdot \mathrm{m}^{-2} \cdot \mathrm{s}^{-1}\right), \mathrm{P}_{\mathrm{n}}\left(17.0 \mu \mathrm{mol} \cdot \mathrm{m}^{-2} \cdot \mathrm{s}^{-1} \mathrm{CO}_{2}\right)$, and $\mathrm{C}_{\mathrm{i}}$ $\left(382.8 \mu \mathrm{L} \cdot \mathrm{L}^{-1}\right)$ occurred at mid-fruiting. Crimson clover and hairy vetch influenced $E$ and $P_{n}$ the most, while $C_{i}$ was highest in the abruzi rye and $0 \mathrm{~N}$ treatments. Results indicate that organic $\mathrm{N}$ from both legumes enhanced $\mathrm{GE}$ of eggplant similar to the commercial $\mathrm{N}$ rates.

\section{Poster 469}

Use of Hairy Vetch to Manage Soil Phosphorus Accumulation from Poultry Litter Applications in a Warm-season Vegetable Rotation

Clydette Alsup and Brian A. Kahn*; Dept. of Horticulture and Landscape Architecture, Oklahoma State Univ., Stillwater, OK 74078

Hairy vetch (Vicia villosa Roth) cover crops were grown in a rotation with sweet corn (Zea mays var. rugosa Bonaf.) and muskmelon (Cucumis melo L. Reticulatus group) to evaluate the legume's ability to remove excess $P$ from soils when poultry litter was used as a fertilizer. Fertilizer treatments were litter to meet each crop's recommended preplant $\mathrm{N}$ requirements (1X); litter at twice the recommended rate $(2 \mathrm{X})$; and urea at the $1 \mathrm{X}$ rate as the control. Following the vegetable crops, hairy vetch was planted on half of each replication, while the other half was fallowed. The vetch was removed from the field in a simulated haying operation in the spring. Soil samples were taken at $0-15 \mathrm{~cm}$ and $15-30 \mathrm{~cm}$ depths at the onset of the study and after each crop to monitor plant nutrient levels. The vetch sometimes raised soil test $\mathrm{N}$ levels at the $0-15 \mathrm{~cm}$ depth. Soil test $P$ levels at the $0-15 \mathrm{~cm}$ depth in the vetch system were consistently lower numerically, but not statistically, relative to plots in the fallow system. Soil test $P$ at the $0-15 \mathrm{~cm}$ depth was usually increased by litter at the $2 X$ rate relative to the urea control, regardless of cropping system. Yields of both vegetable crops were comparable among all cover crop and fertilizer treatments.

\section{Poster 470}

Cover Crops Management and Weed Suppression in Notillage Sweet Corn Production

Abdul-Baki*, L.M. Carrera, and J.R. Teasdale; USDA/ARS, ANRI, SASL, Beltsville Agricultural Research Center, Beltsville, MD 20705

Sweet corn (Zea mays var. rugosa L.) production under no-tillage can minimize chemical inputs, conserve the soil, and improve water availability. A 2-year study (1999-2000) was undertaken at Beltsville, $M D$, to determine the most feasible cover crop management practice and its effectiveness in weed suppression and yield. The experimental design was a split-split plot with three cover crops [hairy vetch (Vicia villosa Roth), a mixture of hairy vetch, and rye (Secale cereale L.), and bare soil] as the main plot. The first split was residual herbicide (plus and minus) and the second was cover crop killing method (mowing, chopping, and contact herbicide). We evaluated the effect of cover crops on emergence, growth, yield, and weed suppression. Results showed that all cover crop treatments yielded higher than the bare soil. There were two significant interactions, killing method $x$ residual herbicide, and residual herbicide $x$ cover crop. In 1999, yields were significantly higher in treatments with than without residual herbicide, but were independent of the cover crop killing method. In the year 2000 , yields in cover crops with hairy vetch alone or hairy vetch + rye treatments were similar with and without residual herbicide, suggesting the effectiveness of the cover crops on weed suppression. The residual herbicide application on the bare soil treatment was necessary for weed suppression and resulted in significant lower yields when the residual herbicide was not applied.

\section{Poster 471}

Cowpea Cover Crop Varieties Resist Weed Competition Guangyao Wang*, Jeff Ehlers, Eddie Ogbuchiekwe, and Milt McGiffen; Dept. of Botany and Plant Sciences, Univ. of California, 


\section{Riverside, CA 92521-0124}

Crops can be bred to resist weed competition if the traits that confer competitive advantage are known. Field experiments in 1999 and 2000 examined the competitive abilities of three cowpea [Vigna unguiculata (L.) Walp.] genotypes with similar maturity and vegetative vigor but that differed in growth habit. Iron-Clay (IC) grows erect, while IT89KD-288 is a semi-erect and UCR 779 grows prostrate. Three weed treatments were established for each cowpea genotype: weedfree, purslane planted within the cowpea row, or sunflower planted within the cowpea row. Light intensity above and below the canopies and leaf area index (LAl) and dry weights of each species were measured biweekly in 1999 and weekly in 2000. Sunflower reduced the amount of light that cowpea received and reduced cowpea yield. Cowpea reduced the light received by purslane but purslane had little effect on cowpea. Although the combined LAI of sunflower and cowpea was constant, the leaf area of cowpea was reduced when sunflower was present. Cowpea shoot dry weight was reduced by sunflower but unaffected by purslane, while both sunflower and purslane dry weight were reduced by cowpea varieties. Cowpea variety IC was the most tolerant and UCR 779 the most susceptible to weed competition. This suggests the erect growth habit may be more effective in suppressing weeds than the prostrate growth habit, although additional tests are needed to concretely establish the importance of growth habit apart from the influence of the genetic background of these lines.

\section{Poster 472}

Biomass Yield of Winter Legume Cover Crops with and without Rye

M. Rangappa* and H.L. Bhardwaj; Agricultural Research Station, Virginia State Univ., Petersburg, VA 23806

Legume cover crops in sustainable agricultural system can be beneficial in protecting the soil, in reducing fertilizer input costs and water pollution from fertilizer run-off. Additionally, there are indications that inclusion of rye in the mixture enhances the benefits of legume cover crops. Our objectives were to quantify the biomass yields of four cover crop treatments and to determine if a legume and rye mixture produces more biomass as compared to a pure stand of legumes alone. We conducted five experiments during 1997-98 and 1998-99 seasons with hairy vetch and crimson clover in pure and mixed stands (I:I ratio of legumes and rye) resulting in four cover crop treatments. Three experiments were planted during fall of 1997 at Petersburg, King William County, and James City County and two experiments were planted in fall of 1998 at Petersburg and Prince George County in Virginia resulting in five environments. The experiments were laid out as RCBD with four replications. During the following spring, $1 \mathrm{~m}^{2}$ of each plot was harvested when legumes began to flower. Analysis of data combined over five environments indicated that environments and cover crop treatments significantly affected the biomass yield on dry weight basis. The interaction between environments and cover crop treatments was not significant. The mean biomass yield was 315 $\mathrm{g} / \mathrm{m}^{2}$ with a range of $25 \mathrm{l}$ to $387 \mathrm{~g} / \mathrm{m}^{2}$. Significant differences existed among the five environments with Prince George location during 1998-99 being the highest yielding and King William County location during 1997-98 being the poorest. The dry matter yield at Petersburg location during both 1997-98 and 1998-99 was similar. The dry matter yield of both crimson clover and hairy vetch were significantly enhanced by inclusion of rye in the mixture ( $274 \mathrm{vs} .332 \mathrm{~g} / \mathrm{m}^{2}$ for crimson clover and $284 \mathrm{vs}$. $37 \mathrm{l} \mathrm{g} / \mathrm{m}^{2}$ for hairy vetch). Further details of these studied will be presented.

\section{Poster 473}

\section{Pepper Plant Growth and Yield in Alternative Production} Systems

Nancy Roe ${ }^{* 1}$, Monica Ozores-Hampton ${ }^{2}$, Thomas Obreza ${ }^{2}$, Robert McSorley ${ }^{3}$, and Phillip Stansly ${ }^{2} ;{ }^{1}$ Farming Systems Research. Inc., 5609 Lakeview Mews Dr., Boynton Beach, FL 33437; ' Univ. of Florida/IFAS, Southwest Florida Research and Education Center, Immokalee, FL; ${ }^{3}$ Dept. of Entomology and Nematology, Univ. of
Florida, Gainesville, FL

Loss of methyl bromide soil fumigant and pressure on growers to reduce fertilizer usage has increased interest in modifying the intensive vegetable growing systems used in south Florida. Some of the potential methods which may be used as alternatives to these systems include use of composts and solarization. We are studying ways to combine these materials and methods into productive systems. Treatments were: solarized with aged yard trimmings as a mulch $(\mathrm{OM})$, solarized with polyethylene mulch (SP); solarized with 56 $\mathrm{mg} \cdot \mathrm{ha}^{-1}$ compost incorporated and polyethylene mulch (SC); and the control treatment of methyl bromide fumigant with polyethylene mulch (MB). Total fertilizer rates were similar for all treatments, although the alternative treatments were fertilized through the drip system and the control with the grower's standard pre-plant banded. Plant biomass was measured by taking samples of whole plants 6 weeks after planting. Mean plant dry weights were $14.9,14.3,21.7$, and $26.0 \mathrm{~g}$ for OM, SP, SC, and MB. The MB plants were larger, SC were medium, and $\mathrm{OM}$ and SP were smallest. Yields from one harvest were: 10.9, $13.9,14.4$, and $20.0 \mathrm{mg} \cdot \mathrm{ha}^{-1}$ for OM, SP, SC, and MB, respectively. There were no significant differences in yields between alternative treatments, but yields of fumigated plots were higher than alternative treatments. There was no difference in fruit size between treatments (242, 259, 247, and $271 \mathrm{~g}$ for OM, SP, SC, and MB, respectively). Plants in the control treatment using methyl bromide and conventional fertilization were generally larger and more productive than the alternatives. This project is continuing to study the effects of these treatments over the longer term.

\section{Poster 475}

Soil Solarization Affects Weed and Nematode Populations in a Large-scale Vegetable Production System

Monica Ozores-Hampton ${ }^{* 1}$, Nancy. E. Roe ${ }^{2}$, RobertMcSorley ${ }^{3}$, Dan O. Chellemi', Phillip A.Stansly', and Thomas Obreza' ${ }^{1} ;{ }^{1}$ Univ. of Floridal IFAS, Southwest Florida Research and Education Center, 2686 State Road 29 North, Immokalee, FL 34142-9515; '2Farming Systems Research. Inc. Boynton Beach, FL; ${ }^{3}$ Dept. of Entomology and Nematology, Univ. of Florida, Gainesville, FL.; ${ }^{4}$ USDA-ARS, Ft. Pierce, FL

Many growers rely completely on methyl bromide fumigant to manage soil pathogens, nematodes, and weeds. This growing system, which generally includes raised beds, polyethylene mulch and drip irrigation, has been very effective in producing high vegetable yields. Non-chemical alternatives such as solarization and organic amendments are as yet largely unproven, but do offer promise of more sustainable solutions free of government regulation. The objective of this research was to study the effects of longterm, large-scale use of sustainable methods on weed populations and nematodes on peppers (Capsicum annuum L.) and cucumbers (Cucumis sativus L.), utilizing soil solarization and organic amendments. The field experiment was conducted during 1998 and 1999 on a commercial vegetable farm in Boynton Beach, FL. Treatments consisted of 3 years of soil solarization with compost, 2 years of soil solarization with compost, 2 years of soil solarization without compost, and methyl bromide without compost as a control. A pepper crop was grown on the plots, followed by a cucumber crop. Compost did not affect weed or nematode populations. At the end of the cucumber crop, solarized treatments had higher percent weed cover, primarily bermudagrass (Cynodon dactylon L. Pers.), a warm season perennial weed, as compared with the methyl bromide system, which was dominated by redroot pigweed (Amaranthus retroflexus L.), an annual weed. Populations of the root-knot nematode (Meloidogyne incognita) fluctuated throughout the experiment. The lowest numbers occurred in the conventional system with methyl bromide. However, on each sampling date, nematode populations in at least one of the solarized systems were statistically similar to those in the methyl bromide-treated plots. Soil solarization was effective in controlling annual weeds, but failed to control perennial weeds. Nematodes were controlled by both soil solarization and methyl bromide. 


\section{Poster 476}

Effect of Soil Solarization on Survival of Arbuscular Mycorrhizal Fungi in Western Mexico

C. Guzmán-Loza*, J. Farias-Larios, J.G. López-Aguirre, and J. Molina-Ochoa; Universidad de Colima, Facultad de Ciencias Biológicas y Agropecuarias, Apartado postal 36, Km. 240 Carretera Jiquilpan-Manzanillo, 28100 Tecomán, Colima, México

Soil solarization is used for pathogens control in horticultural production. However, if this technique reduce the fungi populations in soils probably also affect the beneficial microorganisms such as mycorrhizae arbuscular fungi. In this study was evaluated the effect of soil solarization on the viability of indigenous fungi and Glomus intraradices. Experiment was carried out in a sandy soil. 21 beds were prepared and covered with transparent polyethylene film 150 $\mathrm{m}$ thick as a single layer. Previously $30 \mathrm{~g}$ of inoculum $\mathrm{G}$. intraradices was introduced at $20-\mathrm{cm}$ depth in a nylon bag. Soil moisture was maintained at $70 \%$ hold capacity and monitored by tensiometer. Soil temperatures were registered at $08: 00,13: 00$ and $18: 00$ at 5,10 , and $20-\mathrm{cm}$ depth. Solarization treatments of $0,2,4,6$ and 8 weeks were carried out in plots with three beds $5 \mathrm{~m}$ long and $0.80 \mathrm{~m}$ wide. The experiment was conducted in a randomized block design with 4 replicates. Soils were sampled in the central bed at $20-\mathrm{cm}$ depth to the end of each period of soil solarization. After this sampling, Glomus intraradices and the mean of indigenous MA fungi were used for inoculation of bean plants grown in pots with sterilized soil and cultivated under greenhouse conditions. Results show that the soil solarization periods have a detrimental effect on viability and infectivity of AM fungi evaluated because of high temperatures in soil (more of $40^{\circ} \mathrm{C}$ ). Is suggested that is necessary the establishment of vegetable crops for transplant inoculated previously with AM fungi in greenhouse for restitution of beneficial microbial population.

\section{Poster 477}

Effect of Soil Temperature on Viability of Arbuscular Mycorrhizal Fungi

C. Guzmán-Loza*, J. Farias-Larios, and J.G. López-Aguirre; Universidad de Colima, Facultad de Ciencias Biológicas y Agropecuarias, Apartado postal 36, Km. 240 Carretera JiquilpanManzanillo. 28100 Tecomán, Colima, México

Soil solarization was developed primarily for controlling soil borne pathogens occur in soils used for vegetable crops production. Currently, it is not known whether arbuscular mycorrhizal fungal survive the solarization treatments and how is affected the viability and colonization capacity of inocula. In this study was evaluated the effect of several soil temperatures on the viability of indigenous fungi and Glomus intraradices. Experiment was carried out in metallic pots (4-kg capacity) containing sandy soil. $30 \mathrm{~g}$ of inoculum of $G$. intraradices ( 20.75 spores/g aproximately) was introduced at $20-\mathrm{cm}$ depth in a nylon bag. Soil moisture was maintained at $70 \%$ of hold capacity and monitored by tensiometer. The metallic pots were then placed in a furnace and heated to $30,35,40,45$, and $50{ }^{\circ} \mathrm{C}$ and incubated for, 24, 48, and 72 hours and 0 hours as a control. Following heat treatment, the bag containing $G$. intraradices and a soil sample, for native AM fungi, were transferred into a pot (1-kg capacity) and sown with bean (Phaseolus vulgaris) seeds. Plants were grown in a greenhouse during 4 weeks. The experiment was conducted in a completely randomized design with 4 replicates. Results show that a temperature of $50{ }^{\circ} \mathrm{C}$ for $24 \mathrm{~h}$ affect AM spore viability, root colonization decrease from 14.48 to $2.71 \%$ for native AM fungi, and 10.52 to $3.05 \%$ for $G$. intraradices. At $45{ }^{\circ} \mathrm{C}, \mathrm{G}$. intraradices colonization was not affected. Control had a root colonization of $32.90 \%$ for native AM fungi and $23.86 \%$ for G. intraradices. We suggest to study the effect of solarization on AM fungi colonization in field conditions.

\section{Poster 478}

Effect of Compost Application on Strawberry Plant Growth and Fruit Quality

Shiow Y. Wang* and Shin-Shan Lin; Fruit Laboratory, Beltsville
Agricultural Research Center, Agricultural Research Service, U.S. Dept. of Agriculture, Beltsville, MD 20705-2350

Compost enhanced strawberry plant growth and fruit quality when used as a soil supplement. The combination of $50 \%$ soil plus $50 \%$ compost produced the greatest plant dry mass, fruit production, and fruit size in two strawberry cultivars ('Allstar' and 'Honeoye'). Compost also enhanced leaf chlorophyll content in strawberry plants. Nitrate reductase activity was increased in leaves and roots with the addition of compost. The greatest increases were seen when using $50 \%$ soil plus $50 \%$ compost. Strawberry fruit grown with compost had higher levels of $\mathrm{N}$ and $\mathrm{K}$ compared to fruit grown without compost. However, fruit grown with compost had lower levels of $\mathrm{Mn}$, $\mathrm{Fe}, \mathrm{Mo}$, and $\mathrm{Ni}$. With regards to heavy metals, addition of compost in the soil mix did not change $\mathrm{Zn}$ and $\mathrm{Cd}$ levels but did decrease $\mathrm{Ni}$ levels in fruit. Use of compost increased levels of organic acids (malic and citric acid), sugars (fructose, glucose, and total sugars), soluble solids content, and titratable acids content in both 'Allstar' and 'Honeoye' cultivars. Our results indicate that the use of composts can reduce the amount of fertilizer required for optimum strawberry plant growth.

\section{Poster 479}

Topdressing Compost on Bermudagrass: Its Effect on Turf Quality and Weeds

Michelle Le Strange ${ }^{* 1}$ and Pamela Geisel'; ${ }^{1}$ Univ. of California Cooperative Extension, Farm Advisor Tulare \& Kings Counties; ${ }^{2}$ Univ. of California Cooperative Extension, Horticulture Advisor Fresno County, $C A$

California's Integrated Waste Management Act (AB 939) required Californians to reduce landfill waste by $50 \%$ by the year 2000 . This Act mandates that reduction be met through specific methods such as source reduction, recycling, and composting. Many municipalities have implemented a green waste pick-up and composting program as one method of solid waste reduction. From this green waste, thousands of tons of compost are generated each year. Methods to efficiently utilize it are being sought. Possible applications of compost could include topdressing compost on municipal turfgrass sites such as community recreation fields and parks. A field study on common bermudagrass [Cynodon dactylon (L.) Pers.] was conducted from Oct. 1994 through Dec. 1997 to compare topdressing composted municipal green waste and biosolids with conventional fertilizer applications, to determine optimum depth and timing of application, and to evaluate the benefits and risks of compost topdressing from cultural and financial perspectives. Turfgrass quality, color, and weed populations were evaluated. Other parameters measured included clipping yield, total nitrogen $(\mathrm{N})$ content in clippings and soil, organic matter content in soil, and the effects on thatch development. Fertilizer and steer manure treatments were applied to yield $4 \mathrm{lb} / 1000 \mathrm{ft}^{2}\left(195.6 \mathrm{~kg} \cdot \mathrm{ha}^{-1}\right)$ of $\mathrm{N}$ per year. Compost treatments included single or multiple applications per year at rates ranging from $1-8 \mathrm{lb} / 1000 \mathrm{ft}^{2}\left(48.9-391.3 \mathrm{~kg} \cdot \mathrm{ha}^{-1}\right)$ of N. Topdressing composted green waste had a positive effect on turf. Quality and color were improved and summer grass weeds were reduced compared to untreated plots. Although thatch was not affected, an organic matter layer did develop causing an undesirable mounding effect. Compared to all treatments consistently higher turfgrass ratings and lower weed populations were observed with compost rates of $1110 \mathrm{lb} / 1000 \mathrm{ft}^{2}\left(24 \mathrm{t} / \mathrm{a}, 53.8 \mathrm{t} \cdot \mathrm{ha}^{-1}\right)$ topdressed four times per year.

\section{Poster 480}

Alternative Methods of Raspberry Production and Root Rot Control

Chuhe Chen*, Carol Miles, and Stephen Klauer; Vancouver Research and Extension Unit, Washington State Univ., 1919 NE 78th St., Vancouver WA 98665

Studies of alternative methods to control raspberry root rot (Phytopthora fragariae var. rubi) were conducted at Vancouver REU and in an organic growers' field (Pigman's farm) in last 2 years. The 
treatments included manures, biological fungicides Trichoderma ( $T$ 22) and Gliocladium (G-41), and Gypsum. A chemical fungicide (Ridomil) was also included in the Vancouver site, and raised beds vs. flat beds were compared at Pigman's farm. In 1999, the efficacy of the treatments to control raspberry disease differed between the raised and flat beds at Pigman's Farm. On raised beds, chicken manure produced the highest yield while on flat beds; horse manure produced the highest yield. T-22 produced the second highest yield on both raised and flat beds. In 2000, fruit yield in raised beds was higher than on flat beds at Pigman's Farm, but this difference was nonsignificant. Dairy and horse manure treatments produced the highest yields at each site. At Vancouver REU, yields in response to dairy manure, $\mathrm{T}-22$, and G-41 were comparable to yield in response to Ridomil. Manure + T-22 produced lower yield than manure or T22 alone at both sites, indicating a possible negative interaction. Benefits of manure may be due to suppression of root rot pathogen and enhancement of beneficial fungi, as well as improved plant nutrition. There were no differences in root rot ratings of fruiting canes due to any of the treatments. Fruiting canes at Vancouver REU began to show nitrogen stress symptoms in early June, which was likely due to the slow release activity of the organic fertilizer (blood meal) under low soil temperatures in the spring.

\section{Poster 481}

Effect of Certified Organic Treatments on Insects, Disease, and Yields of Organic Apples

Heather Friedrich* and Kathleen Delate; lowa State Univ., Ames, IA 50011

Insect pest management constitutes the greatest constraint to organic apple production in the Midwest. In an experiment conducted in Altoona, lowa, in 2000, six organic treatments: control, Fuji bags, apple maggot balls, Surround ${ }^{T M}$, Surround ${ }^{T M}$ plus apple maggot balls, Fuji bags plus apple maggot balls, were randomly applied to rows of 'Redfree', 'Jonafree', and 'Liberty' cultivars for control of codling moth, plum curculio, and apple maggot. We sampled bimonthly for insect occurrence and disease incidence on fruit and leaves. Harvested apples were weighed and rated for insect damage. 'Redfree' and 'Jonafree' apples treated with Fuji bags alone and with apple maggot balls, and with Surround ${ }^{\mathrm{TM}}$ alone and with apple maggot balls, had significantly lower levels of codling moth compared with the control. 'Jonafree' apples treated with Fuji bags alone and with apple maggot balls, and with Surround ${ }^{\mathrm{TM}}$ alone and with apple maggot balls also had significantly lower levels of plum curculio. The treatments did not affect the percentage of marketable fruit for the 'Redfree' apples. Within the 'Jonafree' cultivar, all treatments except the apple maggot balls alone, had a significantly greater percentage of marketable fruit than the control. Apple fruit weight was not significantly different among treatments. The effect of Surround ${ }^{\text {TM }}$ on apple leaf diseases was not as significant as the effect on insect pests in this experiment.

1:00-2:00 p.m. CC Ballroom

\section{Poster Session 8: Extension/Technology Transfer Poster 482}

Texas Superstar.com-Web-based Promotion of a Plant Trialing Program

Christine MacAlpine ${ }^{* 1}$, D. Lineberger ${ }^{1}$, J. Parsons ${ }^{1}$, M. Arnold ${ }^{1}, S$. George $^{1}$, W. Mackay', C. McKenney', T. Davis', and G. Grant'; ${ }^{1}$ Texas A\&M Univ., Horticulture Program, College Station, TX 77843; ${ }^{2}$ Agriculture Dept., Stephen F. Austin State Univ., Nacogdoches, TX

Texas A\&M Univ. research scientists and Extension specialists have operated the CEMAP plant trialing program for over 5 years. Outstanding ornamental plants are evaluated, improved, and tested at sites representing the diverse environments of Texas and selections deemed meritorious are designated "Texas Superstars" and are released to the industry for rapid increase. Two Web sites are used to deliver information about the Texas Superstars. One is housed on the educational Web site Aggie Horticulture, while the other is operated as a .com domain. The .com Web site is constructed using frames technology, so that most of the content actually resides on the .edu Web site. Additional features of the .com site include a searchable database of cooperating retailers, plant description pages, large format color images, and informational leaflets related to landscape gardening in Texas. The Texas Superstar Web site can be viewed at http://TexasSuperstar.com/.

\section{Poster 483}

A Cold Chain Association for Eastern Indonesia

Lisa Kitinoja*1 and William J. Gucker ${ }^{2} ;{ }^{1}$ Extension Systems International, Woodland, CA; ${ }^{2}$ Winrock International, Bali, Indonesia

This poster focuses upon solving the problems found with postharvest handling during shipping and distribution as well as with maintaining the cold chain. Economically appropriate recommendations and ideas are provided for Indonesian shipping companies, wholesalers, and retailers on how to improve current refrigerated transport and cold storage facilities in order to better maintain produce quality and reduce losses. This will allow importers and distributors to increase the shelf life of fresh produce, expand the marketing period and improve profits. Twelve port cities in Java, Kalimantan, Sulawesi, and Eastern Indonesia were surveyed during Apr. 2000, an activity supported by the USDA Quick Response Marketing Fund. The authors spoke with many food service operators shippers, wholesalers, transport operators, and port authorities in order to determine where postharvest losses were occurring and what practices might be possible to implement in order to better protect food quality, safety, and value. The poster will describe and document objectives and outcomes of the survey including: 1) Coordinating with the FAS offices at the U.S. Embassy in Jakarta in identifying government policies that could be put in place or changed in order to facilitate better operations and improve trade opportunities;2) Producing a document that can be used as an information tool for USDA, Government of Indonesia, and other institutions to assist in designing future infrastructure development programs; 3) disseminating findings to appropriate private and public institutions in Indonesia; and 4) beginning to build a network with food importers and cold chain related businesses for the purpose of developing a Cold Chain Association.

\section{Poster 484}

Univ. of California and the USAID ATUT/Egypt Project (19992000)

Lisa Kitinoja ${ }^{* 1}$ and Farbod Youssefi'; ${ }^{2}$ Extension Systems International, Woodland, CA 95695; 2 Office of International Programs, Univ. of California, Davis, CA 95616

As part of the RONCO Consortium, UC has been involved in Egypt and the USAID Agricultural Technology Utilization and Transfer (ATUT) Project. During 1999, UC personnel were contacted and inquiries were made regarding their interests, expertise and availability to assist UC in meeting project needs identified in Egypt. Since that time, applied, problem solving research projects, educational/ training programs and technical assistance activities were proposed and implemented by more than 50 individuals representing UC campuses and UCCE offices as well as by several private, CA-based horticultural consultants. The activities undertaken by UC faculty and staff have targeted the expressed needs of the Horticultural Export Improvement Association (HEIA), as a key clientele group of the ATUT project. Activities were scheduled for 1999-2000, and additional technical assistance visits or educational programs may arise from these initial visits. Technology transfer activities fall into five major categories including Collaborative Applied Research, Technical Assistance and Educational/Informational activities. The poster will document completed activities and their outcomes, focusing upon training and educational programs for improving the quality and value of horticultural crops produced in Egypt. A few examples: 1) UC assistance has served to directly increase communication and technology transfer between government organizations and the private sector; 2) technical assistance has strengthened knowledge/ 
skills development in a wide range of problem areas related to strawberries, grapes, melons, and postharvest management; and 3) workshops and short courses objectives have been to transfer, along with technical information on horticulture to participants, the complex knowledge and skills required for conducting successful informational/educational programs in Egypt.

\section{Poster 485}

Performance of Native Midwestern Herbaceous Perennials in a Low-maintenance Landscape

Denny Schrock ${ }^{* 1}$ and Andrew L. Thomas ${ }^{2}$; 1 Univ. of IllinoisChampaign-Urbana, 1033 Plant Sciences Lab, 1201 S. Dorner Dr., Urbana, IL 61801; '2Univ. of Missouri-Columbia, Southwest Research Center, 14548 Highway H, Mt. Vernon, MO 65712

The objectives of the study were to determine the landscape potential of selected native Midwestern herbaceous plant species to low-maintenance landscape conditions in Southwest Missouri, and to demonstrate the potential of developing native herbaceous perennials as commercial nursery crops. The experiment was conducted over 5 years at the Univ. of Missouri-Columbia's Southwest Research Center in Mount Vernon, Mo. Container-grown herbaceous perennials, six plants each of 70 different taxa, were randomly assigned to blocks within the trial area. The plants were transplanted through holes in a water-permeable weed barrier fabric, which was then covered with wood chips to suppress weed growth. After establishment, no supplemental irrigation was provided. Top growth of all perennials remained in place until late winter, at which time it was cut back and removed. Otherwise, no pruning, shearing or staking of plants occurred. Insect and disease problems were allowed to develop without intervention. The following performance data were collected: plant height, plant width, plant growth habit, primary and secondary flower color, flower effectiveness, flower coverage, fruit effectiveness, fruit color, foliage type, foliage color (summer and fall), pest problems, overall plant quality, survival. Data were weighted more heavily to the bloom period because this is the time of greatest effectiveness in the landscape. Data indicate there are many native plants with good to excellent potential performance in low-maintenance landscape situations. Many show potential as commercial nursery crops.

\section{Poster 486}

Getting the Word Out: Graphic Campaign to Communicate Tree-planting Principles

Susan S. Barton ${ }^{* 1}$, Thomas W. Ilvento ${ }^{2}$, and Peter Jamieson ${ }^{2} ;{ }^{1}$ Dept. of Plant \& Soil Sciences, ; ${ }^{2}$ Food \& Resource Economics, Univ. of Delaware, Newark DE 19717

This project produced a display that can be used in garden centers to effectively educate customers about proper tree selection, planting and care. Design criteria were gathered from the industry. Focus group research and model testing with garden center owners and managers provided input in the design process. A graphic artist designed a vertical banner and tree hanging tags to communicate simple planting methods. The display was produced and distributed to a select group of garden centers who agreed to provide survey information. Surveys were conducted at four pilot site locations during the summer and fall. In the customer pre survey, most customers described their overall knowledge of tree planting as good $(37 \%)$ but some respondents describing their tree planting knowledge as fair $(28 \%)$ or weak $(18 \%)$. This data indicates an opportunity to increase knowledge and ultimately increase tree sales. In the post survey, customer response to the Trees Add Life banner was very positive. Over three-fourths of the respondents had a positive response to the overall look of the banner, the color scheme and the clarity of information. Customers had a similar response to the tree hangers. Garden center customers agreed that the Trees Add Life display materials were helpful (95\%), gave them confidence to plant trees (80\%), increased their knowledge about tree planting (75\%) and encouraged planting (70\%). An industrymarketing firm sold banners during Spring 2000. Widespread use of this display in garden centers will help consumers learn to implement simple, but critical tree selection, planting and care techniques.

\section{Poster 488}

The Illinois Small Farm Enterprise Project

John Masiunas*, Juli Brussell, Deborah Cavaugh-Grant, and Dan Anderson; Dept. of Natural Resources and Environmental Sciences, Univ. of Illinois, Urbana, IL 61801

Small-scale farms are a critical but threatened portion of Illinois agriculture. Because of low grain and animal prices,small-scale farms need alternative enterprises to ensure their profitability and survival. Our project, funded by NCR SARE, will provide training to small-scale farmers so they are able to evaluate and possibly adopt alternative enterprises. These alternative enterprises include grape and wine production, organic vegetable production, specialty meat production, and agro-tourism. We will use $\mathrm{Nx}$-Level training to provide small-scale farmers with the knowledge and skills needed to evaluate these alternative enterprises. Full day seminars will also be conducted to provide production and marketing information on alternative enterprises to these farmers. The farmers will be matched with mentors who will work with farmer-participants to evaluate and potentially adopt these alternative enterprises. We want to assist farmers in moving from evaluating alternative enterprises to their adoption. We believe that the only way to ensure the survival smallscale farms and to foster community development is to develop the skills these farmers need to successfully adopt alternative enterprises.

\section{Poster 489}

\section{Educating Farmers about New Crop Opportunities in} Kentucky

Dewayne Ingram ${ }^{* 1}$, and Christy Cassady ${ }^{2} ;{ }^{1}$ Dept. of Horticulture, Univ. of Kentucky; Larry Grabau, Dept. of Agronomy, Univ. of Kentucky; ${ }^{2}$ Dept. of Horticulture, Univ. of Kentucky

The New Crop Opportunities Center at the Univ. of Kentucky coordinates multidisciplinary teams of faculty, staff, and students to research and set guidelines for producing and marketing selected crops at a profit. The Center offers electronic and printed educational materials, and provides on-farm demonstrations of selected crops. Initial research is being conducted in the Depts. of Horticulture and Agronomy on bell and specialty peppers; blackberries; native plants and underutilized landscape plants; greenhouse production of vegetables, herbs and bedding plants; breeding soft white winter wheat for Kentucky; soybean breeding; and IPM and evaluation of highvalue traits for corn in Kentucky. Cooperative Extension Service agents, as well as farmers, compose the primary audience for this information, which is available 24 hours a day through the Center's Web site http://www.uky.edu/ag/newcrops. In addition to information about crops that are the focus of the Center's research, the Web site offers information about numerous other crops that have potential for Kentucky.

\section{Poster 490}

Adoption and Adaption of a New On-farm Trial Design in Southern and Eastern Africa

Vicki L. Morrone ${ }^{* 1}$, and Sieglinde Snapp $2 ;{ }^{1}$ Consultant, East Lansing, Ml; ${ }^{2}$ Michigan State Univ. East Lansing, MI 48895

Farmer input and consultation is frequently discussed by researchers but historically has rarely been actualized. Recently a new on-farm approach, involving a design called central-satellite or "mother/baby trials" has been widely adopted by researchers and extension organization in Southern and Easter Africa because it provides an easy means to include farmers and growers. This design provides a means to link formal research with farmers' experiments in community-based trials. This method has been used to: evaluate different napier grass varieties in Central Kenya, understand integrated pest management for potato through farm schools, involve thousands of farmers in Zimbabwe to evaluating new droughttolerant corn varieties, enhanced striga control in corn in East Africa 
countries, and improve "best bet" options for soil fertility improvement in Malawi smallholder gardens. In earlier, on-farm research yield maximization tended to be the main objective of the researcher. Now, farmer priorities are being incorporated earlier and often in actual technology development. These priorities include maximizing return from limited inputs and enhanced food security. We will report how this unique trial design is used to meet different objectives of researchers and farmers' groups.

\section{Poster 491}

\section{Planttalk Colorado ${ }^{\mathrm{TM}}$}

James E. Klett*, Harriett McMillan, and Susan Eubank; Dept. of Horticulture and Landscape Architecture, Colorado State Univ., Fort Collins, CO 80523 and Denver Botanic Gardens, 909 York Street, Denver, CO 80206

Planttalk Colorado ${ }^{\mathrm{TM}}$ established in the fall of 1997 is a 24 -hour toll-free automated phone service and website that provides gardening consumers with reliable and timely information on a variety of horticultural topics. Planttalk Colorado ${ }^{\mathrm{TM}}$ is unique in that it is sponsored by Colorado State Univ. Cooperative Extension, Denver Botanic Gardens and the Green Industries of Colorado. Over 400 topics edited and approved by all the entities range from annuals to Xeriscape $^{\mathrm{TM}}$ and everything in between-that gardeners need to know in the variable climate and microclimates of Colorado and Rocky Mountain Region. In 1997, it started as a toll-free system only but in 1998 also went to web-base information system. In 1998, phone calls hit a peak of 3,358 in June of 1998 and have fallen to 1,596 in May of 2000. However, web hits have gone from 1,791 in June of 1998 to reaching over 46,500 in May of 2000. In 2001, we are adding linkages to our scripts and desire to add graphics in the near future. Planttalk Colorado ${ }^{\mathrm{TM}}$ has increased the visibility of Cooperative Extension throughout the state and has built partnerships with Denver Botanic Gardens and the Green Industry of Colorado for delivering reliable and accurate horticulture information to all the citizens of Colorado and beyond.

\section{Poster 492}

The Clemson Extension Home \& Garden Information Center: A "24/7" Approach to Delivering Information to South Carolina Residents

R.F. Polomski"', J.H. Blake', C.S. Gorsuch ${ }^{3}$, and E.H. Hoyle ${ }^{4}{ }^{1}{ }^{1}$ Dept. of Horticulture, ${ }^{2}$ Home \& Garden Information Center, ${ }^{3}$ Dept. of Entomology, ${ }^{4}$ Dept. of Family and Youth Development, Clemson Univ., Clemson, SC 29634

The Clemson Extension "Home \& Garden Information Center" (HGIC) provides easily accessible information about gardening, plant and household pests, food safety, and food preservation. The intent of the HGIC is to complement Clemson Extension's network of agents and volunteers, such as Master Gardeners and Master Food Preservers, by answering routine and seasonal calls. The HGIC started operating in May 1999. It uses a computerized interactive voice response system to provide information 24 hours a day via a toll-free phone number. The messages, averaging 2 minutes in length, can be accessed by entering a unique four-digit code. A list of the coded messages is in the HGIC User's Guide, which can be obtained by calling the toll-free number. Copies are also available at government offices, libraries, garden centers, and other retail establishments. Messages can be accessed without the User's Guide via a touch-tone menu system. In June 1999, the Center launched its web site (http://hgic.clemson.edu), which includes over 400 fact sheets in PDF and HTML formats and the User's Guide. A "Related Links" page updated monthly offers visitors a wide selection of other educational resources. In addition to recorded messages, callers contacting the HGIC have the option of speaking to five Information Specialists Monday through Friday, from 9 a.m.-1 p.m. The Specialists are supported by Clemson Extension faculty in Horticulture, Plant Pathology, Entomology, and Food Safety and Nutrition. Through Dec. 2000, the HGIC has received 17,493 calls and the web site has documented over 300,000 user sessions.

\section{Poster 493}

Monitoring of Major Worm Pests in Central California and Validation of Insect Degree-day Models in Tomatoes and Melons

Kent Brittan ${ }^{* 1}$, Michael Cahn ${ }^{2}$, Carolyn Picke ${ }^{\beta}$, Benny Fouche ${ }^{4}$, Robert Mullen ${ }^{4}$, Bill Weir ${ }^{6}$, and Richard Coviello 6 ; ${ }^{1}$ UC Cooperative Extension Advisor, Sacramento County , 4145 Branch Center Rd., Sacramento, CA 95827; '2UC Cooperative Extension, Sutter/Yuba Counties, 142A Garden Hwy, Yuba City, CA 95991; '3C IPM, Sacramento Valley, 142A Garden Hwy, Yuba City, CA 95991; ${ }^{4}$ UC Cooperative Extension, San Joaquin County, 420 S. Wilson Way,

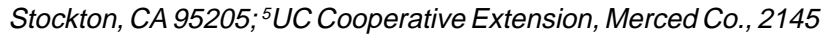
W. Wardrobe Ave., Merced, CA 95340-6496; ' UC Cooperative Extension, Fresno Co., 1720 S. Maple Ave., Fresno, CA 93702

This Extension project was conducted to help target field checking for Lepidoptera species that are commonly considered pests in tomatoes and melons. Practices that better target pesticide applications to periods when crops risk economic damage reduce the amount and frequency of pesticide applications. Economic population thresholds have been established for many insects in tomatoes, but professional crop advisors (PCAs) usually cannot afford the time for frequent and intensive sampling. Pheromone traps can be useful for determining if adult insects are present, but are less successful for determining economic thresholds, especially if the larvae or nymphs cause crop damage. Using traps for to determine the start of a cycle, known as a biofix, and using degree-days to predict generations can help growers and PCAs create a window for critical monitoring in the field. Also, if growers cannot sample crops for economic thresholds, developmental degree-day models may be useful for timing pesticide applications. In tree crops, developmental degree-day models have been used to time sprays for codling moth, peach twig borer, oriental fruit moth, and San Jose scale. Developmental degree-day models predict insect phenological events from cumulative heat units. Because insects do not regulate their temperature, their rate of growth is dependent on the temperature of their environment: warm temperatures foster rapid development. The relationship between climate and the physiology of an insect species is measure in degree-days. Degree-days are the accumulated product of time and temperature above a minimal growth threshold. During the past 30 years, the parameters of developmental models has been determined for many pests common to vegetable crops and summarized in the Univ. of California Integrated Pest Management (IPM) IMPACT. However, using degree-days in the field has not been tied to practical application in the field. In the past, determining the beginning of an insect generation cycle in the field limited the usefulness of degree-day models, but developments in adult pheromone traps have provided an easier method to determine the biofix. Pheromone insect trap sites were established in 2 locations in 5 counties of central California in 2000. Bucket traps with pheromone lures were used to monitor adult male populations of Lepidoptera species that are commonly considered worm pests in tomatoes and melons. Six species monitored were: tomato fruit worm, variegated cutworm, western yellow-striped armyworm, beet armyworm, black cutworm and cabbage looper. Weekly moth counts were used to determine the beginning (biofix) and length of a generation. We arranged with the California Tomato Commission to notify local growers and pest control advisors of peak moth flights so that monitoring activities for worm pests can be initiated and directed towards specific pest activities in the region. In San Joaquin County, participating growers and PCAs were notified by fax. In Merced County the notification was by U.S. mail. In Fresno County the peak activity was posted on the Pest Activity Phone Line currently being maintained for local growers at Kings River College. Degree-day (phenology) models for each worm species monitored were evaluated by Carolyn Pickel and Michael Cahn using the trap count data. Calendar dates of biofixes and generation cycles were estimated using the phenology models and accumulated degree-days. Temperature data from the nearest California Irrigation Management Information System (CIMIS) weather stations were used to calculate 
degree-days. The biofixes and generation cycles of the insect phenology models were compared with trap data using regression analysis.

\section{Poster 494}

Development of a Computerized Decision Support Tool for Selecting and Locating Residential Trees to Maximize Energy Savings

Ling Sun*, Jim Simpson, Greg McPherson, and J. Heinrich Lieth; Environmental Horticulture, Univ. of California, Davis CA 95616

While the use of trees in residential landscape horticulture results in improved aesthetic quality, trees can also reduce annual building energy consumption. A simulation program (Windows Shadow Pattern \& Energy Use Simulator) was developed to simulate the effect of trees on residential building energy usage. It quantifies annual energy impacts by various types and ages of trees in various locations around a residence. Growth curves are used to estimate a tree's dimensions over time. The program calculates the position of the sun and the resulting energy load at hourly intervals throughout a typical meteorological year. It then simulates the projection of shadows of several trees diurnally on the building as a function of crown shape, size, and density as well as radiation attenuation through the tree canopies. The hourly heating and cooling energy consumption is approximated using this information in conjunction with data on building structure, types of insulation material, and installed heating/cooling equipment. Simulations for daily energy performance with and without trees can be repeated over multi-year time-frames to gauge effects of the trees on building energy use over any desired time period. The principal use of this tool is to help residents and urban landscape professionals with tree selection and siting so as to obtain maximal energy savings.

2:00-4:30 p.m. CC 205

\section{Workshop 12: Managing Seedborne Disease in Greenhouse Transplant Production}

Working Group Sponsor: Seedling Establishment (SEST)

Presiding: Thomas Björkman, Dept. of Horticultural Sciences, Cornell Univ., Geneva, NY 14541

Summary: Seedborne disease is a serious problem in cucurbit transplant production. Producing quality transplants requires a source of minimally infested seed. This workshop will cover producing such seed, detecting infestation, and an inspection program to assure quality. Finally, we will learn techniques for identifying and managing diseased plants that do appear.

2:00 Introduction Thomas Björkman

\section{2:05 Detection of Seedborne Pathogens}

\section{Ron R. Walcott*; The Univ. of Georgia, Athens, GA 30602}

Plant pathogens continue to present a serious threat to the quality and performance of seed of certain horticultural crops. This threat increases significantly when seed are planted under conditions that are favorable for disease development. Hence, pathogen exclusion by detecting and eliminating infested seedlots remains a requisite tactic for managing important seedling diseases. Unfortunately, the numbers of contaminated seed within a lot may be low and infested seed may be asymptomatic making their detection and subsequent elimination difficult. To address these issues many assays have been developed for detecting seedborne pathogens. Ideally, seed detection techniques should be rapid, reliable, inexpensive, simple, specific and sensitive. Examples of frequently used seed assays include selective media, seedling grow-out and serological assays which, while appropriate for some pathogens, often display low levels of detection sensitivity and specificity. Recently, the polymerase chain reaction (PCR) has emerged as a tool for detecting microorganisms in many diverse environments. Thus far, there is ample evidence that PCR-based detection systems exhibit greater sensitivity than other conventional detection assays. Unfortunately, PCR-based seed detection assays are limited by the facts that PCR-quality DNA must be rapidly extracted and amplified from target organisms in backgrounds of non-target and non-viable target organisms and PCR inhibitory compounds derived from seed. These shortcomings have severely restricted the acceptance and application of PCR for seed detection. To overcome these limitations several modified PCR protocols have been developed including enrichment PCR and immunocapture PCR. These techniques seek to selectively increase the populations of target organisms to enhance detection and both have been successfully applied for detecting bacteria in seed. Another technique with great potential for rapid detection of seedborne fungi and viruses is magnetic capture hybridization which relies on anchored single-stranded DNA probes to clean up and concentrate target DNA prior to PCR. In addition, technological advances including TaqMan, which provides real-time monitoring of DNA amplification will improve the rapidity of PCR testing. Ultimately, PCR will be available for the detection of all seedborne pathogens and may supersede conventional detection methods.

2:35 CCIA Disease Inspection Program: Best Production Practices for Clean Seed

Frederick J. (Chip) Sundstrom*, Pablo Guzmán, and Bob Stewart; California Crop ImprovementAssociation (CCIA). Parsons Seed Certification Center, Univ. of California, Davis, CA 95616

The bacteria, Acidovorax avenae subsp citrulli, is a well-known seedborne pathogen in watermelon (Citrullus lanatus [Thunb]. Matsum \& Nakai) and other Cucurbits. In the past ten years, reports indicate that the presence of this pathogen in transplants and in commercial fields has resulted in devastating crop losses and significant litigation. The production and use of clean seed plays a critically important role as a control measure of this disease. The CCIA Disease Inspection Program is a voluntary quality assurance program that has been developed between CCIA and the vegetable seed industry. This program includes: accreditation of laboratories for sample analysis, inspection schedules (in the greenhouse and field), sampling and analysis, inspection reports, auditing, labeling of containers, certificate issuance, and workshops for training of accredited company inspectors. The procedures, implementation and value of this successful program will be described.

3:05 Production Steps to Reduce Seed Contamination by Pathogens of Cucurbits

Branko Lovic*, Syngenta Seeds, Inc. Woodland, CA 95695

Selecting production areas for low disease pressure, implementation of preventive spray programs, and continuous monitoring of fields for disease symptoms are important steps to keep the production fields free of potentially seedborne pathogens, especially bacteria such as Acidovorax avenae ssp. citrulli. However, seeds of cucurbit crops and other fleshy vegetables typically remain remarkably free of pathogenic bacteria and fungi while in intact fruits. The most significant risk for seed contamination comes at seed harvest when the inoculum present in the field or in the seed harvesting area may contaminate the seeds. Properly executed fermentation and seed drying processes significantly reduce the possibility for this seed contamination. Application of a no-rinse disinfectant formulation to freshly harvested seed just before drying may be the single most efficacious procedure to reduce the seed contamination risk. Benefits of modifying the seed harvest process to reduce the risk from seed contamination and a potential value of monitoring those modifications as part of the seed certification process are discussed.

3:35 Managing Seedborne Diseases Once They Have Appeared in the Greenhouse

Art Greathead*, e-mail:vegdr@redshift.com 
One of the unique pleasures I have had in my career as Farm Advisor/plant pathologist and now as Consultant/plant pathology has been that of working the discipline of plant pathology into the very practical world of agriculture integrating what is known or strongly suspected into systems that will hold plant disease problems to either undetectable levels or to levels that are of no practical consequence. Success at this endeavor has been varied for a number of reasons. Greenhouse production of vegetable transplants offers its own unique set of challenges in this respect. Frequent irrigation (overhead or by hydroponics techniques), dense plant populations, temperature controls, repeated cropping practices in the same limited area and often seed contamination at levels that are extremely difficult to detect all play an important role. Diseases that are seldom, if ever, a problem in the arid west can become serious in the greenhouse. We have seen new pathogens become problems. Systems for handling these must be worked out in spite of no (or very limited) published information. On the other hand greenhouse production offers the opportunity to manipulate a number of environmental and physical factors and offers opportunities for sanitation measures that cannot be accomplished under field conditions. Human and economic factors are of paramount importance and these sometimes transcend the application of good science and at least must be taken into account when developing greenhouse managment systems that will keep disease problems under tight control.

\section{Business Meeting of the SEST Working Group}

Presiding: Thomas Björkman

2:00-4:30 p.m. CC 305

\section{Workshop 13: "Contacting" for Private and Commercial Consulting}

Working Group Sponsor: International Horticultural Consultants (ICON) Presiding: Usha Palaniswamy, Univ. of Connecticut

Summary: As a follow-up of the ICON Working Group's workshop last year that described ways to get into consulting in national and international consulting through universities and world organizations, such as UNDP, UNV, and USAID, this workshop will discus the ways of developing contacts for private and public consultancy nationally and locally. This workshop will discuss the importance of such consulting and share some experiences by the speakers, who are actively consulting in the private and public arena.

\section{2:00 Introduction Usha Palaniswamy}

\section{2:30 Consulting in Private Enterprise}

$$
\text { Bob Maloney, Novartis Seeds }
$$

3:00 Private Consulting Experiences

$$
\text { Shirley Kline, Private Consulting }
$$

3:30 The Do's and Don'ts of Contracting with a Public Agency Wesley Kline, Rutgers Cooperative Extension of Cumberland County

4:00 Business Meeting of the ICON Working Group Presiding: Usha Palaniswamy

2:00-4:30 p.m. CC 301

Workshop 14: Leading Edge of Plant Protection for Walnut, Almond, Hazel, and Pistachio Production

Working Group Sponsor: Temperate Tree Nut Crops (NUTS)

Presiding: Richard P. Buchner, Univ. of California Cooperative Extension, Red Bluff CA 96080

Summary: Societal and economic issues require new technology for viable nut crop production. This workshop is designed to present and discuss new concepts, challenges, and novel approaches to plant protection for walnut, almond, pecan, hazel, and pistachio. Experts in each of the five nut crops will present new advances and thoughts in pest and disease management for each production system.

\section{2:00 Introduction Richard P. Buchner}

\section{2:05 Leading Edge of Plant Protection for Walnut}

William H. Olson ${ }^{* 1}$ and Richard P. Buchner ${ }^{2}{ }^{1}$ Univ. of California Cooperative Extension, Oroville Ca 95965; ${ }^{2}$ Univ. of California Cooperative Extension, Red Bluff CA 96080

California walnut producers compete with many insect and disease pest in order to produce a viable crop. Traditional control strategies work reasonably well for most pests. However, environmental concerns and new or impending regulations threaten the use of traditional techniques for control of many pests. This presentation describes the key insect and disease pest of walnuts, the traditional and, where possible, the "leading edge" approaches to walnut insect and disease pest control. Codling moth, walnut husk fly, mites, aphids, scale and navel orangeworm are typical insect pest that have an impact on California walnut production. Control strategies that use Integrated Pest Management, beneficial insect releases, mating disruption, insect growth regulators, precise treatment timing based on pest life cycle, orchard sanitation and early harvest are "leading edge" techniques available for insect control of walnuts. Major diseases include Phytophthora crown and root rot, crown gall, oak root fungus and walnut blight. With the exception of walnut blight, control strategies deal primarily with sight selection, orchard management and rootstock selection. A new computer model "Xanthocast" is now available to forecast the need for controlling this pest.

\section{2:29 Leading Edge of Plant Protection for Almond}

Joseph H. Connelı*; Univ. of California Cooperative Extension, Oroville, CA 95965

Almond, [Prunus dulcis, (Mill.) D.A. Webb, syn. Prunus amygdalus Batsch] planted on $\approx 580,000$ acres, is California's largest acreage tree crop. California's Central Valley accounts for nearly $100 \%$ of the U.S. domestic production of almonds. IPM programs that integrate cultural practices and pest and disease monitoring with selective controls have improved plant protection in almond. Effects of tree nutrition and orchard floor management must also be taken into account. Minimizing dust, early harvest, and destruction of overwintering refugia are all cultural practices that reduce mite and worm damage. Improved methods of field sampling and monitoring have reduced the need for chemical pest control applications while improving timing and effectiveness of needed sprays. Selective controls have further reduced the impact on non-target species and augmentative parasite releases have been helpful in managing navel orangeworm. A better understanding of life cycles coupled with monitoring of the fungus diseases; shothole, scab, and anthracnose have reduced the need for fungicide applications. New selective fungicides require improved application timing and greater knowledge of diseases and resistance management for their effective use. Challenges include potential losses of effective materials, the continued need to develop new strategies, and the economic ability to sustain production.

2:54 Oregon State University's Integrated Pest Management Program for the Pacific Northwest Hazelnut Industry

J.L. Olsen*, Oregon State Univ. Extension Service, McMinnville, OR 97128

Oregon State Univ. developed an Integrated Pest Management program in hazelnuts in the early 1980's, through a USDA grant. Sampling schemes and action thresholds were refined over a period of four years for the filbertworm, filbert aphid, filbert leafroller, and obliquebanded leafroller, which are the most important insect pests in Oregon hazelnuts. A classical biological approach was employed in the mid-1980's when the filbert aphid parasitoid, Trioxys pallidus was imported from European hazelnut orchard into Willamette Valley hazelnut orchards. Grower survey results for 1981 and 1997 show the 
amount of pesticides applied for filbert aphid control has declined from 15,010 pounds in 1981 to 970 pounds in 1997, with $92 \%$ of the growers reporting reduced use. The registration of synthetic pyrethroids for filbertworm control and the use of pheromone trapping have reduce the amount of active ingredient applied in the industry from 88,000 pounds in 1981 , to only 3,200 pounds in 1997 . The annual cost savings to Oregon hazelnut growers due to use of the OSU IPM program are estimated at one half million dollars. The current research focuses on the development of an even softer program, resulting in the recent registrations of Success and Confirm. The most serious hazelnut disease, Anisogramma anomala, or Eastern Filbert Blight (EFB) fungus was first detected in the Pacific Northwest in 1970. It has now spread its way throughout two thirds of the hazelnut industry in Oregon The current OSU IPM recommendations include preventative fungicide sprays in the spring, scouting for and cutting out blight infections, and replacement of the most susceptible varieties when possible. The long-term approach to the problem is the development of EFB immune varieties. The OSU hazelnut breeding program will release its first immune variety in 2004.

3:18 Leading Edge of Plant Protection for Pistachios

Brent A. Holtz; ${ }^{*}$ Univ. of California Cooperative Extension, Madera CA, 93637

Pistachios were successfully introduced into California and were initially touted as a tree nut crop with no disease or insect pests. Unfortunately, these expectations did not last as a number of diseases and pests followed, making plant protection practices integral to production. Verticillium Wilt devastated early plantings but is now controlled with the use of resistant rootstocks. Botryosphaeria and Alternaria Blights are recently arrived foliar fungal diseases which have blighted nut clusters and defoliated trees, respectively, and multiple fungicide applications have been applied for control. Conversion to low volume irrigation systems, specifically to drip or buried drip have reduced disease. Pruning out Botryosphaeria blighted cankers has reduced overwintering inoculum and disease, while current research aims at accurately predicting infection events to increase fungicide efficacy. A number of hemipteran pests have been associated with epicarp lesion: spring treatments have been replaced with dormant Sevin and oil applications which are softer on beneficials while controlling Phytocoris and soft scale pests. Early season insect damage can be tolerated due to the tree's ability to compensate by filling a higher percentage of remaining nuts. Some mirid pest species (Calocoris) can be effectively reduced by eliminating alternate hosts in an effective weed control program. If Lygus populations are present weeds should not be disturbed from bloom until shell hardening to prevent movement into the trees where feeding can result in epicarp lesion. Stink bugs and Leaffooted bugs can also cause internal nut necrosis along with epicarp lesion since they are capable of penetrating the hardened shell. Trap crops have been used to monitor pest populations in order to develop treatment thresholds. Timing studies have shown degree day based treatments can increase insecticide efficacy for the control of Navel Orangeworm (NOW) and Obliquebanded Leafroller (OBLR), but NOW populations can also be effectively managed by destroying unharvested wintering nuts. Bacillus thuriengiensis $(\mathrm{Bt})$ sprays and biological control show promise in controlling OBLR.

3:42 Advanced Pest Management Systems for Pecans

William Reid*; Pecan Experiment Field, Kansas State Univ., Chetopa, KS 67336-0247

Pecans are produced under a wide array of environmental conditions-from the warm humid southeastern states, to the continental climate of the central plains, to the arid climates of the American west. In addition, pecan cultural systems vary from the low-input management of native stands of seedling trees to the intensive management of single-cultivar pecan orchards. This wide diversity of pecan agroecosystems has fostered the development of innovative, site-specific approaches toward pecan IPM. Current pecan IPM programs require an intimate knowledge of orchard ecology. Growers utilize monitoring methods and prediction models to track pest populations. Biological control agents are conserved by habitat manipulation and/or augmented through inoculative releases. Selective pesticides are used to control target pests while conserving natural enemies. Four cutting-edge IPM programs are described in detail to illustrate how ecological principles are applied to widely diverse pecan agroecosystems.

4:05 Business Meeting of the NUTS Working Group Presiding: Richard P. Buchner

2:00-4:30 p.m CC 304

\section{Workshop 15: Ethylene in Controlled Environments}

Working Group Sponsor: Growth Chambers and Controlled Environments (CE)

Presiding: Meriam G. Karlsson, Univ. of Alaska, Fairbanks

Summary: Ethylene is usually not a concern in field settings or wellventilated environments, but may be important in chambers where the atmospheric exchange is low. The workshop will include discussions on ethylene production and effects on plants growing in controlled environments, as well as discussions on ethylene issues related to postharvest commodities and ethylene biosynthesis in plants.

2:00 Introduction Meriam G. Karlsson

2:05 Ethylene and Postharvest Commodities

Elizabeth A. Baldwin*; USDA/ARS Citrus \& Subtropical Products Laboratory, Winter Haven, FL

In 1864, gas lamps, observed to cause injury and defoliation of nearby trees, and kerosene heaters, used to degreen lemons, were found to emit a simple 2 carbon molecule called ethylene. This gaseous plant hormone was found to be the active compound for defoliation and degreening. The discovery of ethylene and its effect on plants led to its commercial use in the horticulture industry. Ethylene-releasing chemicals are used to promote early development of stone fruits and ripening of pineapple fruits in the field, ripening of bananas and tomatoes postharvest, and as thinning and harvesting aids due to ethylene's promotion of abscission and ripening. Ethylene can also induce resistance to sprouting and black spot in potatoes and either impart susceptibility or resistance to spoilage organisms and chilling injury depending on the organism and/ or commodity. Conversely, absorbent chemicals may be used to remove ethylene to prevent some of its deleterious effects such as induction of senescence, yellowing and abscission of leafy or floral vegetables, russet spotting of lettuce, undesirable texture changes, and bitterness or off-flavor in certain produce. Ethylene can cause physiological reactions in fruits and vegetables at concentrations as low as $0.005 \mathrm{ppm}$. Climacteric fruits and vegetables, for which ethylene is autocatalytic, can contain internal concentrations from 3-2500 ppm as they ripen. Basal level ethylene production, typical of non-climacteric fruit, is around $0.1 \mu \mathrm{L} \mathrm{kg}{ }^{-1} \cdot \mathrm{h}^{-1}$, while climacteric fruit production levels can range from 5 to $200 \mu \mathrm{L} \mathrm{kg}^{-1} \cdot \mathrm{h}^{-1}$ during ripening.

2:30 Ethylene Production by Plant Stands

Raymond M. Wheeler* and Barbara V. Peterson; NASA Biological Sciences Branch and Dynamac Corp., Kennedy Space Center, FL 32899

Ethylene production by plants has typically been tracked uses two approaches: 1) placing excised tissue samples in sealed vessels and then sampling the headspace, or 2) enclosing intact plants in chambers and then sampling the chamber headspace or outflow. Use of excised tissue is convenient but 
must consider wounding effects and the fact that samples may not characterize the whole plant. Enclosure of whole plants can provide a more integrated measurement, but requires specially designed chambers to allow accurate ethylene sampling. Our group at Kennedy Space Center has used closed chamber studies to simulate plant growing environments in space, which has allowed direct measurements of ethylene production from entire plant stands. Several general observations can be offered from these studies: 1) ethylene production by plant stands varies among species; 2) ethylene production is high for some species during vegetative growth and then drops off during seed filling (e.g. soybean and wheat); 3) environmental perturbations can cause transient increases ethylene production (e.g. changes in photoperiod with potato); and 4) ethylene production can increase rapidly during fruit ripening stages for some species (e.g., tomato). The findings indicate that ethylene build-up from plant growth and metabolism must be considered in developing environmental management approaches for tightly closed, plant growth environments.

2:55 The Effects of Elevated Atmospheric Ethylene Levels on Growth and Development of Crop Plants

Steve Klassen and Bruce Bugbee*; Crop Physiology Laboratory, Utah State Univ., Logan, UT 84322

The effects of low (ppb) levels of atmospheric ethylene on plants are poorly characterized. We examined the sensitivity of wheat, lettuce, and rice to ethylene levels from 10 to $1,000 \mathrm{ppb}$ compared to clean air controls. Significant yield reductions were observed in all crops at 10 to $50 \mathrm{ppb}$ ethylene. However, exposure to $1,000 \mathrm{ppb}$ ethylene prior to anthesis had only a minimal effect on wheat growth and yield. The differential sensitivity of two wheat cultivars (Super Dwarf and Apogee) to $50 \mathrm{ppb}$ ethylene at three levels of $\mathrm{CO}_{2}(350,1200,5000 \mathrm{ppm})$ was also examined. Apogee wheat was more tolerant of elevated ethylene than Super Dwarf wheat. High $\mathrm{CO}_{2}$ levels did not increase ethylene sensitivity. Our findings suggest that: 1) the effects of ethylene are most pronounced during anthesis;2) ethylene effects may be more pronounced at higher temperatures; and 3 ) there is considerable potential to mitigate ethylene effects by selection of ethylene tolerant cultivars.

\section{Ethylene Metabolism in Plants}

Sylvia M. Blankenship*; North Carolina State Univ., Raleigh In plants ethylene is synthesized from methionine, with intermediates of s-adenosylmethionine and 1aminocyclopropane-1-carboxylic acid. Under some circumstances ethylene can be produced in large quantities, such as in ripening fruit. Ethylene is autocatalytic, stimulating it's own synthesis. Whether from a plant or industrial source, ethylene binds to specific receptors in plants. With binding, a cascade of biochemical events takes place resulting in physiological effects such as epinasty, abscission and chlorophyll loss. An ethylene molecule doesn't permanently attach to the binding site as evidenced by experiments with 14C-ethylene. Therefore the length of plant exposure to ethylene may determine if ethylene effects are permanent. There are ethylene binding inhibitors, such as 1-methylcyclopropene, which do appear to bind permanently to the site. There is variability in the number of binding sites in plants. In tomato leaves chronic ethylene exposure almost doubled the number of binding sites. Apple pulp and morning glory flowers contain $3.2 \times 10-11$ and $3.8 \times 10-9$ moles/ $\mathrm{kg}$ ethylene binding sites, respectively. Total number of sites in apple pulp does not appear to change over maturation, but the affinity of the sites for ethylene does seem to change, with more ethylene being needed to saturate $50 \%$ of the binding sites as ripening progresses. Growing plants and some harvested plants/ parts have the ability to synthesize new binding sites. It is unknown exactly what relationship ethylene binding sites have to ethylene sensitivity.

\section{3:50 Discussion}

4:00 Business Meeting of the CE Working Group

Presiding: Meriam G. Karlsson

2:00-3:30 p.m. CC 316

Oral 13: Cross-commodity: Nutrition

Presiding: Alexander A. Csizinszky, Gulf Coast REC, Univ. of Florida, Bradenton

2:00 p.m.

Nitrification Rates in Liquid Hydroponic Solutions with

Ammonium Nitrogen

Dawn Muhlestein, Bruce Bugbee*, and Jenny Norton; Dept. of Plants, Soils and Biometerology, Utah State Univ., Logan, UT 84322-4820

Nitrifying organisms are ubiquitous and there is significant potential for high rates of nitrification to occur in hydroponic solutions when part of the nitrogen is supplied as ammonium. However, the plant nutrition literature has largely ignored nitrification potential and has assumed that the disappearance of ammonium is caused solely by plant uptake. Padgett \& Lenoard (Plant Physiology, 1993) reported that nitrification occurred in 5 to 8 days in hydroponic solutions, but their analytical procedures could not quantify the kinetics of nitrification. We used a $2 \times 2 \times 2$ factorial design to examine the effect of $\mathrm{pH}$ (5.8 vs. 7); inoculated vs. not inoculated; and planted vs. unplanted on rates of nitrification. $\mathrm{A} 15-\mathrm{NO}_{3}$, isotopic dilution technique was used to measure nitrate production and consumption. Nitrification rates were significant in all treatments, but only after 15- to 35-day lag times. As expected, the lag times were shortest ( 15 days) at $\mathrm{pH}$ 7 , with inoculum. Nitrification rates were higher in the unplanted than the planted bottles, suggesting that root surfaces do not provide an optimal environment for nitrification.

2:15 p.m.

\section{Developing Nitrogen Efficient Systems: The Case of the} Michigan Potato

Sieglinde Snapp ${ }^{* 1}$, Heather Borden ${ }^{1}$, and Don Smucker ${ }^{2}{ }^{1}$ Michigan State Univ., East Lansing, MI 44824; ${ }^{2}$ Michigan State Univ. Extension

Potato farmers are under increasing pressure to develop and utilize more efficient nitrogen strategies. In Michigan, these strategies encompass monitoring plant nitrogen status and a range of application methods, fertilizer sources, cover crop systems and rotation sequences. We surveyed farmer satisfaction with nitrogen monitoring tools, nitrogen sources and cover crop strategies. Results are reported from a statewide formal survey of all growers, and semi-structured interviews with growers. We found that growers are reexamining nitrogen practices. The majority use less nitrogen fertilizer than they historically used, and more intensive cover crops. Establishment of cover crops is challenging before winter frosts, and sometimes involves aerial seeding and inputs such as irrigation. Another problem is the ability to predict nitrogen supply as petiole testing and soil monitoring techniques were widely questioned. Yet, many growers and consultants are attempting to predict potato $\mathrm{N}$ response. There is a ways to go in developing optimal plant $\mathrm{N}$ fertilization strategies. Some gains have been achieved in $\mathrm{N}$ fertilization efficiency, which may limit nitrate losses to deep percolation.

\section{2:30 p.m.}

Interactive Effects of Nitrogen Fertility and Fungicide Program on Early Blight and Potato Yield

Carl J. Rosen ${ }^{\star 1}$, and Jeff S. Miller ${ }^{2}{ }^{-1}$ Dept. of Soil, Water, and Climate, Univ. of Minnesota, St. Paul, MN 55108; ' Dept. of Plant, Soil, and Entomological Sciences, Univ. of Idaho, Aberdeen, ID 83210

Nitrogen deficiency can increase the incidence of early blight (Alternaria solani) infestation, a foliar disease that can significantly reduce potato (Solanum tuberosum L.) yield. A newer fungicide, azoxystrobin (Quadris), has been shown to effectively control early blight leading to the suggestion that $\mathrm{N}$ requirements for potato may be 
lower when Quadris is used to control the disease. This study was conducted to determine if the use of Quadris affects $\mathrm{N}$ fertilizer requirements for potato (cv. 'Russet Burbank'). Plots were established in 1999 and 2000 at Becker, MN on a Hubbard loamy sand as a complete factorial, split-plot arrangement using a randomized complete block design with four replications. Fungicide treatments were used as the whole plot factor and included an untreated control, Bravo, and Quadris rotated with Bravo. Fertility treatments were used as the sub-plot factor and included $\mathrm{N}$ applied at three levels $(170,250$, and $330 \mathrm{~kg} / \mathrm{ha} \mathrm{N}$ ) and two timings (pre-chilling and all season). Early blight was problematic in 1999 and both early and late blight (Phytophthora infestans) were severe in 2000. Significant interactions were observed between fungicide and fertility treatments for disease control in both study years. Control of early blight with fungicides was generally more effective at higher $\mathrm{N}$ rates, especially when Quadris was not used. Timing of $\mathrm{N}$ was less important in controlling disease than rate of N. Conflicting results for yield were found. In 1999, use of Quadris increased yield potential and hence $\mathrm{N}$ requirement was the same as when early blight was present. In 2000 , controlling early blight with Quadris reduced the $\mathrm{N}$ requirement compared to more conventional fungicide programs where a higher incidence of early blight occurred. Interactions between early blight disease incidence and $\mathrm{N}$ requirement for potato appear to depend on environmental factors regulating tuber bulking potential.

\section{2:45 p.m.}

Impact of Supplemental Calcium Application to Developing Seed Tubers on Performance the Following Season

Christopher C. Gunter ${ }^{* 1}$, and Jiwan P. Palta'; ' Purdue Univ., Southwest Purdue Agricultural Program, 4369 North Purdue Road, Vincennes, IN 47591; '2Univ. of Wisconsin-Madison, 1575 Linden Dr., Madison, WI. 53706

Production of high quality seed tubers is of paramount concern to potato growers. High quality seed tubers are required to have freedom from defects and diseases, minimal sprouting and the capability for vigorous growth after planting. The impact of the calcium concentration of seed tubers on the quality of the plant produced by that tuber the following season has not been examined. Plots were established at a commercial seed production farm, on silt loam soil, in northern Wisconsin using the following cultivars: Superior; Dark Red Norland; Atlantic; Snowden; and Russet Burbank. During seed tuber production, calcium was applied in a split application, using calcium nitrate $(9 \mathrm{~N}-0 \mathrm{P}-\mathrm{OK}-11 \mathrm{Ca})$ at a rate of $168 \mathrm{~kg} \cdot \mathrm{ha}^{-1}$. Control plots received nitrogen only, from ammonium nitrate $(34 \mathrm{~N}-0 \mathrm{P}-0 \mathrm{~K})$, delivered at the same rate and timing as the calcium plots. All plots received the same nutrition during the evaluation season. The mean calcium content of the seed tuber can be raised following supplemental calcium application, resulting in an increased proportion of high calcium tubers in plots treated with calcium the previous season. Supplemental calcium during seed tuber production influences the growth of above ground foliage and can increase mean tuber yield. Results of these studies indicate that the odds of obtaining high yield are better if the seed piece contains high calcium and may indicate a positive relationship between calcium and yield when plotted across seasons.

\section{3:00 p.m.}

\section{Syncronizing the Nutrient/Water Input with Removal by the} Root

C.M. Geraldson*, Gulf Coast Research and Education Center, Univ. of Florida, Bradenton, FL 34203

The gradient concept was initiated and evaluated in Florida during the 1960's as the nutritional component in the shift to a full bed mulch procedure. Conventionally nutrients move in the soil to the root by mass flow with the water. As a function of water requirement, nutrition can be variable. To syncronize the nutrient requirement with input, a soluble source of $\mathrm{N}-\mathrm{K}$ banded on the soil bed surface moves by diffusion to establish and maintain the gradient. The input coincides with the rate of removal from the gradient by the root. Roots proliferate in the increments of the gradient ranging from a maximum tolerable concentration decreasing gradient wise. The unlimited buffer potential of the gradient replaces the soils limited buffer potential and the soil remains essential as the framework for the gradient. A mix of gradient and conventional procedure can weaken or destroy the gradient. Fertigation, often used with microirrigation is not compatible with gradient procedure. Conventionally, a soils buffer is limited and diminishes as the soil/plant ratio decreases. That ratio also decreases when a portion of the soil is not wetted. Unwetted soil has no buffer potential. Whether grown in the field or container, a limited soils buffer can be replaced by an unlimited gradient buffer. Nutritionally, productivity is potentially unlimited.

\section{3:15 p.m.}

Differential Yield Response of Bell Pepper (Capsicum annuum) Cultivars to Foliar-applied Biostimulant Alexander A. Csizinszky*, Gulf Coast Research \& Education Center, Univ. of Florida, Bradenton, FL 34203

Bell peppers, Capsicum annuum, cvs. Brigadier and Camelot were grown in the summer-fall (Sept.-Dec.) 1999 with the full-bed polyethylene mulch system with micro (drip) irrigation. Soil was an EauGallie fine sand. Plants were treated with the 'Magnet' (DXL 510) (Donlar Corp.) foliar-applied biostimulant 14 days after transplanting at $4.67 \mathrm{~L} / \mathrm{ha}$, then 21 days after the first application at 2.33 L/ha. In the control plots, plants were sprayed with water. Fruits were harvested four times: 8, 18 and 29 Nov., and 16 Dec. 1999 and graded according to U.S. standards. 'Magnet' treatments increased U.S. Fancy grade fruit yield of 'Brigadier' by $46 \%$ in the first two harvests and by $31 \%$ for the season. Yields of U.S. No. 1 and U.S. No. 2 fruits were higher with the control than with the biostimulant treatment. 'Camelot' yields with 'Magnet' biostimulant were higher in the first harvest only. The yield increase with the 'Magnet' treatment was due to a heavier weight per fruit rather than larger number of fruits per plant. Plant heights, fruit firmness and elemental concentrations in shoots were similar with biostimulant or water treatment.

2:00-4:00 p.m CC 103

\section{Oral 14: Vegetable Crops: Sustainable Agriculture}

Presiding: Wayne F. Whitehead, Fort Valley State Univ., Fort Valley, GA

2:00 p.m.

\section{Plant Development of Greenhouse Tomatoes in Organic} Media and Fertilizers

Janet F. Miles*, Mary M. Peet, and Paul V. Nelson, Dept. of Horticultural Sciences, North Carolina State Univ., Raleigh, NC 27695

Interest in organic farming has been stimulated by an average annual increase of $24 \%$ in national sales of organically produced fruits and vegetables. Available information about organic growing focuses mainly on field production. This study's purpose was to explore effects of various organic media and fertilizers on production of greenhouse tomatoes. Two commercial fertilizers, Earth Juice (EJ) and Magna Gro (MG), were formulated to match N-P-K levels typical of conventional fertigation. Within each fertilizer treatment, plants were grown in four organically acceptable media: 1) Fafard's Special Organic Mix : vermi-compost (OM1) plus an organic wetting agent $(85: 15)$; 2) peat moss : perlite plus an organic wetting agent (OM2) (70:30); 3) Scott's 366 coconut coir mix : pine bark (OM3) (70:30); and 4) Scott's 366 coconut coir mix : pine bark : vermicompost (63:22:15). All organic media were amended with $10 \mathrm{lbs} . /$ cu. yd. $\left(6 \mathrm{~kg} \cdot \mathrm{m}^{-3}\right)$ dolomitic lime, and $2.5 \mathrm{lbs} . / \mathrm{cu}$. yd. $\left(1.5 \mathrm{~kg} \cdot \mathrm{m}^{-3}\right)$ blood meal ( $12 \mathrm{~N}-0 \mathrm{P}-0 \mathrm{~K})$, bone meal $(0 \mathrm{~N}-4.84 \mathrm{P}-0 \mathrm{~K})$ and potassium sulfate $(0 \mathrm{~N}-0 \mathrm{P}-41.5 \mathrm{~K})$. Control plants were grown conventionally. Plant development was assessed by the number of days from seeding to flower and fruit set on each cluster, and total leaf area. Data were analyzed using split-plot analysis with fertilizer as the main plot and media as the sub-plots. Plants grown in OM2 and OM3 took longest to develop flowers and fruit in both organic fertilizers. 
Leaf area was greatest in the $\mathrm{OM} 2+\mathrm{MG}$ and smallest in the $\mathrm{OM} 2+$ EJ treatments. Plants fertilized with EJ and grown in OM1 and OM4 developed flowers and fruit in a time period similar to conventionally grown plants. Plant development was variably affected by organic media/fertilizer interactions. Media containing vermi-compost produced results similar to conventional practices.

\section{2:15 p.m.}

Organic vs. Inorganic Nitrogen Effect on Vegetative Matter and Yields of Eggplant

Wayne F. Whitehead* and Bharat P. Singh, Agricultural Research Station, Fort Valley State Univ., Fort Valley, GA 31030-4313

During the 2000 growing season, a study was conducted to determine how winter cover crops and recommended fertilizer $\mathrm{N}$ rates affect eggplant yield, fruit number, and vegetative dry matter. The following winter-spring fertility treatments were applied using randomized complete block design with four replications: 1) $0 \mathrm{~N}$ winter-0 N spring, 2) $0 \mathrm{~N}$ winter-70 kg N/ha spring, 3) $0 \mathrm{~N}$ winter$140 \mathrm{~kg} \mathrm{~N} /$ ha spring, 4) $0 \mathrm{~N}$ winter + abruzi rye $-0 \mathrm{~N}$ spring, 5) $0 \mathrm{~N}$ winter + hairy vetch-0 $\mathrm{N}$ spring, and 6) $0 \mathrm{~N}$ winter+crimson clover$0 \mathrm{~N}$ spring. In spring, 'Megel' eggplants were transplanted in all plots. Total yield and fruit number was compiled over eight weeks, while seasonal vegetative dry matter was measured at final harvest. Highest vegetative dry matter ( $217.5 \mathrm{~g} / \mathrm{plant})$ and fruit number (22/plant) was produced by hairy vetch. Total yield were highest $(52.1 \mathrm{Mg} / \mathrm{ha})$ in the hairy vetch plots and lowest $(21.0 \mathrm{Mg} / \mathrm{ha})$ in abruzi rye. Organic $\mathrm{N}$ from hairy vetch and crimson clover produced significantly higher dry matter compared to other treatments, while fruit number and yield were comparable to those receiving synthetic $\mathrm{N}$. Results indicate that legume cover crops are an effective $\mathrm{N}$ source in supporting plant dry matter, fruit number, and yield of eggplant.

\section{2:30 p.m.}

The Effect of Bone Meal and Chicken Manure on the Growth and Yield of Jicama (Pachyrhizuz Erosus) in Hawaii

Hector R. Valenzuela* and Ted Goo, Dept. of Tropical Plant and Soil Science, Univ. of Hawaii at Manoa, Honolulu, HI 96822-2279

Jicama is an increasingly popular specialty tuberous root crop used in salad bars or in ethnic dishes from Asia and Latin America. An increased demand also exists to use locally available organic amendments as an alternative to the use of inorganic fertilizers. Thus, three experiments were conducted over two years to evaluate the effect of bone meal (BM) and chicken manure (CM) applications on the yield of jicama in Waimanalo, Hawaii. In two experiments, treatments included a control, synthetic fertilizer, bone meal at a $1 \mathrm{x}$ (2.5 ton/ha) application rate, $\mathrm{CM}$ at a 2.5 ton/ha rate, $\mathrm{BM}$ at a $4 \mathrm{x}$ rate, and $\mathrm{BM}$ at a $1 \mathrm{x}$ rate in combination with chicken manure. Each treatment was a 12-m long double-row bed, replicated four times, with the plots arranged in a CRD design. The third experiment was conducted as part of a long-term organic farming study. Treatments included controls, low and high rates of compost alone, BM plus low or high rates of composts, and synthetic fertilizer alone. Data collected included soil nutrient levels, stand establishment, top growth fresh weight, and root length, width, and fresh weight over a three-month harvest period. High BM application rates, and high compost/BM treatments affected stand establishment and depressed yields by over $30 \%$. Chicken manure and BM combinations resulted in the greatest yields and in the largest root sizes. Yields from the low BM applications treatments were similar to those obtained with synthetic fertilizers, which were in turn, similar or numerically greater than those observed in the controls.

\section{2:45 p.m.}

\section{Nutrient Constituents of Salicornia (Salicornia bigelovii} Torr.), A Seawater-irrigated New Green Vegetable

Zhongjin Lu*, Roy M. Hodges, Carlos J. Mota-Urbina, Paul L. Gallawa, Rahul Chaturvedi, and Carl N. Hodges; Seaphire International, 4500 North 32nd Street, Suite 100, Phoenix, AZ 85018
Salicornia bigelovii Torr. has been developed as the first green vegetable grown on full-strength seawater irrigation, whose brand name is Seaphire ${ }^{T M}$ (salicornia's green tips). This species, commonly known as glasswort, marsh samphire, sea asparagus, passe pierre, or sea bean, is a succulent, leafless, salt-tolerant, annual herb in the goosefoot family Chenopodiaceae. S. bigelovii is a native of North America and naturally colonizes shifting mud flats in coastal salt marshes through its prolific seed production. When S. bigelovii plants are harvested during vegetative growth, the succulent, crisp tips can be eaten as a fresh green vegetable. In terms of $100 \mathrm{~g}$ fresh tips, salicornia contains $\approx 90 \mathrm{~g}$ water, $1.4 \mathrm{~g}$ protein, $0-0.5 \mathrm{~g}$ fats, $5.8 \mathrm{~g}$ carbohydrates, $2.0 \mathrm{~g}$ fiber, and $2.6 \mathrm{~g}$ ashes, with a total energy of 25-36 calories. Like other Chenopodiaceae vegetables, such as spinach (Spinacia oleracea), palak (spinach-beet; Beta vulgaris var. orientalis), Swiss chard (seakale beet; Beta vulgaris var. cicla), table beet greens (Beta vulgaris), epaspote (Mexican tea; Chenopodium ambrosioides), and quinoa (lambsquarter; Chenopodium quinoa), salicornia is rich in beta - carotene (vitamin A; $2400 \mathrm{IU})$ and vitamin C (10.7 mg/ $100 \mathrm{~g}$ ). In addition, the content of vitamin B1, riboflavin (B2), and niacin in salicornia green tips is $0.27 \mathrm{mg} / 100 \mathrm{~g}, 0.04 \mathrm{mg} / 100 \mathrm{~g}$, and $1.5 \mathrm{mg} / 100 \mathrm{~g}$, respectively. Since $S$. bigelovii grows on full-strength seawater irrigation, its fresh green tips have a salty flavor that comes from a wide range of minerals. The content of sodium $(\mathrm{Na})$, potassium $(\mathrm{K})$, magnesium $(\mathrm{Mg})$, calcium $(\mathrm{Ca})$, nitrogen $(\mathrm{N})$, sulfur (S), and phosphorus (P), was assayed to be $1660 \mathrm{mg}, 217 \mathrm{mg}, 131$ $\mathrm{mg}, 59 \mathrm{mg}, 406 \mathrm{mg}, 54 \mathrm{mg}$, and $26 \mathrm{mg}$ per $100 \mathrm{~g}$ fresh tips, respectively. It also contains a variety of micro-elements that are necessary for human nutrition, such as $710 \mathrm{mg}$ iron $(\mathrm{Fe}), 730 \mathrm{mg}$ aluminum (Al), $650 \mathrm{mg}$ manganese (Mn), $500 \mathrm{mg}$ iodine (I), $250 \mathrm{mg}$ boron (B), $200 \mathrm{mg}$ zinc $(\mathrm{Zn})$ and $130 \mathrm{mg}$ copper $(\mathrm{Cu})$. However, heavy metals such as arsenic ( $\mathrm{As})$ and lead $(\mathrm{Pb})$ which are considered harmful to health were found in a very marginal concentration, less than $0.2 \mathrm{mg} / 100 \mathrm{~g}$ and $0.3 \mathrm{mg} / 100 \mathrm{~g}$, respectively. Thus, this new green vegetable is a good source of minerals, protein, beta-carotene, and vitamin C. Nutritionally, salicornia green tips appear to be comparable to other Chenopodiaceae vegetables and the Amaranthaceae vegetables such as legos or silver spinach (Amaranthus sp.) in the Carribbean area. In Europe and North America, salicornia green tips are traditionally harvested in the wild and have been enjoyed as a seasonal delicacy for several centuries. At present, S. bigelovii has been domesticated into a new green vegetable and cultivated on seawater-irrigated farms. Salicornia seeds can be sown in winter, spring, late summer, and fall to allow fresh vegetable harvests throughout the year. Vegetable yield can be as high as 8-9 MT per hectare, based on investigations from one-square-meter plots. The commercialization of salicornia as a green vegetable would be helpful in alleviating pressures of vegetable production on arable land and freshwater and stimulating marginal land economies.

3:00 p.m.

Agricultural Offsite Impacts: Using REMM to Assess Buffer Management

Lee S. Altier ${ }^{* 1}$, Randall G. Williams ${ }^{2}$, and Charles E. Poteet ${ }^{3} ;{ }^{1} \mathrm{Col}-$ lege of Agriculture, California State Univ., Chico, CA, 95929-0310; ${ }^{2}$ Southeast Watershed Research Laboratory, USDA-ARS, Tifton, GA, 31793; ${ }^{3}$ Dept. of Computer Science, California State Univ., Chico, CA, 95929-410

Riparian areas can be effective buffers for mitigating pollution from agricultural fields. Their potential for controlling water quality depends upon a variety of environmental and management factors. The Riparian Ecosystem Management Model (REMM) is a comprehensive field-scale model that keeps track of hydrologic, erosion, nutrient, and vegetation dynamics in order to identify optimal management of riparian ecosystems for reducing upland pollution. REMM is increasingly being used to characterize and estimate the impact of production on water quality. Its ability to generate a mass balance for nitrogen in the system is crucial for 
elucidating key control processes and the circumstances in which they predominate. Use of REMM has made clear the limitations of this scale of model and where a watershed approach is needed. It has also reinforced our understanding of the importance of a holistic approach to managing agricultural production and adjacent riparian areas.

\section{3:15 p.m.}

\section{New Agricultural Crops to Save Water in Arid Baja California Sur, Mexico}

E. Troyo-Dieguez*, B. Murillo-Amador, J.L. Garcia-Hernandez, A. Nieto-Garibay, and J.A. Larrinaga-Mayoral; CIBNOR, S.C. (Center for Biological Research of Northwest Mexico)

Baja California Sur, with an extension of $72,000 \mathrm{~km}^{2}$, is one of the driest Mexican States. Here, 450,000 inhabitants depend on ground water for social and economic development. Agriculture takes more than $90 \%$ of the available water; hence it is the activity with the highest rate of water consumption. Nearly $30 \%$ of agricultural lands in this geographical area have some level of salinity. Conventional crops used to be cotton, corn, wheat, alfalfa, and sorghum, among others; these crops use $\approx 70 \%$ of the agricultural water in the State, but ground water depletion does not allow such type of crops. CIBNOR, S.C. (Northwest Biological Research Center) is promoting the cultivation of "nopal" (Opuntia sp.) for the production of forage, fresh fruit and edible vegetable "cladodes" (nopalitos). Other experimental horticultural crops are the pickle weed (Salicornia bigelovii), to be irrigated with seawater, savila (Aloe vera), "Cimarron" wild plum, the oilseed jojoba (Simondsia chinensis), and the medicinal or tea-purpose "Damiana" (Turnera difussa). These three last species survive under dry conditions and are able to stand low leaf water potential values. With the adoption and promotion of these new horticultural crops we expect to reduce from $40 \%$ to $50 \%$ the water consumption in the agricultural and horticultural fields.

\section{3:30 p.m.}

Biochemical Changes in Pepper (Capsicum annuum L.) Fruit Associated with Blossom-end Rot

Beny Aloni and Karni Leah, Institute of Field and Garden Crops, The Dept. of Vegetable Crops in the A.R.O. The Volcani center, BetDagan, P.O.B. 6, Israel

Blossom end rot (BER) is a fruit physiological disorder occurring under various environmental stresses and known to be associated with Ca deficiency, however the biochemical changes leading to the appearance of the symptoms have not been investigated. In the present study it is demonstrated that pepper (Capsicum annuum L.) fruits were prone to BER at an early developmental stage and were not sensitive in a more advanced stages. Histochemical staining for $\mathrm{H}_{2} \mathrm{O}_{2}$ with Tetramethylbenzidine dihydrochloride (TMB) indicated that at the sensitive stage, $\mathrm{H}_{2} \mathrm{O}_{2}$ concentrations were highest and declined with the advancement of fruit development. At the most sensitive stage catalase activity was relatively low and the activity of the oxygen radicals generating enzyme, NADPH oxidase was highest compared to the activity in more advanced developmental stages. TMB staining indicated that in nonaffected fruits, $\mathrm{H}_{2} \mathrm{O}_{2}$ is located mainly at the fruit placental tissue close to the fruit tip and much less in the pericarp tissue. In addition, staining was associated with the sieve elements located in the pericarp tissue. In the BERaffected fruits $\mathrm{TMB} / \mathrm{H}_{2} \mathrm{O}_{2}$ staining was more pronounced, in the placental and pericarp parts of the fruit. Exposure of young, detached fruits to environmental conditions that commonly encourage BER (high light/ high temperature conditions) led to increase in placental $\mathrm{H}_{2} \mathrm{O}_{2}$ staining and this was eliminated in fruits kept in the dark or $60 \%$ shade. Likewise, NADPH oxidase activity was enhanced under high light/high temperature conditions. The results suggest that the induction of BER symptoms in bell pepper is associated with generation of $\mathrm{O}_{2} \cdot \mathrm{H}_{2} \mathrm{O}_{2}$, initially in the placental tissue. $\mathrm{O}_{2} \cdot / \mathrm{H}_{2} \mathrm{O}_{2}$ radicals may cause membrane lipids peroxidation, thereby initiating the BER symptoms.
3:45 p.m.

Response of Sweetpotato and Peanut to Low Mars Ambient Photosynthetic Photon Flux (PPF)

D.G. Mortley*, J.H. Hill, C.K. Bonsi, W.A. Hill, and C.E. Morris; Center for Food and Environmental Systems for Human Exploration of Space and G. W. Carver Agricultural Experiment Station, Tuskegee Univ., Tuskegee AL 36088

Significant reduction in equivalent system mass can be achieved if available solar irradiance could be used solely or in combination with artificial lighting on planetary surfaces such as on Mars. Mars is further from the sun, relative to the earth, reducing solar radiation ( $<20 \mathrm{~mol} / \mathrm{m}^{2} /$ day) reaching the surface. As part of the National Aeronautics and Space Administration's (NASA) Advanced Life Support (ALS) program, growth chamber studies were conducted to evaluate the response of sweetpotato and peanut to low light levels. Four TU-82-155 sweetpotato stem cuttings (15-cm long)or peanut seedlings (cvs. Georgia Red, Tamspan 90) were grown in rectangular nutrient film technique hydroponic troughs $(0.15 \times 0.15 \times 1.2 \mathrm{~m})$ for 120 days. Two troughs were placed into each of eight growth chambers and subjected to daily PPFlevels of $4.32,8.64,12.96$, and $17.28 \mathrm{~mol} / \mathrm{m}^{2} /$ day, respectively. Chamber conditions included a 12/ $12-\mathrm{h}$ photoperiod, $70 \%$ relative humidity, and a diurnal $28 / 22{ }^{\circ} \mathrm{C}$ or $28 / 24^{\circ} \mathrm{C}$. The number, fresh and dry weight of sweetpotato storage roots produced increased with daily PPF. Likewise, foliage fresh and dry weight and harvest index also increased with PPF. Total fresh and dry biomass, seed yield, and harvest index increased with PPF for both peanut cultivars. Plants flowered an average of 7-11 days later for both cultivars at the lowest PPF, and the number reaching anthesis was substantially reduced. Typically, the daily Martian PPF is $\approx 17.28 \mathrm{~mol} / \mathrm{m}^{2} /$ day with 12 -h days, and these results that crop responses may be inhibited under these lower light levels if not supplemented with artificial lighting.

2:00-4:00 p.m CC 319

\section{Oral 15: Vegetable Crops: Genetics/Breeding/ Biotechnology}

Presiding: Edward J. Ryder, ARS/USDA, Salinas, Calif. 2:00 p.m.

Chilling Injury : A Cytoplasmically Inherited Trait in Cucumber (Cucumis sativus L.)

Sang-Min Chung*, Gennaro Fazio, and Jack E. Staub; USDA/ARS, Dept. of Horticulture, 1575 Linden Dr., Univ. of Wisconsin, Madison WI 53706

Although chilling temperatures $\left(<12{ }^{\circ} \mathrm{C}\right)$ can cause significant damage to cucumber (Cucumis sativus L.) plants, the inheritance of chilling injury and its linkage to other genes in cucumber has not been documented. Genetic variation for chilling tolerance exists in cucumber. Therefore, a study was designed in which cucumber lines [susceptible Gy-14 $\left(P_{1}\right)$, tolerant 'Chipper' $\left(P_{2}\right)$, and tolerant 'Little John' $\left.\left(P_{3}\right)\right]$, and their cross-progeny $\left(F_{1}, F_{2}\right.$, and $\left.B C_{1}\right)$ were evaluated to determine the inheritance of chilling injury (first true-leaf stage; $4^{\circ} \mathrm{C}$ for 5.5 hours). Generation mean analyses were performed under the assumption that chilling injury was controlled by nuclear gene(s). However, chi-square tests suggested that a three and a six-parameter model were not adequate for explanation of the inheritance of chilling injury. Exact reciprocal $F_{1}$ and $F_{2}$ cross-progeny of $P_{1} \times P_{2}$ and $P_{1} \times P_{3}$ matings indicated that the control of chilling injury in cucumber is due to cytoplasmic factor(s). The mean chilling ratings [1 (trace) -9 (dead)] of progeny comparisons were: $F_{1}\left(P_{1} \times P_{2}\right)=6.2$ vs. $F_{1}\left(P_{2} \times P_{1}\right)=1.2$; $F_{2}\left(P_{1} \times P_{2}\right)=6.4$ vs. $F_{2}\left(P_{2} \times P_{1}\right)=2.7 ; F_{1}\left(P_{1} \times P_{3}\right)=5.4$ vs. $F_{1}\left(P_{3} \times\right.$ $\left.P_{1}\right)=1.7$, and; $F_{2}\left(P_{1} \times P_{3}\right)=5.8$ vs. $F_{2}\left(P_{3} \times P_{1}\right)=2.2$. When the chilling tolerant line was used as the female parent, all $F_{1}$ and $F_{2}$ progeny were chilling tolerant. The mitochondria genome of cucumber is paternally transmitted. Therefore, the chilling tolerant trait identified is likely associated with the chloroplast genome, which is itself maternally transmitted in cucumber. This is the first genetic demonstration that chilling injury is controlled by cytoplasmic genetic factor(s) in a plant species. 
2:15 p.m.

Breeding for Altered Glucosinolate Profiles in Broccoli (Brassica oleracea) and Implications for Cancer Chemoprotection

Allan F. Brown ${ }^{* 1}$, Gad G. Yousef', Elizabeth H. Jeffery², Barbara P. Klein², Mosbah M. Kushad", Mathew A. Wallig', and John A. Juvik'; ${ }^{1}$ Dept. of Natural Resources and Environmental Sciences, Univ. of Illinois, 61801; ${ }^{2}$ Dept. of Food Science and Human Nutrition, Univ. of Illinois, 61801; ${ }^{3}$ Dept. of Veterinary Pathobiology, Univ. of Illinois, 61801

Glucosinolate surveys in Brassica oleracea over multiple environments have identified lines with unique aliphatic glucosinolate profiles that differ in both a qualitative and quantitative manner. These results suggest that the genes necessary for altering aliphatic glucosinolate profiles are present within existing broccoli germplasm. These lines have been used in crosses to develop breeding populations that are segregating for aliphatic glucosinolate content and molecular markers have been used to identify genomic regions in broccoli responsible for aliphatic glucosinolate biosynthesis. The implications for developing broccoli lines with unique chemoprotectant activity are discussed.

\section{2:30 p.m.}

\section{A New Gene Controlling Flowering Time in Lettuce (Lactuca} sativa)

Edward J. Ryder*; U.S. Dept. of Agriculture, Agricultural Research Service, 1636 E. Alisal St., Salinas, CA 93905

Genes for early flowering have been reported in several plant species, including pea, turnip rape, wheat, rice, soybean, and common bean. In lettuce, two genes for flowering time have been reported previously. Both genes are partially dominant, encompassing a total range of $\approx 100$ days of flowering time. The double dominant genotype, Ef-1Ef-1Ef-2Ef-2, is the earliest flowering combination of the two genes. In summer in the greenhouse, the two genes reduce flowering time to about 45 days, as compared to $\approx 140$ days for a normally flowering crisphead lettuce. A population of the genetic line $87-41 \mathrm{M}$, which combines a gene for endive-like leaf with the early flowering trait, produced plants with an earlier flowering time than expected. One plant was crossed with another early flowering line, D-3-22M. Investigation of the $F_{2}$ and of $F_{3}$ families showed that a third dominant gene was segregating, which reduced flowering time by $\approx 9$ days from that of the double dominant genotype of the original material. Also, the height of the seed stalk was reduced by about ten centimeters. The usefullness of early flowering genes as an educational tool and as a means of accelerating the breeding cycle will be discussed.

\section{2:45 p.m.}

Molecular Cloning and Characterization of a cDNA Encoding Gibberellin 3 beta -hydroxylase from Potato (Solanum tuberosum)

Seo Hyo-Won ${ }^{* 1}$, Cho Hyun-Mook, Yi Jung-Yoon, Cho Ji-Hong, Hahm Young-Il, and Park Kuen-Woo; ' Dept. of Horticultural Science, Korea Univ., Seoul 136-075, South Korea

Gibberellin (GA) 3 beta -hydroxylase is one of the key regulatory enzyme in the GA biosynthetic pathway. We identified two distinct potato (Solanum tuberosum) genes encoding GA 3beta-hydroxylase, in correspond to previous report of two genes in tomato seedling. The genes, designated to $\mathrm{St} 3 \mathrm{bOH}-1$ and $\mathrm{St} 3 \mathrm{bOH}-2$, have a high similarity in sequence with tomato genes $\mathrm{Le} 3 \mathrm{OH}-1$ and $\mathrm{Le} 3 \mathrm{OH}-2$, respectively. This GA 3beta-hydroxylase gene family regulate the conversion of GA20 to active GA1. Tuberization in potato is promoted by short photoperiod, by nitrogen deficiency, and is inhibited by endogenous

The program schedule and abstracts are presented in chronological order and presenting authors are indicated by asterisks (*).

An index of all participants listed in the program by page number is provided at the end if this issue.
GA1. Using northern blot analysis, we detected the different patterns of tissue-specific mRNA transcripts that corresponding to those genes. The expression of two genes were shown different patterns during the growth and tuberization stages. The $\mathrm{St} 3 \mathrm{bOH}-1$ transcripts were shown stable expression level in leaf and stolen tissue during the growth and tuberization stage. But the St $3 \mathrm{bOH}-2$ mRNA drastically decreased in stolon and leaf of potato plant of the early tuber-inducing stage. This observation suggests that GA 3beta-hydroxylase encoded by St3bOH-2 might play a major role in the control of tuberization by regulation of the active GA1 biosynthesis.

\section{3:00 p.m.}

\section{Marker-aided and Phenotypic Selection for Multiple Lateral} Branching in Cucumber

Gennaro Fazio, and Jack Staub*; USDA/ARS Dept. of Horticulture, Univ. of Wisconsin, Madison; WI 53705

Yield increase in processing cucumber (Cucumis sativus L.) is positively correlated with increased number of fruit bearing branches per plant. Multiple lateral branching (MLB) is controlled by at least five factors. The objective of this investigation was to determine if marker-assisted selection (MAS) could be effective as an indirect selection tool for MLB in processing cucumber, and to identify the map position of other yield and quality components. Using previously identified SSR, STS and RAPD markers (5), MAS was practiced on a $B C_{1}$ population to produce $B C_{2}$ families and on a $B_{2}$ population to produce $\mathrm{BC}_{3}$ families. The $\mathrm{BC}_{2}$ and $\mathrm{BC}_{3}$ families resulting from MAS $\left(\mathrm{BC}_{2} \mathrm{MAS}, \mathrm{BC}_{3} \mathrm{MAS}\right)$ were compared to $\mathrm{BC}_{2}$ and $\mathrm{BC}_{3}$ families developed through phenotypic selection $\left(\mathrm{BC}_{2} \mathrm{PHE}, \mathrm{BC}_{3} \mathrm{PHE}\right)$ and to control $\mathrm{BC}_{2}$ and $\mathrm{BC}_{3}$. families $\left(\mathrm{BC}_{2} \mathrm{RND}, \mathrm{BC}_{3} \mathrm{RND}\right)$ selected randomly from the same source populations. Although no significant differences between phenotypic and marker aided selection were detected, both treatments were higher than the random control. These data indicate that MAS can be useful for MLB selection in cucumber. The mean MLB for $\mathrm{P}_{1}$ (G421), $\mathrm{P}_{2}(\mathrm{H} 19), \mathrm{F}_{1}, \mathrm{BC}_{2} \mathrm{PHE}$, $\mathrm{BC}_{3} \mathrm{PHE}, \mathrm{BC}_{2} \mathrm{MAS}, \mathrm{BC}_{3} \mathrm{MAS}, \mathrm{BC}_{2} \mathrm{RND}$, and $\mathrm{BC}_{3} \mathrm{RND}$ were $7.4,1.5$, $4.7,3.0,3.3,3.1,3.1,2.2$, and 2.4, respectively. The map position of yield and quality components such as fruits/plant, fruit length diameter ratio, days to anthesis, and sex-expression were mapped using a set of 170 recombinant inbred lines.

\section{3:15 p.m.}

\section{Plant Regeneration and Transformation of Galia Melon} (Cucumis melo L.)

H. Nunez-Palenius, D.J. Cantliffe, and H.J. Klee, Horticultural Sciences Dept., Univ. of Florida, IFAS, PO Box 110690, Gainesville, FL 32611-0690

There are more than 70 different published protocols on in vitro melon regeneration. Some report a regeneration frequency up to $73 \%$ (Guis et al., 2000), but others have failed to obtain plants with some cultivars (Oridate et al., 1992). This difference can be due to differential sensitivity of in vitro melon to ethylene and GA, which inhibit shoot initiation. We have obtained a regeneration system by organogenesis for Galia melon female and male parental lines. This involved inhibition of GA and ethylene action, in order to induce the greatest number of shoots. Regeneration frequency up to $90 \%$ for both parental lines was obtained using this system. Mature seeds were surface-disinfected with $70 \%$ ethanol, followed by $3 \%$ (v/v) sodium hypochlorite and then rinsing with sterile distilled water. Sterile mature cotyledons were cut in two pieces, which were placed onto regeneration medium containing MS salts and vitamins, sucrose $30 \mathrm{~g} \cdot \mathrm{L}^{-1}$, agar $7 \mathrm{~g} \cdot \mathrm{L}^{-1}$. We tested 5 different levels of 1-naphthaleneacetic acid (NAA) and 5 of 6 benzylaminopurine (BA) under a factorial experimental design, in order to obtain the best combination for initiation shoots and elongation. Four levels of Indol-3-acetic acid (IAA) and NAA were evaluated for their effect on rooting under a factorial experimental design. We transitorily transformed melon cotyledons with Agrobacterium containing the gene Gus. NAA at $0.0054 \mu \mathrm{m}$ and $4.44 \mu \mathrm{m}$ BA gave the maximum shoot initiation ( $>90 \%)$. Root initiation was greatest with 1 $\mathrm{mg} \cdot \mathrm{L}^{-1}$ IAA and $8 \mathrm{~g} \cdot \mathrm{L}^{-1}$ agar (100\% in 7 days) for the female parental 
line. For the male parental line the best combination was $10 \mathrm{mg} \cdot \mathrm{L}^{-1}$ IAA with all agar levels (100\% in 6 days). Transformed cotyledons developed shoots, which were Gus positive. It is proposed that this system can be applied with equal success to all melon lines.

3:30 p.m.

Improvement of Lettuce Regeneration and Rooting after Transformation

Ivanka Kozareva*1, Daniel J. Cantliffe ${ }^{1}$, Antonio C. Torres ${ }^{2}$, and Russell T. Nagata'; ${ }^{1}$ Horticultural Sciences Dept., Univ. of Florida, IFAS, PO Box 110690, Gainesville, FL 32611-0690; '2EMBRAPA/ CNPH PO Box 218, Brazilia-DF, 70359-970 Brazil

There have been several reports describing methods for lettuce plant regeneration after transformation (Michelmore et al., 1987; Torres et al., 1993; Curtis et al., 1994), along with numerous reports utilizing these methodologies for transformation. The objective of the present work was to improve regeneration and rooting efficiency after transformation of lettuce. Sterile seeds of South Bay (S.B.) (crisphead type), Everglades (EVE), and Dark Green Boston (DGB) (butterhead types) were germinated at $25^{\circ} \mathrm{C}$, light intensity- $40-60$ $\mu \mathrm{mol} \cdot \mathrm{m}^{-2} \cdot \mathrm{s}^{-1}$ and 16 hours of light on media, supplemented with $0.7 \%$ Phytagar. After two days, cotyledons were excised and placed on regeneration medium containing MS salts at $4.3 \mathrm{~g} \cdot \mathrm{L}^{-1}$, sucrose- 30 $\mathrm{g} \cdot \mathrm{L}^{-1}$, and 6-Benzylaminopurine (BA)- $0.2 \mathrm{mg} \cdot \mathrm{L}^{-1}$. On this medium, EVE and DGB had $53 \%$ and $56 \%$ regenerants, respectively, as compared to $65 \%$ for S.B. Reducing the BA concentration from 0.2 to 0.05 or $0.1 \mathrm{mg} \cdot \mathrm{L}^{-1}$ significantly increased the number of regenerants to $78 \%$ and $69 \%$ respectively for EVE and $74 \%$ and $73 \%$ respectively for DGB. Decreasing MS salts and sucrose concentrations by $50 \%$ from the generally used method increased rooting of DGB from $8 \%$ to $20 \%$ and of S.B. from $3 \%$ to $63 \%$. Use of 1 -naphthaleneacetic acid (NAA) $-0.2 \mathrm{mg} \cdot \mathrm{mL}^{-1}$ in place of indole-3-butyric acid (IBA)- $0.5 \mathrm{mg} \cdot \mathrm{L}^{-}$ ${ }^{1}$ led to a decrease in the percentage of rooted plants. Medium containing $50 \%$ of the normal MS salts concentration, $10 \mathrm{~g} \cdot \mathrm{L}^{-1}$ sucrose, and dipping the stem into $0.25 \mathrm{IBA} \mathrm{mg} \cdot \mathrm{mL}^{-1}$ led to plant rooting levels of $80 \%$ for S.B., $63 \%$ for EVE and $31 \%$ for DGB. High frequency shoot and root formation was observed in both butterhead and crisphead lettuce types.

\section{3:45 p.m.}

Sweetpotato Genetic Diversity in Northeastern Uganda: Germplasm Collection, Farmer Knowledge, and Morphological Chracterization

Putri E. Abidin ${ }^{\star 1}$, and Edward E. Carey ${ }^{2} ;{ }^{1}$ Lecturer at Arapai Agricultural College, Soroti, Uganda; ${ }^{2}$ Dept of Horticulture, Forestry and Recreation Resources, Kansas State Univ.

Sweetpotato germplasm was collected at sites in five districts of northeastern Uganda, and subsequently evaluated at an experimental field in the same region. Farmer participatory methods were used to identify cultivars to be collected and to obtain information from farmers about them. Two hundred six accessions with 124 different names were collected for evaluation. Farmers identified various horticultural and culinary attributes of their cultivars as important. These included relative earliness or lateness of production, resistance to pests and diseases, drought tolerance, perishability, root dry matter content, and suitability for cultivation on sand or clay soils. Many more accessions were collected from relatively remote rural areas, than from areas with good access to main roads, where a few commercially important cultivars predominated. All accessions were planted in a multiplication nursery and subsequently in an observational trial for evaluation of morphological characteristics and duplicate identification. Morphological descriptors of accessions were analysed using NTSYS, and similarity coefficients were calculated. Of the 206 accessions assessed, 17 were classified as identical and 28 as near duplicates, while the remainder were distinct accessions, with similarity coefficients of less than 0.9 . Results of germplasm collection and characterization will be presented, and implications of these findings for conservation and utilization of sweetpotato genetic diversity will be discussed.
2:00-6:00 p.m. CC 202

Workshop 16: Ornamental or Invasive: Managing Invasive Plants of Horticultural Origin

Working Group Sponsor: Ornamentals/Landscape and Turf (O/LT) Presiding: Tom Fernandez, Dept. of Horticulture, Michigan State Univ., East Lansing

Summary: Invasive plants "can, have, or are likely to spread into native flora or managed plant systems, develop self-sustaining populations, and become dominant and/or disruptive to those systems." Methods to identify potential invasives, manage invasives, and regulatory and industry perspectives regarding invasives introduced as ornamental plants will be discussed.

2:00 Introduction Tom Fernandez

2:05 Invasive Pest Plants of Horticultural Origin

Carl Bell and Cheryl Wilen; Univ. of California Cooperative Extension

2:30 The Challenge of Trying to Reach Consensus on Assessing Which Non-native Plants are Invasive in Natural Areas

Alison M. Fox* and Randall K. Stocker; Agronomy Dept. and Center for Aquatic Plants, Univ. of Florida, Gainesville, Fla.

The Florida Exotic Pest Plant Council's (FLEPPC) List of Florida's Most Invasive Species is an important tool for conservationists and land-managers needing to set priorities for vegetation management programs. For each species, a committee of botanical and land-management experts evaluates its ecological impact on native communities. This list includes some commercially important plants, and when adopted as the basis for local ordinances questions have been raised by members of the horticulture industry concerning the lack of written criteria and type of evidence used for placing species on this list. Recently, the University of Florida (UF) released a questionnaire designed to assess aspects of non-native plants currently found in Florida, including ecological impacts, potential for expansion, management difficulty, and commercial value. The purpose of this assessment is to provide a transparent and defendable basis from which both weed scientists and horticulturalists can develop mutually acceptable recommendations for action concerning plants that are becoming established in natural areas. For undeniably problematic species such as Melaleuca quinquenervia, the conclusions of this assessment will be similar to those of the FLEPPC listing process, but such agreement is less likely for species such as Asparagus densiflorus. Such differences reflect the precautionary intent of the FLEPPC lists, as compared to the application of a broader set of criteria and the much stricter requirements for documentation of evidence in the UF assessment. Initial evaluations of 20 species using the UF assessment have been compared with their status on the FLEPPC lists. As improvements to the assessment are identified, this document will continue to evolve, and to accommodate such flexibility a web-based version is being developed.

2:55 Status and Direction of Government Initiatives on Invasive Plants-An Industry Perspective

Craig Regelbrugge; American Nursery \& Landscape Association

3:20 Meeting the Challenge of the Plant Protection Act: A Collaboration Between Industry and Government

Tom Bewick, USDA CRSEES PAS

3:45 Controlling the Slow-motion Explosion-Management of Invasive Plants of Horticultural Origins

Ed McWilliams; Texas A\&M Univ.

4:10 Management and Control of Invasive Exotics

Steven Dewey; Utah State Univ.

4:35 Assessing Invasive Potential in Plants: Theory and Practice Sarah Reichard; Univ. of Washington

5:00 Panel Discussion

HortSCience, Vol. 36(3), June 2001 
2:30-3:30 p.m. CC 303

\section{Emerging Issues Committee Meeting}

Chair: John W. Kelly

2:30-4:30 p.m. CC 302

Research Advisory Council

Chair: William R. Woodson

2:30-4:30 p.m. CC 317

\section{ASHS Editorial Coard Meeting}

Chair: Jules Janick

2:30-4:30 p.m. CC 318

\section{Extension Advisory Council}

Chair: Mary L. Lamberts

3:30-4:30 p.m. CC 303

\section{Horticultural Landmarks Committee}

Chair: Paul E. Read

4:00-4:30 p.m. CC 316

Business Meeting of the Vegetable Breeding (VGBR) Working Group

Chair: Teddy E. Morelock

4:30-5:00 p.m. CC Ballroom

\section{Networking Coffee Break}

Sponsored by: AgraQuest

5:00-7:00 p.m. CC 317

APS Executive Board and Advisory Council Meeting Presiding: David M. Hunter

5:00-6:00 p.m. CC Ballroom

\section{Poster Session 9: Genetics/Breeding/Biotechnology}

Poster 19

\section{Fragaria Species Differ in DNA Content}

Robert H. Bors' and J. Alan Sullivan ${ }^{* 2} ;{ }^{1}$ Univ. of Saskatchewan, Sask, Canada; ${ }^{2}$ Univ. of Guelph, Ont., Canada

Flow cytometry was used to determine DNA content of diploid $(F$. daltoniana, F. gracilis, F. iinumae, F. nilgerrensis, F. nipponica, $F$. nubicola, F. pentaphylla, F. viridis, F. vesca), tetraploid (F. orientalis), hexaploid ( $F$. moschata), and octoploid ( $F$. chiloensis, $F$. virginiana). Fragaria species to provide a baseline for determining ploidy level of interspecific hybrids and colchiploids. Fragaria species ranged from $0.62 \mathrm{pg}$ ( $F$. chiloensis, $F$. virginiana, and $F$. nubicola) to $0.82 \mathrm{pg}$ DNA/ genome ( $F$. daltoniana). The 22 diploid accessions varied by as much as $0.23 \mathrm{pg}$ DNA/genome while the nine octoploid accessions varied by only $0.12 \mathrm{pg} \mathrm{DNA} /$ genome. This variability among species indicates that ploidy levels of interspecific tetraploids and octoploids need to be based on a comparison for DNA levels with their parental species rather than natural tetraploids or octoploids. The lower DNA/genome levels for octoploid species could indicate that DNA has been lost in their evolution or that octoploids evolved from the species with lower levels of DNA. Comparison of 242 samples having primary (G1 period cells) and secondary (G2 period plus mitotic cells) peaks indicated that a doubling in ploidy results in flow cytometry readings being $\approx 3 \%$ lower than expected $\left(R^{2}=0.9829\right)$. This discrepancy should be taken into account when estimating ploidy levels of colchiploids. The flow cytometry protocol developed was successfully used to differentiate ploidy levels of interspecific hybrids and colchiploids.

\section{Poster 20}

Abundance of Simple Sequence Repeats (Microsatellites) in Strawberry
Shiow Y. Wang ${ }^{\star 1}$, Perry B. Cregan ${ }^{2}$, Hongjun Jiao ${ }^{1}$, Edward Fickus ${ }^{2}$, Richard W. Jones ${ }^{3}$ and Stan Hokanson'; ${ }^{1}$ Fruit Laboratory, ${ }^{2}$ Soybean Genomics and Improvement Laboratory, and ${ }^{3}$ Vegetable Laboratory, U.S. Dept. of Agriculture, Agricultural Research Service, Beltsville Agricultural Research Center, Beltsville, MD 20705-2350

Simple Sequence Repeat (SSR) DNA markers, also known as microsatellites or Short Tandem Repeats (STR), have been used successfully for the purpose of genotype identification in plants; however, no SSR research has previously been performed in strawberry. We initiated a research project involving the screening of genomic DNA from a variety of strawberry genotypes including a Fragaria $x$ ananassa type, 'Earliglow', a F. virginiana type, 'Fra 23'(RH23), a F. chiloensis type, 'Pigeon Point', and a F. vesca type, the virus indicator UC5, to determine the abundance of several di, tri-, and tetrameric SSR motifs. The DNA samples were digested with EcoR I, Rsa I and Hinf I, and labeled (32P) oligonucleotide probes complementary to di-, tri-, and tetrameric repeats were hybridized to Southern blots of digested DNAs. Various SSRs were evident among the different genomic DNA samples tested. Among the di-nucleotide motifs, (CA/GT)n and (CT/GA)n appeared to be the most abundant repeats. With regards to tri-nucleotide motifs, (GGA/CCT)n and (GAA/CTT)n were apparently the most abundant repeats, followed by (CAC/GTG)n, (CAA/GTT)n, and (CGT/GCA)n. Meanwhile (TAA/ATT)n, (CGA/GCT)n, (ATG/TAC) and (GAT/CTA)n were the least common repeats in strawberry genomic DNA. Limited hybridization of the tetranucleotides, (GATA/CTAT)n, (TAGA/ATCT)n, and (GAAT/CTTA)n, was observed to the strawberry genomic DNA, possibly due to their low frequency in the genomes examined.

\section{Poster 21}

L'Authentique Orleans: A New Strawberry Cultivar with High Levels of Antioxidants

Shahrokh Khanizadeh', Louis Gauthier', Johanne Cousineau', Deborah Buszard ${ }^{3}$ and Claire Hebert'; ${ }^{1}$ Agriculture and Agri-Food Canada, 430 Blvd. Gouin, St-Jean-sur-Richelieu, QC., Canada J3B 3E6; 'Les Fraises de l' lle d'Orleans Inc., St-Laurent, Ile d'Orleans, QC, Canada, GOA 3Z0; ${ }^{3}$ Dept. of Plant Science, McGill Univ., SteAnne-de-Bellevue, QC, Canada, H9X 1 CO.

A new project was started in 1996 by Agriculture and Agri-Food Canada, Les Fraises de l'île d'Orleans Inc. and McGill Univ. to develop firm strawberry cultivars with a long shelf life suitable for transportation. Initially, five selections (FIO-9623-55, FIO-9524-74, FIO-968-1, FIO-9624-11, FIO-9623-40) were retained and entered into advanced trials. FIO-9623-55 was re-selected for its good shelf life and high yields of firm, large fruit. Selection FIO-9623-55 is being released under the name 'L'Authentique Orléans'. It is a Junebearing strawberry cultivar (Fragaria $x$ ananassa Duch.) bred for Eastern Central Canada and more specifically for lle d'Orleans growing conditions. 'L'Authentique Orléans' is a progeny resulting from a cross between two recently released cultivars from our station, 'AC-L'Acadie' and 'AC-Yamaska', made by S. Khanizadeh. 'L'Authentique Orléans' has been tested at the Agriculture and AgriFood Canada substation in L'Acadie, Quebec and at Île d'Orleans, Quebec, since 1997. It outyielded 'Annapolis' and 'Kent' in both trials and had the highest levels of the antioxidants ellagic acid, gallic acid, catechin and epicatechin compared to 23 other strawberry cultivars tested including 'Kent' and 'Annapolis'. Additional information on this new cultivar can be obtained from Les Fraises de l' île d'Orleans Inc. (LG) or from Agriculture and Agri-Food Canada (SK).

Poster 22

Potential for the Domestication of Western Huckleberries Danny L. Barney*; Plant, Soil, \& Entomological Sciences Dept. Univ. of Idaho, Sandpoint, ID 83864

Several species of western huckleberries show potential for cultivation as fruit crops. Black huckleberry (Vaccinium membranaceum Douglas ex Hooker) and blue huckleberry ( $V$. deliciosum Piper) were used for food and trade by Native Americans 
in the northwestern United States and western Canada. Recent commercial demand for the fruits has increased significantly, primarily because the ester-rich berries have strong, highly desirable flavors. Because of their reputed anthocyanin contents, the leaves are also in limited commercial demand. Presently, all fruit and leaves are harvested from the wild. Restrictions on logging and access to public lands have limited harvests and reduced crops, creating shortages in the commercial market. Oval-leaved blueberry ( $V$. ovalifolium Smith) lacks the fruit qualities of the other species, but is highly adaptable, growing from sea level to $2100 \mathrm{~m}$ elevation, from the seacoast to inland subalpine areas. All three species appear to readily interbreed. $V$. membranaceum and $V$. deliciosum have desirable fruit qualities, while $V$. ovalifolium parents may provide site adaptability, higher yields, taller canes, and erect habit. Progress toward domestication of the species is described.

\section{Poster 23}

Anthocyanins, Phenolics and Oxygen Radical Absorbing Capacity of Berry Germplasm

Richard A. Moyer ${ }^{1}$, Kim E. Hummer ${ }^{* 2}$, Ronald E. Wrolstad ${ }^{3}$, and Chad E. Finn ${ }^{4}$; ${ }^{1}$ King College, 1350 King College Road, Bristol, TN, 37620; '2USDA, ARS, NCGR 33447 Peoria Road, Corvallis, OR, 97333-2521; ${ }^{3}$ Oregon State Univ., Dept. of Food Science and Technology, Corvallis, OR, 97330; USDA, ARS, HCRL, 3420 NW Orchard Ave. Corvallis, OR, 97330

High antioxidant content of berry crops may provide human health benefits such as reduced coronary heart disease, improved visual acuity, or anti-viral and anti-cancer activity. We were greatly interested to determine the range of total anthocyanin content (ACY), total phenolic content (TPH) and oxygen radical absorbing capacity (ORAC) in diverse species and cultivar germplasm of black currants (Ribes L), blackberries and black raspberries (Rubus L.), and blueberries (Vaccinium L.). Ripe fruit was harvested from 22 June 2000 to 15 Sept. 2000 from 107 berry genotypes growing in fields in Oregon's Willamette Valley. Fruit was hand-picked, stored on ice, and frozen at $-10 \circ \mathrm{C}$ in the laboratory that same afternoon. ACY was determined by the $\mathrm{pH}$ differential method. Anthocyanin pigments were separated by high pressure liquid chromatography (HPLC). TPH was determined by the Folin-Ciocalteau method. ACY for Ribes nigrum $\mathrm{L}$. cultivars ranged from 128 to $411 \mathrm{mg} / 100 \mathrm{~g}$ fruit (mean = $231 ; n=33$ ); for Vaccinium species from 34 to $515 \mathrm{mg} / 100 \mathrm{~g}$ fruit (mean $=230 ; n=31$ ); for blackberries (Rubus hybrid) from 80 to 230 $\mathrm{mg} / 100 \mathrm{~g}$ fruit (mean $=179 ; \mathrm{n}=32$ ); for black raspberries (Rubus occidentalis L., Rubus niveus Thunb.) from 230 to $627 \mathrm{mg} / 100 \mathrm{~g}$ fruit (mean $=466 ; n=4)$. Some black currants were rich sources of ACY, though gooseberries and jostaberries were not. Small fruit size was correlated with ACY $(r=0.82)$ in highbush blueberries ( $V$. corymbosum), was but was not correlated across nine Vaccinium species $(r=0.29$ ), in Ribes nigrum $(r=0.36)$, or Rubus hybrids ( $r=$ 0.003 ). A wild collected rabbiteye blueberry, $V$. ashei Ait., had the highest ACY (515 mg/100g fruit), TPH, and ORAC of the tested Vaccinium. 'Marion' had the highest blackberry ACY $(230 \mathrm{mg} / 100 \mathrm{~g})$; Rubus occidentalis 'Munger' had the highest ACY ( $627 \mathrm{mg} / 100 \mathrm{~g}$ ) of all berries tested. TPH values (expressed as $\mathrm{mg}$ gallic acid equivalents $/ 100 \mathrm{~g}$ ) averaged 748+295 in Ribes, $521+244$ in Vaccinium and $505+179$ in Rubus. ORAC values (expressed as umoles Trolox equivalents/g) ranged from 17-116 in Ribes, 19-131 in Vaccinium, and 13-146 in Rubus. In conclusion, a wide range of ACY, TPH and ORAC levels are present within Ribes, Vaccinium, and Rubus.

\section{Poster 24}

\section{A Disease Resistance Database for Blueberry Cultivars}

Mark K. Ehlenfeldt ${ }^{\star 1}$ and Allan W. Stretch ${ }^{2} ;{ }^{1}$ Blueberry \& Cranberry Research Center, 125A Lake Oswego Road, Chatsworth, NJ08019; 2USDA-ARS, Fruit Laboratory, Beltsville, $M D$

A primary objective of the USDA breeding program has been identifying sources of disease resistance to fungal diseases. A comprehensive collection of highbush blueberry cultivars has been assembled and screened for resistance to mummy berry blight, mummy berry fruit-rot, and anthracnose fruit-rot in a nursery type setting utilizing concentrated inoculum. Screening has been fully or partially completed on 108 cultivars for mummy berry blight resistance, 68 cultivars for mummy berry fruit- rot resistance, and 87 cultivars for anthracnose resistance. Screening results are being used to build a database incorporating disease resistance, firmness, antioxidant levels, flowering time, ripening time, and other pertinent characteristics.

\section{Poster 25}

RAPD Markers Linked to the $\mathrm{Cr}$ Gene Conferring Resistance to White Pine Blister Rust in Black Currant

Deric D. Picton ${ }^{* 1}$ and Kim E. Hummer ${ }^{2} ;{ }^{1}$ Dept. of Horticulture, Oregon State Univ., Corvallis, OR 97331; 2 USDA-ARS NCGR, Corvallis, OR 97333

White Pine Blister Rust (Cronartium ribicola Fisch.), is an important disease of black currant (Ribes nigrum L.) and five needled pines (Pinus subsect. Strobus). Our objective was to identify RAPD markers linked to the $\mathrm{Cr}$ gene that confers rust resistance in Ribes. Bulked segregant analysis of an $F_{1}$ population of black currants 'Ben Lomond' (rust susceptible) X 'Consort' (rust heterozygous resistant) was performed. Resistance/susceptibility for parental genotypes and $F_{1}$ 's was determined by artificial inoculation in greenhouse and growth chamber using aecial and uridinial spores from local rust sources. DNA from leaves of parental and bulked $F_{1}$ genotypes was screened with 200 Univ. of British Columbia RAPD primers. Eight primers produced distinct polymorphic banding patterns in parental genotypes. Markers linked to the $\mathrm{Cr}$ gene are being identified and will be reported. These markers could aid in identification of rust resistant black currants and for investigation on resistance mechanisms in diverse Ribes species.

\section{Poster 26}

Agrobacterium-mediated Transformation of 'Marion' Blackberry Rengong Meng ${ }^{* 1,2}$, Tony H.H. Chen ${ }^{\star 2}$, and Chad E. Finn ${ }^{* 1,2 ; 1}$ USDA/ ARS HCRL, 3420 NW Orchard Ave., Corvallis, OR 97330; ${ }^{2}$ Dept.of Horticulture, 4017 ALS, Oregon State Univ., Corvallis, OR 97331

Using an in vitro regeneration system optimized for 'Marion' trailing blackberry (Rubus sp. L), we have attempted to develop an Agrobacterium-mediated transformation protocol for this important blackberry cultivar. We tested a series of hygromycin and kanamycin concentrations and found that hygromycin $>8 \mu \mathrm{g} \cdot \mathrm{mL}$ and kanamycin $>40 \mu \mathrm{g} \cdot \mathrm{mL}$ completely inhibited the in vitro regeneration of shoots. Three Agrobacterium tumefaciens strains: EHA105 (pGiPTVHP+), EHA105 (pTOK47/pGiPTVHP+), and LBA4404 (pTOK233), each carrying an intron-interrupted uidA (GUS) gene encoding betaglucuronidase and the appropriate antibiotic resistant genes as selection markers, were used for transformation. Each Agrobacterium strain was grown in YEP medium for 2-3 days, and then resuspended in AAM medium containing $100 \mu \mathrm{m}$ acetosyringone. Leaf explants were cut, cocultivated with Agrobacterium cells, and then cultured on an antibiotic selection medium. Three factors were examined for their effects on transformation efficiency, they were: 1) the length of time that Agrobacterium cells were incubated in AAM medium with $100 \mu \mathrm{m}$ acetosyringone (15,30,60 $\mathrm{min}) ; 2$ ) the number of days for cocultivation $(3,6,9,12,15 \mathrm{~d})$; and 3$)$ the acetosyringone concentration $(100,200,400,800 \mu \mathrm{m})$ in the cocultivation medium. The Agrobacterium strain did not seem to have significant effect on transformation as the number of regenerated shoots per 100 explants was 5, 4, and 7 for EHA105 (pGiPTVHP+), EHA105 (pTOK47/ pGiPTVHP+), and LBA4404 (pTOK233), respectively. Putative transgenic (antibiotic resistant) shoots were assayed for the expression of the GUS activity and $1.7 \%$ of the shoots from LBA4404 (pTOK233) were GUS-positive, whereas the shoots from other Agrobacterium strains were all GUS-negative. The best result, as indicated by the highest percentage of GUS-positive shoots, was obtained with the incubation of Agrobacterium cells for 30 minutes in the AAM medium containing $100 \mu \mathrm{m}$ acetosyringone, followed by 6 
days of cocultivation on medium with $400 \mu \mathrm{m}$ acetosyringone, and finally, selected on the medium with $8 \mathrm{mg} / \mathrm{L}$ hygromycin. Efforts are being made to further improve the rate of transformation and characterization of putative transgenic blackberry plants.

\section{Poster 27}

Performance of Sweet Cherries (Prunus avium L.) on a Dwarf Chinese Cherry (Prunus Pseudocerasus L.) Rootstock in Field and Plastic Greenhouses

Yongbing Yuan ${ }^{1}$, Chenglian Liu ${ }^{* 1}$, and Zhiguo Ju2 ; ${ }^{1}$ Dept. of Horticulture, Laiyang Agricultural College, Laiyang, Shandong Province, China; ${ }^{2}$ USDA ARS Tree Fruit Research Lab, 1104 N. Western Ave., Wenatchee, WA 98801

'Laiyang Dwarf' is a cultivar selected from Chinese cherry (Prunus pseudocerasus L.) in 1981 and released in 1991 in China. Compared with regular Chinese cherries, Laiyang Dwarf reduces tree height by $40 \%$ to $50 \%$. Height of a six-year-old tree is about $1.8 \mathrm{~m}$ and 42 -yearold tree is $\approx 2.8 \mathrm{~m}$. As rootstock, it is compatible with sweet cherries and reduced tree height by $40 \%$. Compared with standard rootstocks such as Colt, using 'Laiyang Dwarf' as rootstock also advanced fruit maturity and reduced 'root cancer' disease without affecting fruit quality. 'Laiyang Dwarf' or sweet cherries grafted on 'Laiyang Dwarf' are widely grown in plastic greenhouse in China and fruit maturity was advanced by 20 to 60 days depending the temperature control in the greenhouse.

\section{Poster 28}

The S-ribonuclease Gene of Sweet Cherry is Expressed in Anthers and Germinating Pollen Tubes

Lili Zhou*, Paul A. Wiersma, Guus Bakkeren, Cheryl Hampson, and Frank Kappel; Agriculture and Agri-Food Canada, Pacific Agriculture Research Centre, Summerland, B.C.

Self-incompatibility in sweet cherry is controlled by a single genetic locus (S locus) with many alleles. Rejection of pollen occurs when the single $S$ allele present in the haploid pollen grain matches either of the S alleles present in the diploid tissues of the pistil. These $S$ alleles code for S-ribonucleases (S-RNases) which are style specific proteins necessary for rejection of self pollen in the style of sweet cherry. To understand the mechanism of self-incompatibility in sweet cherry, we investigated the expression of various $\mathrm{S}$ alleles in different tissues of a self compatible cultivar, Lapins, and two self-incompatible cultivars, Early Burlat and Salmo. Using RT-PCR on total RNA preparations, expression of the S-RNases was found as expected in styles but also in developing anthers of Lapins, Salmo, and Early Burlat cultivars, as well as germinating pollen tubes of 'Lapins'. cDNA clones representing the coding region for mature $\mathrm{S} 1$ and $\mathrm{S} 4$ protein were obtained from the anthers of 'Lapins', and S3 from 'Early Burlat' respectively. Sequence analysis indicated that they are identical to the S-RNases from style previously reported. No sequence difference was found between self-incompatible and self-compatible cultivars.

\section{Poster 29}

Characterization and cDNA Cloning for Style-specific S-like RNases of Sweet Cherry

H. Yamane ${ }^{* 1}$, R. Tao ${ }^{1}$, H. Mori ${ }^{2}$, and A. Sugiura ${ }^{1} ;{ }^{1}$ Graduate School of Agriculture, Kyoto Univ., Kyoto, Japan; ${ }^{2}$ Graduate School of Bioagricultural Science, Nagoya Univ., Japan

In this study, we identified basic S-like RNases in the style of sweet cherry (Prunus avium L. cv. Satohnishiki), which has an RNase based self-incompatibility system. Two S-like RNase spots with molecular weight and pl similar to those of S-RNases were found in 2D-PAGE profiles of stylar extracts. These S-like RNase spots reacted with the anti-S4-serum raised against S4-RNase of Japanese pear, as did SRNases of sweet cherry. In contrast to S-RNases, however, these Slike RNase spots were not glycoproteins that react with Concanavalin A. Two kinds of cDNAs encoding these S-like RNases were cloned based on their internal amino acid sequences. The deduced amino acid sequences from the cDNAs contained two histidine residues that are essential for RNase acitivity in the T2/S-RNase superfamily.
However, they shared only about $30 \%$ sequence identity with SRNases of sweet cherry although S-RNases of sweet cherry shared about $70 \%$ identity with each other. The S-like RNases also shared about 30\% identity with S-RNases of other Rosaceae species and Solanaceae, and other S-like RNases. RNA blot analysis revealed that the S-like RNase genes, in contrast to many other S-like RNase genes, were specifically expressed in the style. At least four bands were detected with DNA blot analysis using the cDNAs as probes, suggesting the presence of a multigene family of S-like RNase genes in sweet cherry. Possible biological functions of S-like RNases, such as disease resistance and RNA turn over in style, are discussed.

\section{Poster 30}

\section{Genetic Structure and Differentiation in Cultivated Grapes,} Vitis vinifera $\mathrm{L}$.

Mallikarjuna K. Aradhya ${ }^{1 *}$, Bud Dangl', Bernard H. Prins ${ }^{2}$, and

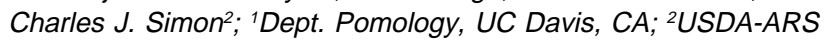
Germplasm Repository, Davis, CA

Genetic diversity and differentiation within the cultivated grapes, V. vinifera L. was assessed using SSR markers. A total of 426 accessions representing a wide range of distribution of cultivated grapes including ten accessions of the wild form of $V$. vinifera $s p$. sylvestris (C.C. Gmelin) Berger and twelve of vinifera $x$ sylvestris hybrids were fingerprinted for eight SSR loci. The data from a subset of 244 unique genotypes were subjected to genetic diversity and structure analyses. Examination of multivariate relationships among accessions using a cluster analysis resulted in the identification of three major clusters and a number of sub-clusters within each cluster. The French wine grapes formed a unique cluster along with a number of mostly Greek and Italian wine grapes and exhibited a greater affinity towards the wild and hybrid forms. Table grapes including some of the seedless types along with some European table grapes formed the second major cluster. The rest of wine types from southern and eastern European regions formed a third cluster. Further analysis of genetic diversity within and between different clusters and sub-clusters revealed a wide range of variation for various diversity indicators such as mean number of alleles, polymorphic index, and observed and expected levels of heterozygosity. It is evident from the hierarchical gene diversity and cluster analyses that most variation resides within clusters (85\% to $90 \%$ ) and only marginal levels (10\% to $15 \%$ ) accounts for genetic differentiation within cultivated grapes.

\section{Poster 31}

Genetic and Biochemical Analysis of Anthocyanin in Muscadine Grape

Hong Huang and Jiang Lu*; Center for Viticulture, Florida A\&M Univ., Tallahassee, FL 32307

Red wine is popular among consumers because of health benefits of anthocyanin (Acy). Color changes very rapidly in the juice, from which wine is made, due to the instability of complex system of anthocyanins. Similarly, color instability with aging is one of the major problems in producing high-quality red muscadine wines. A spectroscopic studies of scan survey and browning index for Noble (Muscadinia) and Cabernet Sauvignon (Euvitis) red wines indicated that the pigments in muscadine wine is less stable than the ones in Euvitis. In the mean time, a quantitative method to study Acy stability was developed by HPLC analysis. Results from this study demonstrated that among the five anthocyanins in Noble wine, the ones possessing methoxyl substitution in B-ring decomposed slower than those only with hydroxyl groups. In other words, the stability of the pigments increases with methoxyl substitution and decreases with hydroxyl substitution. Southern analysis indicated that muscadine grape may have different structural and regulatory genes for Acy synthesis from Euvitis.

\section{Poster 32}

Effect of Apple Maturity and Treatment Temperature on the Efficacy of 1-MCP 
D. MacLean ${ }^{* 1}$, D.P. Murr' ${ }^{1}$, and J.R. DeEII; ; Dept. of Plant Agriculture, Univ. of Guelph, Guelph, Ont., N1G 2W1, Canada; ${ }^{2}$ Ontario Ministry of Agriculture, Food and Rural Affairs, Vineland, Ont., Canada

The cyclicolefin 1-methylcyclopropene (1-MCP) is a physical antagonist to the ripening action of ethylene in pre-climacteric apple fruit. The molecular structure of 1-MCP mimics that of ethylene, and binds irreversibly to the ethylene binding protein. The application of $1-\mathrm{MCP}$ at refrigerated temperatures requires a prolonged treatment period, but enhances the effectiveness of 1-MCP during cold air storage. 'McIntosh' and 'Delicious' apples harvested at optimum maturity for long-term storage were treated with $600 \mathrm{~nL} \cdot \mathrm{L}^{-1}-\mathrm{MCP}$ at temperatures of $3^{\circ} \mathrm{C}$ or $13^{\circ} \mathrm{C}$ for $24 \mathrm{hr}$ at 3 day intervals postharvest, and subsequently stored in air for 45 and 90 days $\left(0\right.$ to $1{ }^{\circ} \mathrm{C}, 90 \%$ to $95 \%$ relative humidity). Ethylene production was inhibited significantly in 'Mclntosh' treated with $1-\mathrm{MCP}$ at $3{ }^{\circ} \mathrm{C}$ immediately after harvest and 3 days postharvest, whereas at $13^{\circ} \mathrm{C}$ appreciable inhibition of ethylene production was evident only when fruit were treated immediately after harvest. Likewise, 'Mclntosh' fruit treated at $3^{\circ} \mathrm{C}$ had greater flesh firmness retention than fruit treated at $13^{\circ} \mathrm{C}$. Effective inhibition of ethylene production was evident up to 3 days postharvest in 'Delicious', whereas retention of flesh firmness was evident up to 6 days postharvest when treated at $3{ }^{\circ} \mathrm{C}$. Thus, it appears uptake of 1 -MCP by the fruit was enhanced at $3{ }^{\circ} \mathrm{C}$, effectively prolonging the postharvest window for 1-MCP treatment.

\section{Poster 33}

Variation in Antioxidant, Total Anthocyanins, and Total Phenolics in American Hybrid and Vitis vinifera L. Seedless Table Grapes

John R. Clark*, Luke Howard, and Steve Talcott; Dept. of Horticulture and Food Science, Univ. of Arkansas, Fayetteville, AR 72701

Twenty-two seedless table grape genotypes were analyzed for oxygen radical absorbance capacity (ORAC), total anthocyanins, and total phenolics from fresh fruit samples collected in 2000. These genotypes included 19 hybrids of $V$. labrusca $L$. and $V$. vinifera, and three pure $V$. vinifera. Also among the genotypes, nine were bluefruited, five were red, and eight were white (yellow-green). The ORAC content (expressed in $\mu$ mol Trolox equivalents per gram of fruit based on fresh weight) varied from highs of 14.9 and 14.7 for A2412 and 'Mars', respectively (both hybrids), to lows of 6.7 and 7.0 for A-2053 and 'Reliance', respectively, also both hybrids. Overall means were 10.2 for the 19 hybrids, and 8.8 for the three $V$. vinifera cultivars. Means among blue-fruited genotypes were 11.9 for the eight hybrids compared to the $V$. vinifera cultivar Midnight Beauty which had an ORAC value of 11.5. For the red-fruited hybrid genotypes, the average ORAC value was 9.1 for the hybrids while the $V$. vinifera 'Crimson' Seedless' was 7.5. For the white-fruited genotypes, the hybrids averaged 8.9 in ORAC value compared to the 7.4 value for the $V$. vinifera cultivar Thompson Seedless. Total anthocyanins for the blue-fruited genotypes ranged from a high of 881.4 malvadin-3-glucoside equivalents in $\mathrm{mg} / \mathrm{kg}$ of fruit (fresh weight) for A-2412, to 223.7 for A-2312. For the red genotypes, the anthocyanin values were substantially less, and no anthocyanins were detected for the white genotypes. Total phenolics for the blue genotypes ranged from 10,987 chlorogenic acid equivalents in $\mathrm{mg} /$ $\mathrm{kg}$ of fruit (fresh weight) for A-2412, to 5,125 for A-2034. White genotypes ranged from 8,868 chlorogenic acid equivalents in $\mathrm{mg} / \mathrm{kg}$ of fruit (fresh weight) for 'Neptune', to 3,340 for A-2098. The V. vinifera genotypes fell within the ranges of the hybrids for both total anthocyanins and total phenolics.

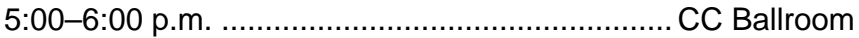

\section{Poster Session 10: Genetics/Breeding/Biotechnology Poster 34}

Effects of Diallelic Polymorphism of bot1 on Fruit Quality and Field Performance of Tomato Genotypes

Zhiping Deng and Avtar K. Handa*; Dept. of Horticulture and Land- scape Architecture, Purdue Univ., West Lafayette, IN 47906-1165

We have cloned and characterized bot1 (Bostwick 1), a gene whose expression is positively correlated with juice thinness in diverse tomato genotypes (Deng et al., Plant Biology 99 Abstract \# 919). Southern blotting indicated the presence of diallelic EcoRI polymorphism for bot1 in tomato varieties. One of the EcoR1 bot1hybridizing DNA fragment (bot1 allele) is associated with the higher accumulation of bot 1 transcripts and thinner juice, whereas the other DNA fragment [bot1 LTA (Low Transcript Accumulation) allele] with lower to undetectable levels of bot1 transcripts and thicker juice phenotype. Some of the varieties contained both bot1 and bot1 LTA alleles. The selfed progenies of these genotypes segregated in Mendelian manner suggesting that the two alleles are diallelic on the same locus of tomato genome. Progenies homozygous for bot1 or bot1 LTA alleles were identified from two independent genotypes using allele specific PCR and grown at the Purdue Research Farms to evaluate effects of the presence of these alleles on vegetative growth, fruit set, size, yield and ripening, and attributes of the processed juice. Juice from the fruits homozygous for the bot1 showed lower serum viscosity and precipitate weight ratio compared to the fruits homozygous for the bot 1 LTA allele, confirming that bot1 is associated with fruit thinness. However, no differences were observed for the $\mathrm{pH}$, NTSS and color between the fruit juices of genotypes. Fruits homozygous for bot1 LTA allele ripened slowly compared to bot1 allele, but significant effects of bot1 and bot1 LTA alleles on fruit set, weight and yield, and vegetative growth were not obtained. Taken together these results suggest that bot 1 plays roles in fruit ripening and determining attributes of tomato juice.

\section{Poster 35}

Transfer Late Blight Resistance to Processing Tomatoes Min-Jea Kim* and Martha Mutschler; Dept. of Plant Breeding, Cornell Univ., Ithaca, NY

The disease late blight (caused by Phytophthora infestans Mont.) de Bary) is an increasingly significant problem to processing tomato production. We have been working on the rapid transferal of late blight resistance from the L. pimpinellifolium accession L3708 to processing tomato populations. This source of resistance is reputed to hold up under conditions in which Hawaii 7998 source and lines possessing the $\mathrm{Ph}-2$ gene fail. In the process of transferring the resistance, we have also been testing it for stability and coverage of multiple isolates of the pathogen. The starting materials were $\mathrm{BC}_{1} \mathrm{~F}_{2}$ selections created by R. Garnder by with L. pimpinellifolium accession L3708 and the freshmarket tomato NC215E. Backcrossing with selection in the $\mathrm{BC}$ and $\mathrm{BCF}_{2}$ generations was used in transferring the resistance. Several processing tomatoes were used in the backcrosses, to generate populations with the potential for different characteristics. Field and lab screens for Late Blight were both used for selections, allowing use of multiple isolates of the pathogen. The breeding program has resulted in the creation of a series of lines fixed for strong resistance to late blight. There was no relationship between indeterminant or any other visually scorable trait and late blight resistance. Lab and field trials in NY, NC, and CA show that the lines have good resistance to all isolates of the pathogen tested to date. Tests by cooperators in California show that the lines are nearing the type needed for processing inbreds. A number of these lines had Brix levels that matched or exceeded the cultivated hybrid controls, and also increased viscosity levels.

\section{Poster 36}

Introgression of the Genes for Sesquiterpene Carboxylic Acids Into Cultivated Tomatoes for Enhanced Insect Resistance

James E. Frelichowski, Jr. ${ }^{*}$ and John A. Juvik; 311 Edward R. Madigan Laboratory, Urbana, IL

The sesquiterpene carboxylic acids (SCA), (+)-(E)- $\alpha$-santalen12-oic, $(-)-(E)$-endo- $\alpha$-bergamoten-12-oic and $(+)-(E)$-endo- $\beta$ bergamoten-12-oic acid, are produced in glandular trichomes of Lycopersicon hirsutum f. typicum accession LA 1777, which is highly 
resistant to a range of pests of cultivated tomatoes, $L$. esculentum, L. hirsutum f. typicum LA 1033 is susceptible to insects and does not produce these SCA. Selected $F_{2}$ genotypes of the cross LA $1033 x$ LA 1777 were used as a source of leaflet tissue to assay foliar SCA content and corresponding survival of larvae of tomato fruitworm [Helicoverpa zea (Boddie)] and beet armyworm [Spodoptera exigua (Hübner)], two economically important lepidopteran (Noctuidae) pests of cultivated tomatoes. Strong correlations were observed between mortality and SCA content of leaflets, and levels exceeding $2 \mathrm{mg}$ of SCA per $\mathrm{g}$ of fresh leaf weight were effective in significantly reducing larval survival. Repeated measurements of this $F_{2}$ and $a$ second of the cross of $L$. esculentum $\times$ LA 1777 were used to assess the effect of genotype, environment, and their interaction on the foliar SCA level. Within each population, DNA was pooled of the $F_{2}$ genotypes with similar levels of SCA and subjected to bulked segregant analysis. Bulked DNA was the template for PCR reactions using an amplified fragment length polymorphism (AFLP) protocol. Polymorphisms were identified between the bulks to putatively identify loci linked to genes governing the presence and amount of SCA. Marker assisted backcrossing using the AFLP markers would expedite the introgression of these loci, from LA 1777, into cultivated tomatoes and ensure their selection in cultivar development for high SCA as a mechanism for enhanced insect resistance.

\section{Poster 37}

Enhancement of Bacterial Wilt Resistance in Transgenic Tomato Plants Expressing Non-plant Antibacterial Lactoferrin Gene

Tae-Jin Lee, Dermot P. Coyne*, Thomas E. Clemente, and Amitava Mitra; Univ. of Nebraska, Lincoln, NE 68583

Expression of human lactoferrin (HLF) gene, a cationic iron-binding glycoprotein, was investigated in transgenic tomato plants (Lycopersicon esculentum Mill.). The resistance of the transgenic tomato plants to the pathogen (Ralstonia solanacearum) causing bacterial wilt was also determined. Tomato line F7926-96 susceptible to bacterial wilt was transformed with Agrobacterium strain C58C1 containing a plasmid construction carrying a modified HLF cDNA. The introgression of HLF cDNA into the susceptible tomato line was confirmed by Southern blot and the expression of full-length human lactoferrin transcript and protein was also detected by Northern and Western blots, respectively. Based on resistance to kanamycin, a stable Mendelian segregation for a single gene was observed in the $\mathrm{T}_{1}$ and $\mathrm{T}_{2}$ generations and all $\mathrm{T}_{1}$ and $\mathrm{T}_{2}$ plants resistant to kanamycin showed the single corresponding band of HLF CDNA in Southern blot analysis. Two transgenic tomato lines exhibited significantly enhanced resistance to bacterial wilt in comparison with susceptible tomato line. The enhancement of resistance to bacterial wilt in transgenic tomatoes with the stable Mendelian segregation patterns for the lactoferrin gene may provide a new approach to control bacterial diseases of tomato. The value of this novel gene, along with plant genes to control bacterial pathogens, is discussed.

\section{Poster 38}

Increased Resistance to Oxidative Stress in Transgenic Tomatoes (Lycopersicon esculentum) That Overexpress Mnsuperoxide Dismutase from Rubber Tree (Hevea brasiliensis) Yueju Wang ${ }^{*}$, Charles Boyer ${ }^{1}$, Lailiang Cheng ${ }^{2}$, Leslie Fuchigami', Michael Wisniewski ${ }^{3}$, Richard Meilan ${ }^{4}$, and Abhaya Dandekar ${ }^{5} ;{ }^{1}$ Dept. of Horticulture, Oregon State Univ.; ${ }^{2}$ Dept. of Horticulture, Cornell Univ.; ${ }^{3}$ USDA-ARS, West Virginia; ${ }^{4}$ Dept. of Forest Science, Oregon State Univ.; ${ }^{5}$ Dept. of Pomology, Univ. of California

To evaluate the feasibility of using engineered antioxidant enzymes as an approach to improve the resistance of plants to stress, transgenic tomato plants that express a chimeric gene that encodes $\mathrm{Mn}$ superoxide dismutase (SOD) from rubber were developed. Transformed plants produced several fold greater levels of MnSOD than the wildtype plants. The transformed plants showed greater resistance to the superoxide-generating herbicide methyl viologen and low $\left(6^{\circ} \mathrm{C}\right)$ temperatures.

\section{Poster 39}

Transferal of Acylsugar-mediated Multiple Pest Resistance to Cultivated Tomato

M.A. Mutschler*, A.M. Wally, Kathy Rojas, and E. Cobb; Dept. of Plant Breeding, Cornell Univ., Ithaca, NY

Tomatoes are attacked by a large variety of insect pests that damage the plants, reducing yields and quality. Insect pests are controlled with synthetic pesticides, a practice that is increasingly limited by evolution of pesticide-resistant insects, regulatory changes, and health and environmental concerns. The incorporation of resistance into cultivated crop species from their wild relatives provides an alternative method of pest control. Lycopersicon pennellii (Corr.) D'Arcy LA716 has high densities of type IV trichomes, and $\approx 90 \%$ of the type IV trichome exudate is comprised of a complex of acylsugars. In prior work, we showed that these acylsugars are responsible for resistance of $\mathrm{L}$. pennellii to potato and green peach aphids, silverleaf whitefly, leafminer, tomato fruitworm and the beet armyworm, and also identified 5 QTL affecting acylsugar production. In the current work described here, we report the use hybrid analysis to confirm the action of the major acylsugar QTL detected earlier and to identify of two additional unlinked QTL affecting acylsugar production. We also detail the recent success in the breeding program toward transferring acylsugar production to cultivated tomato.

\section{Poster 40}

Regeneration and Transformation of Tomato (Lycopersicon esculentum)

Yueju Wang ${ }^{* 1}$, Charles Boyer ${ }^{1}$, Lailiang Cheng ${ }^{2}$, Leslie Fuchigami', Michael Wisniewski ${ }^{3}$, Richard Meilan ${ }^{4}$, and Abhaya Dandekar; ${ }^{1}$ Dept. of Horticulture, Oregon State Univ.; ${ }^{2}$ Dept. of Horticulture, Cornell Univ., Ithaca, NY; ${ }^{3} U S D A-A R S, W V ;{ }^{4}$ Dept. of Forest Science, Oregon State Univ.; ${ }^{5}$ Dept. of Pomology, Univ. of California

An Agrobacterium-mediated transformation procedure was developed for tomato (Lycopersicon esculentum, cv. Zhongshu No.5). Factors that affect transformation efficiency, such as type, position, and age of explants, concentration of Agrobacterium, hormone composition, and plate sealant were examined by transforming tomato plants with a binary vector that contained an nptll(pnos) gene and a reporter GUS-intron (p35S) chimeric gene. Transformed tomato plants were selected at 50- $\mathrm{mg} / \mathrm{l} \mathrm{kanamycin}$ and were analyzed by PCR and GUS histochemical assay. By optimizing the procedure for all the factors, an average transformation efficiency of $35.4 \%$ was obtained.

\section{Poster 41}

An Australian Cherry Tomato (Lycopersicon esculentum) Ideotype for Improved Field Crop Productivity James B. Hill ${ }^{*}$ and Norman L. Darvey; Plant Breeding Institute (PBI) PMB 11, Cobbitty NSW Australia 2570

Recommended varieties of cherry tomato are exhibiting less than satisfactory variation in fruit size and maturity when grown commercially in unprotected field situations under temperate climatic conditions around Sydney, Australia. In the process of defining a new plant "ideotype" for a locally adapted variety of cherry tomato, researchers at the PBI Cobbitty have screened characters of merit from a collection of 95 wild tomato accessions and 55 commercial cherry tomato varieties. Examining yield and other attributes within this germplasm at the PBI, Cobbitty (60 km from Sydney) has led to: 1) the development of a determinate cherry tomato "ideotype" with superior yield and uniformity characters compared with current industry standards; and 2) a systematic breeding methodology which brings together favorable alleles within breeding populations, which are then effectively screened for these characters in single cross and/or backcross/topcross populations. This project is funded by Top Class Fruit Pty Ltd in association with the Plant Breeding Institute of the Univ. of Sydney.

\section{Poster 42}

Marker-assisted Selection for Quantitative Traits in Sweet Corn 
Gad G. Yousef* and John A. Juvik; Univ. of Illinois at UrbanaChampaign

The integration of DNA marker technology has been proposed to increase selection efficiency in plant breeding. Two studies were designed to test the application of marker-assisted selection (MAS) for quantitative traits in sweet corn. The first compared rates of gain in composites developed using MAS and phenotypic selection (PS) over one cycle of selection. MAS and PS were applied to a mapped $F_{2: 3}$ population of 214 families to generate two sets of $C 1$ composites each homozygous for an endosperm mutation [sugary1 (su1) and sugary enhancer1 (se1)]. MAS was based the additive effects of five RFLP loci associated with significant effects. One cycle of MAS selection increased emergence by $8.3 \%$ and $14.9 \%$ while PS by only $1.5 \%$ and $3.1 \%$ over C0 performance in su $1 \mathrm{Se} 1$ and su 1 se $1 \mathrm{com}-$ posite populations, respectively. Selection gains from MAS were also significantly greater than PS for two traits that determine sweet corn eating quality (kernel tenderness and sucrose content) in both su1Se1 and su1se1 composites. In a second study, three regions carrying QTL that were previously found to improve seedling emergence in a shrunken2 population were introgressed using markerassisted backcrossing into three elite inbreds. $\mathrm{BC}_{2}$ plants with none, one, two, or all three of the linked RFLP marker loci were crossed to the nonrecurrent inbreds as testers. Comparisons of field seedling emergence were made between 50 different $\mathrm{BC}_{2} \mathrm{~F}_{1}$ families. Results showed significantly enhanced emergence was associated with two marker loci (umc139 and bnl9.08) across all the three genetic backgrounds. The data suggests that beneficial QTL identified in a mapping population can exert similar effects in other genetic backgrounds.

\section{Poster 43}

Development of Sweetpotato Host Differential Genotypes for Meloidogyne sp.

Jim C. Cervantes-Flores', G. Craig Yencho', and Eric L. Davis'; ${ }^{1}$ Dept. of Horticultural Science, North Carolina State Univ.; ${ }^{2}$ Dept. of Plant Pathology, North Carolina State Univ.

Sweetpotato [Ipomoea batatas (L.) Lam.] genotypes were evaluated for their resistance to North Carolina root-knot nematode populations: Meloidogyne arenaria (Neal) Chitwood (races 1 and 2), $M$. incognita (Kofoid \& White) Chitwood (races 1, 2, 3, and 4), and $M$. javanica (Treub) Chitwood. Resistance screening was conducted using $150-\mathrm{cm}^{3}$ Conetainers ${ }^{\mathrm{Tm}}$ containing 3 sand : 1 soil mix. Nematode infection was assessed as the number of egg masses produced by root-knot nematodes (RKN) per root system. Host preference of the RKN populations differed among the sweetpotato genotypes. Five out of 27 genotypes ('Beauregard', L86-33, PDM P6, 'Porto Rico', and 'Pelican Processor') were selected as potential differential hosts for RKN, so host status of these five genotypes was tested against 12 populations of $M$. incognita belonging to four host races, collected from different geographical regions. 'Beauregard', L86-33, and PDM P6 were hosts for all $M$. incognita populations, but differences in the aggressiveness of the isolates were observed. 'Porto Rico' and 'Pelican Processor' had different reactions to the $M$. incognita populations regardless of the host race. Two other genotypes were observed to have resistance to all $M$. incognita populations tested. These responses suggest that different factors might be responsible in conferring virulence in the nematodes, and that several genes could be involved in the resistance to RKN in sweetpotato. The results suggest that Meloidogyne populations should be tested against sweetpotato differential hosts to determine the pathotypes affecting sweetpotato and to standardize the evaluation of resistance to RKN in sweetpotato breeding programs.

\section{Poster 44}

Development of Species-specific PCR Band Markers in Ginseng

Helen C. Harrison*, Geunhwa Jung, James Nienhuis, and Michell Sass; Univ. of Wisconsin, Madison, WI 53706

American ginseng is indigenous to North America and is a crop of considerable economic importance. Little research has occured to determine the genetic diversity between this species, Panex quiquefolium and the less valuable $P$. ginseng; which although native to Asia, is often grown in North America. Our recent studies showed significant genetic distancing between these two species (the two species of most economic prominence) as well as determining the needed buffers to use to extract high quality DNA from all plant tissue types including the dried powder frequently used in commerce. Our published research shows RAPD amplifications of cultivated and wild American and cultivated Asian ginseng DNA. With suspected illegal species mixing being a problem of potentially enormous proportions, we decided to try to develop a quick, reliable test to determine RAPD markers for powdered product identification. In previous research we identified RAPD markers that could discriminate between $P$. quiquefolium and $P$. ginseng. RAPD markers are based on PCR amplification of genomic DNAs using 10-mer oligonucleotide primers of arbitrary sequence. RAPDs have become a fast, powerful tool for the analysis of genetic relationships; however, the intensity and reproducibility of RAPD banding patterns are sensitive to various PCR amplification procedures used in different laboratories. Also, it is difficult for an experienced person to score bands correctly due to multiple amplified bands. To solve this problem, RAPD bands can be converted to intense, often single band, products by extension of the 10-mer of the RAPD primers to a sequence characterized amplified region (SCAR). The method for conversion requires cloning and partial sequencing of RAPD bands allowing the design of unique full length primers. Polymorphism can be retained as the presence/absence of an amplified band, or can appear as a length polymorphism that converts a dominant RAPD into a codominant SCAR. Nine SCAR markers differentiating the two ginseng species ( $P$. ginseng and $P$. quinquefolium) were developed through the conversion of five RAPD primers. Four of these SCAR markers amplify a single, unique PCR band in P. ginseng and four amplify a different, unique band in $P$. quinquefolium, respectively. In addition, one SCAR primer also amplifies two bands at different molecular weights in a co-dominant pattern that distinquishes the two species. These robust PCR-based markers can be utilized for DNA fingerprinting in any laboratory setting.

\section{Poster 45}

Effect of Sugar and Basal Medium Concentration on Sweetpotato Somatic Embryogenesis

Lianghong Chen ${ }^{*}$, Ajmer Bhagsari, and Rao Mentreddy; Agricultural Research Station, Fort Valley State Univ., Fort Valley, GA 310304313

The effect of sugar concentration and strength of basal medium salts were studied to produce plantlets, roots, and somatic embryogenic calli from embryogenic multicellular clusters (EMC) of sweetpotato. The EMC were obtained from shoot tips of sweetpotato selection 75-96-1 when cultured on Murashiege and Skoog (MS) medium with $2.0 \mathrm{mg} / \mathrm{L} \mathrm{2,} \mathrm{4-D} \mathrm{for} \mathrm{four} \mathrm{weeks} \mathrm{followed} \mathrm{by} \mathrm{subculture}$ on MS medium with $2.0 \mathrm{mg} / \mathrm{L} 2,4-\mathrm{D}+0.25 \mathrm{mg} / \mathrm{L} \mathrm{BA}$ for 10 weeks. Subsequently, the EMC were cultured on hormone free medium supplemented separately with glucose, mannitol, sucrose, at three concentrations of $1 \%, 3 \%$, and $5 \%$, and sorbitol at $0,1 \%, 2 \%$, and $3 \%$. There was a significant difference among the sugar levels but not among the sugars types tested, except mannitol, on the growth of plantlets and the production of somatic embryogenic calli. Sugars at $5 \%$ concentration enhanced the growth of somatic embryogenic calli, while sugars at $1 \%$ concentration improved the conversion of somatic embryos to plantlets. On the other hand, root growth significantly differed among the sugars tested, but the concentrations of sugars did not show any difference. Glucose showed the highest increase in root fresh weight per somatic embryo cluster, while mannitol showed the least increase among the sugars. Increasing concentrations of sorbitol in the EMC culture medium (MS $+1 \%$ sucrose), reduced the somatic embryo conversion to plantlets. When the EMC were cultured on half, full, twice the strength of MS salts with MS vitamins and with $3 \%$ sucrose in the media, the root 
fresh weight per somatic embryo cluster and the number of plantlets were decreased with the increasing salt strength.

\section{Poster 46}

Transmission of a Bacillus thuringiensis crylllA transgene to tetraploid potato using $4 x-2 x$ hybridization

A.A.T. Johnson*, B.A. Nault, and R.E. Veilleux; Dept. of Horticulture, Virginia Polytechnic Inst. \& State U., Blacksburg, VA 24061 and Eastern Shore Ag. Res. Ext. Ctr., Painter, VA 23420

Transgenic potato cultivars resistant to feeding by the Colorado potato beetle (CPB), such as NewLeaf ${ }^{\circledR}$ Atlantic, have been developed by selection and propagation of single transformants into which the Bacillus thuringiensis cryIllA gene has been inserted. As an alternative to this engineering scheme, a highly heterozygous, interspecific diploid $(2 x)$ potato hybrid (APM-2) that produces $2 n$ pollen by first division restitution was transformed with a codonmodified cryIIIA gene via Agrobacterium tumefaciens leaf-disc inoculation. Single or multiple insert transformants were then crossed to the tetraploid cv. Atlantic through $4 x-2 x$ hybridization to yield tetraploid progeny. In a no-choice assay, Colorado potato beetle (CPB) adults consumed significantly less leaf area from all APM-2 diploid transformants compared to untransformed APM-2 and cv. Atlantic. Four transformants were as resistant to CPB as NewLeaf ${ }^{\boxplus}$ Atlantic. A DAS-ELISA test using antibodies for the CryllIA protein showed a high negative correlation $(r=-0.90 ; P<0.01)$ between leaf area consumed in the assay and the amount of CryllIA protein detected. A replicated ELISA screen of $254 x-2 x$ progeny derived from a single insert transformant showed no differences in CryllIA expression between the transformant and progeny. However, 17 of $254 x$-2xprogeny derived from a multiple-insert transformant showed significantly lower ELISA readings than the parent, with 8 progeny exhibiting virtually no CryllIA protein production. The results demonstrate that transgenes can be transmitted through unreduced gametes to $4 x-2 x$ progeny. This may facilitate the production of transgenic true potato seed (TPS) cultivars.

\section{Poster 47}

Interspecific Somatic Hybridization between Solanum Tuberosum and Wild Species for Introgression of Resistance to Bacterial Soft Rot and Late Blight in Potato

Yul-Kyun Ahn ${ }^{* 1}$, Hyo-Guen Park ${ }^{2}$, and Hei-Young Kim ${ }^{3}{ }^{1}$ Vegetable Breeding Division, National Horticulture Research Institute 540-41 Tap-dong, Gwonseon-gu, Suwon 441-440, Republic of Korea; ${ }^{2}$ Dept. of Horticulture, Seoul National Univ., Suwon, Republic of Korea, ${ }^{3}$ Dept. of Agrobioloy, Dongguk Univ., Seoul, Republic of Korea

Interspecific somatic hybridization was carried out to overcome sexual incompatability between cultivated potatoes and wild species and to introduce disease-resistant genes (Solanum brevidens; soft rot and blackleg resistant, Solanum bulbocastanum; late blight resistant) from wild species to cultivated potato. A total 322 of somatic hybrid plants were obtained from between $S$. breviden and S. tuberosum cv Superior, Dejima or dihaploid of Superior. Also, a total of 62 somatic hybrid plants were obtained from between $S$. bulbocastanum and $S$. tuberosum cv. Superior or dihaploid of Superior. Putative somatic hybrids could be selected through the detection of polyploidy by flow cytometry and counting of the chromosomes and true somatic hybrid plants could be selected through SSR and AFLP. Overall morphological characteristics of the somatic hybrids were intermediate of the parents and tetraploid somatic hybrids had closer morphological similarity to $S$. brevidens or $S$. bulbocastanum than the hexaploid hybrids did. There were wide variations in morphology, such as leaf, tuber, or reproductive organs, among the hybrids even though they are originated from the same parents. Some somatic hybrids had male and female fertility and they could be utilized for cross-breeding.

\section{Poster 48}

TAM Mild Jalapeño 2-A New Multiple Virus Resistant and Heat Tolerant Mild Jalapeño
Kevin M. Crosby ${ }^{*}$ and Benigno Villalon; Texas A\&M Univ., Texas Agricultural Experiment Station, Weslaco TX

The pepper breeding program at the Texas Agricultural Experiment Station, Weslaco, has been committed to developing virus resistant varieties for over 25 years. The newest development in the series of TAM hot peppers is the TAM Mild Jalapeño 2. This open pollinated pepper variety possesses many desirable attributes. These include: concentrated set of large $(7 \mathrm{~cm} \times 3 \mathrm{~cm})$, crackless fruit, high temperature fruit set, low anthocyanin and purple coloration, and virus resistance. Young plants exhibited no symptoms after five mechanical inoculations with PVY in a $0.05 \mathrm{M}$ Phosphate buffer $(\mathrm{pH} 7.5)$ and no symptoms were observed as the plants matured. Inoculations with TEV and PeMV produced mild symptoms on the inoculated leaves but no symptoms on subsequent growth were observed. Yields were not reduced in inoculated plants compared to noninoculated. In the Fall 1999 season, fruit matured five days earlier than 'Mitla,' hybrid and had significantly thicker flesh $(4.6 \mathrm{~mm}$ vs. $4.1 \mathrm{~mm})$ and significantly greater fruit weight (31 g vs. $23 \mathrm{~g})$. Fruit length of TAM MJ $2(7.2 \mathrm{~cm})$ was nearly identical to the $7.3 \mathrm{~cm}$ average length of 'Mitla' fruit. Yield of TAM MJ 2 (412 g/plant) was not significantly different than the $430 \mathrm{~g} / \mathrm{plant}$ produced by 'Mitla.' Yields of TAM MJ 2 were lower in the Spring 2000 season ( $305 \mathrm{~g} /$ plant). This was significantly lower than the $372 \mathrm{~g} /$ plant yield of 'Grande' hybrid and the $390 \mathrm{~g} /$ per plant yield of TAM Vera Cruz. However, average fruit size was larger in the Spring $(8.1 \mathrm{~cm}$ and $34 \mathrm{~g})$. Both of these fruit traits were significantly greater than 'Grande,' which averaged $7.1 \mathrm{~cm}$ and $30 \mathrm{~g}$. Average plant height of TAM MJ 2 is shorter than TAM MJ 1 and 'Grande'. The combination of disease resistance, heat tolerance and fruit quality are attributes which should enable TAM MJ 2 to be grown in a wide range of environments for multiple use.

\section{Poster 49}

Inheritance and Breeding for Resistance to Sclerotinia Minor in Lactuca sp.

R. Grube'; E. Ryder'; B. Robinson', J. Hubbard"; and K. Subbarao; ${ }^{1}$ U.S. Dept. of Agriculture/ARS; Salinas, CA; ${ }^{2}$ Dept. of Plant Pathology, Univ. of California, Davis; Salinas, $C A$

Sclerotinia minor causes the disease 'lettuce drop' on lettuce and its relatives (Lactuca sp.), which results in complete collapse, decay and death of infected plants. Breeding and genetic studies of resistance to S. minor have been hindered by sizeable variability in disease incidence (DI) between experiments, resulting from influence of environmental factors on artificial inoculation procedures. To increase the reproducibility of greenhouse screening in the context of this breeding program, we have examined several factors including age of inoculated plants, quantity of inoculum (a mixture of $S$. minorsclerotia and mycelia), and S. minor isolates. Several candidate resistant/ tolerant lines have been identified by artificial inoculation experiments. Select candidate lines have been further evaluated in randomized replicated greenhouse and field experiments, either naturally or artificially inoculated with $S$. minor. Complete resistance has not been identified in any line; however, several lines show a statistically significant reduction in overall DI and/or increased interval between first observation of symptoms and plant death, as compared with susceptible control cultivars. The most resistant lines, none of which are commercially acceptable varieties, have been intercrossed with susceptible cultivars with desirable agronomic characters. $F_{2}$ and $\mathrm{BC}_{1} \mathrm{~F}_{2}$ populations have been evaluated for resistance, and results from the breeding program will be presented. We have chosen to focus on one resistant genotype, 'PI251246', a primitive L. sativa, to determine the genetic basis of resistance to $S$. minor. Recombinant inbred lines (RILs) are being generated from a ('Salinas' X 'PI251246') F2 population to determine the heritability and action of genes involved in resistance derived from 'PI251246'.

\section{Poster 50}

Determination of Lutein and Beta-Carotene Content of Selected Leafy Vegetables

R.A. Gard ${ }^{* 1}$, T.E. Morelock', J.B. Murphy', and L.R. Howard ${ }^{2}{ }^{1}$ Dept. of Horticulture, Univ. of Arkansas, Fayetteville, AR; ${ }^{2}$ Dept. of Food 
Science, Univ. of Arkansas, Fayetteville, AR

Recent national trends in human nutrition have increased interest in nutrient content of most leafy green vegetables. It is well documented that spinach, collards and kale are excellent sources of lutein and beta-carotene. Both these compounds are strong antioxidants and lutein has been shown to be valuable in prevention of agerelated macular degeneration (AMD). Earlier studies with spinach have shown tremendous variation in both lutein and beta carotene between different genotypes. Present work is designed to determine differences in lutein and beta-carotene among many of the different leafy vegetables used in the more common salad mixes. Several types of swiss chard, beets and mustards are being assayed for carotenoid content by high performance liquid chromatography (HPLC). Preliminary data indicate wide variation in lutein and betacarotene content between the various vegetables and between the different genotypes within types of vegetable.

\section{Poster 51}

\section{Evaluation of Eggplant Germplasm for Fruit Phytonutrient Content}

John R. Stommel ${ }^{* 1}$ and Bruce D. Whitaker ${ }^{2}$; USDA-ARS, Vegetable Laboratory, Plant Sciences Institute, Beltsville, MD 20705; ${ }^{\text {USDA- }}$ ARS, Produce Quality and Safety Laboratory, Plant Sciences Institute, Beltsville, MD 20705

The cultivated eggplant, Solanum melongena L., is a species of considerable economic importance in many tropical and sub-tropical parts of the world. Consumption of eggplant is growing in the United States as ethnic diversity of urban areas increases and consumer health and diet related education expands. Eggplant is included among the top ten vegetables when ranked in terms of their ORAC (oxygen radical absorbance capacity) value. This is attributed to the fruit's phenolic content. When consumed regularly in the human diet, the protective effects of phenol antioxidants may help to prevent diseases such as atherosclerosis and cancer. In eggplant, phenolic acids and anthocyanins comprise the principal dietary phenolics. We have evaluated phenolic acid content in eggplant fruit flesh of the USDA core collection. The eggplant core collection is comprised of 115 accessions which are representative of the genetic diversity within $S$. melongena, plus accessions of the related wild relatives $S$. aethiopicum, S. anguivi, S. incanum and S. macrocarpon. HPLC analysis of eggplant fruit extracts demonstrated that a number of phenylpropanoid phenolics were present in fruit flesh and that esters of caffeic acid were the most abundant. Our results also demonstrated variation for total phenolic acid content within fruit from blossom to stem end, with higher levels of phenolic acids typically present in the blossom end. Within the core collection, considerable variation for phenolic acid content was evident between eggplant accessions.

\section{5:00-6:00 p.m. .............................................. CC Ballroom}

\section{Poster Session 11: Propagation/Tissue Culture \\ Poster 106}

Influence of Various Oxygen Levels on the Growth, Morphogenesis, and Secondary Product Formation of Mint (Mentha sp.) and Thyme (Thymus vulgaris L.) Tissue Cultures

Brent Tisserat*, Steven F. Vaughn, and Robert Silman; USDA-ARS, National Center for Agricultural Utilization Research, Peoria, IL 61604

Little research has been conducted to determine the influence of various $\mathrm{O}_{2}$ concentrations on growth (fresh weight), morphogenesis (leaves, roots and shoots) and secondary metabolites. Mint (Mentha $s p$. L.) and thyme (Thymus vulgaris L.) shoots were cultured under $5,10,21,32$, or $43 \% \mathrm{O}_{2}$ employing either 350 or $10,000 \mathrm{~mL} \mathrm{CO} / \mathrm{L}$. Shoots were grown in vitro on Murashige and Skoog salts, $3 \%$ sucrose and $0.8 \%$ agar employing $180 \mu \mathrm{mol} \cdot \mathrm{s}^{-1} \cdot \mathrm{m}^{-2}$ PPFD $16 \mathrm{hr}$ photoperiod. Growth and morphogenesis responses varied considerably among the two plant species tested depending on the level of $\mathrm{O}_{2}$ administered. Nevertheless, growth was enhanced considerably for shoots under all $\mathrm{O}_{2}$ levels tested with $10,000 \mathrm{~mL} \mathrm{CO} / \mathrm{L}$ when compared to growth responses obtained from cultures grown on the same $\mathrm{O}_{2}$ levels with $350 \mathrm{~mL} \mathrm{CO} / \mathrm{L}$. Mint shoots did not exhibit any difference in growth and morphogenesis regardless of the $\mathrm{O}_{2}$ level tested with $10,000 \mathrm{~mL} \mathrm{CO} / \mathrm{L}$. In contrast, thyme shoots exhibited enhanced growth and morphogenesis when cultured in $\geq 21 \% \mathrm{O}_{2}$ compared to shoots cultured under lower $\mathrm{O}_{2}$ levels. The monoterpene, piperitenone oxide from mint and the aromatic phenol, thymol from thyme were analyzed by $\mathrm{CH}_{2} \mathrm{Cl}_{2}$ extracts via gas chromatography from plants grown in all $\mathrm{O}_{2}$ levels. Highest levels of thymol were produced from thyme shoots cultured under $15 \%$ and $21 \% \mathrm{O}_{2}$ with $10,000 \mathrm{~mL} \mathrm{CO} / \mathrm{L}$ and were considerably less from shoots when grown under either lower or higher $\mathrm{O}_{2}$ levels. Highest levels of piperitenone oxide were obtained from mint cultures when grown with $\geq 21 \% \mathrm{O}_{2}$ with $10,000 \mathrm{~mL} \mathrm{CO} / \mathrm{L}$.

Poster 107

Ultrahigh $\mathrm{CO}_{2}$ Levels Increase Growth and

Phytonutraceutical Production in St. John's Wort (Hypericum perforatum)

Steven F. Vaughn*, Brent Tisserat, Charles L. Cantrell, and Mark A. Berhow; USDA-ARS, National Center for Agricultural Utilization Research, Peoria, IL 61604

St. John's Wort (Hypericum perforatum L.) is a medicinal plant which has been used since antiquity for its medicinal properties, and is being studied as a potential alternative crop for Illinois growers. We are studying the effect of increasing $\mathrm{CO}_{2}$ concentrations $(350,1000$, $3000,10,000$, and $30,000 \mu \mathrm{L} \mathrm{CO}_{2} / \mathrm{L}$ ) on plant growth and tissue concentrations of the putative active compounds, the naphthodianthrones hypericin and pseudohypericin. Purified naphthodianthrone standards were isolated using both open column and preparative HPLC procedures and identified by liquid chromatography-electrospray ionization-mass spectroscopy (LC-ESI-MS) and NMR. For quantitation of naphthodianthrones, plant material was exhaustively extracted with methanol, and separated using HPLC with UV detection at $590 \mathrm{~nm}$. Hypericin and pseudohypericin concentrations were calculated from a standard curve of purified hypericin. While elevated $\mathrm{CO}_{2}$ levels had dramatic effects on plant growth, with growth continually increasing as $\mathrm{CO}_{2}$ concentrations increased, levels of naphthodianthrones were highest when plants were grown at 1000 and $3000 \mu \mathrm{L} \mathrm{CO} / \mathrm{L}$. Our data indicate that growing St. John's Wort plants under ultrahigh $\mathrm{CO}_{2}$ levels could substantially increase biomass without adversely affecting phytonutraceutical production, therefore allowing enhanced production of these desirable compounds.

\section{Poster 108}

The Effectiveness of Oregano Oil as a Surface Disinfestation Agent in Plant Tissue Culture

Mustafa Ozden* and Houchang Khatamian; Dept. of Horticulture, Forestry and Recreation Resources, Kansas State Univ., Manhattan, KS 66506

Oregano (Origanum vulgare) oil is well known for its ability to slow down food spoilage through its antibacterial, antifungal, antiparasitic, and antioxidant activity. Carvacrol and thymol are major phenols present in oregano oil with antiseptic properties. In this study, the effectiveness of oregano oil as a surface-sterilization agent was tested using stem nodel sections of a miniature rose (Rosa hybrida L. 'Savalav'), turkish oregano (Origanum onites L.), and petiole sections of begonia (Begonia $x$ erythrophylla 'Beefsteak'). The explants were surface sterilized in 0.2 to $0.8 \mathrm{~g} / \mathrm{L}$ of oregano oil containing 2-3 drops of Tween 20 for 5-30 minutes, then rinsed three times with sterile water for $5 \mathrm{~min}$. Miniature rose and begonia explants were then placed in shoot-inducing medium containing $\Pi$ Murashige and Skoog (MS) basal salts, supplemented with $20 \mathrm{~g} / \mathrm{L}$ sucrose, $6.5 \mathrm{~g} / \mathrm{lagar}, 1 \mathrm{mg} / \mathrm{LBA}$, and $0.1 \mathrm{mg} / \mathrm{L}$ NAA. Turkish oregano explants were placed in MS basal salts, containing $30 \mathrm{~g} / \mathrm{L}$ sucrose,

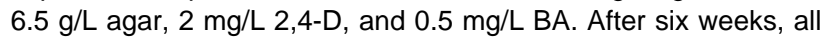
cultures were evaluated for contamination. Miniature rose, begonia and turkish oregano explants sterilized in $0.4 \mathrm{~g} / \mathrm{L}$ of oregano oil for five 
$\mathrm{min}$., $0.6 \mathrm{~g} / \mathrm{L}$ of oregano oil for $20 \mathrm{~min}$., and $0.2 \mathrm{~g} / \mathrm{L}$ of oregano oil for $10 \mathrm{~min}$. showed free of contamination respectively. All explants in contamination free culture vessels continued to grow normally compared with explants surface-sterilized in commercial bleach solution.

\section{Poster 109}

Cupric Sulfate Enhances Rooting of Rosemary (Rosmarinus officinalis) Cuttings

Keun Ho Cho* and Chiwon W. Lee, Dept. of Plant Sciences, North Dakota State Univ., Fargo, ND, 58105

The influence of cupric sulfate $(\mathrm{CuSO} 4.5 \mathrm{H} 2 \mathrm{O})$ on the rooting of rosemary (Rosmarinus officinalis L.) cuttings was investigated. Softcuttings (5-cm long) obtained from one-year old plants grown in the greenhouse were treated at the cut end with $0,50,100,200$, or 500 $\mu \mathrm{m}$ cupric sulfate solution for $30 \mathrm{~min}$. and rooted in a peat-lite medium (Sunshine Mix \#2) under mist. Rooting was scored after culture for 30 days in the mist room. Percent rooting increased as cupric sulfate concentration increased up to $200 \mu \mathrm{m}(16.7 \%, 50.0 \%, 76.5 \%$, and $81.8 \%$ rooting, respectively, for $0,50,100$, and $200 \mu \mathrm{m}$ cupric sulfate). The number of roots produced per rooted cutting was 1.0 for the control and 4.1 for cuttings treated with $200 \mu \mathrm{m}$ cupric sulfate. Average lengths of roots were also greater in the treated cuttings compared to the control. Results of this study suggest that cupric sulfate may be used as a means of enhancing adventitious root formation in rosemary.

\section{Poster 112}

In Vitro Proliferation of Capparis spinosa Shoots

Elizete Beatreiz Radmann', Cibele dos Santos Ferrari', and Gerson Renan de Luces Fortes*; FAEM/UFPel, P.O. Box 354, 96001-970, Pelotas, RS, Brazil; ${ }^{2}$ Embrapa Temperate Climate, P.O. Box 403, Pelotas, RS, Brazil

Micropropagation, as compared to traditional plant propagation, allows the increase in yield and plant quality. This work aimed to establish better conditions for in vitro multiplication of Capparis spinosa. The experiment was performed by carrying out two trials. In the first trial, different MS salt concentrations were tested $(25 \%$, $50 \%, 75 \%, 100 \%$ and $125 \%$ ), and type of explants (apical and basal ones). The material was kept in a growth room with controlled temperature $\left(25 \pm 2{ }^{\circ} \mathrm{C}\right)$, light intensity $(1500 \mathrm{Ix})$ and 16 -h photoperiod. The explants remained in this condition for 30 days, then number of buds formed and number of shoots/explant were evaluated. In the second trial, the position of explants as related to nutrient medium, was tested along with the number of initial buds. The material was cultivated as in the previous trial. After 30 days of cultivation, the mean number of bud shoots/explant was evaluated along with the plantlet height. The greatest number of buds was obtained by using 2-bud basal explants in the horizontaly position with $125 \%$ MS medium, which did not differ from $100 \%$ MS. The number of shoots/explant and plantlet height presented significantly differences for the type of explant. 3-bud basal explants promoted higher number of shoots. Higher plantlets were favored for explants displayed in horizontal position in the culture medium.

\section{Poster 113}

How Plant Growth Regulators \& Biological Additives Influence Growth in a Preformed Transplant Plug Joel G. Canestrino*; Grow-Tech, Inc., 20 Elderica Way, Lodi, CA 95242

Over the last several years, vegetable producers have shown increasing interest and reliance on transplants for field production. For some crops (i.e., hybrid, triploid watermelons) the growth has been driven by seed costs and very precise horticultural requirements. For other crops (i.e., processing tomatoes and cauliflower) the reliance on transplants is a result of the growers' need to meet very precise delivery schedules, take advantage of early season planting windows or maximize crop rotations. The Grow-Tech Cellular Rooting Sponge ${ }^{\circledR}$ has long been popular for the propagation of woody ornamentals from mature cuttings, ornamentals propagated from soft cuttings, and microplants from tissue culture. The preformed plug consists of over $90 \%$ organic material and less than $10 \%$ polymer binder. The rheology of the polymer offers physical protection to tender roots during mechanical transplanting. The polymer binds the organic material, so plants can be handled earlier without the need for a fibrous root system to develop. Also, pore spacing is fixed and will not compact after repeated watering. The polymer binder is hydrophilic and the release kinetics are such that a material, such as a PGR or micronutrient fertilizer, that is incorporated during manufacturing will be slowly released into the plug during propagation. Research presented in the poster will focus on the results of greenhouse trials where the pre-formed plugs were loaded with a range of materials including plant growth regulators, plant growth stimulants, biological plant growth promoters and water-soluble fertilizers. Test crops include fresh market tomato (L. esculentum), diploid watermelon (Citrullus lanatus), bell pepper (Capsicum annuum) and cauliflower (Brassica oleracea L. var. botrytis L.).

5:00-6:00 p.m. ................................................. CC Ballroom

\section{Poster Session 12: Crop Production}

Poster 151

Supplemental Pollination Improves Seed Content and Fruit Size in Kiwi

Thomas E. Ferrari ${ }^{* 1}$ and Frank Wisehart ${ }^{2}{ }^{1}$ Plant Development Int., Bakersfield, CA 93380;'2 Sun Pacific Farming, Bakersfield, CA 93308

Kiwi plants are dioecious and require either wind or honeybees to transfer pollen from stamens to pistils. The females' fertile ovary possesses numerous ovules and can produce nearly 1600 seeds. In California, males in commercial plantings bloom several days before females. Fruit produced from early flowers have greater size and seed numbers than fruit from late blossoms. During peak bloom, manually pollinated flowers produce greater fruit size and seed set. Fruit size is linear and positively correlated with seed set $\left(R^{2}=0.25\right.$, $\mathrm{Y}=856+6.31 \mathrm{X})$. These results imply natural pollination is less than optimum. To determine how much enhanced pollination would increase fertilization and fruit production, extra pollen-produced in vitro from immature anthers collected from early male flowers-was applied to females. The number of viable pollens per gram was determined: doses were 300 million viable pollens per acre per application. Three applications were made: prior to, during and after peak bloom. Pollen was released in the dry state from below the vines using an auger-fed dispenser and blower. Flowers exposed to extra pollen produced fruit with greater seed numbers $(+11 \%)$ and weight $(+10 \%)$ than flowers pollinated naturally. No differences in seed set was observed when open flowers were exposed to pollen on 1, 2, or 3 successive days, or when open flowers were exposed on the same day to 300,600 , or 900 million viable pollens per acre. Evidence indicates supplemental pollination increased fruit size and the dose applied was optimal.

\section{Poster 152}

The Effectiveness of the Western Bumblebee (Bombus occidentalis) in Pollinating 'Hass' Avocado Trees

William L. Pidduck and Robert J. McNeil*, Crop Science Dept., California Polytechnic State Univ., San Luis Obispo, CA 93407

There has been recent interest in the use of alternative pollinators for the Hass avocado in California. Eight bumblebee hives were placed in the middle of an .86 ha (2.125 acres) block of 2-year old 'Hass' avocado trees during bloom in May 1998. Numbers of three types of pollinating insects (bumblebees, honeybees, and syrphid flies) visiting blossoms were surveyed for three weeks. The number of fruit set on each tree was counted in the winter of 1999. Percentages of insect pollinators visiting blossoms were $9.8 \%$ for bumblebees, $10.1 \%$ for honeybees, and $80.1 \%$ for syrphid flies. Fruit numbers per tree were greater in rows within $16.46 \mathrm{~m}(54 \mathrm{ft})$ of the bumblebee hives than they were for trees in rows further from the hives. This was statistically significant for three out of six rows adjacent to bumblebee hives. This study demonstrated that the 
western bumblebee (Bombus occidentalis) will pollinate 'Hass' avocado flowers and thereby increase fruit numbers per tree. A hive

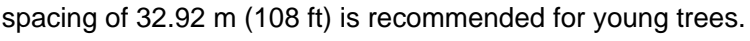

\section{Poster 153}

Organic Blossom Thinning of Apple

James R. Schupp ${ }^{* 1}$ and Terence L. Robinson ${ }^{2} ;{ }^{1}$ Dept. of Horticultural Science, Cornell's Hudson Valley Lab, Highland, NY; ${ }^{2}$ Dept. of Horticultural Science, NYSAES, Cornell Univ., Geneva, NY

Two studies were conducted in NY to evaluate organically acceptable blossom thinners for increasing fruit size, fruit quality and return bloom of apple. Mature 'Delicious'/M.7 trees in the Hudson Valley were thinned with either NC 99, a calcium/magnesium brine solution (G.S. Long Co., Yakima, WA); or Crocker's fish oil tank mixed with liquid lime sulfur (FOLS). Timings were at $80 \%$ bloom, or a double application, with one spray at $20 \%$ bloom plus a second spray at $80 \%$ bloom. A similar thinning study was conducted in a certified organic apple orchard in western New York to compare the effectiveness of FOLS, NC 99, or Ammonium Thiosulfate (ATS) at $80 \%$ bloom on mature 'Mclntosh', 'Cortland', and 'Delicious' trees, all on seedling rootstock. In the Hudson Valley, FOLS reduced fruit set compared to controls, and FOLS applied at $80 \%$ bloom reduced yield. Both organic thinners increased fruit size; however double applications were no better than a single spray at $80 \%$ bloom. In western New York, both of the organic blossom thinning chemicals reduced fruit set while ATS did not. NC 99 caused the most thinning, while FOLS resulted in slightly less thinning. The organic bloom thinning chemicals reduced fruit set on 'Cortland' and 'Delicious' but not on 'McIntosh', which may have been thinned too late. For Delicious, the FOLS treatment increased fruit size compared to the controls. Our preliminary conclusion is that both NC 99 and FOLS show promise as organic thinners for apple.

\section{Poster 154}

Response of the Sevillano Olive Cultivar to Post Bloom Thinning With Napthalene Acetic Acid

William H. Krueger ${ }^{\star}$ and Zachary Heath; Univ. of California Cooperative Extension, Glenn County, $C A$

Post bloom application of Napthalene Acetic Acid (NAA) has been available for post bloom thinning during the predicted "on" year for control of alternate bearing in olives in California for more than 25 years. NAA was originally reported to be ineffective for thinning the Sevillano cultivar and has not been used on this variety. Sevillano is an important table olive cultivar in California with $\approx 2400$ ha or about $18 \%$ of the total table olives under cultivation. Three years of thinning studies have shown that post bloom sprays of NAA can reduce fruit set in Sevillano. Multivariate regression analysis showed that this response is highly correlated with the number of days after full bloom that the treatment is applied and the sum of the daily maximum temperatures four days after treatment. Therefore treatment response can be predicted 4 days after treatment, allowing for additional practices such as pruning or a second application of NAA (shown in an earlier study with the Manzanillo cultivar to result in additive thinning) to reduce cropping if a poor thinning response is predicted.

\section{Poster 155}

Rain-induced Cracking in Sweet Cherries and Its Control with Vegetable Oil Emulsion

Yousheng Duan*, Zhiqiang Ju, Zibo Wanquan, Shandong, China, Zhiguo Ju, USDA ARS Tree Fruit Research Lab, 1104 N. Western Ave., Wenatchee, WA 98801

In the first experiment, 'Rainier' cherry trees were sprayed with $1 \%, 2.5 \%$, or $5 \%$ corn oil emulsion, respectively, one day before forecasted rain. Untreated trees served as control. The second experiments with 'Rainier' cherry trees included the following treatments applied one day before rain: 1) orchard floor under tree canopy was covered by plastic films; 2) all mature leaves on two branches from each tree were hand defoliated; or 3) fruit on selected bracnes were bagged with waxed paper bags. Untreated trees or branches served as control. At 1\%, corn oil reduced fruit cracking by half. At $2.5 \%$ or $5 \%$, corn oil emulsion reduced fruit cracking from $30 \%$ to $50 \%$ to about $10 \%$ in three consecutive years. Oil application did not cause phytotoxicity to fruit or trees. Covering orchard floor did not reduce fruit cracking, defoliation reduced fruit cracking by $25 \%$, and bagging fruit prevented cracking completely.

\section{Poster 156}

Preharvest Apple Drop: A Ten-year Study of Seasonal Drop Variability and Chemical Stop Drop Response

\section{C.R. Unrath*; North Carolina State Univ.}

Yearly, natural variability in fruit drop at the "open of the harvesting window" (OHW) ranged from 2 to $18 \%$ of the total crop load. However, by 7 weeks after OHW, fruit drop varied from a low of $50 \%$ in 1992 to a high of $95 \%$ in 1995 with great variability in the time of "onset of excessive fruit drop" (OEFD) (>20\%). Drop control chemicals and timings evaluated included two applications of NAA at 10 ppm, each starting at $\mathrm{OHW}$ and repeated 7 days later (Traditional NAA). Four NAA applications of 5 ppm each applied weekly at 4, 3, 2, and 1 weeks before anticipated OHW (Preloaded NAA) and a ReTain $^{\circledR}$ application of $123.5 \mathrm{gai} / \mathrm{ha}(50 \mathrm{gai} / \mathrm{A}$ ) with $0.1 \%$ Silwet applied at 4 weeks before anticipated OHW $\left(\right.$ ReTain $\left.^{\oplus}\right)$. Traditional NAA delayed the onset of excessive fruit drop, but Preloaded NAA was generally more effective in the delay. By 7 weeks after OHW, traditional NAA had $45 \%$ (in 1994) to $95 \%$ (in 1995) cumulative fruit drop, while Preloaded NAA had $45 \%$ (in 1992) to $85 \%$ (in 1999) cumulative fruit drop. ReTain ${ }^{\circledR}$ was the most effective in delaying the OEFD and in reducing late season drop. By 7 weeks after OHW 10\% (in 1992) to $80 \%$ (in 1999) of the total crop load had dropped. A 4 year comparison of these treatments (1997-2000) with the combined response of ReTain ${ }^{\circledast}$ plus Preloaded NAA showed the combination to be superior to the individual treatments. A year by year comparison of natural (ck) drop vs. chemical drop control treatments will be presented to show considerable flip-flopping of drop control strength depending on environmental factors of individual years.

\section{Poster 157}

Concentrated Sprays of Horticultural Petroleum Oils Affect Fruit Number, Fruit Size and Yield of Navel Orange

C.E. Kallsen*; Univ. of California Cooperative Extension, Kern County, $C A$

In two separate experiments, one completed (Expt. I, 1996-98) and one underway (Expt. II, 1999-2000), horticultural petroleum oils altered fruiting characteristics of 'Navel' orange. The experiments were located in growers' fields near the city of Bakersfield, California. Concentrated, narrow-range medium to heavy weight oils in a range of applications from $2.5 \%$ to $15 \%$ by volume in a total spray volume of $200 \mathrm{gal} / \mathrm{acre}\left(1870 \mathrm{~L} \cdot \mathrm{ha}^{-1}\right)$ increased the number of large-sized fruit per tree. In Expt. II after three years of oil application, oil applications ( $7.5 \%$ to $15 \%$ oil by volume) produced more large fruit and less small fruit per tree, while maintaining or slightly decreasing total weight of fruit (i.e., yield) per tree compared to untreated controls. Consecutive annual oil applications appear to increase the degree of change in the fruiting response resulting in consecutively larger fruit and, possibly less yield (Expt. I). Lower rates of oil ( $5 \%$ by volume) increased the number of larger fruit per tree and produced more yield per tree in the second, and most recent year, of Expt. II. In both experiments, oil produced changes in fruiting the year following the year that it was applied, whether oil was sprayed the second year or not. Oil sprayed in July produced greater changes in fruiting response the following year, than when sprayed shortly after petal fall. Oil was applied to unstressed trees. Leaf and twig phytotoxicity was minimal, while fruit color, texture, the ratio of soluble solids to acid, and the amount of marketable fruit remained unaffected by concentrated oil sprays.

\section{Poster 158}

Effect of Gibberellic Acid Applications on the Fruit Quality of 'Sweetheart' Sweet Cherry 
Frank Kappel* and Richard MacDonald; Agriculture and Agri-Food Canada

A single application of gibberellic acid (GA) to improve fruit quality has become standard procedure for sweet cherry growers in the Pacific Northwest of the United States and British Columbia, Canada. The objective of this trial was to determine if multiple applications of GA can be used to increase fruit firmness and size, and delay maturity of 'Sweetheart' sweet cherry. Whole trees of 'Sweetheart' sweet cherry were treated for 3 years with single applications of 20 or $30 \mathrm{ppm} \mathrm{GA}$, or two or three weekly applications of $10 \mathrm{ppm} \mathrm{GA}$. Yield was not affected by GA treatment in any of the years of the trial. All GA treated fruit were significantly firmer than the untreated fruit but there were no differences among the various GA treatments. GA treated fruit had significantly higher titratable acidity than untreated fruit. There were no differences in titratable acidity among the GA treatments. All GA treated fruit were larger than untreated fruit and fruit treated with a single application of $20 \mathrm{ppm}$ GA were larger than fruit treated with a single application of $30 \mathrm{ppm}$ GA. GA treated cherries were firmer, larger and could be harvested later than untreated fruit but multiple applications did not provide a significant benefit over a single application.

\section{Poster 159}

\section{Use of Kaolinic Clay to Enhance On-tree Color Retention of} Red Sensation Bartlett Pear Fruit

Rachel Elkins ${ }^{1}$, Elizabeth Mitcham ${ }^{2}$, Dustin Blakey', and Bill Biasi'; ${ }^{1}$ Univ. of California Cooperative Extension; Lake County; Lakeport, CA 95453; '2Univ. of California; Dept. of Pomology; Davis, CA 95616

Hydrophobic particle film is increasingly being used as a crop protectant in western pear orchards, for example, to control pear psylla as well as to enhance tree productivity, fruit yield, and quality. A replicated trial was conducted in 1999 in a 'Red Sensation' Bartlett pear orchard to assess whether kaolinic clay (Surround ${ }^{\circledR}$, Engelhard Corp., N.J.) could prevent fading of red color prior to fruit reaching optimum size for harvest. Three applications of $50 \mathrm{lb}$ each of kaolinic clay were applied to trees beginning at fruit turn-down (3 June, 18 June, and 2 July) and were compared to nontreated controls. Fruit samples were collected weekly for 6 weeks from 27 July [3 weeks prior to the first commercial harvest through 31 Aug. (second commercial harvest)]. Harvest parameters were measured immediately after harvest and again after storage for 1 or 3 months. Claytreated fruit was significantly heavier, firmer, and higher in sugar for nearly all harvest dates. Percentage of red surface and intensity of red color was also significantly greater than for nontreated fruit. Fruit set was significantly lower, but this is based on sampling individual limbs rather than entire trees. Clay-treated fruit also had greater percent red surface, more intense red color and was sweeter after storage for 1 or 3 months, and remained firmer after ripening. This experiment indicates that 'Red Sensation' Bartlett pears could be left on the tree an extra 5-7 days to increase weight and size while retaining red color and that benefits extend into cold storage. These benefits combined with crop protection use could justify the $\approx \$ 35$ per acre per application material cost as growers are rewarded for larger, highly-colored fruit. A key logistical issue to be resolved is acceptance of film-treated fruit by the packinghouse and processor.

\section{Poster 160}

Genetic and Ecotypic Resources of Chinese PearDiversity of Chinese Pear in Fruit Sugar Composition and Concentration

Zeng-Guang Pan ${ }^{* 1}$, Saneyuki Kawabata ${ }^{1}$, Nobuo Sugiyama ${ }^{1}$, Ryozo Sakiyama', and Yu-Fen Cao'; ' Horticultural Laboratory, Dept. of Agriculture and Environmental Biology, Univ. of Tokyo, Bunkyo, Tokyo 113-8657, Japan; ${ }^{2}$ China National Institution of Fruit Tree Sciences, Liaoning Province, China

Sugar is one of the important factors that determine fruit quality. In China, there are many wild and local varieties of pears distributing broad range of area. The pear flesh varied extensively in sweetness, which is reflected in sugar contents and composition. The local varieties and wild pears are excellent materials for physiological and genetic research of sugar accumulation. In this paper, we mainly report the result of sugar analysis of Chinese pear, particularly Qiuzi and Xinjiang pear strains, which are distributed mostly in northeastern and western China, respectively. A total of 63 varieties or cultivars of pear fruit materials was taken from the original producing area or China National Institution of Fruit Tree Sciences. After fruit harvested, immediately squeezing out fruit juice and mixed juice with 4 times volume of ethanol. These mixtures were stored in an icebox for transportation. The constituent sugar concentrations were measured by HPLC or enzymatic analysis. Analysis results indicate: 1) sugar concentration (fructose, glucose, and sucrose) varied broadly among the varieties or cultivars, ranged from $47.6 \mathrm{mg} / \mathrm{mL}$ to $141.7 \mathrm{mg} /$ $\mathrm{mL}$ juice; 2 ) existed varieties or cultivars that had higher content of sugars in Qiuzi and Xinjiang pear strains: 3) fructose was primarily accumulated in most of the varieties and cultivars; 4) Qiuzi and Xinjiang pear strains tend to have smaller fruit weight., 5) sugar content was negatively correlated with fruit fresh weight among the varieties and cultivars analyzed in this study; and 6) DNA fingerprinting of varieties and cultivars also was conducted by non-radioactive AFLP on automatic DNA sequencer.

\section{Poster 161}

\section{Variation in Pecan Kernel Composition in Relation to} Genotype, Crop Load, and Leaf Nutrient Levels

L.J. Grauke*, T.E. Thompson, J.B. Storey, and Laurence Sistrunk; USDA-ARS Pecan Breeding \& Genetics, Rt. 2 Box 133, Somerville, TX 77879

Tree performance and fruit quality at harvest have been studied for several years in pecan trees growing in a replicated test orchard of the National Pecan Advanced Clone Testing System (NPACTS). In 1999 , additional parameters were included for study to more carefully characterize cultivars in relation to leaf nutrient content and nut quality. Leaf samples were collected during July for leaf nutrient analysis, and were measured to determine leaflet area. At harvest, nut samples were destructively evaluated for nut quality and kernels were analyzed for total oil and oil composition. The percentage of water and percentage of oil in kernels varied between pecan cultivars. Although the percentage of water in kernels was small (from $1.7 \%$ to $2.8 \%$ ), controlled cross families could be distinguished by that parameter, to the point that reciprocal cross families were distinct. The percentage of oil in kernels varied from $59 \%$ (mean of 6 determinations for 'Desirable') to $83 \%$ (mean of 6 determinations for 'Pawnee'). There was no apparent correlation between yield and oil content: cultivars producing the largest crops had oil content indistinguishable from those with the smallest crops. Oil composition varied between cultivars and between full sib families of cultivars. Pecan kernels were composed primarily of the following fatty acids: oleic acid ( $57 \%$ to $72 \%)$; linoleic acid $(21 \%$ to $34 \%)$; palmitic acid $(4 \%$ to $6 \%$ ); linolenic acid (0.7\% to $2 \%)$; and stearic acid ( $0.2 \%$ to $1.3 \%)$. There was a strong negative correlation $\left(R^{2}=0.97, \mathrm{n}=94\right)$ between the percentages of oleic and linoleic acids. Pecan cultivars with the greatest yields (expressed as grams of kernels per cross sectional trunk area) produced the lowest amounts of oleic acid. Nut oil content was negatively correlated with leaf $\mathrm{K}$ content $\left(R^{2}=-0.51, \mathrm{n}=91\right)$. As leaf area increased, $\mathrm{K}$ leaf content increased $\left(R^{2}=0.42, \mathrm{n}=94\right)$. Other aspects of leaf nutrient content in relation to leaf condition and yields will be discussed.

5:00-6:00 p.m. ........................................... CC Ballroom

\section{Poster Session 13: Crop Production}

\section{Poster 162}

Dolomite Blend and Rate Influence Substrate pH and Growth of Ornamentals in Douglas-Fir Bark

S.E. Svenson*, J.K. Paxson, J. Buckelew, and K. Sanford; Dept. of Horticulture, Oregon State Univ., NWREC, Aurora, OR 97002-9543

Arctostaphylos uva-ursi 'Radiant,' Armeria maritima 'Rubrifolia,' Heuchera 'Mint Frost,' Thuja occidentalis 'Danica,' Vaccinium 
'Darrow,' and Vinca minor 'Bowles' were potted (00W26) into 2.5-L nursery containers filled with Douglas-fir bark amended with 4 rates $\left(0,1.2,2.4,4.8 \mathrm{~kg} / \mathrm{m}^{3}\right)$ of dolomitic lime interacted with 4 grind blends (0:100, 50:50, 25:75, and 100:0; AG65:AG10, by weight). Initially, $\mathrm{pH}$ increased as the amount of dolomite added increased, and $\mathrm{pH}$ increased faster as the amount of AG65 in the blend increased. By $00 \mathrm{~W} 49$, there were no $\mathrm{pH}$ differences among treatments. Neither dolomite blend nor rate influenced growth of Armeria or Thuja. Use of $100 \%$ AG65 dolomite at any rate inhibited the shoot growth of Arctostaphylos, Heuchera, Vaccinium and Vinca. Shoot growth of Heuchera was increased at $4.8 \mathrm{~kg}$ dolomite $/ \mathrm{m}^{3}$ if $75 \%$ was AG10. Shoot growth of Vaccinium and Vinca was increased at $1.2 \mathrm{~kg}$ dolomite $/ \mathrm{m}^{3}$ if $75 \%$ or $100 \%$ was AG 10 . If pH adjustment of Douglasfir bark substrates is desired, use of AG10 dolomite appears to be a better selection. Results may be different if a different irrigation water source is used.

\section{Poster 163}

\section{Physical Properties of Paper Sludge-amended Media Used} for Evergreen Shrub Production

Robert R. Tripepi* and Mary W. George; Plant Science Division, Univ. of Idaho, PO Box 442339, Mosocw, ID 83844-2339

De-inked paper sludge from a newsprint mill was evaluated as a substitute for softwood bark in container media. Rooted cuttings of 'Youngstown' juniper (Juniperus horizontalis), Fraser photinia (Photinia $x$ fraseri), and 'PJM' rhododendron (Rhododendron) were planted in 3-L plastic pots that contained potting media amended with $0 \%, 20 \%, 40 \%, 60 \%, 80 \%$, or $90 \%$ paper sludge and $80 \%, 60 \%$, $40 \%, 20 \%, 0 \%$, or $0 \%$, bark, respectively, (by volume). All mixes contained $10 \%$ sand and $10 \%$ peat moss, except for the $90 \%$ mix, which lacked peat moss. Initial bulk density, aeration, water-holding capacity, and total porosity were measured for all media. Final aeration, water-holding capacity, and total porosity were also measured after plants grew in the media for 19 weeks. The heights of the potting mix columns in 16 randomly selected pots for each medium were measured during the second and nineteenth weeks to determine if the volume of the growth medium had changed. The mix made with $90 \%$ paper sludge was $\approx 23 \%$ lighter than the control medium that contained $80 \%$ bark (control). Initial aeration, waterholding capacity, and total porosity of paper sludge-amended mixes were significantly higher than those of the control, and aeration of the $90 \%$ sludge mix was over 2.5 -fold higher than that of the control mix. Potting mixes made with $60 \%$ or more paper sludge shrunk by $5 \%$ or more in volume during the experiment. In fact, the volume of the $90 \%$ sludge mix shrunk by almost $13 \%$ during the 17 -week measurement period. This study demonstrated that paper sludge-amended media were light in weight and well aerated, but their volume also shrunk in proportion to the amount paper used in the mix.

\section{Poster 164}

Use of Denim Fiber By-products as a Potting Medium

Pamela Borden*; Dept. of Agriculture, Southwest Missouri State Univ., Springfield, MO

In an effort to evaluate potential uses of a by-product of denim jean stonewashing, the denim fiber/pumice sand by-product of this process was evaluated as a growing medium in two studies, comparing it to sphagnum peat moss as a potting media component and evaluating using the by-product alone or in combination with a commercial potting medium. Species grown in the media mixes included silver maple (Acer saccharinum), Joseph's Coat amaranth (Amaranthus tricolor), flowering tobacco (Nicotiana alata) and wandering jew (Zebrina pendula). After 9 to 12 weeks, plants grown in the $100 \%$ by-product media did not grow as tall or accumulate as much dry matter as plants grown in other single medias or media combinations. In medias containing the by-product mixed with vermiculite or commercial media, the plants grew as well as controls in commercial media or traditional media combinations. Evaluations of the media showed it to have low aeration porosity and high waterholding capacity. The product had a neutral $\mathrm{pH}$ with a low natural nutrient status and low nutrient-holding capacity, similar to sand. It appeared that the by-product alone may not be an effective media for the above species, but its use as a media component may hold promise.

\section{Poster 165}

Paclobuterazol and Uniconazole Applications Improve the Quality of Container-grown Bush Morning Glory

Donita L. Bryan*, Garry V. McDonald, and Michael A. Arnold, Texas A\&M Univ., Dept. of Horticultural Sciences, College Station, TX 77843-2133

Ipomoea carnea von Jacquin subsp. fistulosa (von Martinus ex Choisy) Austin, bush morning glories, were grown in $2.3 \mathrm{~L}$ black plastic nursery containers under typical outdoor container nursery conditions. Paclobutrazol (formulated as Bonzi ${ }^{\circledR}$ ) and uniconazole (formulated as Sumagic ${ }^{\circledR}$ ) were applied as substrate drenches or foliar sprays. Paclobutrazol was tested at drench rates from 0 to 160 $\mathrm{mg} \cdot \mathrm{L}^{-1}$ of active ingredient (a.i.) and as a foliar spray at rates from 0 to $1600 \mathrm{mg} \cdot \mathrm{L}^{-1}$ a.i. Uniconazole was tested at drench rates from 0 to $24 \mathrm{mg} \cdot \mathrm{L}^{-1}$ a.i. and as a foliar spray at rates from 0 to $240 \mathrm{mg} \cdot \mathrm{L}^{-1}$ a.i. Standard form, dwarf, and semi-dwarf genotypes were included in the trials. After evaluation of effects of the growth regulators on production responses, plants were transplanted to landscape beds to evaluate residual or carry-over effects. Paclobutrazol drenches of 40 to $80 \mathrm{mg} \cdot \mathrm{L}^{-1}$ a.i. appear to effectively produce a more compact growth form on the standard bush morning glory plants, without adverse residual effects in the landscape. Uniconazole drenches were usually effective at 1 to $6 \mathrm{mg} \cdot \mathrm{L}^{-1}$ a.i., but this varied with clone and experiment. Uniconazole appeared to have the potential to reduce flowering of the semi-dwarf forms of bush morning glory in the landscape at concentrations of $12 \mathrm{mg} \cdot \mathrm{L}^{-1}$ a.i. or greater. Spray applications of either compound appeared to be less consistent in their effects on bush morning glory growth than their respective drench applications.

\section{Poster 166}

Paclobutrazol as Aids for Phyllirea angustifolia Nursery Production

S. Bañón, J. Ochoa, J.A. Fernández, and J.A. Franco*; Dept. Producción Agaria, Area Producción Vegetal, Universidad Politécnica de Cartagena, Paseo Alfonso XIII, 34, Cartegena, Spain

A study was conducted with native Phyllirea angustifolia seedlings to study the effect of paclobutrazol on the aerial part and root growth. Each seedling was potted into $1860-\mathrm{mL}$ plastic pot filled with a mixture of 2 clay soil: 1 perlite : 1 peat $(\mathrm{v} / \mathrm{v} / \mathrm{v})$, amended with Osmocote (2 g/L substrate) on 20 May 2000 . They were pot-grown in an unheated greenhouse. Paclobutrazol (CULTAR 25\% p/v) at a rate of $6,12,24,48$, and $96 \mathrm{mg}$ per plant was applied to the substrate surface as a single $45-\mathrm{mL}$ liquid-drench on 10 June 2000 . Untreated plants acted as control. No irrigation was applied after the nursery period. Plant parameters were measured on aerial part and roots on 10 Oct. 2000 (end of the nursery period) and survival percentage was determined 2 months after (drought period). For the root growth study, a Winrhizo LA1600 was used. All paclobutrazol doses reduced significantly plant height (by $34.9 \%$ to $69.8 \%$ ), internode length (by $43.5 \%$ to $73.9 \%$ ), leaf blade area (by $12.9 \%$ to $63.2 \%$ ), leaf area (by $33.7 \%$ to $81.4 \%$ ), and dry weight (by $46.5 \%$ to $79.1 \%$ ) compared with the control. Only $96-\mathrm{mg}$ statistically altered the number of shoots per plant, increasing it by $28.6 \%$ compared with the control. Paclobutrazol significantly reduced root volume (by $18.7 \%$ to $31.6 \%$ ), total root length (by $18.2 \%$ to $37.1 \%$ ), and root length $<0.5 \mathrm{~mm}$-diameter (by $22.4 \%$ to $58.9 \%$ ) compared with the control. However, doses at 24 or $96 \mathrm{mg}$ increased root length 1-2 $\mathrm{mm}$-diameter and doses 12, 24, 48, and $96 \mathrm{mg}$ increased root length $>2 \mathrm{~mm}$-diameter (45.4\% to $80.7 \%$ ) compared with the control. The effect of paclobutrazol doses on root dry weight was nonsignificant and only $96-\mathrm{mg}$ dose modified the root/aerial part dry weight ratio, increasing it from 0.36 (control) to 1.21. Doses 24,48 and $96 \mathrm{mg}$ increased the survival percentage during the drought period. These 
results showed the ability of paclobutrazol on both pot plant adaptation and hardening of Phyllirea angustifolia. Research supported by project CICYT-FEDER 1FD97-0420-C02-01.

\section{Poster 167}

Evaluation of Ethephon as a Growth Promoter for Several Horticultural Plant Species

Julie C. Straus and Pamela Borden*; Dept. of Agriculture, Southwest Missouri State Univ., Springfield, MO

Exogenous applications of ethephon were evaluated for their potential to promote growth of seedlings of a number of horticultural plant species. Treatments were applied either as 24 hour, pre-plant seed soaks or as drench applications after seed germination or rooting of cuttings. Seed species evaluated included Adenium obesum, Carya illinoensis (Wangenh.) K. Koch (pecan), Kniphofia uvaria (Red hot poker), Picea pungens Englm. (Colorado blue spruce), Quercus alba L. (white oak), Quercus velutina Lam. (black oak), Tagetes patula (french marigold). Drench treatments were applied to cuttings of Vitis 'Norton,' and Zebrina pendula (wandering jew). Treatments were 0, 50, 100, 200, 400, 800, and 1600 ppm. For Adenium obesum, which received the pre-plant seed soaks, at 12 weeks after treatment, shoot length increased signficantly over controls by all but the two highest rates. Adenium stem diameter, fresh weight and root lengths had the tendency to be greater than controls for all treatments except the 1600 ppm treatment. Presoaking pecan seeds provided the same trends, although none of the data was significant using the $\mathrm{LSD}_{0.05}$ means comparison test. Compared to controls, the $50,100,200$, and 400 ppm treatments produced a strong trend of increased plant dry weight, root length and shoot length. Data from the other species will be included in the poster presentation.

\section{Poster 168}

Effects of Nursery Irrigation on Postplanting Development of Limonium cossonianum 0 . Kuntze in Semiarid Conditions J.A. Franco*, V. Cros, S. Bañón, and J.J. Martínez-Sánchez; Dept. Producción Agraria, Área Producción Vegetal, Universidad Politécnica de Cartagena, Alfonso XIII, 34, 30203 Cartagena, Spain A study was conducted with Limonium cossonianum $O$. Kuntze to analyze the influence of irrigation regime in nursery on the development (root dynamics and top development) after being transplanted with minimum management conditions. Plants were pot-grown in a greenhouse. Each plant was potted into $625-\mathrm{mL}$ plastic pot filled with a mixture of 1 silica sand medium : 1 peat $(\mathrm{v} / \mathrm{v})$ amended with Osmocote plus ( $3.7 \mathrm{~g} \cdot \mathrm{kg}^{-1}$ substrate). Drip irrigation was used, with a 2-L/h emitter per plant. Two irrigation treatments were used: T3, plants watered 6 days a week at the water-holding capacity (leaching $20 \%$ of the applied water); and T1, plants watered twice a week, receiving an amount of water at $30 \%$ of T3 plants troughout the nursery period (45 days). After nursery period, plants were transplanted in the open air at the southeast Mediterranean coast of Spain without establishment irrigation (NW treatment) and with just one establishment irrigation $(50 \mathrm{~mm})$ (YW treatment). There were three replications. Plant root and top growth were measured weekly for 13 months. For the root dynamics study, minirhizotrons were used. Acrylic tubes, 2-m long and 80-mm outside diameter, were placed at a inclination of $24^{\circ}$, reaching a total depth of $160 \mathrm{~cm}$. The evolution of the root length density (RLD) was measured by seven $23-\mathrm{cm}$-deep soil layers. Results indicate that YW plants that were less watered in the nursery showed a greater RLD for the whole soil profile. For $Y W$ treatment, plants root growth, for the top $46 \mathrm{~cm}$ of soil, were not significantly affected by irrigation treatments; between 46 and 115 $\mathrm{cm}$ deep, T1 plants showed greater RLD than T3 (average values of 0.6 vs. $0.3 \mathrm{~cm} \mathrm{~cm}-3$ ); under $115-\mathrm{cm}$ deep (where root growth was more limited), were nonsignificant differences. For the first 6 months, a important plant top growth was observed in YW, there being no significant differences among irrigation treatments. The harsher the conditions after transplantation (no water in the establishment) the more evident the positive effect of hardening in the nursery; never- theless the YW plants showed greater and more rapid root and top growth than the NW plants. Research supported by projects CICYT AGF-96-1136-C02-02 and CICYT-FEDER 1FD97-0420-C02-01.

\section{Poster 169}

Estimation of Relative Water Use Among Ornamental Landscape Species

M. Carmen García-Navarro', Richard Y. Evans ${ }^{* 1}$, and Robert Savé Montserrat2; 'Dept. of Environmental Horticulture, Univ. of California, Davis, CA 95616-8587; ' 2Dept. de Tecnologia Hortícola, Institut de Recercai Tecnologia Agroalimentaries 08348, Cabrils (Barcelona); Spain

Low water use plantings may enhance water conservation in dry landscapes. However, appropriate plant selection is hindered by the dearth of information available on the water needs of different species. A direct method of classification was tested under the hypothesis that relative water use by woody landscape species growing in $4-L$ containers would be representative of the water use of the same species in the landscape. The water use of four species (Leucophyllum frutescens, Spiraea vanhouteii, Viburnum tinus, and Arctostaphylos menziesii) was measured in plants growing in 4-L containers and compared to that of the same species growing in drainage lysimeters, representative of landscape conditions. Half of the plants were subjected to successive cycles of stress by withholding water after irrigation to container capacity in containers, or applying a fraction of the potential evapotranspiration in lysimeters. The good fit of the regression of average daily water use by lysimeter plants on average daily water use by container plants $\left(R^{2}=0.87\right)$ reflects the consistency of relative water use of the four species. Measurement of water use at the end of nursery production may be useful for predicting the relative water use of various species after establishment in the landscape.

\section{Poster 170}

Container Production of Camellia oleifera as Influenced by Level of Light Exclusion

John M. Ruter*; Univ. of Georgia, Tifton, GA

The tea oil camellia, Camellia oleifera, is used extensively in the orient for cooking oil, inks, lubricants, and cosmetics. Commercial production in China has decreased dramatically in the last 10 years while demand has increased. While tea oil has been produced in China since 1949, no production is known to have occurred in the United States. With loss of traditional agricultural commodities and low prices, growers are looking for alternative crops. Seed of Camellia oleifera PI 162475 from the U.S. National Arboretum was obtained in Fall 1999 and germinated. A study was initiated to determine the best levels of light exclusion for production of container-grown seedlings. Treatments consisted of: 1) full sun; 2) $30 \%$ light exclusion under woven shade cloth; and 3) $55 \%$ light exclusion under shade cloth. Plants were grown in \#1 (3.8 L) containers with an 8 pine bark : 1 sand $(\mathrm{v} / \mathrm{v})$ substrate and were fertilized with $30 \mathrm{~g}$ of Osmocote Plus $15 \mathrm{~N}-4 \mathrm{P}-10 \mathrm{~K}$ (8-9 month) fertilizer. The study was initiated in April and terminated in Nov. 2000. Final plant height, leaf area, leaf dry mass, stem dry mass, specific leaf area, root dry mass, and total biomass were greater for plants grown under $30 \%$ light exclusion compared to plants in full sun. Plant growth at $55 \%$ light exclusion was generally intermediate between plants grown in full sun and $30 \%$ light exclusion. Dark-acclimated chlorophyll fluorescence measurements ( $\mathrm{Fv} / \mathrm{Fm})$ made in July indicated that photoinhibition was not a problem in full sun.

\section{Poster 171}

Preemergence Weed Control in Container-Grown Herbaceous Perennials

David Staats* and James E. Klett; Dept. of Horticulture and Landscape Architecture, Colorado State Univ., Fort Collins, CO 80523

During the 2000 season, preemergent herbicides were applied to container grown herbaceous perennials and woody palnts and evaluated for weed control, phytotoxicity, and effect on plant growth. The 
herbicides and rates were: Oxyfluorfen + Pendimethalin (Scotts Ornamental Herbicide II) 3 and 6 lbs ai/A, Napropamide (G) (Devrinol) 3 and $6 \mathrm{lbs}$ ai/A, Oryzalin (Surflan) 2 and $4 \mathrm{lbs}$ ai/A, Oxadiazon (Ronstar) 4 and $8 \mathrm{lbs}$ ai/A, Oxyfluorfen + Oryzalin (Rout) 3 and $6 \mathrm{lb}$ ai/ A, Prodiamine (Barricade) 0.65 and $1.3 \mathrm{lbs}$ ai/A, Pendimethalin (Scotts Ornamental Weedgrass Control) 2 and $4 \mathrm{lbs}$ ai/A, Benefin + Trifluralin (Team) 2 and $4 \mathrm{lbs}$ ai/A. Herbicides were applied to Cytisus purgans Spanish Gold ${ }^{\text {TM}}$, Rhamnus smithii, Buddleja alternifolia 'Argentea', Agastache rupestris, Diascia integerrima Coral Canyon ${ }^{\mathrm{TM}}$, and Zauschneria arizonica. All plant and herbicide combinations did not result in any significant decline in plant growth due to phytotoxicity. Herbicides provided between $70 \%$ and $100 \%$ weed control. In several occasions, Rout, Ronstar and Scotts Ornamental Herbicide II resulted in significantly better weed control than other herbicide treatments.

\section{Poster 172}

Exposure and Plant Size Affect Establishment of Kalmia latifolia

Amy N. Wright ${ }^{\star 1}$, Stuart L. Warren', Frank A. Blazich ${ }^{1}$, Robert D. Wright ${ }^{2}$, and J. Roger Harris ${ }^{2}$; ${ }^{2}$ Dept. of Horticultural Science, North Carolina State Univ., Raleigh, NC 27697-7609; ${ }^{2}$ Dept. of Horticulture, Virginia Polytechnic Institute and State Univ., Blacksburg, VA 240610327

Research was conducted at the Horticulture Field Laboratory, North Carolina State Univ., Raleigh, to determine effects of exposure and transplant size on landscape establishment of Kalmia latifolia L. (mountain laurel). Exposures in four directions (north, south, east, and west) were provided by square structures constructed from four panels of $1.8 \times 2.4 \mathrm{~m}$ spruce fencing material. In May 1999, plants of K. latifolia 'Olympic Wedding' in 1-L, 7.6-L, and 19-L containers were planted in tilled plots in two parallel rows running lengthwise along each side of a structure with one plant of each container size per row. Growth index measurements (plant height + mean plant width) were taken for each plant at the start of the experiment and after one and two growing seasons. Plants were also rated visually for color, foliage denseness, and overall plant quality, and plant mortality was recorded. Mortality was highest for the western exposure $(50 \%)$, occurred less frequently on the southern exposure $(28 \%)$, and the northern and eastern exposures had the lowest mortality $(25 \%$ and $17 \%$, respectively). Mortality was higher for $1-\mathrm{L}(59 \%)$ than $7.6 \mathrm{~L}-$ plants (15\%) and did not occur for 19-L plants. Growth index of the surviving 1-L and 7.6-L plants increased during both growing seasons, whereas growth index of the 19-L plants decreased during the second growing season. Visual ratings for foliage denseness and overall quality were highest for 7.6-L plants, lower for the 1-L plants, and the $19-L$ plants had the lowest values for these two ratings. The decrease in growth index of the 19-L plants at the end of the second growing season coupled with reductions in visual ratings for foliage denseness and overall quality suggest that mortality of these plants may commence with time.

\section{Poster 173}

Crape Myrtle: A Versatile Woody Ornamental

Raul I. Cabrera ${ }^{*, 2}$ and Daniel Lineberger'; Texas A\&M Univ., 'Dept. of Horticultural Sciences and ${ }^{2}$ Texas Agricultural Experiment Station Research and Extension Center, 17360 Coit Road Dallas, TX 75252

The crape myrtle (Lagerstroemia sp. L.), native to China and SE Asia, is a naturalized, and widely popular, woody ornamental flowering shrub/small tree in southern United States. The wide assortment of inflorescence colors, forms and sizes, coupled with a rather long flowering period (up to 120 days), plus a commonly found exfoliating bark, have given rise to the popularity of this genus. Recent breeding programs in USA and Europe, based mostly on three species ( $L$. indica, $L$. fauriei, and $L$. subcostata), have generated a wide range of plant sizes (from miniature $30 \mathrm{~cm}$ shrubs to $+10 \mathrm{~m}$ tall trees), plant shapes (growth habits), cold hardiness (Zone 6-10), disease resistance (powdery mildew), and foliage fall colors. Likely unknown to ornamental horticulturists are the commercial timber and medicinal uses of some species (out of about 50 ) in the Lagerstroemia genus.
Efforts are underway to release a comprehensive, web-based, searchable database with descriptions and pictures of all the Lagerstroemia species and cultivars available in USA and abroad. Details on the database and website will be presented, along with a summary of current research projects with crape myrtles.

\section{Poster 174}

Landscape Evaluation of Grasses Native to Florida

Jeffrey G. Norcini* and James H. Aldrich; Univ. of Florida, North Florida Research and Education Center, Rt. 4 Box 4092, Monticello, $F L, 32344$

A study was initiated to help determine long-term performance of several native grass species under low input landscape conditions. Containerized plants were transplanted in a fenced-in garden during Mar., Apr., or May 1998, and evaluated monthly during the 1998, 1999, and 2000 growing seasons. Most native species in this evaluation were north or central Florida ecotypes. There were six replications per species arranged in a completely random design. The species were: Agrostis hyemalis (Walt.) B.S.P. (ticklegrass); Andropogon capillipes Nash (chalky bluestem); Aristida beyrichiana Trin. \& Rupr. (wiregrass); Aristida spiciformis Ell. (bottlebrush threeawn); Chasmanthium latifolium (Michx.) Yates (Indian woodoats); Ctenium aromaticum (Walt.) Wood (toothache grass); Dichanthelium laxiflorum (Lam.) Gould (openflower rosette grass); Eragrostis hirsuta (Michx.) Nees (bigtop lovegrass); Muhlenbergia capillaris (Lam.) Trin. (gulf muhly grass); Pityopsis graminifolia (Michx.) Nutt. (grassleaf golden aster-a dicot with grass-like foliage); Saccharum alopecuroidum (L.) Nutt. (silver plumegrass); and Sorghastrum secundum (EII.) Nash (lopsided Indiangrass). The topranked grasses, based on aesthetic qualities and survival, were Andropogon capillipes, Chasmanthium latifolium, Eragrostis hirsuta, and Muhlenbergia capillaris.

5:00-6:00 p.m. .CC Ballroom

\section{Poster Session 14: Plant Nutrition \\ Poster 240}

Preliminary Evaluations of Fertilization Practices in ShortDay Dry Bulb Onion Production in Southeast Georgia G.E. Boyhan* and C.R. Hill; Univ. of Georgia

Onions have traditionally been considered heavy feeders, however, over-fertilization can be costly and result in problems such as increased disease and decreased shelf life. This is particularly true with short-day onions. Current Univ. of Georgia recommendations call for $146-168 \mathrm{~kg} / \mathrm{ha}$ of nitrogen from transplanting to harvest with many growers applying even higher rates. Our study looked at nitrogen rates of 112,140 , and $168 \mathrm{~kg} / \mathrm{ha}$ and found no differences in yield. Soil test results indicated the need for $121 \mathrm{~kg} / \mathrm{ha}$ of potassium. Yields with potassium at rates of 65,93 , or $121 \mathrm{~kg} / \mathrm{ha}$ showed no difference as well. There were no yield differences based on nitrogen fertilizer sources. Nitrogen fertilizer sources included diammonium phosphate, ammonium nitrate, calcium nitrate, and fortified peat (10\% nitrogen). These preliminary results suggest that lower fertilizer rates may be applicable in short-day dry bulb onion production in southeast Georgia.

\section{Poster 241}

The Effect of Sulfur Application Rates on the Yield of Sweet Onions in Kula, Hawaii

R. Shimabuku, H.R. Valenzuela*, J. Cho, and W. Sun; Univ. of Hawaii at Manoa, College of Tropical Agriculture and Human Resources, Honolulu, HI 96822-2279; and WS, Hawaii Agricultural Research Center, Aiea, HI 96071

The Kula, Maui sweet onions are a popular high-value crop exported year-round to up-scale specialty markets throughout the U.S. With the goal of developing an integrated crop management program recent research was conducted to identify improved cultivars, drip irrigation timing and rates, and alternative controls for key pests. To improve postharvest quality, nutrition research is also 
needed to identify factors that may affect onion growth and quality within and between fields, shelf-life, and the taste and mildness of the Maui sweet onion. Thus, an experiment was conducted in Spring 2000 to evaluate the effect of 5 sulfur fertilizer rates and the timing of application on the growth, yield, and postharvest quality of onions. The seven treatments included a control; sulfur applied at $1 \times(20 \mathrm{~kg} /$ ha), $2 x, 4 x$, and $8 x$ rates; and two split $S$ applications at the $1 x$ and $8 x$ rate levels. The levels of other fertilizer nutrient applications were the same for all treatments. Each treatment consisted of a 13 by 1.5 $\mathrm{m}$ bed, with 8 rows per bed. Treatments were replicated four times, arranged in a RCB design. Greatest mean bulb weights and lowest coefficient of variation levels were obtained with the $1 \times(20 \mathrm{~kg} / \mathrm{ha}) \mathrm{S}$ application rates. The $8 \times \mathrm{S}$ rates resulted in yields similar to those obtained in the unfertilized controls. Yields obtained with split $S$ applications were similar to those obtained with preplant S applications. The effect of $S$ soil fertility on onion growth and postharvest quality will be further discussed.

\section{Poster 242}

A Comparison of Potassium Chloride and Potassium Magnesium Sulfate as Fertilizers for Muskmelons

Elizabeth T. Maynard*; Northwest Commercial Horticulture Program, Dept. of Horticulture and Landscape Architecture, Purdue Univ.

Potassium chloride $(\mathrm{KCl})$ and potassium magnesium sulfate (KMag) were compared as sources of potassium $(\mathrm{K})$ for muskmelon (Cucumis melo) production in northern Indiana in 1999 and 2000. Muskmelon cv. Eclipse was grown on a sandy loam soil containing $302 \mathrm{~kg} / \mathrm{ha} \mathrm{K}$ and $280 \mathrm{~kg} / \mathrm{ha} \mathrm{Mg}$ prior to fertilization. Three main plot treatments included: 1) $\mathrm{KCl}$, 2) $\mathrm{KCl}$ + Magnesium sulfate (KCIMgS), and 3) $\mathrm{KMag}$. Four $\mathrm{K}$ rates were applied to subplots within each main plot: $0,0.5,1.0$, and 2.0 times the recommended rate of $78 \mathrm{~kg} / \mathrm{ha} \mathrm{K} 2 \mathrm{O}$. The KCIMgS treatments received enough magnesium sulfate to supply magnesium equivalent to that supplied by the KMag treatment at the same K rate. K source did not affect total marketable yield in either year. In 2000 , total marketable yield increased as $\mathrm{K}$ rate increased up to a point, as indicated by significant linear and quadratic trends. Early marketable yield was greater with KMag than with KCl in 1999, and was lowest with KCIMgS in 2000. In 2000 only, early yield decreased as $\mathrm{K}$ rate increased. $\mathrm{K}$ rate did not influence average melon weight in either year. In 2000, average melon weight was less in $\mathrm{KCIMgS}$ treatments than in $\mathrm{KCl}$ treatments. Petiole sap $\mathrm{K}$ concentration and leaf tissue concentrations of $\mathrm{K}, \mathrm{Mg}, \mathrm{S}$, and $\mathrm{Cl}$ were influenced by $\mathrm{K}$ rate, and in some instances by $\mathrm{K}$ source. These results suggest that muskmelons fertilized with $\mathrm{KCl}$ or $\mathrm{KMag}$ produce similar quantities and quality of fruit when grown on sandy loam soils moderately high in $\mathrm{K}$ and $\mathrm{Mg}$. There is no evidence that preplant applications of $\mathrm{K}$ at rates greater than are currently recommended will increase yield or fruit quality.

\section{Poster 243}

\section{Nitrogen Mineralization of Grass Clippings-A Case Study in Fall Cabbage Production}

J.R. Heckman*, U. Krogmann, and L.S. Boyles; Dept. of Plant Science, Rutgers Univ., New Brunswick, NJ 08901-8520

The impact of land application of municipal turfgrass clippings was evaluated over a 3-year period using fall cabbage as a test crop. Our specific objectives were to: 1) characterize the composition of the applied grass clippings, 2) monitor soil $\mathrm{NH}_{4}-\mathrm{N}$ and $\mathrm{NO}_{3}-\mathrm{N}$ concentrations in the surface $30-\mathrm{cm}$ of soil during the initial 10 weeks after application, and 3) determine cabbage yield at various application rates $\left(0,152,304,609\right.$, and $\left.1,218 \mathrm{~m}^{3} / \mathrm{ha}\right)$ of grass clippings. Based on nine samples of municipal collected grass clippings, the minimum-maximum and mean nutrient concentration values on a dry weight basis were as follows: $(\mathrm{g} / \mathrm{kg})$ total Kjeldahl N, 23.4 to 38.0 , $30.4 ; \mathrm{P}, 2.3$ to $5.6,4.0 ; \mathrm{K}, 14.4$ to $23.2,18.8$. The application of 609 and $1218 \mathrm{~m}^{3} /$ ha of grass clippings resulted in excessive mineral $\mathrm{N}$ concentrations in soil and was associated with stunting of cabbage transplanted into the soil. Our findings suggest that grass clippings be applied only at moderate rates $\left(<609 \mathrm{~m}^{3} / \mathrm{ha}\right)$ and that supplemental $\mathrm{N}$ may be applied if necessary to ensure maximum yield. The presidedress soil nitrate test may be used to predict whether or not supplemental $\mathrm{N}$ is needed. Our findings also indicate that immediate incorporation of grass clippings conserves volatile $\mathrm{N}$ and reduce the need for sidedress $\mathrm{N}$.

\section{Poster 244}

Nitrogen Best Management Practices for Broccoli Production in the San Joaquin Valley, CA

Michelle Le Strange ${ }^{* 1}$, Jeffrey P. Mitchell ${ }^{2}$, and Louise E. Jackson ${ }^{3}$; ${ }^{1}$ Univ. of California Cooperative Extension, Farm Advisor Tulare \& Kings Counties; ${ }^{2}$ Univ. of California Cooperative Extension, Vegetable Crops Specialist, Kearney Agricultural Center; ${ }^{3}$ Univ. of California, Vegetable Crops Dept., Davis, CA

Three field studies were conducted on a Panoche clay loam in the San Joaquin Valley. Primary objectives were to: 1) determine N fertilizer best management practices (BMPs) for broccoli production; 2) determine if BMPs change for fall vs. spring harvested broccoli; and 3 ) to identify nitrate movement and potential nitrate leaching losses of applied $\mathrm{N}$ fertilizer under furrow irrigation. A secondary objective was to evaluate the "Cardy meter" for quick test nitrate values for decision-making during the growing season. Thirteen fertilizer treatments ranged from $0-300 \mathrm{lb} / \mathrm{a}(0-336 \mathrm{~kg} / \mathrm{ha})$ of N. Five treatments were split applications at preplant, thinning (sidedress 1 ), and layby (sidedress 2) with less $\mathrm{N}$ applied preplant and at thinning and twice the rate applied at layby. Five treatments were two equal applications (preplant and thinning) of the total applied N. Two treatments investigated high rates of $\mathrm{N}(240 \mathrm{lb} / \mathrm{a}, 269 \mathrm{~kg} / \mathrm{ha})$ applied in a single application either at preplant or thinning. One treatment received no $\mathrm{N}$ fertilizer. Soil, plant tissue, whole plant, and ion exchange resin (IER) bag samples were collected to measure $\mathrm{N}$ and nitrate pools within the soil, plant, and/or leachate water of the broccoli cropping system. Yield and broccoli quality measurements were also collected. Results indicate that the more $\mathrm{N}$ applied, the more yield, the larger the broccoli head, the more $\mathrm{N}$ remaining in the soil, the more $\mathrm{N}$ in petioles and whole plants. The response to increasing applied $\mathrm{N}$ was significantly different for fall versus spring harvested broccoli. There were highly significant correlations between laboratory analysis of petiole nitrate and the Cardy meter ( $r=$ 0.855 ). Although there was no difference in yield between three treatments of $240 \mathrm{lb} / \mathrm{a}$ of $\mathrm{N}$, there were significant differences in $\mathrm{N}$ within the plant, postharvest soil $\mathrm{N}$, and in nitrate collected from resin bags buried $90 \mathrm{~cm}$ in the soil. Best management practices would be to minimize nitrate in the environment after harvest or to use it in a subsequent crop rotation.

\section{Poster 245}

Comparability of Swine Effluent, Chicken Litter, and Inorganic Fertilizers for Early Sweet Corn Production Kent E. Cushman* and Thomas E. Horgan, Horticulture Research \& Education Unit, North Mississippi Research \& Extension Center, Mississippi State Univ., Verona, MS 38879

Five fertilizer treatments, three of which included swine effluent and one of which included chicken litter, were evaluated for early production of sweet corn (Zea mays cv. Arrow II) using black plastic mulch and raised beds. Treatments compared inorganic and organic fertilizer sources applied preplant and postplant. Treatments received equal amounts of $\mathrm{N}, \mathrm{P}$, and $\mathrm{K}$ and were applied as follows. 1) $100 \%$ of $\mathrm{P}$ and $\mathrm{K}$ applied preplant and $100 \%$ of $\mathrm{N}$ applied postplant by drip irrigation. All fertilizers were inorganic. 2) $10 \%$ of $\mathrm{P}$ and $\mathrm{K}$ applied preplant and the remaining $\mathrm{N}, \mathrm{P}$, and $\mathrm{K}$ applied postplant by drip irrigation. Again, all fertilizers were inorganic. 3) $10 \%$ of $P$ and $\mathrm{K}$ applied preplant from inorganic sources and the remaining $\mathrm{N}, \mathrm{P}$, and $\mathrm{K}$ applied postplant from swine effluent. 4) $50 \%$ of N, P, and $\mathrm{K}$ applied preplant from inorganic sources and the remaining $N, P$, and Kapplied postplant from swine effluent. 5) $50 \%$ of N, P, and Kapplied preplant from chicken litter and the remaining $\mathrm{N}, \mathrm{P}$, and $\mathrm{K}$ applied postplant from swine effluent. Experiments were conducted at two 
locations in northern Mississippi in the spring of 2000. Data from both locations were pooled due to no significant treatment by location interaction. There were no significant differences between treatments for dozens of ears per acre, weight per acre, weight per ear, or ear length. Analyses of leaf tissue element concentrations also showed no significant differences between treatments. These results indicate that any of these five approaches for early sweet corn fertilization are adequate to produce high yields.

\section{Poster 246}

Nutrient Analysis of Commercial Organic Fertilizers for Greenhouse Vegetable Production

Robert G. Anderson* and L. Stefanie Schmidt; Dept. of Horticulture, Univ. of Kentucky, Lexington KY 40546

A segment of the greenhouse crop market would like to obtain vegetables and herbs that are certified organic. Commercial organic fertilizers were used to grow 'Ostinata' bibb and 'Red Sails' leaf lettuce in a tank or float production system, and were analyzed weekly for the levels of nutrients. Water soluble materials derived from algae (Algamin and EcoNutrients) had no value as an organic fertilizer for lettuce. Dry weight of lettuce grown with these materials was only $10 \%$ to $18 \%$ of those grown in inorganic fertilizer, depending on cultivar. Nitrate nitrogen and phosphorus levels were less than $1 \%$ and potassium was $5 \%$ to $20 \%$ of the recommended levels at the label rate for these fertilizers and 3 times the label rate. Dry weight of lettuce grown with a formulated organic fertilizer (Omega 6-6-6) was significantly similar or lower than lettuce grown in inorganic fertilizer, depending on the cultivar. Although dry weights were similar, head size was visually smaller with the organic fertilizer. Nitrate levels were $50 \%$, P levels were $300 \%$ and K levels were $100 \%$ to $120 \%$ of recommended levels.

\section{Poster 247}

Effect of Nitrogen Source and Rate on the Nitrogen Status, Pest Pressures, and Yield of Onions Grown on Muck and Mineral Soil in Ontario

S. Westerveld ${ }^{* 1}$, A. McKeown ${ }^{1}$, M.R. McDonald ${ }^{* 1}$, and C. ScottDupree ${ }^{2}$; ${ }^{D e p t}$. of Plant Agriculture, Univ. of Guelph, Guelph, Ont., Canada, N1G 2W1; ${ }^{2}$ Dept. of Environmental Biology, Univ. of Guelph, Guelph, Ont., Canada, N1G 2W1

Nitrogen $(\mathrm{N})$ source and rate experiments were conducted on both muck (60\% organic matter) and mineral soil in Ontario in 1999 and 2000. Onion cultivars, Hamlet and Tribute in both years, Gazette and Turbo in 1999, and Prince and Norstar in 2000, were seeded in muck soil. 'Winner' was seeded on mineral soil in 2000 . On muck soil in both years, $\mathrm{N}$ fertilizers, ammonium nitrate $(34 \%)$, calcium ammonium nitrate $(27.5 \%)$, urea $(46 \%)$, potassium nitrate $(14 \%)$ and calcium cyanamide $(19 \% \mathrm{~N}, 50 \% \mathrm{CaO})$ were applied at $90 \mathrm{~kg} \mathrm{~N} / \mathrm{ha}$, the muck soil recommended rate, along with a no nitrogen check. In 2000 , on muck and mineral soil, rates of $0 \%, 100 \%, 200 \%, 50 \%$ preplant plus $50 \%$ sidedress, and $100 \%$ preplant plus $333 \%$ sidedresses of the recommended rate $(120 \mathrm{~kg} \mathrm{~N} / \mathrm{ha}$ for mineral soil) were tested. Tissue samples from selected cultivars were harvested three times during the growing season. In 2000, a Cardy nitrate meter, and SPAD-502 chlorophyll meter were also used to indicate the $\mathrm{N}$ status of the plants. Onion thrips (Thrips tabacl) were monitored weekly on selected treatments in 2000. There was no effect of $\mathrm{N}$ source or rate on yield, except in 1999 where calcium cyanamide produced the highest yield $(69.7 \mathrm{t} / \mathrm{ha})$. In both years, yield varied with cultivar. There were no differences in $\mathrm{N}$ content among any of the treatments. Nitrate meter readings were poorly correlated with chlorophyll meter readings. Thrips populations were unaffected by treatment. The results suggest that $\mathrm{N}$ recommendations for onions in Ontario may need to be revised.

\section{Poster 248}

The Effects of Applications Forms of Potassium Fertilizer on the Growth, Flowering, Fruiting and Yield of Tomato Plants

Cesar A Ruiz and Juan E Manzano-Méndez*; Méndez. Fondo
Nacional de Investigaciones Agropecuarias-Estación Experimental Falcón, Venezuela S.A.; Posgrado de Horticultura, Decanato de Agronomía, P.O Box 815, Universidad Centroccidental Lisandro Alvarado, Barquisimeto 3001, Venezuela S.A.

Tomato plants (Lycopersicon esculentum Mill. cv. Rio Grande) were fertilized with three levels of potassium chloride $(0,220$, and $330 \mathrm{~kg} / \mathrm{ha}$ ), applied in the soil in three different ways (central down, besides to the plant and to lie down at the bottom in the furrow). Tomato plants were growing in a soil classified as Haplocambirds in Guarabal area, in the Federation county of Falcon State in Venezuela. Seven treatments and six replications were used in a randomized complete-block design. The variables analyzed were height of the plant, number of primary branches, numbers of bloom flowers, number of flowers, number of fruits per plant, percentage of fruit set, percentage of losses flowers, numbers of fruits, fruit weight, average of fruit weight, tomato production $\mathrm{kg} / \mathrm{ha}$, and foliar $\mathrm{N}, \mathrm{P}, \mathrm{K}, \mathrm{Ca}$, and $\mathrm{Mg}$ content in the plant. Height of the plant, number of flowers per plant, and fruit weight were influenced directly positively with the highest potassium chloride doses used. The highest potassium foliar concentration was found in the plant flowering phase. The application's position of the potassium fertilizer did not have any influence on the plant height and on the numbers of the primary branches. The $330 \mathrm{~kg} / \mathrm{ha}$ fertilizer level of $\mathrm{KCl}$ influenced positively in the numbers of flower, fruits set and number of fruit per plant. These results suggested that under our conditions the highest amount of potassium fertilizer used was the best treatment for improving tomato production.

\section{Poster 249}

Potato Yield and Quality Response to Variable Rate Nitrogen Fertilizer

K.M. Whitley ${ }^{* 1}$, J.R. Davenport', and S.R. Manley'; ${ }^{1}$ Washington State Univ.-Prosser; ${ }^{2}$ Benton Conservation District

Potato (Solanum tuberosum L.) is a widely grown, high value crop in Washington State's Columbia Basin. The combination of coarse textured soils (sandy loam to loam) and hilly topography in this region as well as the high nitrogen requirement of potato have lead to interest in nitrogen management. Topography contributes to the movement of nitrogen $(\mathrm{N})$ in the field by affecting water infiltration and the direction of flow. The landscape is typically hilly in the large $(\approx 55 \mathrm{ha})$ center pivot irrigated fields. The movement of the water, thus nitrate-N, results in a wide range of nitrogen values across a field. Potato growth and development can vary with the nitrogen across the field and can be affected by the excess or shortage of nitrogen created. Site Specific Crop Management (SSCM) and Variable Rate Technology (VRT) are potential tools to develop strategies for nitrogen fertilizer management in these systems. In this two-year study, two adjacent potato fields were selected each year (1999 and 2000). Each field was soil sampled on a $61 \mathrm{~m} \times 61 \mathrm{~m}$ grid to determine fertilizer application rates. One field was fertilized with variable nitrogen rate while the other was conventionally fertilized, applying a uniform rate across the field based on the field average. Sites for monitoring seasonal changes were selected based on landscape position (knoll, slope, valley) and soil test organic matter content. In season petiole and soil samples were gathered at two key phenological stages, tuber initiation and tuber bulking. Whole plant samples were collected near the end of the season to determine plant biomass and nitrogen partitioning. Soil moisture was also monitored throughout the growing season. This paper will discuss how variable rate fertilizer application compares to conventional in terms of crop yield, quality, and nitrogen partitioning.

\section{Poster 250}

\section{Perchlorate Accumulation in Lettuce}

Allen V. Barker ${ }^{* 1}$, and Steven H. Lamm²; 'Univ. of Massachusetts, Amherst, MA 01003; ${ }^{2}$ Consultants in Epidemiology and Occupational Health, Inc., Washington, DC

Perchlorate detection in soils and groundwater has occurred as the results of its use in military and industrial activities. Since perchlorate is water soluble and can persist in soils and water, attention has been 
directed to perchlorate accumulation in edible crops. In this experiment, perchlorate accumulation in lettuce (Lactuca sativa L.) was studied in hydroponics with plants grown individually in $1.5 \mathrm{~L}$ of treatment solutions with 0.4 or $4 \mathrm{mg}$ perchlorate per liter. As the plants grew and absorbed water from the vessels, solutions were added daily to maintain the volume at $1.5 \mathrm{~L}$. At weekly intervals, the solutions were discarded and replaced with fresh solutions. Plants were grown for 3 weeks following this protocol. The treatments with perchlorate had no harmful effects on lettuce growth and may have had a beneficial effect. After harvest, the dry mass of each plant sample was ground, and a portion was extracted with $0.005 \mathrm{M} \mathrm{NaOH}$. Perchlorate determinations in the extracts were by ion chromatography. Each time that the nutrient solution in the plant vessels was changed, a portion of the spent solution was retained. These solutions and fresh solutions were analyzed for perchlorate by ion chromatography. Perchlorate bioaccumulation was estimated from the determinations of perchlorate in extracts of dried leaves and by the removal of perchlorate from the nutrient solutions. The lettuce accumulated on a dry mass basis over $900-\mathrm{mg}$ perchlorate/ $\mathrm{kg}$ with the $4 \mathrm{mg} / \mathrm{L}$ treatment and over 130 $\mathrm{mg} / \mathrm{kg}$ with the $0.4-\mathrm{mg} / \mathrm{L}$ treatment. The mean wet mass concentrations of the lettuce grown in $4 \mathrm{mg}$ perchlorate was $54.4 \mathrm{mg} / \mathrm{kg}$ and in the $0.4 \mathrm{mg} / \mathrm{kg}$ treatment was $8.2 \mathrm{mg} / \mathrm{kg}$. The bioaccumulation factors on a fresh mass basis were $\approx 8$ to 12 with the high level of perchlorate and $\approx 12$ to 20 with the low level of perchlorate, with the lower values in the ranges being estimates based on perchlorate removal from solution and the upper ranges being based on tissue analysis. Results suggest that plants accumulate perchlorate in ratios similar to the accumulation of plant nutrients.

\section{Poster 251}

Increasing Spring Phosphorus Availability Without Starter Fertilizer

Thomas Björkman*; Dept. of Horticultural Sciences, Cornell Univ., Geneva, NY 14541

Vegetables are often grown on high-phosphorus soils, but additional phosphorus is often required when they are sown early in cold soil. We have demonstrated that a new granular potassium bicarbonate can release phosphate quickly in such soils, and potentially replace the phosphorus addition. Preliminary experiments with other chemical mineralizers of phosphate, citric acid, and sodium bicarbonate showed that while they released appropriate amounts of phosphate, they injured bean seedlings. Potassium and ammonium bicarbonate were not toxic to snap beans at the relevant concentration of $10 \mu \mathrm{mol} / \mathrm{g}$ soil. High P soil (Strong Bray $=62 \mathrm{ppm}$ ) collected in the fall, and stored at $0{ }^{\circ} \mathrm{C}$ over winter was incubated at $15^{\circ} \mathrm{C}$. Short-term $\mathrm{P}$ availability was assayed using anion exchange membrane extraction. Unamended soil released $P$ slowly, taking 5 days to increase from $10 \mathrm{ppm}$ to $15 \mathrm{ppm}$. Soil amended with $10 \mu \mathrm{mol}$ potassium bicarbonate per gram soil immediately increased to $25 \mathrm{ppm}$. Granulated potassium bicarbonate $(0.5$ to $1 \mathrm{~mm}$ size $)$ is easier to meter accurately, and released $\mathrm{P}$ to $20 \mathrm{ppm}$ immediately and to $25 \mathrm{ppm}$ within a day. The release is similar over the range of soil moisture content that permits sowing, but is inhibited in dried soil (0.1-g water/g dry soil).

5:00-6:00 p.m. CC Ballroom

\section{Poster Session 15: Postharvest}

Poster 293

Heat Treatments Affect Postharvest Quality of Avocado

George Ouma*; Dept. of Horticulture, Maseno Univ., P.O. Box 333, Maseno, Kenya

Studies were conducted in 1999 to determine the effect of different post-harvest heat treatments on the quality and chilling injury of 'Fuerte' Avocado. Mature 'Fuerte' Avocado were obtained at harvest from a packinghouse at Kiboswa market, in Kisumu town, Kenya. The fruits were graded for uniformity of mass (200 \pm $10 \mathrm{~g})$ and freedom from blemishes and placed in a room with relative humidity of $70 \% \pm 10 \%$ and a temperature of $21^{\circ} \mathrm{C} 1$ day before heat treatments started. The fruits were heated at $38^{\circ} \mathrm{C}$ for
$0,24,48$ and 72 hours, respectively, in an oven and then stored at $5{ }^{\circ} \mathrm{C}$ for 21 days. The fruits were then weighed and rated visually for chilling injury and heat damage. A completely randomized design was used and the laboratory studies were conducted at Maseno Univ., Kenya. The unheated fruit developed severe chilling injury, mainly skin blackening which decreased with increased duration at $38^{\circ} \mathrm{C}$. Heating at $38^{\circ} \mathrm{C}$ did not affect respiratory rates but the number of days to attain maximum ethylene evolution was delayed. Firmness of the fruit flesh was similar in unheated and heated fruit at the time of transfer to $21^{\circ} \mathrm{C}$ for ripening and after 12 days at $21^{\circ} \mathrm{C}$. Weight loss of fruit decreased as the number of days at $38^{\circ} \mathrm{C}$ increased while shelf-life (i.e. the number of days to reach ripening at $21^{\circ} \mathrm{C}$ ) also increased.

\section{Poster 294}

Postharvest Heat Conditioning Affects Quality of 'Supreme' Guavas

George Ouma*, Dept. of Horticulture, Maseno Univ., P.O. Box 333, Maseno, Kenya

Studies were conducted at Maseno Univ. laboratories, Kenya in 1999 to determine the effects of different postharvest heat treatments on the quality of 'Supreme' Guavas. Mature Guavas were obtained at harvest from a packinghouse at Kiboswa market, in Kisumu town, Kenya. The fruits were graded for uniformity of mass ( 65 to $240 \mathrm{~g}$ ) and freedom from blemishes and placed in a room with relative humidity of $70 \% \pm 10 \%$ and a temperature of $21{ }^{\circ} \mathrm{C} 1$ day before heat treatments commenced. The fruits were heated at $38^{\circ} \mathrm{C}$ for $0,24,48$, and 72 hours, respectively, in an oven and then stored at $5{ }^{\circ} \mathrm{C}$ for 21 days. The fruits were then weighed and rated visually for chilling injury and heat damage with a 5-point visual acuity scale. A completely randomized design was used. The unheated fruit developed severe chilling injury, mainly skin blackening which decreased with increasing duration at $38{ }^{\circ} \mathrm{C}$. Flesh firmness increased and as the days at $21^{\circ} \mathrm{C}$ increased flesh firmness decreased depending on the duration at $38{ }^{\circ} \mathrm{C}$ (i.e. the longer the duration, the lower the flesh firmness). The number of days to ripening (i.e. shelf-life) increased as the duration at $38^{\circ} \mathrm{C}$ increased and as the number of days at $21^{\circ} \mathrm{C}$ increased the shelf-life increased up to day 8 and decreased. Similarly, as the duration at $38{ }^{\circ} \mathrm{C}$ increased, the percentage of surface injury, $\mathrm{pH}$, and sugar contents increased. Conversely, the weight loss of the fruits decreased as the number of days at $38^{\circ} \mathrm{C}$ increased.

\section{Poster 295}

Chilling Injury and Polyphenol Oxidase Activity in Eggplant cv. Japonesa (Solanum melongena L.)

A. Concellón*, A.R. Chaves, and M.C. Añón; Calles 47 y 116, LaPlata; e-mail:aconcell@quimica.unlp.ar

The relationship of chilling injury symptoms with electrolyte leakage and polyphenol oxidase (PPO) activity was studied in eggplant $\mathrm{cv}$. Japanese (Solanum melongena L.) stored at 0 and $10^{\circ} \mathrm{C}$ during 13 days. Storage at 0 and $5{ }^{\circ} \mathrm{C}$ severely injured fruits, whereas storage at $10^{\circ} \mathrm{C}$ did not cause chilling injury. Electrolyte leakage, an indirect measure of membrane damage, significantly increased in correlation with the development of chilling injury symptoms. It was observed PPO activity in both soluble and nonsoluble fraction, but in all cases, the mayor enzimatic activity was in soluble fraction. After 2 days of storage at 0 and $10^{\circ} \mathrm{C}$, an increase in specific activity of both extracts was observed. At the end of storage, the specific activity from soluble and nonsoluble fraction at $0{ }^{\circ} \mathrm{C}$ was lower than initial, but at $10^{\circ} \mathrm{C}$ a high increase of activity in soluble extract was exhibited.

\section{Poster 296}

Genotypic Differences in Sensitivity to Chilling Injury of Bananas and Plantains

Keri L. Morrelli*, Betty M. Hess-Pierce, and Adel A. Kader; Dept. of Pomology, Univ. of California, Davis, CA 95616

Little is known about responses of specialty banana and plantain cultivars to chilling temperatures. The traditional Cavendish type 
bananas, such as the 'Grand Nain' cultivar, have a minimum safe temperature for handling of $13^{\circ} \mathrm{C}$. Chilling injury symptoms appear as subepidermal vascular browning, surface discoloration (graying), delayed ripening or failure to ripen. 'Burro' and 'Manzano' bananas stored for up to 5 days at $10^{\circ} \mathrm{C}$ and transferred to $20^{\circ} \mathrm{C}$ showed no chilling injury symptoms. The 'Petite' bananas stored for 3 or 5 days and the 'Red' bananas and plantains stored for 5 days at $10^{\circ} \mathrm{C}$ and transferred to $20^{\circ} \mathrm{C}$ for ripening had delayed ripening rates. When the same cultivars were stored for $1,3,5$, or 7 days at $7.2^{\circ} \mathrm{C}$ and transferred to $20^{\circ} \mathrm{C}$ for ripening with $100 \mathrm{ppm} \mathrm{C}_{2} \mathrm{H}_{4}$ there was an obvious difference between the cultivars in their susceptibility to chilling injury. The 'Petite' bananas were the least tolerant of storage at $7.2^{\circ} \mathrm{C}$, as indicated by fruit with severe vascular browning after 3 days of storage. There was no vascular browning seen in 'Red' and 'Burro' banana cultivars or in plantains after 7 days storage at $7.2^{\circ} \mathrm{C}$, however ripening rates were retarded in 'Petite' and 'Red' bananas and in plantains when ripened at $20^{\circ} \mathrm{C}$ with or without $100 \mathrm{ppm} \mathrm{C}_{2} \mathrm{H}_{4}$. Specialty banana cultivars and plantains appear to be more tolerant of temperatures below $13^{\circ} \mathrm{C}$ than the 'Grand Nain' bananas.

\section{Poster 297}

Identifying Anatomical Characteristics of Peeling-off Symptom in the 'Niitaka' Pear (Pyrus pyrifolia B.) Fruit Affected by Changes in Temperature during Cold Storage Y.P. Hong ${ }^{* 1}$, S.D. Yun ${ }^{1}$, I.G. Mok'; and S.K. Lee ${ }^{2} ;{ }^{1}$ National Horticultural Research Institute, Rural Development Administration, Suwon, Korea; ${ }^{2}$ Dept. of Horticulture, Seoul National Univ., Suwon, Korea

Photo-micrograph revealed the morphology of three distinct layers of 'Niitaka' pear fruit skin at harvest. The three layers of the outer fruit skin are the cuticle, epidermis, and hypodermis. When temperature varied during several days of cold storage, the cuticle of the fruit skin was separated from the epidermis by cell division and elongation. There was a new cellular formation between the cuticle layer and epidermis during peeling-off which was not yet described in books illustrating pear fruit structure, so it was termed as peel cambium (PC) for the time being. Carbon dioxide and ethylene production were raised in response to temperature variation during cold storage. Increases in total phenol and electrolyte leakage were observed in the peeling-off process. Simultaneously, fructose, glucose, and sorbitol were increased during peeling-off in the fruit skin. In spite of peelingoff phenomenon, there was no significant difference in firmness between the peeling-off fruit and the normal fruit. We are currently identifying the new cellular structure involved in the experiment. Further investigations will find out structural material of the PC involved in the development of skin tissue from harvest to senescence.

\section{Poster 298}

Methyl Jasmonate Induces Stress-related Gene Expression and Increases Chilling Tolerance in Tomato Fruit

Chang-Kui Ding*, Chien Yi Wang, and Kenneth C. Gross; Produce Quality and Safety Laboratory, Agricultural Research Service, U.S. Dept. of Agriculture, 10300 Baltimore Ave., Beltsville, MD 20705-2350 Treatment of tomato fruit (Lycopersicon esculentum L. cv. Beefstake) with $0.01 \mathrm{~mm}$ methyl jasmonate (MeJA) significantly enhanced their tolerance to chilling temperature and decreased the incidence of decay during low temperature $\left(5^{\circ} \mathrm{C}\right)$ storage. Different accumulation patterns of heat shock protein (HSP) and pathogenesis-related $(P R)$ protein $m R N A s$ in tomato fruit were observed after vapor application of MeJA. HSP 70 family, the main stress molecular chaperone, and class I and II small HSP mRNAs were significantly induced by MeJA vapor treatment. When treated fruit were stored at low temperature $\left(5^{\circ} \mathrm{C}\right)$, class I and II mRNA levels initially decreased but then subsequently increased, while HSP 70 mRNAs maintained higher levels of transcripts up to 28 days. The accumulation of HSP17.6 mRNA was up-regulated during subsequent exposure to chilling temperature and maintained for up to 28 days. Low-level induction of HSP transcription was also observed in nontreated fruits between 7 and 14 days at low temperature, but all of HSPs de- creased to an undetectable level after 21 days. MeJA also significantly increased the transcription of PR-2b, PR-2a, and PR-3b mRNAs encoding intracellular -1, 3-glucanase, extracellular -1, 3glucanase, and intracellular chitinase, respectively. These results demonstrated that the pre-treatment of tomato fruit with MeJA induced the transcription of some stress protein genes. The synthesis of HSPs and PR-proteins can be considered as an adaptive mechanism which leads to increased chilling tolerance and resistance to pathogens and may be essential for cell protection.

\section{Poster 299}

Heat Treatments Can Control Rooting and Sprouting of Garlic Cloves

Junsoo Kang ${ }^{1}$, Gyunghoon Hong ${ }^{2}$, and Marita Cantwell ${ }^{\star 2} ;{ }^{1}$ Dept. of Food Engineering, Dongeui Institute of Technology, Pusan, Korea; ${ }^{2}$ Dept. Vegetable Crops, Univ. California, Davis, CA 95616

Rooting and sprouting defects can occur in minimally processed peeled garlic (Allium sativum L.) cloves when stored under high humidity conditions at higher than recommended temperatures $(0$ to $2.5^{\circ} \mathrm{C}$ ). We investigated the efficacy of heat shock treatments to reduce these defects. Unpeeled cloves were stored at $10^{\circ} \mathrm{C}$ for 4 weeks after no treatment (control) or hot water dips at 45 to $60^{\circ} \mathrm{C}$ for $60-2.5 \mathrm{~min}$. Moderate heat treatments $\left(<50^{\circ} \mathrm{C}\right.$ water) did not control sprout and root growth. Treatments at $60^{\circ} \mathrm{C}$ inhibited the sprout and root growth, but generally caused high levels of heat injury $(80 \%$ to $90 \%$ cloves affected), with the exception of the 2.5 min treatment. For garlic cloves treated between 50 and $60{ }^{\circ} \mathrm{C}$, respiration rates were higher ( $50 \%$ to $75 \%$ ) than those of untreated cloves. Lightness ( $L^{*}$ value) of the clove surface was slightly decreased by heat treatments, whereas chroma and hue values were minimally affected. Most short-term hot water dips had no effect on firmness. Unpeeled garlic cloves tolerated effective treatments of 50 to $60^{\circ} \mathrm{C}$ for $40-2.5 \mathrm{~min}$. with no significant visual quality deterioration.

\section{Poster 300}

Changes in the Activities of Antioxidant System in Sweet Pepper Fruit During Low Temperature Storage Yoshihiro Imahori*, Artemio Z. Tulio, Jr., Megumi Ishimaru, and Yoshinori Ueda; Graduate School of Agriculture and Biological Science, Osaka Prefecture Univ., 1-1 Gakuen-cho, Sakai, Japan

Low temperature storage is the most effective storage for extending the shelf life of fresh horticultural commodities, because it slows their metabolism. However, low temperature below the critical threshold temperature, but above freezing, for fresh horticultural commodities causes chilling injury. Recently, it is reported that chilling may induce oxidative stress in plant tissues, and there is increasing evidence that chilling elevates the levels of active oxygen species. In this study, we have determined changes in the activities of antioxidant system in sweet pepper fruit during storage at low temperature. Chilling injury symptoms such as surface pitting appeared and increased at $1^{\circ} \mathrm{C}$ storage, but were not found at both 10 and $20^{\circ} \mathrm{C}$ during storage. The level of malondialdehyde was not affected by storage temperature and unchanged throughout storage. Hydrogen peroxide levels increased in sweet pepper fruits stored at $1^{\circ} \mathrm{C}$. Ascorbate levels increased during storage, though its level was found to be higher at $10^{\circ} \mathrm{C}$ than the other treatments. However, dehydroascorbate levels did not change throughout storage at both 10 and $20^{\circ} \mathrm{C}$, but showed significant transient increase on day 4 at $1^{\circ} \mathrm{C}$, and then decreased subsequently. Level of reduced glutathione was found to be lower at $1^{\circ} \mathrm{C}$ than the other treatments throughout storage, but levels of oxidized glutathione were not affected by storage temperature and decreased during storage. Superoxide dismutase (SOD) activity increased in sweet pepper fruits stored at $1{ }^{\circ} \mathrm{C}$. These findings indicate that the development of chilling injury symptoms may be related to the activities of the antioxidant system in sweet pepper fruit during storage at low temperature. 


\section{Poster 301}

Chilling Injury of Modern Muskmelon, Pepper, and Tomato Cultivars: From Highly Sensitive to Nonsusceptible

Christian Krarup*, Elizabeth Kehr, Dilver Portillo, and Paz Zamora; Universidad Católica de Chile, Casilla 306, Chile

Recently released hybrids and traditional commercial cultivars of muskmelon (C. melo var. reticulatus, $n=20)$, sweet pepper $(n=$ $15)$, and fresh market tomato $(n=31)$ were screened for chilling injury susceptibility during postharvest by storing them for 14 days at $0{ }^{\circ} \mathrm{C}$, plus 3 days at $20^{\circ} \mathrm{C}$. Response varied widely: muskmelons 'Colima' and 'High Mark', peppers 'King Arthur' and 'EI Paso', and tomatoes 'Colette' and 'FA-870' are examples of high sensitivity and no susceptibility to the disorder, respectively. Visual symptoms of chilling injury were quite variable within cultivars of a given species and, with some striking exceptions, were related to water loss; the most prevalent ones for each fruit will be illustrated. The magnitude of the differences observed in response to chilling warrants the selection of specific cultivars and temperature conditions for long storage or shipping.

\section{Poster 302}

\section{Effects of Heat Shock on Dormancy of Forsythia}

J.A. Young ${ }^{\star}$ and B.C. Moser; Dept. of Horticulture and Landscape Architecture, Purdue Univ., West Lafayette, IN 47907

Manipulating bud dormancy of woody ornamental species provides opportunities for their use in the floral trade. The purpose of this study was to determine the effects of heat shock on breaking dormancy of flower and vegetative buds of Forsythia xintermedia. Stems were subjected to heat shocks of 1 to 4 hours at temperatures of 28 to $55^{\circ} \mathrm{C}$. Treated shoots were forced in a growth room under 16 -h days, and $22.2^{\circ} \mathrm{C}$. Observations of flower bud break following heat shock treatment showed marked differences with regard to harvest date and natural cold accumulation by the stems. Those harvested in early October showed the earliest development and greatest percentages of flower buds broken following ${ }^{\circ} \mathrm{C}$ heat shock, with decreases in bud break as the treatment temperatures decreased. At temperatures above $46{ }^{\circ} \mathrm{C}$, flowering was absent. Stems harvested in early December exhibited flower bud break with the earliest development and greatest percentages at $34{ }^{\circ} \mathrm{C}$, or lower. Percentages of flower bud break decreased steadily from 34 to $46^{\circ} \mathrm{C}$. At temperatures above $46^{\circ} \mathrm{C}$, no flower buds broke. Vegetative bud break was induced simultaneously with flower bud break at $43^{\circ} \mathrm{C}$ at all sampling dates. And, only vegetative bud growth occurred at temperatures above $46^{\circ} \mathrm{C}$, with more buds breaking as the heat shock temperature was increased to ${ }^{\circ} \mathrm{C}$.

\section{Poster 303}

Control of Degreening by Sugar Ester and Heat Treatments in Highly Flavored Acid Citrus Fruit

Naoki Yamauchi*1, Kuniyasu Eguchi', Yukiko Tokuhara', Yukiko Yamashita', and Kenji Sugimoto'; ' ${ }^{1}$ Fac. Agr., Yamaguchi Univ., Yamaguchi 753-8515, Japan; ${ }^{2}$ Hagi Citrus Res. Inst., Hagi 7580011, Japan

Green nagato-yuzukichi (Citrus nagato-yuzukichi hort. ex Y. Tanaka) fruit, which belongs to the Yuzu group, is a kind of highly flavored, acidic citrus, like lemon and lime. The fruit are harvested in late summer when the peel is still green color. For postharvest keeping quality, the green color of the fruit peel is necessary to be retained as long as possible. In this study, control of degreening by a sugar ester ( $1 \%$ or $2 \%$ sucrose laurate ester) and heat treatments in the fruit was determined. The fruit, which were treated with hot water at $50{ }^{\circ} \mathrm{C}$ for $3 \mathrm{~min}$ or with sugar ester solution at ambient temperature or at $50{ }^{\circ} \mathrm{C}$ for $3 \mathrm{~min}$, were placed into a perforatedpolyethylene film bag and stored at $20^{\circ} \mathrm{C}$ for 2 weeks. A decrease in chlorophyll content in the flavedo of the fruit was greatly suppressed if treated with sugar ester at $50^{\circ} \mathrm{C}$, whereas the content of hot water-treated fruit as well as the control decreased significantly during storage. The decrease in chlorophyll content of sugar ester- treated fruit at ambient temperature was also suppressed for the first 6 days of storage. Internal carbon dioxide and oxygen levels of the fruit treated with the sugar ester at $50^{\circ} \mathrm{C}$ markedly increased and decreased during storage, respectively. Chemical components such as ascorbate, citrate, and sugar, however, remained almost unchanged during storage with any treatment. We suggest that sugar ester treatment at $50{ }^{\circ} \mathrm{C}$ could control effectively degreening of green nagato-yuzukichi fruit.

5:00-6:00 p.m......................................... CC Ballroom

\section{Poster Session 16: Crop Physiology}

\section{Poster 344}

Development of the Floret Abscission Zone of the North American Ginseng Inflorescence

A.E. Fiebig, J.T.A. Proctor*, U. Posluszny ${ }^{1}$, and D.P. Murr; Division of Hort. Science, Dept. of Plant Agr. Univ. of Guelph '; Dept. of Botany, Univ. of Guelph, Guelph, ON, N1G 2W1, Canada

New management strategies are being evaluated to ensure that ginseng growers remain competitive. For instance, we showed that manual inflorescence removal in 3-year-old ginseng (Panax quinquefolius L.) increased root yield by $26 \%$. However, manual inflorescence removal is expensive and an abscission-inducing growth regulator treatment might be an alternative. We have shown that foliar application of ethephon [2-(chloroethyl) phosphonic acid] may be a suitable replacement for manual removal, as it induced floral apex abscission. Before such a practice is accepted, we need to know more about the growth and development of the ginseng inflorescence, particularly in relation to abscission zone formation and ethephon application. The objectives of this work were to: 1) characterize inflorescence development in the perennating bud and during flowering; and 2) study the effect of ethylene on the ginseng floral apex abscission zone. Histology and manual dissection of 1and 3 -year-old perennating buds revealed development of the floral apex occurred first at its periphery and progressed centripetally towards the center. Stamen initials were seen as a pentamerous whorl just under the petal primordia, and the characteristic inferior ovary initiated as a slight depression at the centre of the floral meristem. Sections through 3-year-old inflorescences harvested on 23 May 1996 showed that distal floral apices had already formed constriction zones between the apex and the pedicel, indication the position of the abscission zone. Length of time to ethylene-induced abscission zone formation was less than 24 hours in 3-year-old ginseng harvested on 23 July 1997 . The abscission threshold for ginseng berry drop was in the range of 10 to $100 \mu \mathrm{L} \cdot \mathrm{L}^{-1}$ ethylene.

\section{Poster 345}

Accumulation of Ginsenosides in Panax quinquefolius $L$. in Relation to Plant Age, and Growing Locations

Chung-Ja C. Jackson', Jean Paul Dini', Clara Lavandier', H.P. Vasantha Rupasinghe ${ }^{* 1}$, and John T.A. Proctor ${ }^{2} ;{ }^{1}$ Guelph Centre for Functional Foods, Laboratory Services; ${ }^{2}$ Dept. of Plant Agriculture, Univ. of Guelph, Guelph, Ontario, Canada

The active constituents of American ginseng (Panax quinquefolius L.) are dammarane saponins, commonly referred to as ginsenosides. We have determined quantitative differences in total ginsenoside concentration and in the proportions of ten major ginsenosides $\left(R_{0}\right.$, $R b_{1}, R b_{2}, R c, R d, R e, R f, R g_{1}$, Pseudoginsenoside $F_{11}$, and Gypenoside) in relation to plant parts, age, and growth locations in three different geographical regions in Canada (Ontario, British Columbia, and Nova Scotia). In general, the concentrations of ginsenosides in roots increased with the growing year and attained values of $5.8 \mathrm{to} 10.0 \mathrm{~g}$ ginsenosides $/ 100 \mathrm{~g}$ of dried ginseng roots in the fourth year. Interestingly, the total ginsenoside concentrations of leaves $(5.6$ to $8.6 \mathrm{~g} / 100 \mathrm{~g}$ ) did not vary over the growing years and were closer to those of roots. Ginsenoside levels in stems ranged from 1.2 to $6.3 \mathrm{~g} / 100 \mathrm{~g}$ and remained constant over the period of growth and development. The berries, which form during the third year of growth, had total ginsenoside levels ranging from 1.3 to $2.6 \mathrm{~g} /$ 
$100 \mathrm{~g}$. The most abundant ginsenosides in roots of Panax quinquefolius were $R b_{1}$ and $R e$. Characteristically, the levels of $R b_{1}$ in roots increased with the age of the root, whereas Re concentrations decreased slightly. In leaves and berries, $\mathrm{Rd}$ and Re were the most abundant ginsenosides. The ginsenoside $\mathrm{Rf}$ was not detectable in roots, but was detectable in leaves. The distribution patterns of ginsenosides in different parts of the plant over time varied both qualitatively and quantitatively from one sample region to another.

\section{Poster 346}

Shading Affects Leaf Anatomy, Morphology, and Whole-vine Net Carbon Exchange Rate of Greenhouse-grown 'Chardonnay' Grapevines

Justine E. Vanden Heuvel*, K. Helen Fisher, J. Alan Sullivan, and John T.A. Proctor; Dept. of Plant Agriculture Univ. of Guelph, Guelph, Ont., Canada

The effects of shading on leaf anatomy, morphology, and wholeplant net carbon exchange rate (NCER) were investigated on greenhouse-grown 'Chardonnay' grapevines. Vines were subjected to shading levels of $0 \%, 54 \%, 90 \%$, and $99 \%$ three weeks after potting. Data were collected 8 to 10 weeks after potting. Anatomical and morphological characteristics of the leaves were significantly affected by whole-plant shading level. Leaf density and thickness decreased in a linear fashion with increased shading levels, while density of the nongaseous leaf content increased linearly with greater shading levels. Leaf size, fresh weight, volume, volume of internal air spaces, volume of nongaseous leaf content, and chlorophyll content all responded quadratically to greater shading levels, with critical points of regression between $5 \%$ and $33 \%$ shade. The response of wholevine NCER to increasing photosynthetic photon flux density indicated a reduction in saturation rate from $\approx 1150 \mu \mathrm{mol} \cdot \mathrm{m}^{-2} \cdot \mathrm{s}^{-1}$ for vines grown under full sun to $\approx 980 \mu \mathrm{mol} \cdot \mathrm{m}^{-2} \cdot \mathrm{s}^{-1}$ for the $99 \%$ shading treatment. Compensation point did not differ significantly between shading treatments, indicating that anatomical and morphological modifications may allow even severely shaded interior grapevine leaves to make a positive contribution to overall vine carbon balance.

\section{Poster 347}

\section{Early Detection of Grape Water Deficit Stress Using Leaf Spectral Reflectance}

E.M. Perry', J.R. Davenport ${ }^{2}$, J. Tarara ${ }^{3}$, and N.S. Lang ${ }^{* 4} ;{ }^{1}$ Battelle Pacific Northwest National Lab, Richland, WA; ${ }^{2}$ Washington State Univ. Irrigated Agriculture Research and Extension Center, Prosser, WA $;{ }^{3}$ USDA/ARS, Prosser, WA; ${ }^{4}$ Michigan State Univ., E. Lansing, MI

The physiological disorder "blackleaf" in Concord grape (Vitis lambrusca L.) is initiated by high UV light stress and severity of visual symptoms are further increased by drought stress. In a mature, commercial Concord grape vineyard located in the Yakima Valley of Washington State, both leaf and canopy level spectral reflectance measurements (350-2500 nm) were collected using a portable field spectroradiometer at key phenological stages to evaluate the ability to detect early onset of blackleaf. In addition, trunks of twenty vines were fitted with thermal collars to measure plant water use via sap flow on a diurnal basis. During the course of the growing season, a malfunction of the sap flow devices resulted in trunk heating and which damaged phloem, cambium, and xylem tissues resulting in subsequent water deficit to the crop canopy and eventual defoliation and canopy death above the injured trunk area. Leaf spectral reflectance measurements had been made $\approx 3$ weeks prior to and one week after this severe stress, before any visual symptoms became visible (at $\approx 10$ days). Analysis of reflectance data indicate that the early stress response is detectable based on at least four reflectance-derived parameters, all of which can be measured within the Si detector range $(\approx 400-900 \mathrm{~nm})$. The parameters that show promise are dependent upon accurate measurements of narrow spectral reflectance. Further analysis is needed to determine if some of the parameters can be effective based on broader-band (e.g., $10 \mathrm{~nm}$ wide) measurements and thus offer promisefor development of cost effective sensors.

\section{Poster 348}

Differences in Anthocyanin Levels among Eight Grape Cultivars Treated with ABA or Irradiated with Ultraviolet-A Lamp

N. Kubota*, H. Ogawa, F. Fukuda, and Y. Kubo; Faculty of Agriculture, Okayama Univ., Tsushima, Okayama 700-8530, Japan

The effects of ABA and ultraviolet-A (UV-A) treatments on berry coloration were compared among eight grape cultivars, the red type (Aki Queen, Ruby Okuyama, Hiro Humburg, and Kaiji) and the black type (Campbell Early, Pione, Muscat Bailey A, and Gros Colman) grown in plastic houses except for Gros Colman which was grown in a glasshouse. Berry clusters were either sprayed with a $1000 \mathrm{ppm}$ ABA at veraison of each cultivar, or irradiated with an UV-A lamp (maximum wavelength, $352 \mathrm{~nm}$ ) during the day in the course of berry ripening. Five clusters were used for each treatment, including control. Berry weight, total soluble solids content of the juice, and anthocyanin content and L-phenylalanine ammonia-lyase activity (PAL) in the skin were monitored weekly throughout berry maturation. For all cultivars tested, there was no significant difference in berry growth and total soluble solids content among the treatments. In Gros Colman, Pione, and Aki Queen grapes, the highest level of anthocyanin was observed in clusters treated with $A B A$, followed by UV-A and then controls, whereas in Hiro Humburg it was high in UV$A$ than $A B A$ treatment. For Ruby Okuyama, anthocyanin level in clusters treated with ABA and UV-A was almost same. No significant difference in anthocyanin content among the treatments was observed for the other three cultivars. High content of anthocyanin resulted in high activity of PAL in the skin. Results indicate that the response of berry skins to ABA and UV-A treatments, which improve berry coloration, largely differ among the grape cultivars. Increased anthocyanin may be caused by high PAL activity of berry skins.

\section{Poster 349}

Cloning and Characterization of Genes Encoding PAL in Relation to Anthocyanin Synthesis in Grape Skin

Y. Kubo*, T. Kizaki, S. Mano, R. Nakano, A. Inaba, and N. Kubota; Faculty of Agriculture, Okayama Univ., Okayama, 700-8530, Japan

Three cDNA clones, encoding phenylalanine ammonia-lyase were isolated from grape (Vitis vinifera L. $x$ Vitis labrusca L. cv Pione) skin by RT-PCR and RACE-PCR methods. Vv-PAL1 was identical to pBS204 previously cloned by Sparvoli et al. (1994), however, VvPAL2 and VV-PAL3 encoding deduced proteins of 723 and 710 amino acids respectively were novel isogenes in grape. A strong expression of the three genes and a high PAL activity were detected at early stage of fruit growth, followed by a reduction of the expression and activity to trace level at veraison. While in white type cultivars, such as 'Muscat of Alexandria' and 'neo Muscat', gene expression and enzyme activity remained at trace level during fruit ripening, in black type cultivars, such as 'Pione', 'muscat Bailey A' and 'Gros Colman', the increase in gene expression and enzyme activity during ripening stage were observed, correlating with anthocyanin synthesis. The increase in gene expression and enzyme activity were dramatically stimulated by ABA treatment at veraison. Our results suggest that enhancement of anthocyanin synthesis by ABA takes place through transcriptional stimulation of PAL genes.

\section{Poster 350}

\section{Assimilate Limitation in the American Cranberry}

S. Kumudini*; Plant Science Dept. Rutgers Univ., Chatsworth, NJ

Previous studies on cranberry (Vaccinium macrocarpon Ait.) have concentrated on the relationships between yield components (e.g. flower number, fruit set, fruit weight) and yield. Although a single upright may produce several flowers, only a fraction of the flowers will set fruit. Studies with flower and fruit removal have indicated that assimilate limitation may play an important role in the low fruit set. Sink removal experiments, however, may also affect hormonal balance and feedback inhibition. A paucity of information exists on the direct relationship between assimilate supply and yield. The objective of the current experiment was to determine the effect of 
assimilate supply on fruit set, fruit size and partitioning of assimilates to the fruit. Reproductive uprights of the two cultivars, Stevens and Early Black, were rooted and brought to flower in a greenhouse. At the hook stage, the plants were moved into irrigated growth cabinets and exposed to either an ambient or an enhanced (1000 ppm.) $\mathrm{CO}_{2}$ environment for a period of up to 6 weeks. The plants were then moved to a greenhouse and allowed to mature. At maturity, fruit and seed number were counted and dry weights of vegetative tissues, fruits and seeds were determined. The cultivar Stevens partitioned significantly more assimilates to the fruit (i.e. harvest index) than 'Early Black'. The $\mathrm{CO}_{2}$ enhancement treatment increased the partitioning of assimilates to the fruit. Significant increases in fruit number, seed number, fruit weight, and seed weight were measured, however, the ratio of fruit weight to seed weight remained the same. The results of this experiment indicate that cranberry fruit weight is associated with seed number and that both cranberry fruit set, and seed number are assimilate limited.

\section{Poster 351}

A Comparison of Advanced Matted Row and Annual Hill Strawberry Production Systems in Maryland

Brent L. Black*, John M. Enns, and Stan C. Hokanson; Fruit Laboratory, Plant Science Institute, USDA-ARS, Beltsville, MD 20705-2350

In eastern North America, strawberries have traditionally been grown in the matted row production system. In efforts to increase yields and improve profitability, growers in the mid-Atlantic region have also been testing the annual hill or plasticulture system. However, with the scheduled phase-out of methyl bromide and no suitable alternative yet identified, new approaches are needed to address pest problems in strawberry production. A modified or advanced matted row system has been developed at the USDA research station at Beltsville, Md., which incorporates raised beds, sub-surface drip irrigation, and the use of a cover crop residue mulch. Over the past five years, the small fruit breeding program at Beltsville has conducted replicated yield trials on both plasticulture and advanced matted row production systems. Plantings in both systems were established on land which had not grown strawberries or received methyl bromide fumigation for at least 3 years. To compare advanced matted row to annual hill, data for genotypes that were grown in both systems and over multiple years were selected from 1997-2000 seasons. Production was earlier on black plastic mulch, but length of season, as indexed by number of twice-weekly harvests, did not differ with cropping system. Total yields were genotype dependant with several genotypes including 'Allstar', 'Northeaster' and B440 producing $+20 \%$ more fruit in the annual hill system, while B24, B244 and B443 produced more on advanced matted row. A comparison of plant performance in these two systems provides important information for evaluating cropping systems in the absence of methyl bromide, and determining best management practices for the mid-Atlantic region.

\section{Poster 729}

\section{Effect of $\mathrm{pH}$ and Nitrate on Ferric Chelate Reductase and} Nnitrate Reductase in Vaccinium Species

Umpika Poonnachit* and Rebecca L. Darnell; Horticultural Sciences Dept., Univ. of Florida, Gainesville, FL 32611

Vaccinium corymbosum, the major commercially grown blueberry species, is limited to low $\mathrm{pH}$, high organic matter soils, where the primary nitrogen form is $\mathrm{NH}_{4}$. However, the wild species, $V$. arboreum, appears to be adapted to wider soil types, including mineral soils that have higher $\mathrm{pH}$, lower organic matter, and where the primary nitrogen form is $\mathrm{NO}_{3}$. We hypothesized that $V$. arboreum is better adapted to mineral soils compared with $V$. corymbosum due to an increased efficiency in nitrate and/or iron assimilation under mineral soil conditions. Studies on the effect of $\mathrm{pH}$ and nitrate solution on the activities of the enzymes involved in iron and nitrate assimilation (ferric chelate reductase $[\mathrm{FCR}]$ and nitrate reductase $[\mathrm{NR}]$ ) were conducted for 13 weeks in order to determine if differences in iron and nitrogen assimilation existed between the two species. Blueberries were grown hydroponically in a complete nutrient solution containing $5.0 \mathrm{~mm}$
$\mathrm{NaNO}_{3}$ as the nitrogen source. Solution pH was buffered at 5.5 or 6.5 . Leaf and root FCR and root NR activities were quantified every 2 weeks. No interaction between species and pH on either FCR or NR activities were found. $V$. arboreum had increased leaf and root FCR and NR activities compared with V. corymbosum. FCR activities increased as $\mathrm{pH}$ increased from 5.5 to 6.5 for both species. The high activity of FCR and NR in $V$. arboreum under $\mathrm{NO}_{3}$ conditions compared with $V$. corymbosum may partially explain why $V$. arboreum is more widely adapted to mineral soils.

\section{Poster 353}

Temperature Effects on Muskmelon Growth and Development, Fruit Set, Pollen Germination, Photosynrthetic Rates and Stomatal Conductance

S.M. Lutfor Rahman', J.T. Baker', D. Timlin', Wayne Mackay ${ }^{3}$ V.R. Reddy', and Bruno Quebedeaux ${ }^{1} ;{ }^{1}$ Univ of Maryland, College Park, MD; '2USDA, ARS, BARC-West; ${ }^{3}$ Texas Agricultural Experiment Station, The Texas A\&M Univ, Dallas

A temperature experiment with two cultivars of muskmelon (cv.. 'Gold Rush' and 'Hybrid Mission') was conducted in a greenhouse to determine the effect of warm $\left(35^{\circ} \mathrm{C}\right.$ day/ $30^{\circ} \mathrm{C}$ night) and cool $(20$ ${ }^{\circ} \mathrm{C}$ day $/ 15^{\circ} \mathrm{C}$ night) temperatures on fruit set, pollen germination, pollen viability, plant growth, photosynthetic rates, stomatal conductance, and yield. Warm temperatures in both cultivars of muskmelon adversely affected pollen germination percentage. Fruit set at warm temperatures was very low in both cultivars, due to both pollen and stigmatic damage from heat stress. Fruit at warm temperatures grew slower and required more time to mature than those at cool temperatures. Temperature had significant effect on pollen development in both the cultivars. Cool temperatures in both cultivars reduced photosynthetic rates and stomatal conductance while fruit weight was reduced by warm temperature in both cultivars. This reduction was more in gold rush than hybrid mission. Warm temperature significantly reduced yield, pollen germination percentage, shoot and root dry weight. Significant interaction between temperatures regimes and cultivars were not observed for flower number, fruit weight, root dry weight and shoot dry weight. The results of this study indicate that warm temperature affected fruit weight and final yield of muskmelon.

\section{Poster 354}

Growth Response of Tomato Seedlings to Difference Between Photoperiodand Dark Period Temperatures was Altered by Light-dark Cycling Period

Y. Omura*, C. Kubota, and T. Kozai; Chiba Univ., Matsudo, Chiba 271-8510, Japan

Tomato (Lycopersicon esculentum Mill., cv. Momotaro) seedlings 14 days after sowing were grown for $96 \mathrm{~h}$ under an average air temperature of $24^{\circ} \mathrm{C}$ with temperature differences between photoperiod and dark period (DIFs) of $-12,0$ and $+12^{\circ} \mathrm{C}$, combined with light-dark cycling periods (LDCPs) of 12-h (6-h photoperiod/6-h dark period), 24-h (12-h photoperiod/12-h dark period) and 48-h (24-h photoperiod/24-h dark period). The stem lengths under the 12-h and 24-h LDCPs increased from 66 to $76 \mathrm{~mm}$ and from 66 to $80 \mathrm{~mm}$, respectively, as DIF increased from -12 to $12^{\circ} \mathrm{C}$. However, the stem length under the 48-h LDCP decreased from 95 to $81 \mathrm{~mm}$ as DIF increased from -12 to $12^{\circ} \mathrm{C}$. Dry mass per seedling under the $12-\mathrm{h}$ and 24-h LDCPs increased from 146 to $169 \mathrm{mg}$ and from 177 to 222 $\mathrm{mg}$, respectively, as DIF increased from -12 to $12^{\circ} \mathrm{C}$. However, the dry mass under the 48-h LDCP were 158,183 and $178 \mathrm{mg}$ at -12 , 0 and $12^{\circ} \mathrm{CDIF}$, respectively, and there was no significant difference between 0 and $+12{ }^{\circ} \mathrm{C}$ DIF. In short, the effects of DIF on stem elongation and dry mass increase of tomato seedlings under a 48$\mathrm{h}$ LDCP were different from those under a LDCP less than $24 \mathrm{~h}$.

\section{Poster 355}

Effect of High-temperature Stress on Flower Number Per Inflorescence of 11 Lycopersicon esculentum Mill. Genotypes 
Ryan M. Warner ${ }^{*}$ and John E. Erwin; Dept. Horticultural Science, Univ. of Minnesota, 1970 Folwell Ave., Saint Paul, MN, 55108

High temperatures reduce yield of tomato by inducing floral sterility. This experiment was conducted to determine whether high temperatures also reduce yield in tomato by reducing the flower number per inflorescence and/or inflorescence number. Eleven tomato genotypes and/or cultivars, reported to vary in high temperature tolerance, were grown in growth chambers at temperatures of either $32^{\circ} \mathrm{C}$ day $/ 28^{\circ} \mathrm{C}$ night $\pm 0.5^{\circ} \mathrm{C}$ or $22^{\circ} \mathrm{C}$ day $/ 18^{\circ} \mathrm{C}$ night \pm 0.5 ${ }^{\circ} \mathrm{C}$. The photoperiod was maintained at $12 \mathrm{~h}$, using a combination of fluorescent and incandescent $(75 \%$ and $25 \%$ total wattage, respectively) at an irradiance of $350 \pm 30 \mu \mathrm{mol} \cdot \mathrm{m}^{-2} \cdot \mathrm{s}^{-1}$ at canopy level. Flower number on the first three inflorescences was determined. Flower number per inflorescence varied across genotype. For example, 'Longkeeper', 'Enterprise', 'Fla 7771', and 'SunChaser' flower number per inflorescence was reduced on plants grown at $32^{\circ} \mathrm{C}$ day/ $28^{\circ} \mathrm{C}$ night, compared to flower number on plants grown at $22^{\circ} \mathrm{C}$ day $/ 18^{\circ} \mathrm{C}$ night. In contrast, 'CL 11 ' and 'SunCrest' had a similar number of flowers per inflorescence under both temperature regimes. No genotype had a higher flower number per inflorescence at $32{ }^{\circ} \mathrm{C}$ day $/ 28^{\circ} \mathrm{C}$ night than at $22^{\circ} \mathrm{C}$ day $/ 18^{\circ} \mathrm{C}$ night. Implications of these data on ultimate fruit yield will be discussed.

\section{Poster 356}

Quality Curves for Tomato Exposed at Chilling and Nonchilling Temperatures

E. Proulx', M. Cecilia N. Nunes ${ }^{* 1}$, J.P. Emond', and J.K. Brecht'; 'Univ. Laval, Air Cargo Transportation Research Group, Dept. of Soils and Agrifood Engineering, FSAA, Ste Foy, PQ, G1K 7P4 Canada; ${ }^{2}$ Horticultural Sciences Dept., Univ. of Florida, IFAS, Gainesville, FL, 32611-0690

Greenhouse-grown tomatoes (cv. Trust) were harvested at 3/4 color ripeness stage and held for 14 days at $0,5,10,15$, or $20^{\circ} \mathrm{C}$. The objective of this work was to obtain quality curves for tomatoes stored at chilling and non-chilling temperatures and to identify, for each temperature, which quality parameter(s) limits tomato marketability. Tomato weight loss, instrumental color $\left(L^{*} a^{*} b^{*}\right)$, visual color, firmness, shriveling, chilling injury, decay and aroma were evaluated every 2 days for 14 days. Firmness loss was the primary limiting factor and chilling injury was the second most important limiting factor for tomatoes stored at 0 or $5{ }^{\circ} \mathrm{C}$, while color was the primary limiting factor and firmness loss was the second most important limiting factor for those fruit stored at 10,15 , or $20^{\circ} \mathrm{C}$. Signs of loss of quality such as decreased firmness and increased redness were apparent even before weight loss attained the limit of acceptability for marketing ( $6 \%$ to $7 \%)$. Furthermore, the quality curves for each temperature showed that a single quality parameter cannot be used to express loss of quality of tomatoes over the normal physiological range of temperatures.

\section{Poster 357}

Influence of Elevated Atmospheric Carbon Dioxide Concentration on the Carbohydrate Metabolism in Lycopersicon esculentum Mill. Fruits

Md. Shahidul Islam* and Tadishi Ito, Dept. of Vegetable Science, Faculty of Horticulture, Chiba Univ., 648 Matsudo, Chiba 271-8510, Japan

This study examined the influence of preharvest elevated atmospheric carbon dioxide concentration $(750-950 \mu \mathrm{mol} / \mathrm{mol})$ on the fructose, glucose, sucrose, total sugars, soluble and cell wall-bound acid invertase (Beta-fructofuranoside fructohydrolase, EC 3.2.1.26), sucrose synthase (SuSy) (UDP glucose:D-fructose 2-glucosyltransferase, EC 2.4.1.13), sucrose phosphate synthase (SPS) (UDP glucose: D-fructose-6-phosphate 2-glucosyltransferase, EC 2.4.1.14) activities of domesticated tomatoes (Lycopersiconesculentum Mill. cv. Momotaro and Lady First) during fruit development. Tomato plants grown in carbon dioxide enriched conditions accumulated more carbohydrates in their fruit and exhibited significantly larger fruits compared to the control $(350-400 \mu \mathrm{mol} / \mathrm{mol})$. The carbon dioxide enriched tomato fruit contained significantly higher concentration of fructose, glucose and total sugars throughout the fruit development. The amount of reducing sugars ( $\mathrm{mg} / \mathrm{g}$ fresh weight) increased with the advancement of maturity, with fructose being the predominant sugars. The treated fruit also showed significantly higher activity of both soluble and cell wall-bound acid invertase and SuSy compared to the control. There were no significant differences in sucrose concentration and SPS activity between the treatments. The SPS activity did not change; rather it remained relatively constant throughout the fruit development. The decrease in SuSy activity was accompanied by increasing reducing sugar concentrations. The result suggested that enriched carbon dioxide treatment influenced the carbohydrate assimilation as well as metabolism in developing tomato cultivars more than in the control, which might be due to higher and faster translocation of photosynthate with elevated enzyme activities in the carbon dioxide enriched treatment.

\section{Poster 359}

Identifying Key Factors Conferring Salt Tolerance in Diploid Potato Genotypes

J. Shaterian', D. Waterer ${ }^{1}$, F. Georges², A. Hossain², H. DeJong ${ }^{3}$, and K.K. Tanino ${ }^{* 1} ;{ }^{1}$ Dept. Plant Sciences, Univ. of Saskatchewan, 51 Campus Dr., Saskatoon, SK Canada S7N 5A8; ${ }^{2}$ Plant Biotechnology Institute, National Research Council, Saskatoon, SK; ${ }^{3} \mathrm{Ag}$ riculture and Agri-Food Canada, Fredericton, NB, Canada

Twenty-four potato diploid crosses were ranked based on 5 phenotypic traits using cluster analysis under $\mathrm{NaCl}$-stress conditions. Salt sensitive $(S)$ and tolerant $(T)$ lines from determinate $(D)$ and indeterminate (I); ABA-deficient (AD) and ABA-normal-sibling were selected. The objective was to identify mechanisms of salt tolerance in the diploid potato lines and potential selection criteria in a breeding program. Indeterminate lines were $\mathrm{Na}$ +-excluders while the determinate lines were $\mathrm{Na}$ +-includers. The IT line had higher $\mathrm{Ca} 2+$ levels, higher root mass, extended life span, and significant shoot growth compared with the IS line. The determinate lines accumulated ions and differentially distributed them to the lower leaves. High capacity of the DT line to import more $\mathrm{Na}+$ may be related to its enhanced ion partitioning ability to less sensitive older leaves and $\mathrm{Ca} 2+$ leaf distribution. Proline and glucose contents dramatically increased upon exposure to salt stress but were not directly related to tolerance. Compared with its normal sibling, ABA-deficient mutants were not salt tolerant but exogenous $A B A$ application significantly increased salt tolerance in these mutants. However, ABA application did not enhance salt tolerance in the other genotypes tested. Reciprocal grafting studies indicate stressed DS scions on IT rootstocks maintained higher osmotic potentials and longevity compared with the DT rootstock and the reasons are discussed. A high level of calreticulin mRNA was related to salt tolerance in both (D) and (I) genotypes. A low level of calreticulin mRNA was strongly related to low $\mathrm{Ca} 2+$ accumulation. The ABA-deficient line possesses low levels of calreticulin mRNA and consequently may not store significant $\mathrm{Ca} 2+$ in its shoot tissues. The AD scion on the IT rootstock significantly increased both its salt tolerance and calreticulin mRNA levels after grafting.

\section{Poster 360}

Effect of Lysophosphatidylethanolamine (LPE) on the Ripening Stimulation and Ethylene Evolution in Red Pepper Chung-Kil Kang ${ }^{* 1}$, Sung-Eun Kim, Guk-Hoon Chung, and Jiwan Paul Palta; ${ }^{1}$ National Institute of Agricultural Science and Technology, RDA, Suwon 441-707, Korea

This experiment evaluated the effect of lysophosphatidylethanolamine (LPE), a natural lipid, on the ripening and ethylene evolution in red pepper. Spray application of LPE at 100, 200, 400 $\mathrm{mg} \cdot \mathrm{L}^{-1}$ was made in a field near Dongryang-myun, Chungju-si on 10, 17, and 28 Aug. Fruits were hand harvested on 17 Aug., 28 Aug., and 4 Sept. The most effective treatment was LPE $200 \mathrm{mg} \cdot \mathrm{L}^{-}$ ${ }^{1}$. LPE treatment increased ethylene evolution. Ripening stimula- 
tion of red pepper was closely related with ethylene evolution. No significant difference in fruit quality was found as compared with control. LPE treated fruit had reduced fruit hardness which may be related with cuticle strength. In addition an experiment was carried out to evaluate the effect of LPE with or without ethephon on ripening stimulation in red pepper treated at 1 week before first frost. When treated with LPE $200 \mathrm{mg} \cdot \mathrm{L}^{-1}$ at 1 week before the first frost, total weight of ripened fruit was increased by $54 \%$. Presence of ethephon increased the effectiveness of LPE on fruit ripening. These results suggest that LPE can stimulate color production in peppers and a combination of LPE and ethephon can be effective in late fall when damage due to frost can occur.

\section{Poster 361}

Water Relations and Growth Features of a Semidomesticated Hot Pepper (Capsicum frutescens) under Organic Fertilization A. Nieto-Garibay, E. Troyo-Dieguez*, B. Murillo-Amador, J.L. GarciaHernandez, and J.L. Larrinaga-Mayoral; CIBNOR, S.C. Program of Agriculture in Arid Zones. (Center for Biological Research of Northwest Mexico)

A semidomesticated genotype of Capsicum frutescens (the "caribe" type) was evaluated in a Mexican semi-arid zone under organic fertilization. There are some other available wild varieties along the natural vegetation zones, in the Mexican northwest. A manurebased compost was used as an organic treatment, to be compared with conventional chemical-based $17 \mathrm{~N}-17 \mathrm{P}-17 \mathrm{~K}$ fertilization, and against a combination of both. Results suggest that the organic fertilization improved the soil water retention capacity, from $6 \%$ to $9.5 \%$ field capacity (FC). The transpiration rate and stomata conductance were slightly higher in the organic treatment, but the growth variables were not statistically different. Although the number of leaves was higher in the organic treatment, height and total foliar area were statistically similar. A multiple regression model was determined $\left(R^{2}=0.97\right)$ to estimate $\mathrm{g}$ (stomata conductance) as a function of air and leaf temperature, and water vapor deficit. According to the results, a possible adaptation mechanism is based on a temporal adjustment of the osmotic potential. The experimental genotype, rich in capsaicin, was found to be a promissory horticultural crop for arid and semi-arid zones, where sweet or bell pepper fails because of severe drought occurrence.

\section{Poster 362}

\section{Effect of Light Intensity on Spring and Fall Snap Bean} Performance

D.J. Makus*, U.S. Dept. of Agriculture, Agricultural Research Service, Welasco, $T X$

Two snap bean cultivars, Strike and Carlos (Phaseolus vulgaris, $\mathrm{L})$, were planted into a Hebbronville sandy loam soil on 22 Feb. and on 29 Sept. 2000 and grown under $0 \%, 30 \%$, and $70 \%$ of ambient daily light (shade) throughout the 65-day growing seasons. Fall cumulative light was $\approx 60 \%$ that of the spring planting and fall mean daily temperatures were 1 to $2{ }^{\circ} \mathrm{C}$ lower. In both spring and fall the reduced yield response was linear with respect to increased shading, although first harvest and final yields were not affected by a $30 \%$ incident light reduction. Light reduction had little effect on pod sieve size distribution, but did increase pod dry matter. Plant biomass was reduced by shading as was leaf greenness, but leaf area and chlorophyll content (dry wt. basis), as well as the incidence of powdery mildew late in the season, was increased by shading. Leaf, air, and soil (at $10 \mathrm{~cm}$ ) temperatures were measurably reduced by increased shading in the spring, but not the fall planting. Leaf

The program schedule and abstracts are presented in chronological order and presenting authors are indicated by asterisks (*).

An index of all participants listed in the program is provided at the end if this issue. transpiration and stomatal conductance generally decreased with shading, and were further reduced by lower ambient canopy temperatures. Pod yield, leaf chlorophyll content, and rhizobium nodulation were higher in the fall planting but pod set was more concentrated in the spring. Pod mineral nutrients varied between cultivars, but generally were not affected by light intensity.

\section{Poster 363}

Temperature Abuse During Ground and In-flight Handling Operations Affects Quality of Snap Beans

M. Cecilia N. Nunes' ${ }^{* 1}$, J.P. Emond', and J.K. Brecht'; ' Univ. Laval, Air Cargo Transportation Research Group, Dept. of Soils and Agrifood Engineering, , FSAA, Ste Foy, PQ, G1K 7P4 Canada; ${ }^{2}$ Horticultural Sciences Dept., Univ. of Florida, IFAS, Gainesville, FL, 32611-0690

Intact and bruised snap beans (cv. Opus) were stored under two temperature regimes (semi-constant and fluctuating) typically encountered during ground and in-flight handling operations. The objective of this work was to: 1) study the effects of simulated commercial temperature regimes on the quality of snap beans throughout the handling chain; 2) determine which of the handling procedures was primarily responsible for quality losses; and 3) determine which quality parameter(s) limits the salability of snap beans. Weight loss and visual quality evaluations were made for every step of temperature change for intact pods. Bruised pods were evaluated for browning and decay incidence. Intact snap beans stored in semi-constant temperature lost less weight, had better visual ratings for color, firmness and shriveling, less incidence of browning and bruising than those stored in fluctuating temperatures. Bruised snap beans stored in semi-constant temperature had less browning and decay than those stored in fluctuating temperatures. Weight loss, color, browning, and bruising were the main factors that limited the salability of the beans. Losses in quality were more important during simulation of the airport handling operations and retail display. Snap beans from the fluctuating temperature were considered unmarketable before exposure to retail conditions, while those from the constant temperature treatment were no longer acceptable after $24 \mathrm{~h}$ in the retail display. The results indicate that, even for short periods of time, fluctuating and/or high temperatures that are often encountered during handling operations may result in rejection of a whole load of snap beans.

\section{Poster 364}

Salinity Tolerance of Phaseolus Species During Germination and Early Seedling Growth

Jeannette Sofia, Bayuelo-Jimenez*, Richard Craig, J. Franklin Styer, and Jonathan P. Lynch; Pennsylvania State Univ., University Park, PA 16802

The potential for salt tolerance during germination and early seedling growth was evaluated for 24 accessions representing four wild Phaseolus species and four accessions of cultivated common bean (P. vulgaris, L.) at 0 to $180 \mathrm{~mm} \mathrm{NaCl}$. Salinity stress delayed germination in all accessions to varying degrees. Eight accessions of $P$. filiformis, germinated fastest under high salinity. Additional wild accessions exhibiting rapid germination at $120 \mathrm{~mm} \mathrm{NaCl}$ were $P$. angustissimus, $\mathrm{PI535272,} P$. leptostachyus, $\mathrm{PI535326}$, and $P$. microcarpus, PI430196. Among accessions, median germination time (T50) at $120 \mathrm{~mm} \mathrm{NaCl}$ stress was positively correlated $(r=0.74$, $P \leq 0.01)$ with germination in the control treatments. Seeds that germinated rapidly at $60 \mathrm{~mm}$ also germinated rapidly at $120 \mathrm{~mm} \mathrm{NaCl}$. At $180 \mathrm{~mm} \mathrm{NaCl}$, several accessions reached $50 \%$ germination by 6 days, demonstrating high genetic potential within Phaseolus, for salt tolerance during germination. The biomass of radicles plus hypocotyls decreased with increasing salinity, suggesting that seeds germinated with $\mathrm{NaCl}$ generally did not produce vigorous seedlings. Cluster analysis separated the accessions into three groups. Group I included salt sensitive accessions with late germination, intermediate sensitivity index (ratio of median germination time at $120 \mathrm{~mm}$ $\mathrm{NaCl}$ versus control), and reduced seedling growth. Group II included salt tolerant accessions with rapid germination, intermediate HortScience, Vol. 36(3), June 2001 
sensitivity index, and enhanced seedling growth. Group III included cultivated accessions corresponding to the Mesoamerican and Andean gene pool with rapid germination, low sensitivity index, and intermediate seedling growth. The results confirm that wild Phaseolus, species, and in particular $P$. filiformis, represent a genetic resource for improvement of salinity tolerance in common bean.

\section{Poster 365}

\section{Root Traits Involved in Resistance to Fusarium Root Rot in} Common Bean

Sieglinde Snapp ${ }^{* 1}$, James Kelly², and Willie Kirk ${ }^{3} ;{ }^{1}$ Dept. of Horticulture, Michigan State Univ.; ${ }^{2}$ Dept. of Crop and Soil Sciences, Michigan State Univ.; ${ }^{3}$ Dept. of Botany and Plant Pathology, Michigan State Univ.

Bean root rot is primarily caused by Fusarium solanif. sp. Phaseoli in Michigan, where fungicides are used as the primary means of control. However, fungicides are costly, many have become less effective, and regulatory pressures are building. Root rot consistently causes more yield loss than any other snap bean and kidney bean disease, with cases reported in Michigan of $80 \%$ losses. An emphasis on quality traits appears to have significantly reduced the genetic variability in snap bean and kidney bean, which may contribute to severe root rot susceptibility in these bean market types. The inbred backcross (IBC) method was used to develop promising new bean lines, from tropically-adapted root rot resistance sources and market-acceptable parents. We report here on the evaluation stage, presenting information about promising lines that combine root rot resistance with acceptable agronomic and quality traits. Through extensive characterization of root traits, we have found preliminary evidence that a vigorous root system with multiple basal (or adventitious) roots enhances Fusarium root rot resistance. We will discuss the use of genetic tools to elucidate gene by environment factors in root system development and function.

\section{Poster 366}

Watermelon Mosiac Virus Infection of Susceptible and Resistant Yellow Squash and Related Effects on Net Photosynthesis

S. Alan Walters* , S. Kaan Kurtural, Joyce A. Swenson, and Bradley H. Taylor; Dept. Plant, Soil, and General Agriculture, Southern Illinois Univ., Carbondale, IL 62901-4415

Yellow summer squash (Cucurbita pepo L.) production is influenced by several cucurbit viruses, including Watermelon Mosaic Virus (WMV). Several transgenic yellow squash cultivars with WMV resistance are available that allow production in areas that have considerable WMV pressure. A study was undertaken to evaluate the influence of WMV infection on photosynthetic activity of several different yellow summer squash cultivars at four dates during the Fall 2000 production season. The cultivars evaluated were 'Multipik' (with observable virus infection), 'Cougar' (with observable virus infection), 'Patriot II' (transgenic virus resistance with no observable virus infection), and 'Liberator III' (transgenic virus resistance with no observable virus infection). WMV was the only virus identified at the test site. Net photosynthesis $(\mathrm{Pn})$ was significantly lower for 'Multipik' and 'Cougar', as compared to the transgenic WMV resistant cultivars 'Liberator III' and 'Patriot II'. The Pn activity of 'Multipik' was suppressed $\approx 6$-fold and 7-fold as compared to 'Liberator III' and 'Patriot II', respectively; furthermore, the Pn activity of 'Cougar' was suppressed $\approx 3$-fold and 4 -fold as compared to 'Liberator III' and 'Patriot II', respectively. Marketable weights $(\mathrm{kg} / \mathrm{ha})$ of the four cultivars evaluated was highly correlated $(r=0.989, P=0.0108)$ with $P n$ indicating that the suppression of photosynthetic activity in the susceptible cultivars reduced marketable yields.

\section{Poster 367}

Relationship between Seed Reserves and Germination in Triploid Watermelon

T. Wang*, L. Sistruck, D.I. Leskovar, and B.G. Cobb; Dept. of
Horticultural Sciences, Texas A\&M Univ., College Station, TX 77840

Triploid watermelons have few or no seeds, and thus have a great advantage for the consumers. They are hybrids produced by crossing diploid (male) with tetraploid (female). Little work has been done on the metabolism of diploid and triploid watermelon seeds. This study was conducted to provide information on fatty acid composition and starch content within dry seeds as well as respiration and isocitrate lyase within germinating seeds. Fatty acid profiles in triploid watermelon seeds revealed that the major acids were palmitic, stearic, oleic, and linoleic acids. Major increases in linoleic acid were noted with corresponding decreases in the other fatty acids. Fluorescent microscopy indicated the size of lipid bodies of triploid seed were larger than that of diploid seed. The seeds of triploid watermelon contained between 11.6 and $27.3 \%$ starch (dry weight basis), whereas the starch accumulation in diploid seeds was higher at $42.2 \%$. Diploid seeds showed a larger increase relative to triploid seeds in respiration beginning at the first day and reached levels of 1.5 to $2.0 \mu \mathrm{L} \mathrm{O}_{2} \mathrm{~min}^{-1}$. $\mathrm{seed}^{-1}$ after $4 \mathrm{~d}$ of imbibition. During the first few days of germination, the activity of isocitrate lyase dramatically rose, a peak was reached at 3 days of imbibition, and subsequently declined, regardless of ploidy. In conclusion, triploid seeds were found to have higher linoleate, however, it had been reported the fatty acid and lipid levels were almost unchanged for the first three days after initiation of imbibition. Failure to utilize the fatty acids in the early stages of germination and lower starch contents may point to the poor performance of triploid seeds.

\section{Poster 368}

Effect of Elevated $\mathrm{CO}_{2}$ on Photosynthesis and Evolution of Secondary Toxic Substances in Perilla frutescens var. japonica HARA

Sang Gyu Seo ${ }^{1}$, Seong Han Lee ${ }^{1}$, Young Yi Lee ${ }^{1}$, Yong Beom Lee ${ }^{1 *}$, and Kuen Woo Park'; ' ${ }^{D}$ Dept. of Environmental Horticulture, The Univ. of Seoul, Seoul 130-743, Korea; ${ }^{2}$ Dept. of Horticultural Science, Korea Univ., Seoul 136-701, Korea

Increasing atmospheric $\mathrm{CO}_{2}$ concentration might alter crop productivity and also the interaction with other environmental factors. To know change of physiological activities in plant grown under elevated $\mathrm{CO}_{2}$ is very important. In this study, we investigated photosynthetic rate, diffusive resistance and evolution of secondary toxic substances as physiological responses to elevated $\mathrm{CO}_{2}$ in Perilla frutescence var. japonica 'Yangsan'. Plants were exposed to ambient or $700 \mu \mathrm{mol} \cdot \mathrm{mol}^{-1} \mathrm{CO}_{2}$ concentrations for 7 days. Elevated $\mathrm{CO}_{2}$ increased photosynthetic rate by $\approx 40 \%$ and diffusive resistance by $10 \%$ to $20 \%$, and decreased transpiration rate so that water use efficiency might be increased in elevated $\mathrm{CO}_{2}$. The activity of glutathione reductase (GR), an antioxidative enzyme, decreased whereas that of ascorbate peroxidase (APX) increased at elevated $\mathrm{CO}_{2}$. Differences however were nonsignificant between treatments. The amount of ethylene evolution significantly increased but relative ion leakage, an indicator for change of membrane permeability, slightly decreased at elevated $\mathrm{CO}_{2}$. Therefore it was assumed that ethylene induced by elevated $\mathrm{CO}_{2}$ was not involved in oxidative stress and the intrinsic oxidative stress was decreased under elevated $\mathrm{CO}_{2}$. According to above results, it was expected that increase in concentration of atmospheric $\mathrm{CO}_{2}$ had a beneficial effect on plant growth and might provide plants with increased ability to compensate environmental stresses.

\section{Poster 369}

Effects of Elevated $\mathrm{CO}_{2}$ and Water Stress on Physiological Responses of Perilla frutescens var. japonica HARA Seong Han Lee, Sang Gyu Seo, Young Yi Lee, and Yong Beom Lee*; Dept. of Environmental Horticulture, The Univ. of Seoul, Seoul 130743, Korea

The aim of the present study was to investigate the interactive effects of elevated $\mathrm{CO}_{2}$ concentration and drought, as expected environmental constraints, on physiological responses of Perilla frutescens var. japonica 'Arum'. Perilla frutescens var. japonica 
'Arum' was exposed to $700 \mu \mathrm{mol} \cdot \mathrm{mol}^{-1} \mathrm{CO}_{2}$ under both well watered and water stressed conditions. Photosynthetic rate was higher in elevated $\mathrm{CO}_{2}$ concentration. Stomatal resistance was increased with decreasing transpiration rate and thereby, it was thought that water use efficiency could be increased at elevated $\mathrm{CO}_{2}$ concentration. Especially under water stressed condition, elevated $\mathrm{CO}_{2}$ concentration induced much higher stomatal resistance than ambient $\mathrm{CO}_{2}$ level. This suggest that elevated $\mathrm{CO}_{2}$ concentration might increase plant's sensitivity to water stress and thereby, provide plant with increased protection against water stress. Water stress reduced photosynthetic rate. Elevated $\mathrm{CO}_{2}$ concentration mitigated drought induced photosynthetic decline on early stage of drought but such effect was not sustainable. Therefore, it was assumed that elevated $\mathrm{CO}_{2}$ concentration might allow plant to be more resistant to environmental stresses. Moreover, increased amount of ethylene evolution under elevated $\mathrm{CO}_{2}$ concentration might improve plant's capacity for scavenging activated oxygen species by enhancing ascorbate peroxidase (APX) activity.

\section{Poster 370}

Asparagus Root Length Density Altered by On-farm

Production Practices

Dan Drost ${ }^{1}$ and Derek Wilson ${ }^{2} ;{ }^{1}$ Utah State Univ., Logan, UT; ${ }^{2}$ Crop and Food Research, Christchurch, New Zealand

Soil type, crop management practices, annual plant growth patterns and seasonal changes in the soil environment all influence asparagus roots. This study describes the changes that occur in root growth over time in two contrasting soils maintained with different crop management practices. Soil cores $(5-\mathrm{cm}$ diameter $\times 20-\mathrm{cm}$ long) were collected to one meter in on six dates (pre/postharvest, early/mid/late fern growth, and dormant period) and in three locations (15/30/60 cm from row) in 1999-2000. Sites varied with soil type (sandy loam or silty-clay loam) and with crop management systems (normal 12-week harvest or extended 16-week harvest). Fibrous and fleshy roots were collected, separated from the soil and root length density (RLD) determined. Soil type significantly altered fleshy roots rooting depth (sand>clay), dry matter content (clay>sand) and root length density (clay>sand). Fleshy RLD were not affected by sampling date for the two soil types. Use of the soil core technique accounted for $86 \%$ of fleshy RLD when compared with a hand dug sampling approach. Fibrous RLD and dry weights varied with sampling date (harvest<fern period), soil type (sand >clay) and sampling depth (shallow>deep). Distinct periods of root activity were detected for fine roots. Results can be used to improve crop management practices, predict root biomass and increase our understanding of the dynamics of root development in asparagus.

\section{Poster 371}

Isolation of Sulforaphane in Broccoli Sprouts, by ReversedPhase Solid Phase Extraction (SPE), followed by ReversedPhase HPLC and HPLC/MS Analysis

James D. Stuart ${ }^{1}$, Sarah K. Neddermann ${ }^{1}$, Andrew T. Smith ${ }^{1}$, Anthony A. Provatas ${ }^{1}$, and Usha R. Palaniswamy ${ }^{{ }_{2}} ;{ }^{1}$ Dept of Chemistry, U-3060, Univ. of Connecticut; '2School of Allied Health-Asian American Studies Institute, U- 2101, Univ. of Connecticut, Storrs, CT 06269

There is growing interest in the consumption of functional foods demonstrated to provide physiological benefits and/or reduce the risk of chronic diseases beyond basic nutritional functions. Broccoli (Brassica oleracea L.) and other cruciferous vegetables have been reported to have high levels of isothiocyanates, a group of chemopreventives. Various investigators including researchers at John Hopkins Univ. School of Medicine have shown that the active compound in Broccoli, R-sulforaphane [(R)-1-isothiocyanato-(4R)methylsulfinyl)butane)], is a powerful initiator of enzymes effectively blocking the development of various types of cancers in test animals. These reports used time-consuming preparative, reversed-phase liquid chromatography and preparative thin-layer chromatography to isolate the various compounds extracted from broccoli sprouts and mature florets. The solvent extraction and chemical work-up of sulforaphane needs substantial care as sulforaphane undergoes facile solvent hydrolysis and thermal degradation in processed samples. The objective of our research was to develop a more rapid and less expensive extraction method to isolate up-to milligram quantities of sulforaphane from a variety of different commerciallyand home-grown varieties of broccoli sprouts. About five different varieties of broccoli sprouts were analyzed under the isocratic conditions of 35:65 (v/v) acetonitrile:water by reversed phase HPLC using an Aquasil(R) C-18 HPLC column (Keystone Scientific Co.), $150 \mathrm{~mm}$. in length, 4.6-mm ID packed with 5 micron spherical particles. Both an UV photodiode array detector, with the primary wavelength set at $240 \mathrm{~nm}$ and HPLC/MS using positive ion Electrospray lonization (MicroMass, Quattro II) were used. In our studies we also used reversed-phase, solid phase extraction (SPE) cartridges at the initial solid phase extractions for effectively eliminating many of the late eluting peaks in the extract, shortening the actual LC separation time, making the separation easier.

\section{Poster 372}

Relationship between Ubiquinone/Ubiquinol Levels and Respiration Rates during Early Development of Five Species of Etiolated Seedlings

Kathleen D. Munro ${ }^{* 1,2}$, D. Mark Hodges ${ }^{1}$, John D. Delong ${ }^{1}$, Charles F. Forney', and David K. Kristie ${ }^{2}$; ${ }^{1}$ Atlantic Food and Horticulture Research Centre, Agriculture and Agri-Food Canada, 32 Main Street Kentville, Nova Scotia, Canada, B4N 1J5; ${ }^{2}$ Dept. of Biology, Acadia Univ., Wolfville, Nova Scotia, Canada, BOP 1 XO

The ubiquinone molecule functions in the respiratory chain of mitochondria of both plants and animals. Ubiquinone also functions in an antioxidant capacity minimizing oxidative damage due to lipid peroxidation in biomembranes. The purpose of this study was to examine the relationship between the respiration rate of developing dark-grown seedlings and the ubiquinone/ubiquinol content. The five species of plants chosen for this study were mung bean (Vigna radiata L.), broccoli (Brassica oleraceae L. var. italica cv. Laguna), mustard (Brassica juncea L. cv. Florida Broadleaf), pea (Psisum sativum L. cv. Lincoln) and spinach (Spinacia oleraceae L. cv.unipack 151). Ideal germination temperatures were established and rates of senescence for each species were determined at this temperature $\left(20{ }^{\circ} \mathrm{C}\right)$. The ratio of oxidized (ubiquinone) to reduced (ubiquinol) forms of the molecule and the total ubiquinone/ubiquinol content during seedling development were examined. Respiration measures on intact sprouts were made using a flow through system, while oxygen and carbon dioxide levels were analyzed with a GC. Ubiquinone and ubiquinol were extracted from plant tissue and analyzed with an HPLC with detection at $290 \mathrm{~nm}$. Rates of respiration of the etiolated seedlings is related to the ubiquinone/ubiquinol content over time, from germination to senescence.

5:00-6:00 p.m. CC Ballroom

\section{Poster Session 17: Undergraduate Education \\ Poster 495}

Substrate Column Depth and Capillarity Affect Seed Germination-A Laboratory Exercise

Connie J. Kephart and Richard J. Gladon*; Dept. of Horticulture, lowa State Univ., Ames, IA 50011-1100

Most beginning plant science courses do not teach students about the effects of substrate column depth and capillary rise of water on seed germination and plant growth. Our objective was to develop a laboratory exercise that lasted one week and showed the effects of substrate column depth and capillarity on germination of a divergent group of seeds. Plastic pipe of lengths 5, 7.5, 10, 12.5, 15, 17.5, 20, 25,30 , and $40 \mathrm{~cm}$ was fitted with a flat cap with holes drilled in it that allowed the pipes to stand upright, retained the substrate, and permitted transmission of water. The pipes were filled with fine silica sand (used for sandblasting) and placed in a cafeteria tray. Twentyfive seeds of honeylocust, seed geranium, marigold, cucumber, 
snap bean, soybean, or corn were sown in each pipe. The trays were filled with water repeatedly until capillarity was maximized in each pipe, and the water in the tray was replenished daily. Germination counts were recorded daily for seven days, and the percentage water of the top $6 \mathrm{~cm}$ of sand was measured on the last day. Germination percentages depended upon species, column depth, and capillarity, and several generalizations can be made. Virtually no seeds of any species germinated in tubes 5 - and $7.5-\mathrm{cm}$ deep, and an intermediate amount germinated at column depths of 10 and 12.5 $\mathrm{cm}$. Maximum seed germination occurred at substrate column depths of $15,17.5$, and $20 \mathrm{~cm}$. Germination was reduced at 25 and $30 \mathrm{~cm}$, and no germination occurred at $40 \mathrm{~cm}$. This laboratory exercise easily can be adopted and adapted for principles courses in the disciplines of horticulture, forestry, agronomy, botany, general plant science, or soil science.

\section{Poster 496}

Recruitment of African American Students to Horticulture at Fort Valley State Univ.

Clarence Johnson, Jr. * and Yarquita Waller; Horticulture, College of Agriculture, Home Economics and Allied Programs, Fort Valley State Univ., Fort Valley, GA. 31030

The number of students in horticulture in the College of Agriculture, Home Economics and Allied Programs at Fort Valley State Univ. (1890 Land Grant Univ.) has declined in the past ten years. We have taken two approaches to increase the number of African American students enrolled in horticulture programs at our institution. The first approach is that of using a summer research apprenticeship program, whereas we bring high school African American students to work for a period of 7-10 weeks in laboratories with the guidance of scientists. Students are taken on field trips to visit agricultural sites within the state to expose them to many aspects of agriculture. Each student is required to write up results of his or her research results and to do an oral presentation at the end of the summer experience. The second approach to increase the enrollment of African American students in horticulture at Fort Valley State Univ. is to recruit with the use of student testimonials. We have compiled profiles that include pictures and statements of present and former students. Most potential students are able to identify with one or more profiles. These profiles are used at high schools and career fairs to aid us in our recruitment efforts for horticulture programs. We are attracting African American students by the above two approaches to our horticulture programs in the College of Agriculture, Home Economics and Allied Programs. Southern Food Systems and Educational Consortium (SOFSEC) and our Agriculture Research Station provided the funds for these efforts.

\section{Poster 497}

Using a Student Managed Vegetable Farm as an Alternative Learning Experience to Benefit Students and the Local Community

Nathaniel H. Sands*, Wendy Sue Harper, and Milton E. Tignor, Jr.; Plant and Soil Sciences Dept., Univ. of Vermont, Burlington, VT 05405-0082

Eight pioneering undergraduate students established the Common Ground Student-Run Educational Farm in 1994. The farm has gone from producing several hundred pounds of organically grown vegetables 5 years ago to producing several tons during the 2000 growing season. Faculty advisors play only a minor role in the farm and the majority of the management is left to students. Students have been successful in obtaining operating funding from the Univ. of Vermont (UVM) Student Government Association and other outside sources. Over the last 6 years, the farm's management, mission, and production have evolved. In the 2000 growing season, the farm provided weekly produce for 26 share holders, donated over $5,500 \mathrm{lbs}$ of fresh produce to local food shelves, and raised 360 fall flowering chrysanthemums for the UVM Grounds Dept. In running the 2-acre vegetable farm, students have regular contact with a number of individuals, having a variety of expertise, to troubleshoot nutrition problems, resolve pest management issues, and receive safety training. For many students this is their first exposure to the Extension service and one-to-one mentoring with research faculty. 'Common Ground' also hosted several student internships with different organizations including the Center for Sustainable Agriculture, and worked in conjunction with other student organizations such as the Horticulture Club and Alpha Zeta National Agricultural Honor Society. Financial, administrative, and horticultural farm successes of the past five years will be presented along with the pitfalls.

\section{Poster 498}

Using Streaming Video Technology to Teach Vegetable Crops at Virginia Tech as a Asynchronous Distance Education Course on the Worldwide Web

Gregory E. Welbaum*; Dept. of Horticulture, Virginia Tech, Blacksburg, VA 24061

Horticulture 4764 is a required course for Horticulture majors in the "Crops" option at Virginia Tech. A classroom section of the course is taught each Fall Semester on the Virginia Tech campus in Blacksburg. An asynchronous, web-based distance learning section of the course is taught during the Spring Semester. The distance education website (http://www.bsi.vt.edu/welbaum/hort4764/) for the class contains 43 lessons layered by topic areas into short paragraphs or bulleted descriptive summaries in html format that can be easily read from a computer screen. The distance learning website relies heavily on approximately 600 graphic images and brief Quicktime scripted streaming video movies that enable students to view field-based demonstrations of the principles of vegetable production. Net Forum software is used for discussion between the instructor and students. Current restrictions by the Virginia Tech limit formal enrollment in the class only to Virginia Tech students. The website is not password protected and contains a keyword search function to allow extension clients not affiliated with the class to find information of interest.

\section{Poster 499}

An Interactive Internet Database for the Selection of Woody Landscape Plants Hardy in Connecticut

Jonathan M. Lehrer* and Mark H. Brand; Dept. of Plant Science, Univ. of Connecticut, Storrs, CT 06269

The Internet has created new avenues for the delivery of horticultural information. The Univ. of Connecticut has designed an interactive online database of woody plants which allows students, homeowners, and horticultural professionals to search a collection of nearly 600 trees, shrubs, and vines hardy in USDA zone 6 . This resource is intended to aid these constituencies in the proper selection of landscape material, while reducing the costs associated with traditional printed extension literature and allowing easy amendment of information impossible with traditional paper documents. Users of the database select traits related to plant form, culture and ornamental traits by filling out a form, after which the database searches for plants that match these specifications. The online HTML search form is linked to a FileMaker database that generates a list of matching plants quickly. The user may then review pictures and information about each species contained in The Univ. of Connecticut's plant database. FileMaker enables this powerful search function with a relative minimum of programming. The flexibility provided by this interactive resource allows planting choices to be identified quickly and in many settings, including the classroom, retail horticulture business, extension office, landscape architecture firm, and home office. Initial verbal and written communication indicates widespread acceptance of the plant selector and database, while an online questionnaire is being used for thorough evaluation that will lead to future improvements.

\section{Poster 500}

Development of a Mentoring Kit for Traditional and Nontraditional Students in Landscape Architecture and Horticulture

Marihelen Kamp-Glass* and Darlene Primas; North Carolina A\&T 
State Univ.

The Landscape Architecture and Horticulture Programs at North Carolina A\&T State Univ. has a broad mix of traditional and nontraditional students in a racially diverse student body. We have developed a mentoring kit to bridge the gap between traditional and nontraditional students which greatly strengthens our mentoring and retention efforts. Mentoring is a behavioral activity that refers to the one-on-one relationship that evolves through reasonably distinct phases between the mentor and the student. A mentor's role is comprised of a combination of interrelated behavioral functions that are put into the mentoring relationship to assist the student. This kit will help mentors focus on the 6 behavioral activities known to have positive motivational outcomes. These behavioral functions are: 1 ) Relationship Emphasis - to establish trust; 2) Information Emphasis - to offer tailored advise; 3) Facilitative Focus - to introduce alternatives; 4) Conformation Focus-to challenge; 5) Mentor Model-to motivate; and 6) Mentee Vision-to encourage initiative. In addition to a focus on specific mentor behaviors, the value of modern mentors should also be understood in reference to the wide sociocultural context in which they might exert a positive influence. The kit describes those processes that energize behavior and gives direction or purpose to behavior. When we consider human functions in learning such as attention, concentration, effort, perseverance and initiative; we are dealing with motivational processes that are activated and sustained by human energy. We constantly have to shift our attentions in the effort to cope with the world around us. It is to this end we must work diligently to be effective mentors.

\section{Poster 501}

The Academic Performance of Women Landscape Contracting Students at the Pennsylvania State Univ.

Hala F. Nassar', Dan T. Stearns ${ }^{\star 2}$, and David J. Beattie ${ }^{2}$; ${ }^{1}$ South Dakota State Univ:: ${ }^{2}$ Penn State Univ., Dept. of Horticulture, Pennsylvania State Univ., Univ. Park, PA 16802

Representation of women students in the Landscape Contracting program at the Pennsylvania State Univ. has increased since its inception in 1989; however, the percentage of women in the program has never exceeded 24 percent. Program administrators suspected that the low percentage of women did not result from an inability to compete academically. A review of student grades in five courses specific to the major revealed that in three of the courses, there was no significant difference between grades received by women and men. In the other two courses, women received significantly higher grades than their male counterparts. Cumulative grade averages at graduation were also reviewed, with women students attaining significantly higher averages than men.

\section{Poster 502}

\section{Establishment of Live Horticultural Plant Collections for} Teaching Nonhorticulture Courses

Usha R. Palaniswamy*; School of Allied Health-Asian American Studies Institute Univ. of Connecticut, Storrs, CT 06269-2101

In 1999, a collection of medicinal plants of Asian origin and culture was started in the Univ. of Connecticut, Storrs, CT. Currently there are $\approx 61$ plant species in this collection. These plants play an important role in Asian cultures and traditional medical systems and this collection proves to be an invaluable teaching tool for the Allied Health and Asian American Studies courses AH/AASI 215 Critical Health Issues of Asian Americans and AH/AASI 216 Asian Medical Systems. Since these courses are open to all majors, a majority of the students enrolled in these courses are Humanities, Social Sciences, or Allied Health majors with very little knowledge about plants. The students rated the use of this living collection of plants as the most valuable and well-designed teaching aid in these courses and believed that this stimulated their interest in horticulture and Botany. Additionally, this collection was showcased as part of Asian American awareness activities during October 2000. There was general agreement among the 95 participants that diet can effectively modify the pathophysiological pro- cesses of various metabolic disorders and can be an effective preventive strategy for various disease processes. Interest in plants and plant-based food has enhanced since the identification of phytochemicals present in a number of plants of Asian origin reported to possess substantial anticarcinogenic, antioxidative, anti-inflammatory, hypocholesterolemic, hypolipidemic, or hypoglycemic properties now described as functional foods and nutraceuticals. Similar live plant collections can be developed and effectively used to teach non-horticulture courses and to stimulate interest in horticulture among all majors and promote knowledge of use of plants in different world cultures in a college campus.

\section{Poster 503}

\section{A Long-term Study of Knowledge, Risk and Ethics for} Students Enrolled in an Introductory Biotechnology Course S.L. Kitto ${ }^{\star 1}$, L.G. Griffiths ${ }^{2}$, and J. Pesek ${ }^{3}$; ${ }^{1}$ Plant and Soil Sciences, ${ }^{2}$ Animal and Food Science, and ${ }^{3}$ Food and Resource Economics, Delaware Experiment Station, College of Agriculture and Natural Resources, Univ. of Delaware, Newark, DE 19717-1303

In 1989, we started an undergraduate course addressing issues concerning biotechnology in agriculture. To determine the extent to which students were engaged in classroom instruction and assimilated knowledge from the course, students were asked to complete an 'Attitudes About Biotechnology' survey. Students were queried about their knowledge of biotechnology, perceptions of risks associated with biotechnology and ethics and attitudes toward the use of biotechnology in agriculture. Responses to the survey questions were evaluated both pre-and post-course. Data were collected from 13 classes over a 10-year period. Pre-course GPA for all students was consistent over the course of this study. Course grades also were level over the time studied. Females perceived that they had an increased understanding of science and technology after the class as compared to the males. Students' knowledge of biotechnology, both actual and perceived increased as a result of the course. There was a modest increase overall in student acceptance of risk associated with genetic engineering; however, there was no evidence to support that as a result of the course students were more accepting of genetic engineering of animals. Females perceived more risk but there was no discernable pattern over the ten years studied. While males were more accepting, pre-and post-course, of genetic manipulation of animal cells in a laboratory, our overall conclusion is that there was no evidence that ethical positions were altered due to the course.

\section{6:00-7:30 p.m. ................... Hyatt Regency Upper Pool Deck International Division Reception}

Held at the Hyatt Regency, this reception recognizes ASHS'S diverse international membership.

\section{7:00-9:00 p.m. ......................... Hyatt Regency Big Sur A\&B Industry Division Dinner \\ Cocktail Reception Sponsored by the United Fresh Fruit \& Veg- etable Association}

7:00-9:00 p.m. CC 316

\section{American Pomological Society Annual Business Meeting}

Chair: David A. Hunter

\section{Tuesday $\cdot 24$ July 2001}

